\title{
The tacit bargain in short-term medical missions
}

Citation for published version (APA):

Caldron, P. H. (2016). The tacit bargain in short-term medical missions: Why US physicians go and what it costs. [Doctoral Thesis, Maastricht University]. Boekenplan Maastricht.

https://doi.org/10.26481/dis.20161123pc

Document status and date:

Published: 01/01/2016

DOI:

10.26481/dis.20161123pc

Document Version:

Publisher's PDF, also known as Version of record

\section{Please check the document version of this publication:}

- A submitted manuscript is the version of the article upon submission and before peer-review. There can be important differences between the submitted version and the official published version of record.

People interested in the research are advised to contact the author for the final version of the publication, or visit the DOI to the publisher's website.

- The final author version and the galley proof are versions of the publication after peer review.

- The final published version features the final layout of the paper including the volume, issue and page numbers.

Link to publication

\footnotetext{
General rights rights.

- You may freely distribute the URL identifying the publication in the public portal. please follow below link for the End User Agreement:

www.umlib.nl/taverne-license

Take down policy

If you believe that this document breaches copyright please contact us at:

repository@maastrichtuniversity.nl

providing details and we will investigate your claim.
}

Copyright and moral rights for the publications made accessible in the public portal are retained by the authors and/or other copyright owners and it is a condition of accessing publications that users recognise and abide by the legal requirements associated with these

- Users may download and print one copy of any publication from the public portal for the purpose of private study or research.

- You may not further distribute the material or use it for any profit-making activity or commercial gain

If the publication is distributed under the terms of Article $25 \mathrm{fa}$ of the Dutch Copyright Act, indicated by the "Taverne" license above, 


\section{THE TACIT BARGAIN IN SHORT-TERM MEDICAL MISSIONS}

Why US Physicians Go and What It Costs 
(C) Paul Henry Caldron, 2016

ISBN: 9789086664078

Published by Boekenplan, Maastricht www.boekenplan.nl

All rights reserved. No part of this publication may be reproduced, stored in a retrieval system, or transmitted in any form or by any means, electronic, mechanical, photocopying, recording or otherwise, without the written permission from the author. 


\title{
THE TACIT BARGAIN IN SHORT-TERM MEDICAL MISSIONS \\ Why US Physicians Go and What It Costs
}

\author{
DISSERTATION \\ To obtain the degree of Doctor at Maastricht University \\ on the authority of the Rector Magnificus, \\ Prof. Dr. Rianne M. Letschert \\ in accordance with the decision of the Board of Deans, \\ to be defended in public \\ on Wednesday, 23 November 2016, at 16:00 hours
}

By

Paul Henry Caldron 


\section{Promoter:}

Prof. Dr. W.N.J. (Wim) Groot

\section{Co-Supervisors:}

Dr. Milena Pavlova

Dr. Ann Impens, Midwestern University, USA

Assessment Committee:

Prof. Dr. J.A.M. (Hans) Maarse (chair)

Prof. Dr. David Beyda, University of Arizona, USA

Prof. Dr. Helmut Brand

Prof. Dr. Annelies Boonen

Prof. Dr. Judith Lasker, Lehigh University, USA 


\section{Table of Contents}

List of Abbreviations ....................................................................................... vii

Chapter 1: General Introduction ............................................................... 1

Chapter 2: A Systematic Review of Social, Economic and Diplomatic Aspects of Short-Term Medical Missions

Chapter 3: The Physicians' Giving Back Survey: Keeping up with American Generosity 47

Chapter 4: Economic Assessment of US Physician Participation in ShortTerm Medical Missions 65

Chapter 5: Demographic Profile of Physician Participants in Short-Term Medical Missions

Chapter 6: Why Do They Care? Narratives of Physician Volunteers on Motivations for Participation in Short-Term Medical Missions Abroad....... 107

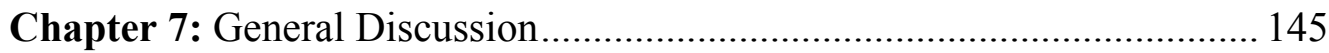

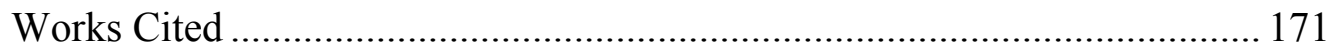

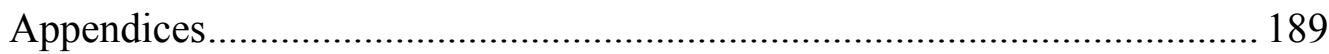

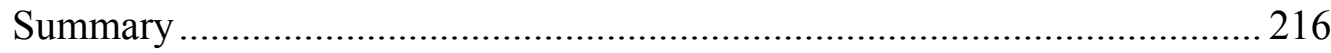

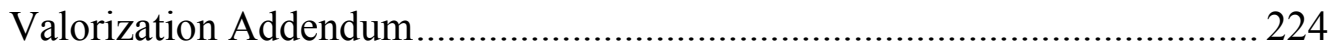

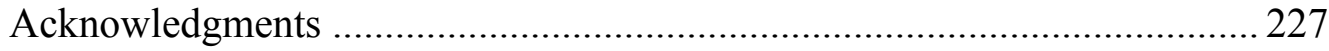


Curriculum Vitae

229

MGSoG Dissertation Series................................................................. 232 


\section{List of Abbreviations}

STMM - short-term medical mission

LMIC - low- and middle-income countries

MSF - Médecins Sans Frontières

NGO - Non-governmental organization

MD - medical degree, Medicinae Doctor, Doctor of Medicine

DO - medical degree, Doctor of Osteopathic Medicine

IMG - International Medical Graduate

PGBS - Physicians' Giving Back Survey

DALYS - Disability adjusted life years saved

PPACA - Patient Protection and Affordable Care Act

MGMA - Medical Group Management Association

AMA - American Medical Association

ACP - American College of Physicians

ACS - American College of Surgeons

USD - United States dollars 
Chapter 1: General Introduction 


\subsection{Scope of the Dissertation}

Short-term medical missions (STMMs) represent a form of grassroots, i.e., popular and non-hierarchical, transnational aid from persons in wealthy countries to low- and middle-income countries (LMICs) ${ }^{1}$, wherein primarily professional services rather than funds or material are transferred. As this permutation of aid has developed in the last half century, the scant literature accumulated on this topic has touched on both the attractive and worrisome features of these missions, yet much remains unclear about its dimensions and dynamics. The scope of this dissertation is to identify and fill in some of the missing pieces in the picture of this ostensibly humanitarian activity.

Beyond descriptive accounts, kudos, criticisms, and reflections on potential ethical conflicts, the discussion borne in the relatively sparse existing literature on STMMs lacks a more granular and dispassionate portrayal of the physicians who conduct these 'excursions', why they do it, and the providerside ramifications of doing so. Beyond conjecture, an assessment of the magnitude of participation and expenditures related to the activity is missing. The relevance of the scope of this dissertation to physicians is heralded by the increasing participation among their peers, increasing attention of medical colleges and trainees to global health, and by articles and editorials on the topic in leading medical and surgical journals. The relevance to government and other policy makers is the need for more quantitative data in order to determine if this type of aid is of material consequence in terms of composite annual outlays of cash and man hours.

This dissertation focuses on the dynamics of the physician side of STMMs, and thereby fills gaps in the picture of STMM activity regarding prevalence, motivations, and expenditures related to these missions, specifically for US physicians. The perspectives gained broaden the knowledge base regarding direct international humanitarian medical services.

\footnotetext{
${ }^{1}$ World Bank list of economies, February 2014, siteresources.worldbank.org/DATASTATISTICS/Resources/CLASS.XLS
} 


\subsection{Brief Overview of STMMs}

\section{Descriptions and Parameters}

The pre-eminent features of STMMs, also referred to in the literature as shortterm medical trips, short-term medical outreaches, or short-term medical service trips, are the short segments of time that the physician is continuously engaged in the process of providing medical services to persons in developing countries, and that the physicians pay the expenses to do this rather than receiving compensation. This dissertation confines itself specifically to STMMS that involve participation of physicians who are licensed for the full scope of medical practice in the US and excludes activities that may use the same or similar nomenclature, but do not include physician participation. One can identify physicians who spend years or even a career in foreign environments plying their medical and surgical skills away from their home countries. In that long-term setting, the physician's livelihood derives from a funding organization or governmental body intended to support the activity. An STMM, in contrast, refers to periods of non-paid medical work, usually six weeks or less, performed by physicians whose livelihood is generated through their own private enterprise in their home country, or by paid employment within a private or public entity. Some physicians' careers may include both long-term and short-term humanitarian work, though for the most part, it is one or the other.

Martiniuk et.al. reviewed the literature on the subject of STMMs over a period of 25 years from 1985 through 2009 and found that four countries have been the source of most of these missions: United States of America (US), Canada, United Kingdom, and Australia (Martiniuk, Manouchehrian, Negin, \& Zwi, 2012). These countries have notably common characteristics: British postcolonial status, language, Christian religious predominance, open democracies and ranking near the top of world scales for economic strength, transparency, and quality of life.

The Spectrum of STMM Models

Visualizing what a "mission" looks like on the ground is a bit complicated since there is very little standardization in size, make-up of staffing, 
sponsorship sources, relationship with target country or community, or collaboration with local in-country entities. Although one may find several large clearing houses on-line where individual physicians can find STMM opportunities, no federal agency regulates the process beyond issuing individual passports and visas, and potential government travel bans of citizens to areas of conflict or unrest. To be clear, short-term outreach labeled in the rubric of "global health" that does not include direct physician participation in the care of patients is not considered in this dissertation.

The simplest STMM model is a single physician with a focused skill who establishes a contact in a community of poorer people abroad wherein that service is not readily available to that segment of the population. Examples readily found in published reports include plastic surgeons performing repairs of cleft palates, and ophthalmologists performing cataract surgery. Nonetheless, primary care physicians and dermatologists have also "gone it alone" (Landau, 2001; Norton, 1999). The case has been made that the costbenefit ratio and productivity is optimized in this "minimalist" model, because the traveling physician brings little or no assistant staff, and utilizes local staff and facilities as well as local mechanisms for patient recruitment and organization (Dupuis, 2006; Wolfberg, 2006).

The most common expression of an STMM, however (albeit that no proportional data are available on mission model types), is likely the model wherein a team consisting of a few physicians, nurses and non-professional support persons, along with perhaps a few interested students at postsecondary level, travels under the auspices of a US hospital, church or civic organization, and works in collaboration with a similarly oriented host country organization for a period of 1-2 weeks. Usually the team's functional focus is purely surgical or purely medical (in this context meaning nonsurgical). Occasionally, the team will have a mix of surgical and non-surgical clinicians that will convene at a multipurpose facility. For non-surgical teams, a local organization typically designates one or more sites of operation that may be central to a small town or village, and might conduct day trips to more remote rural or mountain communities for a clinical day. The pejorative terms "duffle bag medicine" and "voluntourism", among others, have arisen as a corollary to the criticisms of the limitations and potential harms of these missions (Roberts, 2006; Wallace, 2012). 
The technical scope of these trips varies considerably. In general, surgical trips will focus on a selected, small set of relatively low technology procedures in orthopedics, plastic surgery, ophthalmology, general and gynecologic surgery. The travelers often bring advanced levels of technological sophistication compared to local resources. Shrime et al have compared surgical mission platforms, suggesting that permanent facilities perform better than hospital ships and mobile units (Shrime, Sleemi, \& Ravilla, 2014). Comparisons have also been made between approaches that utilize travelling versus local support staff on the basis of cost per disability adjusted life years saved (DALYS) (Chen et al., 2012; Gosselin, Gialamas, \& Atkin, 2011; Krishnaswami, 2010). On medical (non-surgical) trips, the more common tasks are screening for and treating acute infectious illnesses, identifying chronic conditions such as diabetes, hypertension, hypothyroidism and musculoskeletal disorders, then initiating treatments and attempting to arrange further evaluation and management through what local resources may be available. Lest no one who has waited in a long queue leave empty-handed, single dose anti-parasitic ("de-worming") medicines and a month's count of a multivitamin given out to all patients seen are common staples of medical STMMs.

While this dissertation focuses on the characteristics and motivations of physicians who have completed all formal training and are engaged in practice at home, there has been a growing academic interest in creating and sustaining organized opportunities for medical students and residents to gain experience, and to pique their interest in global health careers. Several such partnership models have developed and may be referred to as "twinned" partnerships or "short-term experiences in global health (STEGHs)"(Melby et al., 2015; Morse, 2010). These programs provide exposures for students and residents to healthcare circumstances in the developing world. The sustainability of these partnerships requires the deep collaboration of a US medical university with an in-country reciprocal entity. The collaboration in these programs seeks to upgrade health resources available to poorer patients through continuous development of local specialist skills.

Over time, a physician who participates in STMMs may do so through a variety of the models described above. As yet, evidence is lacking that any of these models perceptively alter the health status or boost the local economy in the communities they serve in the way that improved healthcare typically does (Currier, 2008; Smith, 1999). 
The physicians who carry out STMMs exercise the art of the possible in matching their impulses for humanitarianism to existing opportunities, wedged into the context of full professional and private lives. Commitment to long-term humanitarian medical work would involve a radically different career path, or at least a restructuring of one's life conduct to accommodate a time for continuous humanitarian work, given that long-term commitments and domestic practice are not simultaneously possible. Long-term, funded humanitarian positions for US physicians, usually sponsored by faith-based NGOs, appear to be rare; identifying and aggregating information on such projects is difficult. World-wide, the most recognizable long-term humanitarian civilian medical force is the Nobel Prize-winning organization Médecins Sans Frontières (MSF - Doctors without Borders), an organization quintessentially identified with reaction to conflict, unrest and famine. STMMs are not associated with such ad hoc response. Taking this distinction into account, the greater global visibility of MSF makes it an entity with which STMMs are commonly compared and contrasted. Although this dissertation focuses expressly on STMMs only, to supply context, its empirical findings are briefly juxtaposed to comparable features of MSF in the General Discussion, Chapter 7, section 7.4.

\subsection{Brief Conceptual Overview of Social Dynamics of US Physicians and Involvement with STMMs}

Western societies, especially the US, behave in a manner that suggests that health-related spending is a dominant target for necessary as well as discretionary expenditures. The advancement of their learning institutions and economies has been accompanied by great progress in the sciences, including human medicine and health care delivery (Albrecht, Fitzpatrick, \& Scrimshaw, 1999). The ever-evolving frontier for new medicines and medical devices sustains a robust industry and a worldwide market for products that address deepening understanding of disease mechanisms (Graves \& Langowitz, 1993). A high level of development in the healthcare sector and implementation of public health policy and standards are established. Healthcare expenditures as part of GDP reflect the societal value of progress in disease management and health. 
By contrast, in developing countries, priorities for government expenditures often remain primarily at the public health level including the development of clean water sources, sanitation requirements and some public health education initiatives. Vaccination programs and maternal health care constitute a secondary level health care. The tertiary activity of a physician seeing an individual patient for a specific malady is common only at higher income levels in more metropolitan areas. Supportive infrastructure including treatment facilities, laboratories and imaging technologies is limited. Trained physicians may be salaried by government and staff the local public facilities where available. The private sector for medical services is typically more limited and congregated in more affluent areas, serving those who can pay. Much private care may exist in the informal economy. As a result, sizable portions of poorer and rural populace have extremely limited opportunities for direct medical care and may go a lifetime without interacting with trained or licensed medical personnel (Im, 2016; Mills, 2014; Peters et al., 2008).

Physicians in the US have an opportunity for personal and economic satisfaction in the context of treating the infirm and promoting health. It is accepted and, dare say, expected that medical practitioners will fare well economically in relation to the society as a whole. It is also expected that physicians will behave ethically and altruistically, and place high priority on individual patient care and outcomes. In return, physicians are held in society's esteem as a result of their ethical and economic stature. High standards of performance for US physicians are dictated in concert by the quality of personal health care available, the market for health services, societal ethical standards, federal and local regulatory agencies, and the framework of legal precedent. Concomitantly, individual performance by both general physician and specialist has become dependent on an infrastructure of technology. Can one expect these same physicians to perform at a similar level of expertise outside that technological infrastructure and performance expectations? What kinds of US physicians would choose to attempt this and why?

In the US, as well as in communities in other high-income countries, inefficiencies and disparities in the delivery mechanisms of health services still exist. The resulting gaps create ample opportunities domestically for physicians to provide some of their skilled services free of charge to needy persons who face barriers of access to care. Nevertheless, the praxis wherein Western physicians travel on their own time and at their own expense to low 
technology areas in developing and least-developed countries to provide probono medical services to "the poor" is a phenomenon that may be growing with respect to the volume of such excursions, though accurate numbers are not readily available (Maki, Qualls, White, Kleefield, \& Crone, 2008; Martiniuk, Manouchehrian, et al., 2012; Sykes, 2014). At the same time, the increased penetration of managed care insurance coverage for medical care in the US may be linked to a relative reduction on domestic charitable care by physicians (Cunningham \& May, 2006; Cunningham, Grossman, St Peter, $\&$ Lesser, 1999). Does this trend suggest that physicians perceive a greater marginal utility for the man-hours in transnational work than in domestic charitable work, despite the relative lack of supportive infrastructure in those poorer countries? Societal approval appears to be a given for such charitable efforts with little question of motivation, attempt at regulation or accountability, and bestows honorability on the participating physician. Is private value being confused with societal value by these physicians?

If one could identify a profile of who goes, then one could potentially infer why they go (Heidarian, Kelarijani, Jamshidi, \& Khorshidi, 2015; Kukanja, 2013; Sheth, 2016). Are the physicians that go proportionately male or female? Are they more likely to be immigrant or second generation American? Are there ethnic representations that deviate from the population strata? Are physicians more likely to go if they already speak the language or have other ties to where they go? Are volunteer physicians more likely to come from the "Bible Belt" or other cultural pockets of the US? Do the volunteers aggregate to higher tax brackets than the physician demographic in general? If the costs were not tax-deductible, how likely to go would the physician be? Is there a mode in the age histogram of volunteers? Do physicians go while they have small children at home?

A greater challenge may lie in quantifying the non-demographic determinants such as the relative value that participants place on the rewards that may be garnered from helping others: feeling good about themselves, the attendant prestige, the adventure, and some education. Nonetheless, such intangibles may be critical determinants in the analysis of why physicians go in growing numbers. Reflective published articles suggest indeed that the ideals of charity and values of volunteerism are a compelling element in the decision to go on an STMM. Martiniuk et al, however, dismissed most such reports from their selected cohort of articles deemed to have extractable analytic usefulness (Martiniuk, Manouchehrian, et al., 2012). Mission participants' 
insights nevertheless underscore an inescapable fillip of altruistic motivation mixed with utilitarianism, noting that while not all patients could be well served, the process makes all the difference to the singular patients served that otherwise might not have been (Badlani, 2009). Some participants suggest the activity gives a face to the local poor, and signals acknowledgement that their plight is being recognized by outside countries (Buchman, 2007). Nonetheless, the more common themes woven into these reflections are related to the benefit to the provider, e.g., getting "recharged", honing skills, witnessing cases only previously seen in textbooks, a sense of giving something back, and the admission that slide shows and testimonies of mission-goers directly facilitate church or secular NGO fund-raising for future missions and other objectives (Boyd, 2012; Bryden, 2007; Montgomery, 1993).

Martiniuk et al point out in 2012 the relative paucity of published articles on STMMs (several of the prior 25 years had seen less than 10 pieces per year). In contrast, there is a rich literature on volunteerism theory available to be applied to our understanding of motivation in STMM activity. Mowen and Sujan regard volunteerism as charitable activity that resembles consumer behavior (Mowen \& Sujan, 2005). Marta et al emphasize the need to distinguish between altruistic and egoistic behaviors. Is the motivation behind STMMs linked to utilitarian desire to expand a social good in a global community context that would otherwise have to be brought to market in another way (Erlinghagen, 2003; Marta, Guglielmetti, \& Pozzi, 2006)? Are wealthy and skilled physicians who do not volunteer essentially "free-riders" in the global society (Kollock, 1998; Unger, 1991)? Do physicians on STMMs merely crowd-out regular jobs for local physicians (Lindenmeier, 2008)? These moral and market questions reasonably apply to STMMs, yet we have little accounting to show us the answers.

\subsection{The Aims of the Dissertation}

This dissertation seeks to examine specifically the prevalence, profile and motivations of private physicians in high-income countries, herein specifically the US, who participate in STMMs, and the measurable economic and manpower inputs of the activity. The research aims conceived for this dissertation seek to provide physicians and policy makers with quantitative and qualitative data to better inform deliberation on STMMs. 
To understand if this question is even worth asking, it is useful to clarify if the activity is indeed increasing or on the wane. The analysis of why one does anything is also helped by an assessment of available alternatives. The research of the dissertation begins by seeking any previously published critical analysis on this question. An appreciation for the role played by peer influence, nationalistic or diplomatic considerations, market-based forces, and available data on costs and manpower inputs (as surrogates for willingness to do STMMs) may inform a broader understanding of physician motivation. The research then adopts both an observational approach, assessing the type of physician who participates and what we may infer from the participant profile about why they go, and a direct approach, analyzing actual narratives of repeat participants on why they do STMMs. Capturing each of these ingredients in the answer to "why" is facilitated by the following set of sub-questions:

\section{Sub-Questions:}

- What is the prevalence of STMM participation among US physicians?

- What domestic options compete with STMM participation?

- What are the demographic, social and professional determinants of participation?

- What are the personal motivational determinants of participation?

Secondary Question: What are the Measurable Economic and Manpower Inputs Related to STMMs from the US?

Are STMMs simply a curious anomaly of little relevance or are they a serious form of international assistance activity that deserves the investment of research? Do the inputs, by their magnitude, warrant attention and due 
diligence? The dissertation takes aim at this secondary fundamental question by developing primary data on the costs and physician manpower inputs. The indirect subsidy available to STMMS through current US tax code could be influential. Further, are there connections with regions or countries that point to other relationship dimensions underlying these interactions between their citizens? Are there positive or negative externalities arising from STMMs that may affect US relationships within the world community that are not captured in the measurement of inputs? The limited objectives of this dissertation related to monetary and non-monetary costs are governed by the following sub questions:

\section{Sub-Questions:}

- What are the personal and collective expenditures for STMMs on an annual basis?

- Do tax ramifications play a role in participation?

- How are countries selected by participants?

- Are there spillover effects of STMMs on strategic "Soft Power" or attitudes towards aid?

To answer the above questions and sub-questions in this dissertation, three methodologies are utilized to draw closer step-by-step to the cognitive and emotional elements of motivation, while capturing quantitative data on physician characteristics and inputs along the way. The widest circle is pursued through the retrospective methodology of a systematic review of the literature looking for evidence of broad social, economic and diplomatic factors that may influence physicians' participation in STMMs, and, in doing so, provide an overview of accumulated objective information on the praxis. Next, the methodology of an online survey to gather primary data, titled the Physicians' Giving Back Survey tool (PGBS), looks more closely for a demographic and professional profile of STMM physicians that may provide clues as to why these physicians go. Lastly, the high-power lens is turned on motivation by qualitative methods, questioning physicians directly in semi- 
structured interviews. Table 1.1 catalogues the primary and secondary sources of information to answer the questions. 
Table 1.1. Questions and Data Sources

\begin{tabular}{|c|c|c|}
\hline Question & Sub-Questions & Data Source \\
\hline $\begin{array}{l}\text { Why do US } \\
\text { physicians go on } \\
\text { STMMs? }\end{array}$ & $\begin{array}{l}\text { What is the prevalence of } \\
\text { STMM participation among } \\
\text { US physicians? } \\
\text { What domestic options } \\
\text { compete with STMM } \\
\text { participation? } \\
\text { What are the demographic, } \\
\text { social and professional } \\
\text { determinants of } \\
\text { participation? } \\
\text { What are the personal } \\
\text { motivational determinants } \\
\text { of participation? }\end{array}$ & $\begin{array}{l}\text { Survey data (PGBS), } \\
\text { Narrative interviews } \\
\text { Survey data (PGBS), } \\
\text { Systematic review of } \\
\text { literature } \\
\text { Narrative interviews }\end{array}$ \\
\hline $\begin{array}{l}\text { What are the } \\
\text { measurable } \\
\text { economic and } \\
\text { manpower } \\
\text { inputs from the } \\
\text { US? }\end{array}$ & $\begin{array}{l}\text { What are the personal and } \\
\text { collective expenditures for } \\
\text { STMMS on an annual basis? } \\
\text { Do tax ramifications play a } \\
\text { role in participation? } \\
\text { How are countries selected } \\
\text { by participants? } \\
\text { Are there spillover effects of } \\
\text { STMMs on strategic "Soft } \\
\text { Power" or attitudes towards } \\
\text { aid? }\end{array}$ & $\begin{array}{l}\text { Survey data (PGBS) } \\
\text { Survey data (PGBS), } \\
\text { Narrative interviews } \\
\text { Narrative interviews } \\
\text { Systematic literature } \\
\text { review } \\
\text { Narrative interviews }\end{array}$ \\
\hline
\end{tabular}




\subsection{Structure of the Dissertation}

Chapter 2 is based on a systematic review of the literature that builds on previous reviews, and mines for content related to diplomatic, economic and social elements of STMMs that underlie US physician motivation to give of their services abroad.

Chapter 3 draws from the results of the PGBS, a survey of physician volunteer activities in the US. This portion explores the array of volunteering and philanthropic options that physicians may select, the proportion of physician involvement, and attempts to identify demographically who does what among these options.

Chapter 4 attempts to substantiate the materiality of the short term medical mission activity from the US. The results of the PGBS are descriptively analyzed in terms of annual expenditures and manpower utilization, benchmarked to relevant US federal assistance spending.

Chapter 5 utilizes descriptive statistics and multivariate regressions of physician response data from the PGBS to profile physicians who elect participation in STMMs. Chapter 5 goes on to explore what such a profile may empirically reveal about motivation to participate.

Chapter 6 transitions the methodology from quantitative economic and demographic features of participation to qualitative study of motivation though semi-structured interviews with physicians experienced in STMMs. Subjects are queried on a spectrum of broad concepts such as foreign aid, diplomacy and economics as well as highly personal drivers as they relate to the decision to participate.

Chapter 7, the General Discussion, utilizes the defense of 6 key statements gleaned from the quantitative and qualitative components of this research to summarize the new information arising from this dissertation, citing the strengths and limitations of each statement. In addition to policy implications and future research relevant to each statement, the general discussion will also give these statements, and the dissertation overall, more meaning by placing 
them in context in two ways: a) a reconciliation with the motivations of patients and NGOs; and b) a comparison of STMM and MSF physician and organizational motivations. A brief reflection on how the ongoing global debate on aid effectiveness may translate to STMMs is followed by general conclusions of the dissertation, including speculation on the future direction of collaborative international pro-bono healthcare. 
Chapter 2: A Systematic Review of Social, Economic and Diplomatic Aspects of Short-Term Medical Missions

This chapter draws upon:

Caldron PH, Impens A, Pavlova M, Groot W. A systematic review of social, economic and diplomatic aspects of short-term medical missions. BMC Health Serv Res. 2015;15(1):380. DOI:10.1186/s12913-015-0980-3. 


\begin{abstract}
Background: STMMs represent a grassroots form of aid, transferring medical services rather than funds or equipment. The objective of this chapter is to review empirical studies on social, economic and diplomatic aspects of STMMs.
\end{abstract}

Methods: A systematic literature review was conducted by searching PubMed and EBSCOhost for articles published from 1947-2014 about medical missions to LMICs. Publications focused on military, disaster and dental service trips were excluded. A data extraction process was used to identify publications relevant to our objective stated above.

Results: PubMed and EBSCOhost searches provided 4138 and 3262 articles respectively for review. Most articles that provide useful information have appeared in the current millennium and are found in focused surgical journals. Little attention is paid to aspects of volunteerism, altruism and philanthropy related to STMM activity in the literature reviewed (1 article). Evidence of professionalization remains scarce, although elements including guidelines and tactical instructions have been emerging (27 articles). Information on costs (10 articles) and commentary on the relevance of market forces (1 article) are limited. Analyses of spill-over effects, i.e., changing attitudes of physicians or their communities towards aid, and characterizations of STMMs as meaningful foreign aid or strategic diplomacy are few (4 articles).

Conclusions: The literature on key social, economic and diplomatic aspects of STMMs and their consequences is sparse. Guidelines, tactical instructions and attempts at outcome measures are emerging that may better professionalize the otherwise unregulated activity. A broader discussion of these key aspects may lead to improved accountability and intercultural professionalism to accompany medical professionalism in STMM activity. 


\subsection{Introduction}

The appellation "short term medical missions" (STMMs), as outlined in Chapter 1, appears to have been informally adopted generally to distinguish these excursions from ad hoc responses to domestic or external disasters, compensated full-time relief practice such as MSF, military and other governmental relief expeditions and residency training programs (Maki et al., 2008; Martiniuk, Manouchehrian, et al., 2012; Sykes, Le, Sale, \& Nicklaus, 2012). Authors on STMMs commonly conjecture that the praxis of STMMs has increased over time, although formal evidence of an increase is not readily found (Maki et al., 2008; Martiniuk, Manouchehrian, et al., 2012; Sykes, 2014). The impact of STMMs on receiving countries' community health or economics may not yet be measurable (Martiniuk, Adunuri, et al., 2012). Apart from intended direct therapeutic effects sought for individual patients, STMMs may be viewed from outside as foreign aid with diplomatic ramifications, and as a market for unmet needs on both sides of the transaction.

The core competency of medical practice is the reduction of human physical and mental suffering resulting from disease and injury. Physicians in rich countries have ample opportunity to execute these competencies domestically, paid or unpaid. Why do some go abroad pro-bono in the exercise of STMMs? Do the broader consequences of STMMs influence the propensity for physicians to carry out these expeditions?

The objective of this chapter is to review empirical studies on the social, economic and diplomatic aspects of STMMs. For this purpose, the method of systematic literature review was adopted. The review focused on studies published from 1947-2014 about STMMs to LMICs.

The review is of relevance not only to research, but also to fostering a more global discourse on social properties accruing to STMMs that run in parallel to the clinical efforts. Observing the praxis of STMMs through the lens of psychosocial, diplomatic and market dynamics may shed light on pathways to maximize its utility and minimize negative externalities as the activity expands. 


\subsection{Background}

Three previous systematic reviews on STMMs have been published (Martiniuk, Manouchehrian, et al., 2012; Shrime et al., 2014; Sykes, 2014). Martiniuk et al sought "to better understand missions and their potential impact on health systems" in LMICs (Martiniuk, Manouchehrian, et al., 2012). Their review identified the most frequent sending and receiving countries as well as dominant types of medical and surgical activities and tabulated the perceived benefits and common criticisms of short term medical missions. Their analysis punctuated the paucity of literature providing quantitative data on prevalence, costs, quality, regulation and outcomes. Shrime et al compared platforms for elective humanitarian surgery, suggesting that the ad hoc service mission was of value only when selfcontained mission vessels, i.e., hospital ships or aircraft, and dedicated local operating facilities are unavailable (Shrime et al., 2014). More recently, Sykes collated articles about STMMs wherein any attempt was made to collect data on treatment interventions, costs, cost-effectiveness, quality assessment or surveys of perspectives of involved parties. Sykes concluded that reporting has dealt largely with "output rather than outcomes" (Sykes, 2014).

These prior reviews have also suggested that the preponderance of published articles on STMMS, numbering in the hundreds, are reflective in nature and convey the emotional rewards, sense of renewal and adventure garnered by physicians in the course of their participation in STMMs (Martiniuk, Manouchehrian, et al., 2012; Sykes, 2014). The reviews leave aside the search for theory-based exposés on this form of professional volunteerism as well as commentary on potential spill-over effects. Eckhauser and Freishlag suggest that STMM volunteerism proceeds naturally from the elements of the Hippocratic Oath and serves to restore "personal and professional satisfaction" away from the administrative burden of domestic practice (Eckhauser \& Freishlag, 2005). While acknowledging the body of literature on volunteerism, Withers et al accepted that individual motives for volunteering are unknown (Withers, Browner, \& Aghaloo, 2013).

Taking an alternative viewpoint, we sought an understanding of the social, economic and diplomatic consequences on STMM deployment. How do personal expenditures factor in? Has STMM activity reached such a level of organization that peer influence among licensed professionals, quality 
measures, and cost-effectiveness affect the manner in which they are carried out? We address these questions under the rubric of professionalization, a social process whereby an occupation or trade elevates its integrity and competence through association and scientific advancement, among other steps (Abbott, 1991; Wilensky, 1964). Specifically, we refer to professionalization not of the participating physicians, but rather of the praxis of STMMs. Is the activity conceptualized diplomatically as foreign aid or as strategic persuasion? Do STMM participants consider economic or market perspectives, such as the market failures that may be addressed through this kind of philanthropy, relevant? What it is that they seek via the transaction?

Among the universe of potential aspects, we focused on a limited selection distilled in five key questions (Table 2.1) as a framework for meeting the research objective. These questions were chosen because they allow one to organize the current literature for commentary on intended or unintended social, economic, and diplomatic aspects, and what consequences they may have on STMM activity. Thus, the resulting exploratory, qualitative review did not begin from a theory-based perspective nor attempt to generate theory. Rather, we applied a framework synthesis, using categories stipulated by the five key questions (Snilstveit, Oliver, \& Vojtkova, 2012). We selected three of the key questions because they align conceptually with the three broad, principal reasons suggested by $\mathrm{Oxfam}^{2}$ for US foreign aid: national security, economics and applying normative values (Oxfam, 2014). The two additional key questions regarding professionalization and costs were selected because they are relevant to the sustainability of STMM activity, so cogent in our time when international commissions discuss the sustainability of development goals and global governance in health at the political level in the post-2015 agenda (Bryden, 2007). We believe these areas merit attention because of the global socio-economic and geopolitical context in which STMM activity occurs.

${ }^{2}$ Oxfam is an international confederation of 17 organizations working in approximately 94 countries worldwide to find solutions to poverty and what it considers injustice around the world. https://www.oxfam.org/en/about/ Accessed 29 July 2015 


\subsection{Methods}

Keywords and Databases

The construction of the chain of key words and the systematic search in the databases were assisted by a university librarian. Articles were identified from PubMed of the US National Institutes of Health Library of Medicine using key words with MESH terms as the primary search database. A search term algorithm similar to that used by Martiniuk et al was used after adjusting for dates to include the 67 years from 1947 to 2014 (Martiniuk, Manouchehrian, et al., 2012). Additional terms were added to facilitate the exclusion of dental and military based mission articles No requirement for English language was implemented. ESBCOhost was subsequently searched using more limited terms for the same period as the secondary search database (see Search Terms text boxes). Finally, the bibliographies of the articles selected from PubMed and EBSCOhost reviews were searched for additional relevant articles. 
Search Terms:

\section{PubMed}

("medical missions, official"[MeSH Terms] OR "medical missions, official"[MeSH Terms]) OR (((("1950/08/01"[PDAT] : "3000"[PDAT]) AND (("brigade"[All Fields] OR (("mission"[All Fields] AND "shortterm"[All Fields]) OR ("mission"[All Fields] AND "overseas"[All Fields]) OR ("mission"[All Fields] AND "foreign"[All Fields])) OR (("trip"[All Fields] AND "short-term"[All Fields]) OR ("trip"[All Fields] AND "overseas"[All Fields]) OR ("trip"[All Fields] AND "foreign"[All Fields]))) OR (("mission"[All Fields] AND "volunteer"[All Fields]) OR ("trip"[All Fields] AND "volunteer"[All Fields]) OR ("short-term"[All Fields] AND "volunteer"[All Fields]) OR ("overseas"[All Fields] AND "volunteer"[All Fields]) OR ("foreign"[All Fields] AND "volunteer"[All Fields])) OR (("foreign"[All Fields] AND "humanitarian"[All Fields]) OR ("shortterm"[All Fields] AND "humanitarian"[All Fields]) OR ("overseas"[All Fields] AND "humanitarian"[All Fields])) OR ("medical mission"[All Fields] OR "medical missions"[All Fields]) OR (("assistance"[All Fields] AND "short-term"[All Fields]) OR ("assistance"[All Fields] AND "overseas"[All Fields]) OR ("assistance"[All Fields] AND "foreign"[All Fields]) OR ("assistance"[All Fields] AND "humanitarian"[All Fields]) OR ("assistance"[All Fields] AND "volunteer"[All Fields]))) AND "humans"[MeSH Terms]) NOT (("dental clinics"[MeSH Terms] OR ("dental"[All Fields] AND "clinics"[All Fields]) OR "dental clinics"[All Fields] OR "dental"[All Fields]) OR ("dentistry"[MeSH Terms] OR "dentistry"[All Fields]) OR "dent"[All Fields])) NOT ("military personnel"[MeSH Terms] OR "military personnel"[All Fields] OR "military"[All Fields]))

\section{EBSCOhost}

["medical mission" OR "medical missions" AND "short term"]

Screening Process

The PRISMA (Preferred Reporting Items for Systematic Reviews and Metaanalyses) guidelines were implemented to standardize the elements of this systematic review (Moher et al, 2009). Additional file 1 provides the 
PRISMA 2009 checklist. Two researchers independently screened the search results and concurred on the final relevant selections. Eligibility of potentially relevant articles was assessed throughout the entire review process to assure that enough detail was provided in the article to determine if inclusion and exclusion criteria were satisfied. For the primary (PubMed) search, the first filter involved review of titles and abstracts for indications that the article was related to STMMs per the above description. The second filter involved review of titles and abstracts that passed the first filter for indications that the article may be relevant to one of the key questions of the systematic review. The third filter involved reviewing the full text of articles passing the first and second filters to determine if the article satisfied each of our inclusion and exclusion criteria and was in fact relevant to a key question. For the secondary (EBSCOhost) search, the same filters were applied to new titles not found in the primary search. Lastly, the bibliographies of the articles selected from the primary and secondary databases were then evaluated with the filtering algorithm applied to the databases.

\section{Inclusion Criteria}

Articles published between 1947 and 2014 were selected if they were available in indexed journals from the databases and if they discussed medical and surgical missions designed to provide direct patient care in LMICs wherein the physician participants are principally gainfully engaged in their home countries. The scope of this study relates to planned and scheduled (non-emergent) missions using unpaid volunteer physicians for short term direct patient care excursions from high income countries to LMICs. Articles were not excluded on the basis of peer review if they provided at least one unique perspective related to a key question. Because the number of full articles focused on our key questions was low, we elected to include editorials, letters or commentaries in the selection process if they otherwise satisfied all inclusion and exclusion criteria, consistent with a framework synthesis.

\section{Exclusion Criteria}

Articles with a primary focus on relief efforts in participants' home countries, responsive disaster relief or missions that require effective cessation of the physician participants' home practices were not included in this review. Articles that dealt with medical services by government sector agencies or the 
military, the logistics of medical supplies, dentistry, nursing, other ancillary services or not related to direct voluntary medical services to patients were also excluded.

\section{Analysis}

The articles included in the final list were thoroughly reviewed and information related to the five questions listed in Table 2.1 was extracted. Based on this, articles were classified. When articles similarly touched on multiple questions, consensual discretion was used to assign the articles to the categories that appeared most relevant. As articles and studies were primarily qualitative in nature, no summary measures were calculated.

Table 2.1 Key Questions of the Systematic Review

\begin{tabular}{|l|l|}
\hline \multicolumn{2}{|c|}{ Key Questions } \\
\hline 1 & $\begin{array}{l}\text { Have STMMs been critically analyzed with respect to normative values } \\
\text { of volunteerism, altruism and philanthropy? }\end{array}$ \\
\hline 2 & Have elements of professionalization of STMM activity emerged? \\
\hline 3 & $\begin{array}{l}\text { Have authors addressed basic economic principles that govern } \\
\text { transactions between parties, in this context, between physicians and } \\
\text { recipients of care, or other market mechanisms in STMM activity? }\end{array}$ \\
\hline 4 & Are there data on personal costs or cost-effectiveness of STMMs? \\
\hline 5 & $\begin{array}{l}\text { Spill-over effects: Do physicians view STMMS as foreign aid? Do } \\
\text { participating physicians view STMMs as diplomacy or as part of } \\
\text { strategic soft power? }\end{array}$ \\
\hline
\end{tabular}

\subsection{Results}

The results herein are separated into the article selection and characterization, followed by the findings related to the key questions from the selected articles.

\subsubsection{Article selection and characteristics}

Figure 2.1 illustrates the search algorithm and results of the filtering process of the primary and secondary database searches and bibliography review of 
articles selected from the databases on the basis of the inclusion and exclusion criteria. Applying the filters and criteria, composite inter-observer correlation approached 1, with only 10 articles in the search algorithm among more than 4000 initial titles requiring co-deliberation for ultimate selection or rejection. In composite, 41 unique articles were ultimately deemed to meet criteria and provide relevant information on short-term non-compensated medical missions as distributed among the key questions (Table 2.2). One article (Maki et al, 2008) applied to 3 key questions and one article (Chapin and Doocy, 2010) applied to 2 key questions; the remainder applied to a single key question. Relevant information was extracted from the publications and analyzed as described in the methods section. Characteristics of the publishing journals including country origin, manuscript type, refereed status and discipline base of the selected articles are displayed in Table 2.2. The key findings of the review are subsequently described. 


\title{
Figure 2.1 Systematic Review Search and Selection Algorithm
}

\author{
Primary Search \\ PubMed \\ 30 April 2014
}

("1950/01/01"[PDAT]: "3000"[PDAT]) AND (("brigade"[All Fields] OR (("mission"[All Fields] AND "short-term"[All Fields]) OR ("mission"[All Fields] AND"overseas"[All Fields]) OR ("mission"[All Fields] AND "foreign"[All Fields])) OR (("trip"[All Fields] AND "short-term"[All Fields]) OR ("trip"[All Fields] AND "overseas"[All Fields]) OR ("trip"[All Fields] AND "foreign"[All Fields]))) OR (("mission"[All Fields] AND"volunteer"[All Fields]) OR ("trip"[All Fields] AND "volunteer"[All Fields]) OR ("short-term"[All Fields] AND "volunteer" [All Fields]) OR ("overseas" [All Fields] AND "volunteer" [All Fields]) OR ("foreign"[All Fields] AND "volunteer"[All Fields])) OR (("foreign"[All Fields] AND "humanitarian"[All Fields]) OR ("short-term"[All Fields] AND "humanitarian"[All Fields]) OR ("overseas"[All Fields] AND "humanitarian"[All Fields])) OR ("medical mission"[All Fields] OR "medical missions"[All Fields]) OR ("medical tourism"[All Fields] OR "health tourism"[All Fields] OR ("tourism"[All Fields] AND "medical"[All Fields])) OR (" "assistance"[All Fields] AND "short-term"[All Fields]) OR ("assistance"[AllFields] AND "overseas"[All Fields]) OR ("assistance"[All Fields] AND "foreign"[All Fields]) OR ("assistance"[All Fields] AND "humanitarian"[All Fields]) OR ("assistance"[All Fields] AND "volunteer"[All Fields]))) AND ("humans"[MeSH Terms] AND English[lang])

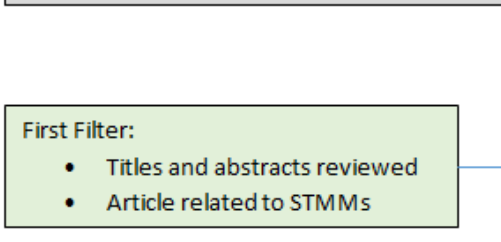

\section{Second Filter:}

- Titles and abstracts reviewed

- May be relevant to key questions

\section{Third Filter: \\ - Full text reviewed \\ - Meets inclusion/exclusion criteria \\ - Relevant to key question}
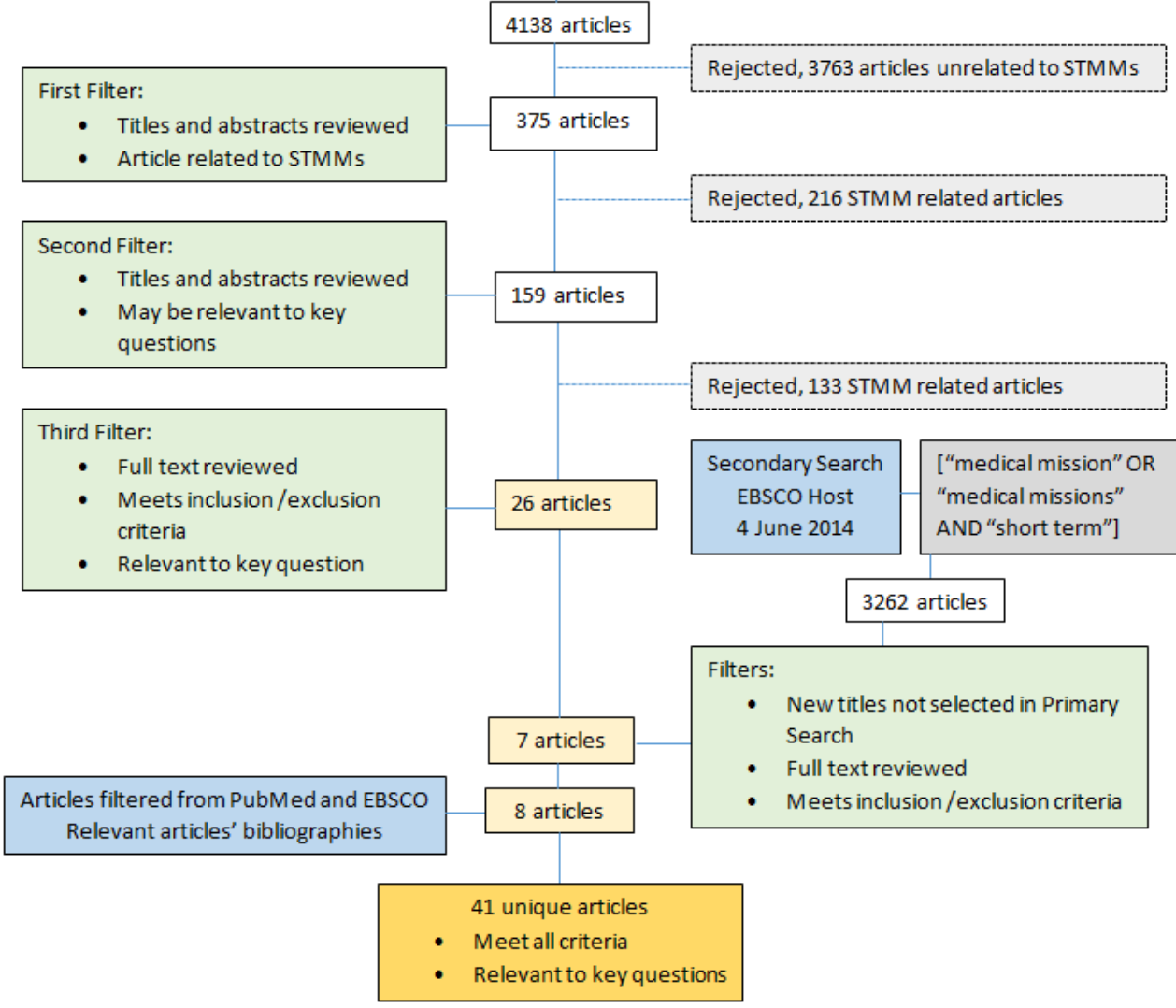
Table 2.2 Overall Description of the Articles Selected for the Review

\begin{tabular}{|c|c|c|c|}
\hline $\begin{array}{l}\text { Relation to systematic review question } \\
\text { areas }\end{array}$ & Total & $\begin{array}{l}\text { Used in prior } \\
\text { category(ies) }\end{array}$ & Unique \\
\hline $\begin{array}{l}\text { 1. Volunteerism, altruism and } \\
\text { philanthropy }\end{array}$ & 1 & - & 1 \\
\hline $\begin{array}{l}\text { 2. Professional professionalization } \\
\text { a. Professionalization } \\
\text { b. Guidelines } \\
\text { c. Organization - "How to" }\end{array}$ & $\begin{array}{l}5 \\
14 \\
9 \\
\end{array}$ & $\begin{array}{l}- \\
1 \\
-\end{array}$ & $\begin{array}{l}5 \\
13 \\
9 \\
\end{array}$ \\
\hline 3. Analysis of market forces & 1 & - & 1 \\
\hline 4. Expenditures for STMMs & 10 & 2 & 8 \\
\hline 5. Spill-over effects & 4 & - & 4 \\
\hline \multicolumn{4}{|l|}{ Year of publication } \\
\hline 1. $1947-1980$ & \multicolumn{3}{|l|}{-} \\
\hline 2. $1981-2000$ & \multicolumn{3}{|l|}{3} \\
\hline 3. $2001-2005$ & \multicolumn{3}{|l|}{6} \\
\hline 4. $2006-2010$ & \multicolumn{3}{|l|}{14} \\
\hline 5. $2011-2014$ & \multicolumn{3}{|l|}{18} \\
\hline \multicolumn{4}{|l|}{ Journal origin } \\
\hline 1. USA & \multicolumn{3}{|l|}{36} \\
\hline 2. Netherlands & \multicolumn{3}{|l|}{1} \\
\hline 3. Canada & \multicolumn{3}{|l|}{1} \\
\hline $\begin{array}{l}\text { 4. International or nationality } \\
\text { indeterminate }\end{array}$ & \multicolumn{3}{|l|}{3} \\
\hline \multicolumn{4}{|l|}{ Type of manuscript } \\
\hline 1. Journal article & \multicolumn{3}{|l|}{37} \\
\hline 2. Editorial or letter & \multicolumn{3}{|l|}{4} \\
\hline
\end{tabular}


Table 2.2 Overall Description of the Articles Selected for the Review (continued)

\begin{tabular}{|c|l|}
\hline Peer review & \\
\hline 1. Refereed & 37 \\
\hline 2. Non-refereed & 4 \\
\hline Discipline of journal & \\
\hline 1. Craniofacial / plastic surgery & 12 \\
\hline 2. General surgery & 9 \\
\hline 3. General medical & 5 \\
\hline 4. Health science/ public health & 5 \\
\hline 5. Orthopedics & 3 \\
\hline 6. Dermatology & 3 \\
\hline 7. Anesthesiology & 2 \\
\hline 8. Pediatric medical & 1 \\
\hline 9. Economics & 1 \\
\hline
\end{tabular}

2.4.2 Findings Related to the Key Questions

Volunteerism, Altruism and Philanthropy

While it may be considered a sine qua non that altruism and philanthropy motivate medical and surgical volunteerism, our systematic review retained a singular article that addressed our key question on volunteerism, altruism or philanthropy in reference to STMMs (Rose-Ackerman, 1996). In the context of an exhaustive paper designed to orient surgeons to international volunteerism, Pezzella briefly referred to proceedings of an October, 2003 symposium at Trinity College as reported by Alkire and Chen wherein the motivation for unspecified global health initiatives was characterized as 
deriving from four schools of moral values (Pezzella, 2006) (Alkire \& Chen, $2004)^{3}$.

Professionalization and Elements of Professionalization

Our review identified no journal wholly dedicated to STMMs. Reports are generally scattered among medical and surgical specialty and subspecialty publications. Further, our online search did not reveal a national or international periodic congress dedicated to the issues and practice of STMMs. The publications in Table 2.3 convey commentary on or attempts at collectivism beyond a collaborative project, guidelines or set of instructions. Butler published a worldwide online search for any networks for volunteer pediatric surgery and found none (Butler, 2009). Fisher and Fisher lucidly describe the need, challenges and barriers to collaboration among surgical STMM NGOs (Fisher \& Fisher, 2014). In the enduring competition among NGOs for sources of funding, failure to cooperate with other NGOs and military resources was catalogued by Welling et al as the third of seven sins of humanitarian medicine (Welling, Ryan, Burris, \& Rich, 2010).

3 Humanitarianism, acting virtuously towards those in need, based on compassion, empathy, or altruism as mandated in the philosophy of great religions; utilitarianism, maximizing aggregate subjective happiness, since general good health is in the best interest of all including those not inclined to altruism; equity, a fairer distribution of health capabilities; rights - fulfilling our obligations so others are dignified (Alkire \& Chen, 2004). 
Table 2.3 Professionalization in STMMs

\begin{tabular}{|l|l|l|l|}
\hline Author & Journal & Year & Contribution \\
\hline $\begin{array}{l}\text { Maki et al (Maki } \\
\text { et al., 2008) }\end{array}$ & $\begin{array}{l}\text { BMC Health Services } \\
\text { Research }\end{array}$ & 2008 & $\begin{array}{l}\text { Designed } \\
\text { instruments to } \\
\text { evaluate mission } \\
\text { quality }\end{array}$ \\
\hline $\begin{array}{l}\text { Butler (Butler, } \\
\text { 2009) }\end{array}$ & $\begin{array}{l}\text { Journal of Pediatric } \\
\text { Surgery }\end{array}$ & 2009 & $\begin{array}{l}\text { Published Online } \\
\text { Search that failed } \\
\text { to find } \\
\text { collaborative } \\
\text { volunteer } \\
\text { pediatric surgery } \\
\text { network }\end{array}$ \\
\hline $\begin{array}{l}\text { Kingham } \\
\text { (Kingham, Price, } \\
\text { Casey, Rogers, \& } \\
\text { Kushner, 2011) }\end{array}$ & $\begin{array}{l}\text { American College of } \\
\text { Surgeons }\end{array}$ & 2011 & $\begin{array}{l}\text { Noted absence of } \\
\text { mission and } \\
\text { volunteer } \\
\text { credentialing } \\
\text { body }\end{array}$ \\
\hline $\begin{array}{l}\text { Welling et al } \\
\text { (Welling et al., } \\
\text { 2010) }\end{array}$ & $\begin{array}{l}\text { World Journal of } \\
\text { Surgery }\end{array}$ & 2012 & $\begin{array}{l}\text { Argues that } \\
\text { effectiveness of } \\
\text { missions suffers } \\
\text { from lack of } \\
\text { collaboration }\end{array}$ \\
\hline $\begin{array}{l}\text { Fisher and } \\
\text { Fisher (Fisher \& } \\
\text { Fisher, 2014) }\end{array}$ & $\begin{array}{l}\text { Anesthesia and } \\
\text { Analgesia }\end{array}$ & 2014 & $\begin{array}{l}\text { Reviews pitfalls of } \\
\text { non-integration } \\
\text { of effort and } \\
\text { discusses } \\
\text { solutions }\end{array}$ \\
\hline
\end{tabular}

In contrast, our literature review pointed to online sites that function as "clearing houses" to direct and match physicians to planned missions and mission organizations. Examples include the American College of Surgery's OperationGivingBack.facs.org and globalpaediatricsurgery.org, the Global Paediatric Surgery Network (Casey, 2007; Politis et al., 2011). 
Elements of professionalization are identifiable in our review. Fourteen articles, all from refereed journals, promoted guidelines for the execution for STMMs. The earliest publication by Yeow et al in 2002 summarized a consensus congress of volunteer cleft palate mission groups from multiple nations, and stands out in its international collectivism (Yeow et al., 2002). Indeed, half of the articles that espouse guidelines for volunteer missions are found in journals of facial plastic and reconstructive specialties.

Table 2.4 tabulates the sets of guidelines from various sources identified in this review. One finds sophisticated and detailed guidelines, reviewed and approved by multiple specialty societies linked with surgical procedures (Eberlin \& Zaleski, 2008; Schneider, Politis, et al., 2011). Schneider et al provided check list forms for mission preparation; the content of their guidelines draws from collaboration and co-authorship across specialties in alignment with the VIPS Guidelines (Politis et al., 2011; Schneider, Politis, et al., 2011) ${ }^{4}$. Ethical guidelines for surgical informed consent, surgical photography in the context of STMMs and pediatric craniofacial missions, as well as guidelines for emergency preparedness and response during STMMs and the performance of special multi-staged reconstructive procedures are available (Hadlock, 2008; Holt, 2012a, 2012b; Schneider, Migliori, Gosain, Gregory, \& Flick, 2011; Vyas, Eberlin, \& Hamdan, 2013).

\footnotetext{
${ }^{4}$ Plastic Surgery Education Foundation: Volunteers in Plastic Surgery (VIPS) Guidelines for the Care of Children in the Less Developed World. Version 5.0. January 15, 2009
} 
Table 2.4 Published guidelines for STMMs

\begin{tabular}{|c|c|c|c|}
\hline \multicolumn{4}{|c|}{ Guidelines (Surgical) } \\
\hline Author & Publication & Year & Contribution \\
\hline $\begin{array}{l}\text { Yeow et al } \\
\text { (Yeow et al., } \\
2002)\end{array}$ & J Craniofacial Surgery & 2002 & $\begin{array}{l}\text { International } \\
\text { consensus guidelines } \\
\text { for cleft missions }\end{array}$ \\
\hline $\begin{array}{l}\text { Eberlin et al } \\
\text { (Eberlin \& } \\
\text { Zaleski, 2008) } \\
\end{array}$ & $\begin{array}{l}\text { Cleft Palate } \\
\text { Craniofacial Journal }\end{array}$ & 2008 & $\begin{array}{l}\text { Quality assurance } \\
\text { guidelines based on } \\
20 \text { years' experience }\end{array}$ \\
\hline $\begin{array}{l}\text { Hadlock } \\
\text { (Hadlock, 2008) }\end{array}$ & $\begin{array}{l}\text { Archives of Facial and } \\
\text { Plastic Surgery }\end{array}$ & 2008 & $\begin{array}{l}\text { Keys to optimizing } \\
\text { outcomes in } \\
\text { multistage } \\
\text { procedures }\end{array}$ \\
\hline $\begin{array}{l}\text { Schneider et al } \\
\text { (Schneider, } \\
\text { Politis, et al., } \\
2011 ; \\
\text { Schneider, } \\
\text { Migliori, et al., } \\
\text { 2011) }\end{array}$ & $\begin{array}{l}\text { Plastic and } \\
\text { Reconstructive } \\
\text { Surgery }\end{array}$ & 2011 & $\begin{array}{l}\text { Guidelines for plastic } \\
\text { surgery in pediatrics } \\
\text { (Part I); Ethical } \\
\text { Guidelines (Part II) }\end{array}$ \\
\hline $\begin{array}{l}\text { Politis et al } \\
\text { (Politis et al., } \\
\text { 2011) }\end{array}$ & $\begin{array}{l}\text { Anesthesia and } \\
\text { Analgesia }\end{array}$ & 2011 & $\begin{array}{l}\text { Guidelines for } \\
\text { perioperative care in } \\
\text { pediatrics } \\
\text { (collaborating } \\
\text { specialties) }\end{array}$ \\
\hline $\begin{array}{l}\text { Holt (Holt, } \\
\text { 2012a, 2012b) }\end{array}$ & $\begin{array}{l}\text { Archives of Facial and } \\
\text { Plastic Surgery }\end{array}$ & 2012 & $\begin{array}{l}\text { Ethical guidelines for } \\
\text { informed consent (I) } \\
\text { and case photography } \\
\text { (II) }\end{array}$ \\
\hline $\begin{array}{l}\text { Vyas et al (Vyas } \\
\text { et al., 2013) }\end{array}$ & $\begin{array}{l}\text { Plastic and } \\
\text { Reconstructive } \\
\text { Surgery }\end{array}$ & 2013 & $\begin{array}{l}\text { Guidelines for surgical } \\
\text { emergency } \\
\text { preparedness and } \\
\text { response }\end{array}$ \\
\hline $\begin{array}{l}\text { Grimes et al } \\
\text { (Grimes et al., } \\
\text { 2013) }\end{array}$ & $\begin{array}{l}\text { World Journal of } \\
\text { Surgery }\end{array}$ & 2013 & $\begin{array}{l}\text { General guidelines } \\
\text { applicable to any type } \\
\text { of surgical mission }\end{array}$ \\
\hline
\end{tabular}


Table 2.4 Published guidelines for STMMs (continued)

\begin{tabular}{|c|c|c|c|}
\hline \multicolumn{4}{|c|}{ Guidelines (Non-surgical) } \\
\hline Author & Publication & Year & Contribution \\
\hline $\begin{array}{l}\text { Suchdev et } \\
\text { al(Suchdev, } \\
\text { Ahrens, \& Click, } \\
\text { 2007) }\end{array}$ & Ambulatory Pediatrics & 2007 & $\begin{array}{l}\text { Ethical guidelines for } \\
\text { sustainable non- } \\
\text { surgical pediatric } \\
\text { missions }\end{array}$ \\
\hline $\begin{array}{l}\text { Maki et al(Maki } \\
\text { et al., 2008) }\end{array}$ & $\begin{array}{l}\text { BMC Health Services } \\
\text { Research }\end{array}$ & 2008 & $\begin{array}{l}\text { Developed six } \\
\text { instruments to assess } \\
\text { mission quality }\end{array}$ \\
\hline $\begin{array}{l}\text { Chapin \& Doocy } \\
\text { (Chapin \& } \\
\text { Doocy, 2010) }\end{array}$ & $\begin{array}{l}\text { World Health \& } \\
\text { Population }\end{array}$ & 2010 & $\begin{array}{l}\text { Integrated broad } \\
\text { guidelines for all } \\
\text { (surgical/non- } \\
\text { surgical) missions }\end{array}$ \\
\hline $\begin{array}{l}\text { DeCamp } \\
\text { (Decamp, 2011) }\end{array}$ & HEC Forum & 2011 & $\begin{array}{l}\text { Aligns ethical } \\
\text { guidelines for STMMs } \\
\text { with those } \\
\text { implemented in the } \\
\text { conduct of } \\
\text { international clinical } \\
\text { drug/device trials }\end{array}$ \\
\hline
\end{tabular}

Grimes et al recently proposed more general guidelines for surgeons when going on a volunteer mission (Grimes et al., 2013). Drawing attention to the burden of surgical need not addressed by typical world health initiatives, their key recommendations emphasized designing trips to focus on actual local needs, locally coordinated training of host country surgeons and support staff, providing the financial assistance to make the training results sustainable and monitoring not only surgical outcomes but also quality of life outcomes.

No similar sets of proposed tactical guidelines directed toward medical (nonsurgical) STMMs were found in this systematic review. Following their convenience survey of predominately general medicine and pediatric mission participants, Chapin and Doocy blended suggestions from the existing literature to reiterate broad strategic guidelines for all manner of STMMs 
(Chapin \& Doocy, 2010). Ethical guiding principles have been proposed for selecting or organizing pediatric care STMMs by Suchdev et al (Suchdev et al., 2007). DeCamp insightfully juxtaposed these guidelines with similar principles governing clinical drug trials in developing countries (Decamp, 2011; Emanuel, Wendler, Killen, \& Grady, 2004).

The contribution of Maki et al has been cited frequently in the relevant literature since its publication in 2008 (58 count by Google Scholar, May 2014) (Maki et al., 2008). The authors point out the absence of national and international sanctioning organizations for STMMs as well as the absence of standardized quality measurement instruments for missions or mission organizations. Maki and colleagues pooled impressions from several mission goers to develop a set of instruments designed to assess mission quality. In addition, the lead author established a web site as a clearing house for mission organizations and participants to pool their experiences using these six instruments to serve as templates (STMMconnect.com). Despite the prevalence of citations to Maki's work, we found only a singular application of the Maki instruments (Chiu, Weng, Chen, Yang, \& Lee, 2012). After five years of disuse, the STMMconnect.com website has been taken down as of May 2013 for lack of activity and funding.

Nine articles could be grouped as "How to", wherein authors codified single or multiple mission experiences into steps and checklists to assist others in planning and executing missions (Table 2.5). These differ from guideline articles in that they address the pragmatics of mission accomplishment more than concept or propriety. While the selected set varied broadly in the level of formality, it appears likely that each would engage a readership that other sources might miss, and provided at least one unique perspective. Our selection excluded mission reports with anecdotal advice. 
Table 2.5 "How to" Publications on STMMs

\begin{tabular}{|c|c|c|c|}
\hline Author & Journal & Year & Contribution \\
\hline $\begin{array}{l}\text { Norton } \\
\text { (Norton, 1999) }\end{array}$ & Dermatologic Clinics & 1999 & $\begin{array}{l}\text { Planning } \\
\text { dermatologic missions }\end{array}$ \\
\hline $\begin{array}{l}\text { Landau } \\
\text { (Landau, 2001) }\end{array}$ & $\begin{array}{l}\text { North Carolina } \\
\text { Medical Journal* }\end{array}$ & 2001 & $\begin{array}{l}\text { Detailed instructions } \\
\text { on executing primary } \\
\text { care missions }\end{array}$ \\
\hline $\begin{array}{l}\text { Kightlinger } \\
\text { (Kightlinger, } \\
\text { 2003) }\end{array}$ & Medical Economics* & 2003 & $\begin{array}{l}\text { Self-care for the } \\
\text { mission participant }\end{array}$ \\
\hline $\begin{array}{l}\text { Hoover et al } \\
\text { (Hoover et al., } \\
\text { 2005a) }\end{array}$ & $\begin{array}{l}\text { Journal of the } \\
\text { National Medical } \\
\text { Association }\end{array}$ & 2005 & $\begin{array}{l}\text { Operational } \\
\text { preparations for } \\
\text { missions to African } \\
\text { countries }\end{array}$ \\
\hline $\begin{array}{l}\text { Hollier et al } \\
\text { (Hollier et al., } \\
\text { 2010) }\end{array}$ & $\begin{array}{l}\text { Journal of Craniofacial } \\
\text { Surgery }\end{array}$ & 2010 & $\begin{array}{l}\text { Preparation, } \\
\text { implementation }\end{array}$ \\
\hline $\begin{array}{l}\text { Boyd (Boyd, } \\
\text { 2012) }\end{array}$ & $\begin{array}{l}\text { Journal of the } \\
\text { American Academy of } \\
\text { Dermatology }\end{array}$ & 2012 & $\begin{array}{l}\text { Specific therapeutic } \\
\text { suggestions for } \\
\text { dermatologic missions }\end{array}$ \\
\hline $\begin{array}{l}\text { Ramirez- } \\
\text { Fort(Ramirez- } \\
\text { Fort, 2013) } \\
\end{array}$ & $\begin{array}{l}\text { International Journal } \\
\text { of Dermatology }\end{array}$ & 2013 & $\begin{array}{l}\text { Planning } \\
\text { dermatologic missions }\end{array}$ \\
\hline $\begin{array}{l}\text { Patel et al } \\
\text { (Patel et al., } \\
\text { 2013) }\end{array}$ & $\begin{array}{l}\text { Annals of Plastic } \\
\text { Surgery }\end{array}$ & 2013 & $\begin{array}{l}\text { Sustainable burn } \\
\text { missions }\end{array}$ \\
\hline $\begin{array}{l}\text { Birman \& } \\
\text { Kolkin (Birman } \\
\text { \& Kolkin, 2013) }\end{array}$ & $\begin{array}{l}\text { The Journal of Hand } \\
\text { Surgery }\end{array}$ & 2013 & $\begin{array}{l}\text { Planning hand surgery } \\
\text { missions }\end{array}$ \\
\hline
\end{tabular}

Landau exhaustively parlayed his experience from a general and family practice perspective into a concise and practical treatise for primary care missions anywhere (Landau, 2001). Other reports cater to burn, hand and craniofacial surgery missions, dermatology and the well-being of the mission- 
goer (Birman \& Kolkin, 2013; A S Boyd, 2012; Hollier et al., 2010; Kightlinger, 2003; Norton, 1999a; Patel et al., 2013; Ramirez-Fort, 2013). Hoover et al published extensive operational instructions focused on the preparation for missions to African countries in the Journal of the National Medical Association, a periodical that advocates the interests of African American physicians in the US (Hoover et al., 2005a).

\section{Economic and Market Forces}

Altruism may be in part a societal response to market failures to provide public goods (Andreoni, 1990). In our single retained article for this key question, Mendoza provided an accessible account of how medical missions arise to redress market failures for essential medical services (Mendoza, 2009). Using cleft lip/palate interventions in the Philippines as an example, Mendoza contemplated how the interplay of public, private and mission partnerships can operate and still avoid a crowding-out effect to local physicians. Mendoza further discussed the pitfalls that threaten the success of such partnerships in developing or corrupt environments

No articles were found in our search that address other basic market forces that underlie the transactions that take place between individual medical providers and medical care recipients during STMMS. Such analysis might inform the concerns regarding distortions between cost and benefit related to STMMs (Crown, 2005).

\section{Expenditures for STMMs}

In parallel to Sykes, our systematic review revealed no identifiable sources or reports on pooled data for expenditures for short-term medical missions (Sykes, 2014). Casual references to rough estimates of single missions' and other cost or cost-effectiveness data occur in isolation (Table 2.6). Estimating an average expense of $\$ 47,000$ per mission, Maki et al projected that an annual direct investment in STMMs from the US alone could readily exceed \$250 million (Maki et al., 2008). Other unsystematically obtained single mission costs and round figures from mission organization expenditures are seen in sparse reports (Chapin \& Doocy, 2010; Crown, 2005; Propsner, 1998). 
Table 2.6 Expenditures for Short Term Medical Missions

\begin{tabular}{|c|c|c|c|}
\hline Author & Journal & Year & Contribution \\
\hline $\begin{array}{l}\text { Propsner } \\
\text { (Propsner, 1998) }\end{array}$ & $\begin{array}{l}\text { New Jersey } \\
\text { Medicine* }\end{array}$ & 1998 & $\begin{array}{l}\$ 147,000 \text { spent on one US } \\
\text { facial reconstruction surgical } \\
\text { mission to Africa. } \$ 28 \mathrm{M} \text { in free } \\
\text { services annually by one } \\
\text { organization }\end{array}$ \\
\hline $\begin{array}{l}\text { Crown (Crown, } \\
\text { 2005) }\end{array}$ & $\begin{array}{l}\text { Tennessee } \\
\text { Medicine* }\end{array}$ & 2005 & $\begin{array}{l}\$ 40,480 \text { in direct and } \\
\text { opportunity cost for } 24 \\
\text { persons for five days' work }\end{array}$ \\
\hline $\begin{array}{l}\text { Dupuis (Dupuis, } \\
\text { 2006) }\end{array}$ & $\begin{array}{l}\text { Plastic and } \\
\text { Reconstructive } \\
\text { Surgery }\end{array}$ & 2006 & $\begin{array}{l}\text { \$78 average cost of operations } \\
\text { if local staff utilized } \\
\text { ("minimalist approach") }\end{array}$ \\
\hline $\begin{array}{l}\text { Wolfberg } \\
\text { (Wolfberg, 2006) }\end{array}$ & $\begin{array}{l}\text { The New } \\
\text { England Journal } \\
\text { of Medicine }\end{array}$ & 2006 & $\begin{array}{l}\text { Dramatically higher } \\
\text { expenditures if full surgical } \\
\text { team travels (in contrast to } \\
\text { minimalist approach) }\end{array}$ \\
\hline $\begin{array}{l}\text { Maki et al (Maki } \\
\text { et al., 2008) }\end{array}$ & $\begin{array}{l}\text { BMS Health } \\
\text { Research }\end{array}$ & 2008 & $\begin{array}{l}\$ 47,000 \text { per mission; } \$ 250 M \\
\text { annually from US }\end{array}$ \\
\hline Magee et al & $\begin{array}{l}\text { World Journal of } \\
\text { Surgery }\end{array}$ & 2010 & Proposal for re-valuing DALYS \\
\hline $\begin{array}{l}\text { Chapin \& Doocy } \\
\text { (Chapin \& Doocy, } \\
\text { 2010) }\end{array}$ & $\begin{array}{l}\text { World Health } \\
\text { and Population }\end{array}$ & 2010 & $\begin{array}{l}\$ 22,647 \text { average cost for a } \\
\text { medical mission (convenience } \\
\text { survey) }\end{array}$ \\
\hline $\begin{array}{l}\text { Gosselin et al } \\
\text { (Gosselin et al., } \\
\text { 2011) }\end{array}$ & $\begin{array}{l}\text { World Journal of } \\
\text { Surgery }\end{array}$ & 2011 & $\begin{array}{l}\text { Orthopedic relief mission costs } \\
\text { not more than planned mission } \\
\text { costs in relation to DALYS }\end{array}$ \\
\hline $\begin{array}{l}\text { Chen et al (Chen } \\
\text { et al., 2012) }\end{array}$ & $\begin{array}{l}\text { World Journal of } \\
\text { Surgery }\end{array}$ & 2012 & $\begin{array}{l}\text { Activity based costing for a } 5 \text { - } \\
\text { day orthopedic mission cost } \\
\text { effective in relation to DALYS }\end{array}$ \\
\hline $\begin{array}{l}\text { Moon et al } \\
\text { (Moon, Perry, \& } \\
\text { Baek, 2012) }\end{array}$ & $\begin{array}{l}\text { World Journal of } \\
\text { Surgery }\end{array}$ & 2012 & $\begin{array}{l}\text { Cleft lip/palate mission cost } \\
\text { effective in relation to DALYS }\end{array}$ \\
\hline
\end{tabular}

No articles formally tabulated primary or secondary data on physician direct expenditures or opportunity costs. Pointedly, Crown conjectured that with a visiting non-surgical team's costs “it would be possible to recruit, educate and retain a local physician, nurse and support staff to man the same clinic for a 
year" implying that the trade-off for a five-day "feel-good" experience is unjustified (Crown, 2005).

Platform and local staff integration appear to be factors in mission cost. Arguments suggest that a single physician or small teams of surgeons utilizing local nursing and support staff, i.e., a "minimalist" approach", has a cost efficiency per procedure advantage over fully functional travelling teams (Dupuis, 2006; Wolfberg, 2006) .

Reports are beginning to accumulate wherein activity based costs per disability affected life year saved (DALYS) methodology to assess cost effectiveness is applied (Magee, Vander Burg, \& Hatcher, 2010). Seminal reports of a one week orthopedic trauma surgery mission and a cleft lip/cleft palate mission asserted their cost effectiveness from both sending and receiving party perspectives (Moon et al., 2012). Using DALYS analysis, Gosselin found that cost-effectiveness of trauma surgery in planned STMMs was not favorable compared to disaster-related short-term excursions (Gosselin et al., 2011).

Spill-Over Effects: Diplomacy, National Security and Attitudes Toward Aid

Table 2.7 lists identified articles with messages on STMMs with diplomatic connotations. In a chilling tale of perverse consequences in Afghanistan, Fowles' 1989 editorial punctuated the potent effects that the mere presence of foreign medical teams might have politically (Fowles, 1989). Chiu (nonUS) noted that $71.9 \%$ of Taiwanese mission goers saw STMMs as a means to advance Taiwan's foreign relations (Chiu et al., 2012). Gorney editorialized incisively on this concept in the context of a facial plastic surgery mission (Gorney, 2005). In describing the role of surgical volunteerism globally, Casey specifically examined survey data and diplomatic literature that supports the concept of medical diplomacy in the domain of counter-terrorism and evolving American security strategy (Casey, 2007). With the exception of Chiu's survey results from Taiwanese volunteers, other direct connections between diplomatic concerns and STMMS are not forthcoming from the literature. 
Table 2.7 Spill-Over Effects - National Security

\begin{tabular}{|l|l|l|l|}
\hline \multicolumn{1}{|c|}{ Author } & \multicolumn{1}{|c|}{ Journal } & Year & \multicolumn{1}{c|}{ Contribution } \\
\hline $\begin{array}{l}\text { Fowles } \\
\text { (Fowles, } \\
\text { 1989) }\end{array}$ & Orthopedic Review & 1989 & $\begin{array}{l}\text { Cautionary } \\
\text { report on } \\
\text { geopolitical } \\
\text { ramifications of } \\
\text { STMMs }\end{array}$ \\
\hline $\begin{array}{l}\text { Gorney } \\
\text { (Gorney, } \\
\text { 2005) }\end{array}$ & $\begin{array}{l}\text { Plastic and Reconstructive } \\
\text { Surgery }\end{array}$ & 2005 & $\begin{array}{l}\text { Recognized } \\
\text { STMM activity } \\
\text { as a potential } \\
\text { element of } \\
\text { diplomacy }\end{array}$ \\
\hline $\begin{array}{l}\text { Casey et al } \\
\text { (Casey, 2007) }\end{array}$ & $\begin{array}{l}\text { Surgical Clinics of North } \\
\text { America }\end{array}$ & 2007 & $\begin{array}{l}\text { Attitudes in } \\
\text { LMICs towards } \\
\text { US improved by } \\
\text { medical aid }\end{array}$ \\
\hline $\begin{array}{l}\text { Chiu (Chiu et } \\
\text { al., 2012) }\end{array}$ & $\begin{array}{l}\text { Evaluation and the Health } \\
\text { Professions }\end{array}$ & 2012 & $\begin{array}{l}\text { Prevalent } \\
\text { foreign relations } \\
\text { motivation in } \\
\text { Taiwanese }\end{array}$ \\
& & & $\begin{array}{l}\text { STMM } \\
\text { participants }\end{array}$ \\
\hline
\end{tabular}

We discovered no articles that explicitly link STMMs to effects on the attitudes of physicians, their families or communities toward any kind of foreign aid or that focus on STMMs as meaningful foreign aid. Commentary on changes in attitudes was confined to other dimensions. For example, Van Tilburg reported a large majority of mission goers responding to a survey felt that their mission experience "broadened their views of the world" and would be willing to repeat the activity (Van Tilburg, 1995). Campbell et al discussed their own and other published survey results of surgical residents-in-training regarding the value of an overseas experience in the development of crosscultural competency (Campbell, Sullivan, Sherman, \& Magee, 2011). Results of a similar small survey published by Aziz et al of trainees on cleft missions indicated an increase "awareness of global healthcare" (Aziz, Ziccardi, \& Chuang, 2012). 


\subsection{Discussion}

Martiniuk et al identified the USA as the largest among the four leading sending countries for STMMs, ahead of Canada, United Kingdom and Australia (Martiniuk, Manouchehrian, et al., 2012). We extended the literature retrospective for this dissertation beyond the reviews of Martiniuk (25 years) and Sykes (20 years) with the objective of capturing any existing seminal publications from near the origins of US hegemony, and subsequent trends in the praxis. Whereas Kickbusch pointed to the need to examine US hegemony in global public health in 2002 (Kickbusch, 2002), we found no indication from literature that US hegemony is correlated with the greater representation of US physicians in STMMs. Our review does indicate that the most impactful articles of the last 67 years on guidelines, and hence on the effort to improve quality of volunteer STMMs, have been published in the current millennium, preceded almost exclusively by descriptive articles of a reflective nature. This has coincided with the increase in attention to, scrutiny of, and physician participation in STMMs. While most published articles are rejected from this and previous systematic reviews for lack of objective or quantitative contribution, the hundreds of articles regarding STMMs that constitute reflections or productivity reports in print, whether in high or low impact, refereed or non-refereed journals, indicate a palpable affinity among editors and medical readership concerning this activity (Martiniuk, Manouchehrian, et al., 2012; Sykes, 2014). The attribution that these missions are charitable and altruistic, and thereby valid in their own right, may interfere with the inclination for data collection and objective analysis (Berry, 2014).

It is notable that professionalization remains limited. As industries, movements and enterprises rise and eventually obsolesce, one measure of viability and vitality is the evidence of guilds or associations. Participants in professions and stable industries cooperate in such collectives formally to share new ideas and scientific advancements, and formulate principles and credentialing by means of repeating, focused congresses and journals for the benefit of both participants and society (Cruess, Johnston, \& Cruess, 2004). STMM participation is indeed not a remunerative activity. The licensed professionals who participate may already endure substantial national, local, and specialty regulation in addition to peer pressure to join, participate in the congresses of, and pay dues to perhaps multiple organizations. We therefore intuit that the non-monetary rewards sought and accumulated through STMM 
activity may be made even more attractive because of the absence from layers of regulation, credentialing and formality.

Most detailed reporting on mission collaborations, issuance of guidelines and leanings towards professionalization come from surgical literature and surgical organizations. Operation Giving Back, with its publication, the Bulletin of the American College of Surgeons (ACS), may be the most proximate example in the US to a burgeoning STMM guild, even though we found no evidence of any recurring congress or membership specifically related to the initiative (Casey, 2007). Similarly, Volunteers in Plastic Surgery (VIPS), through the affiliation of six major related STMM NGOs, have collaborated on guidelines as noted ${ }^{5}$. No discernable evidence of a correlative centralization of effort in family medicine, internal medicine and pediatrics is found. An appealing explanation for the disparity between surgical and non-surgical cohesiveness trends may be that surgical missions tend to be limited to a finite set of discrete procedures within the scope of more focused skill sets, and are more amenable to overall process and outcome assessments. Congruently, the developing world's burden of surgical disease is less amenable to global public health measures and policy remedies than non-surgical disorders, and thus summons the direct relief that surgical STMMs can provide. The direct costs and opportunity costs of surgical missions may be generally more sizable than non-surgical missions, and a higher potential for serious adverse events may warrant greater circumspection.

Crown argues with clarity that the "feel good" reward accruing to missiongoers hardly justifies the itemized and total costs, and that the funds are misapplied (Crown, 2005). Such a position overlooks the realpolitik that most such expenditures are discretionary to the mission-goer. This "feel good" sentiment may equate with the concept of "warm glow" popularized in current theory on philanthropy (Andreoni, 1990) (Nunes \& Schokkaert, 2003). In the context of the face-to-face interactions occurring in pro-bono medical missions, the intangible reward system may indeed be layers more complex, more habit-forming and compelling than other forms of

\footnotetext{
${ }^{5}$ Austin Smiles, Rotaplast, ReSurge International, Nicaplast, Operation Smile, Small World Foundation
} 
philanthropy, and begs to be better understood. Indeed, marketers of products and services, as well as sending and receiving country STMM organizers, recognize the monetized value of these experiences and emotions, and will almost certainly expand ways to exploit them. In this milieu, the first key question of this review regarding normative values should be as rigorously analyzed as outcomes measures, accounting, and impact of STMMs, since this may be where the disconnect between the clinical practice of STMMs and the due diligence is rooted. Ultimately, the execution of STMMs is critically dependent on the motivation of and decision by physicians to participate in them among other domestic opportunities for physician volunteerism and philanthropy. This issue remains vague and not elucidated by the results of any of the five key questions of this literature review. More prospective analysis of the influence of these aspects on participation would be warranted.

In an era of asymmetrical warfare, western strategic defense is migrating from emphasis on conventional expeditionary might towards counter-terrorism and counter-insurgency supported by robust intelligence and diplomatic soft power (Sims, West, \& Lujan, 2012). It is implied that pre-empting conflict will depend on skilled diplomacy and influence linked to managing perceptions of the West among peoples of developing countries where unrest may erupt. Nye points out in The Future of Power that the sources of soft power wherein the elements of attraction and persuasion lie are socially constructed (Nye, 2011). McInnes has skillfully interwoven the concepts of international healthcare strategies with modern concepts of soft power (McInnes, 2004). The Cuban physician diaspora, while controversial, may be the most acknowledged example of a nation providing direct medical assistance as a lever of diplomacy, though it is not voluntary on the part of the physician, nor short term, nor uncompensated (de Albornoz, 2006; Rivero, 1996). Done well, STMMs may have the makings of an effective civil outreach as one fiber of western ground-level diplomacy to undermine popular support for terror and insurgent groups.

\section{Bias and Limitations}

Bias may be expected in several forms beginning with our selection of relevant articles. The limitation of the selection to medical and surgical mission focus may omit some closely related input of value from ancillary 
activities such as dentistry, nursing and medical education. Most articles on STMMs are qualitative in nature and thus bias is inherent; such bias may carry over into this review. Selected articles originate almost exclusively from authorship within a high-income sending country such that bias may arise from a rich country set of values.

A manifest limitation in our analysis is the relatively few articles that satisfied our criteria. The usual danger of such a review as ours is that the absence of evidence would be misconstrued as evidence of absence of a particular effect. The actual impact of these social, economic and diplomatic aspects on the decision of physicians to participate in STMMs should be assessed prospectively through well designed surveys beyond the published retrospective surveys.

\subsection{Conclusions}

Our objective to assess certain social, economic and diplomatic aspects of STMMs reveals little attention from the literature we reviewed. Scant analyses exist in the current literature wherein normative concepts of volunteerism, altruism and philanthropy is applied specifically to the praxis of STMMs. Transactional analysis and study of other market dynamics is wont; the enlightened self-interest of the parties in the exchange, a universal motivator, is not openly explored. Estimations and commentary over related expenditures are found, but accounting of direct physician outlays and how such costs may affect the decision to go is yet unattended. Except as noted in a single report on Taiwanese missions, diplomacy, foreign aid and projection of soft power do not appear to be expressed determinants of participation. Professionalization appears underdeveloped, though elements of professionalization such as guidelines, codified instructions and implementation of cost benefit analysis are accumulating.

STMMs may perform a function of providing needed services where markets have failed. As rich and poor economies converge, the inclination for this and other forms of aid should obsolesce. In the meantime, it is likely that the call for value, meaning a rational return on investment measured by dollars per DALYS or similar unit, will continue in the medical and social science literature and media (Martiniuk, Manouchehrian, et al., 2012; Welling et al., 2010). Mitigation of potential externalities such as crowding-out local health 
care provision and adverse medical events related to inadequate follow-up, among others, is another target. As western security policy evolves, the social perception elements of soft power may render cross-cultural acumen on the part of participating physicians and their support teams an inescapable requirement. Such improvements need not diminish the "warm glow" so precious to the providers and embedded in the answer to why they go. Achieving accountability and cross-cultural skills commensurate with the medical professionalism displayed in STMMs may better advance from greater interchange among disparate actors. Peer pressure and peer acknowledgment as motivators compounded through professionalization would also be unlikely to dim the glow. Formation of a national or international organization specifically focused on STMMs with a dedicated journal and repeating congresses need not add to the regulatory burden on physicians and could serve as a platform for quality enhancement.

An economist would reasonably ask if the composite expenditures on STMMs worldwide are material, then conclude from the lack of data and sources of data, as well as the inattention to the regulation of the activity, that it is not. Nonetheless, there exists at least the impression that this socioeconomic activity is expanding, and the cumulative expenses including expenditures and opportunity costs may be consequential. As aid, Martiniuk and colleagues amply characterize this transfer of skilled labor, as opposed to cash transfers, in their title "Brain Gains..."(Martiniuk, Manouchehrian, et al., 2012). Changing the present US tax code that provides indirect support of STMMs by allowing deduction of all applicable costs from taxable income could have a potential dampening effect on participation. A broader consideration of STMMs as a grassroots expression of foreign aid and a potential instrument of security policy may therein be justified.

As non-state actors, volunteer physicians' professional acumen in the concepts of effective foreign aid and promotion of peace could benefit from a collaborative approach. Educational interaction with actors in diplomatic and security sectors could bring further value to STMM activity. Facilitating a broader awareness of the role of the STMM among overall foreign aid objectives could benefit similarly. Absent these perspectives, the unattractive consequences that sometimes adversely stigmatize STMM activity may expand in similar dimension to growth of the activity itself. 
Neither this nor previous reviews profile "who" goes on uncompensated medical service trips; that may hold much insight into "why". Further perspectives from care-receiving patients and communities, beyond the paucity of on-site surveys available, are needed to refine mission sophistication and prescription (Green, Green, Scandlyn, \& Kestler, 2009; Maki et al., 2008). Quantification and impact of personal costs on physician participation are explored in Chapters 4 and 6 of this dissertation. Recipient communities' attitudes towards "the West" as well as western attitudes towards service aid are potential positive externalities of STMMS that could be better informed through exchange with the diplomatic corp. 
Chapter 3: The Physicians' Giving Back Survey:

Keeping up with American Generosity

This chapter draws upon:

Caldron PH, Impens A, Pavlova M, Groot W. The Physicians' Giving Back Survey: Keeping up with American generosity. J Compassionate Heal Care. 2015;2(1):8. DOI:10.1186/s40639-015-0017-0. 


\begin{abstract}
Background: America scored at the top of the World Giving Index survey in 2014. The objectives of this chapter are to report on and analyze the results of a survey of US physicians about preferences for and prevalence of probono activities devoted to health-related direct medical services and medical teaching, as a reflection of physicians' contribution to American generosity and a basis for research. Profiles related to these preferences are described.
\end{abstract}

Methods: An online survey solicited information on physician participation in selected charitable and volunteer activities. The responses were descriptively tabulated and multivariate regressions were performed to identify associations between the activities and demographic and professional features.

Results: Six hundred one qualified respondents ( $0.62 \%$ response rate) indicated participation in one or more pro-bono activities. Seventy-two percent performed activities domestically and $32 \%$ provided services abroad in low- and middle-income countries. Uncompensated medical teaching (54\%) was the most common activity followed by waiving fees in their practices $(39 \%)$. No differentiating profile emerged that predicts a subset of physicians likely to perform a particular activity.

Conclusions: Unpaid teaching and direct pro-bono services reflect the medical profession's contribution to American generosity. Amounts of fees waived in practice and engagement in volunteer activities have kept pace with historic benchmarks in support of unmet needs for these social goods. Participation in pro-bono activities appears broad, and not the selective domain of particular physician subsets. 


\subsection{Introduction}

Americans are generous people according to the recently published World Giving Index (Charities Aid Foundation, 2014). In 2014, the United States was the singular country to be ranked in the top ten in all three key charitable giving behaviors: volunteering time, donating money and helping a stranger. The US shared the top ranking for overall giving with Myanmar and holds the top ranking for the 5 year giving index. Evidence suggests that the national giving behavior includes US physicians (Frank, Breyan, \& Elon, 2015; Grande \& Armstrong, 2008). Grande and Armstrong utilized secondary data meticulously gleaned from the 2003 Current Population Survey (CPS) Volunteer Supplement to assess rates of physician volunteerism in certain broad areas of health-related and non-health related activities. At a 39\% general rate of volunteerism, characterization modeling found that married physicians working longer hours in their Midwest practices were most likely to volunteer. A 3-year look-back reported by Gruen and Pearson in 2004 indicated a $54 \%$ participation in providing health-related expertise to a community organization by American physicians (Gruen \& Pearson, 2004). In 2006, more than two-thirds of physicians provided some charitable medical services, three quarters of which was within their own practices (Cunningham $\&$ May, 2006). The popular Medscape Physician Lifestyles Surveys between 2012 and 2015 echo that overall volunteerism by physicians runs around twothirds (Peckham, 2012, 2013, 2014, 2015).

US physicians nurture skill sets and capacities that avail them of a wide variety of opportunities for charitable activities. Beyond cash donations to charities, many provide free ("pro-bono") medical care to the needy domestically and/or go abroad, mostly in STMMs as described in Chapters 1 and 2, to give care to the poor in developing countries. By means of a short survey called the "Physicians' Giving Back Survey" (PGBS), we sought to quantify physician preferences for and prevalence of pro-bono activities and to see if profiles would emerge related to these preferences. The survey questions focused on physician time and philanthropy devoted to healthrelated direct medical services and medical teaching rather than involvement in non-health-related domains such as religious or civic organizations, hence the notion of "giving back" to the profession and society that has provided physicians in the US a desirable income and intrinsic respect. The objectives of this chapter are to report on and analyze the results of the PGBS, not only as a reflection of physicians' contribution to American generosity, but also 
for research purposes. The importance of quantifying physician preferences and correlating physician characteristics related to those preferences lies in establishing a foundation for further assessment of physician involvement in the discrete categories for pro-bono activities by physicians. Such a foundation may be relevant to training, professional development, and policy recommendations that could have a downstream influence on the allocation of the scarce resources of physician skills and time more efficiently to the benefit of the healing profession and society as a whole. In exploring for physician types associated with the discrete activities, we elected to cast a wide net touching on the native, acquired, geographic, and professional demographics as grouped in the stable and dynamic domains described in our results.

\subsection{Methods}

The PGBS was conducted as a brief online survey. Beta testing of the PGBS was performed utilizing a selected group of 15 identified physicians whose critiques were incorporated into the final PGBS version (Appendix A). Exempt status was granted for use of human subjects for the survey from the Institutional Review Board of Midwestern University Office of Research and Sponsored Programs, Downers Grove, Illinois, USA. The survey was implemented through SurveyMonkeyC. Deployment of the survey to 109,237 unique physician emails was executed between January 30 and February 27, 2014. Response reception was closed on 30 April 2014. The email list included only physicians who were licensed to conduct the full spectrum of medicine (US MD, IMG, and DO) ${ }^{6}$. The survey targeted $93 \%$ MDs/IMGs and $7 \%$ DOs, proportionate to the US physician population distribution US as provided in the American Medical Association (AMA) 2011 Physician Master File (data as of Dec. 31, 2010). The survey was disseminated equally

\footnotetext{
6 "US MD" refers to physicians who received their Doctor of Medicine degree from a U.S. allopathic medical school. "DO" refers to physicians who received a Doctor of Osteopathy degree from a US-sanctioned osteopathic medical school. International medical graduate (IMG) refers to an individual with an MD or equivalent degree who graduated from a medical school outside the United States and its territories or Canada, including U.S. citizens who have attended such medical schools abroad. To be eligible for licensure and practice in the United States, all IMGs must have completed accredited graduate training in the United States.
} 
to the four regions of the US in close proportion to the specialties practiced by the US physician population (Erikson, Jones, \& Tilton, 2012) ${ }^{7}$. The proprietary postal database of Healthcare Data Solutions (HDS) was used. The HDS database conforms to industry best practice guidelines for businessto-business email acquisition, adheres to US CAN-SPAM guidelines and maintains a quarterly "permissioning" and validation process. HDS's DirectSelect tool herein eliminated titles such as Doctor of Chiropractic, Doctor of Optometry, Doctor of Podiatric Medicine, Licensed Acupuncturist, Naturopathic Doctor, dentists and PhDs.

The first question of the survey screened for target sample of physicians that had completed all formal training and are or had been in practice in the US, followed by questions to capture participation in a variety of activities related to physician skills including teaching and various settings of teaching, direct patient services and various settings of care, pro-bono time spent on professional and patient support organizations, donations and "other". If participation in short-term medical missions abroad was indicated, the respondent was then shunted to additional questions regarding this activity. Demographic and professional characteristics of respondents were solicited at the close of the survey. Table 3.1 displays the core questions of the survey regarding philanthropic and volunteer activities and subtypes of direct medical care and teaching options.

${ }^{7}$ The Northeast includes nine states: Connecticut, Maine, Massachusetts, New Hampshire, Rhode Island, Vermont, New Jersey, New York and Pennsylvania; the Midwest region includes twelve states: Illinois, Indiana, lowa, Kansas, Michigan, Minnesota, Missouri, Nebraska, North Dakota, Ohio, South Dakota and Wisconsin; the Southern region includes sixteen states: Florida, Georgia, Maryland, North Carolina, South Carolina, Virginia, West Virginia, Delaware, Alabama, Kentucky, Mississippi, Tennessee, Arkansas, Louisiana, Oklahoma and Texas; the Western region of the United States includes thirteen states: Montana, Wyoming, Colorado, New Mexico, Idaho, Utah, Arizona, Nevada, Washington, Oregon California, Alaska and Hawaii 
Table 3.1 Philanthropic and Volunteering Activities of Survey Respondents

\begin{tabular}{|c|c|}
\hline Choices of charitable or volunteer activities $(\mathrm{N}=601)$ & $\begin{array}{l}\text { Percent of } \\
\text { respondents }\end{array}$ \\
\hline Pro-bono medical teaching & $54 \%$ \\
\hline $\begin{array}{l}\text { There is a system in my practice to accommodate those } \\
\text { who have limited ability to pay. }\end{array}$ & $39 \%$ \\
\hline $\begin{array}{l}\text { Pro-bono direct medical services provided in local and } \\
\text { domestic clinics or outreaches }\end{array}$ & $38 \%$ \\
\hline $\begin{array}{l}\text { Giving money or donations in kind to charitable } \\
\text { organizations }\end{array}$ & $37 \%$ \\
\hline Pro-bono direct medical services in developing countries & $32 \%$ \\
\hline $\begin{array}{l}\text { Giving time devoted to the organized activities of patient } \\
\text { support organizations }\end{array}$ & $26 \%$ \\
\hline $\begin{array}{l}\text { I am not yet in a position to participate in any volunteer } \\
\text { activity or giving. }\end{array}$ & $13 \%$ \\
\hline $\begin{array}{l}\text { No such activities so far since I have been in medical } \\
\text { practice }\end{array}$ & $2 \%$ \\
\hline Sub-types of pro-bono teaching activities $(\mathrm{N}=601)$ & $\begin{array}{l}\text { Percent of } \\
\text { respondents }\end{array}$ \\
\hline $\begin{array}{l}\text { Teaching of medical students, residents, fellows, nurses or } \\
\text { ancillary service personnel }\end{array}$ & 52.9 \\
\hline $\begin{array}{l}\text { Teaching of medical students, residents, fellows, nurses or } \\
\text { ancillary service personnel }\end{array}$ & 54.7 \\
\hline $\begin{array}{l}\text { Health-related teaching to civic organizations or general } \\
\text { public }\end{array}$ & 39.9 \\
\hline Health-related teaching to public or private schools & 28.1 \\
\hline No pro-bono teaching activities & 8.32 \\
\hline
\end{tabular}


Table 3.1 Philanthropic and Volunteering Activities of Survey Respondents (continued)

\begin{tabular}{|l|c|}
\hline \multicolumn{1}{|c|}{$\begin{array}{c}\text { Sub-types of domestic pro-bono direct medical services } \\
(\mathrm{N}=601)\end{array}$} & $\begin{array}{c}\text { Percent of } \\
\text { respondents }\end{array}$ \\
\hline Other domestic pro-bono medical services & 30.62 \\
\hline No pro-bono direct medical services & 28.12 \\
\hline $\begin{array}{l}\text { screening physicals, team or group doctor for schools or } \\
\text { organizations }\end{array}$ & 22.63 \\
\hline Local free/sliding scale clinic after usual practice hours & 17.47 \\
\hline $\begin{array}{l}\text { Domestic short-term mission work for which I must } \\
\text { schedule time away from my practice }\end{array}$ & 9.32 \\
\hline $\begin{array}{l}\text { Local/domestic disaster response wherein I provide free } \\
\text { medical services }\end{array}$ & 8.82 \\
\hline
\end{tabular}

For the statistical analysis, the Statistical Package for the Social Sciences (SPSS) version 22 was utilized in the chi-square test comparisons of sample and population characteristics. The social studies proprietary statistical software STATA version 12 (College Station, TX) was utilized for statistical correlations and multivariate regressions. Regression models and explanatory variables were considered significant at $\mathrm{P}<=0.05$.

\subsection{Results}

Sample Characteristics

In total, 631 surveys were completed, a "click through" rate of $0.62 \%$, consistent with typical response rates to email surveys generated to physicians from the proprietary HDS database (January 2014: 25 th percentile $0.17,75$ th percentile 0.72) (personal communication with HDS). Six hundred one (response rate $0.55 \%$ ) fit the target criteria of being physicians who had completed all training were therefore included in the analysis. Table 3.2 provides a comparison of the sample and the physician population of the US showing statistical similarity with respect to race, civil status, and type of 
medical degree, and dissimilarity with respect to gender, age, trained in US vs. non-US medical school, religion, and region of the country (chi-square test). The top 16 of 29 specialties of respondents was visually similar in rank order to the population (Table 3.3) (Erikson, Jones, \& Tilton, 2012).

Table 3.2 Demographic Comparison of PGBS Respondents (Sample) to US Physician Population

\begin{tabular}{|c|c|c|c|}
\hline \multicolumn{3}{|c|}{ Demographic review } & \multirow{2}{*}{$\begin{array}{c}\begin{array}{c}\text { Similarity to } \\
\text { population }\end{array} \\
\text { Significance } \mathrm{p}< \\
0.05,95 \% \mathrm{Cl}\end{array}$} \\
\hline Gender & $\begin{array}{c}\text { PGBS } \\
\text { Respondents } \\
(501)\end{array}$ & $\begin{array}{l}\text { US Physicians (Erikson, Jones, \& } \\
\text { Whatley, 2014) }(828,869)\end{array}$ & \\
\hline Male & $57.7 \%(289)$ & $67.4 \%(558,794)$ & \multirow[t]{2}{*}{$P=0.05$} \\
\hline Female & $42.3 \%(212)$ & $32.6 \%(270,075)$ & \\
\hline Medical Degree & $\begin{array}{c}\text { PGBS } \\
\text { Respondents } \\
(501)\end{array}$ & $\begin{array}{l}\text { US Physicians (Erikson, Jones, \& } \\
\text { Whatley, 2014) }(828,914)\end{array}$ & \\
\hline MD* & $94.4 \%(473)$ & $91.6 \%(760,341)$ & \multirow[t]{2}{*}{$+P=0.125$} \\
\hline DO** & $5.6 \%(28)$ & $7.3 \%(60,172)$ & \\
\hline Age Group & $\begin{array}{c}\text { PGBS } \\
\text { Respondents } \\
(501)\end{array}$ & $\begin{array}{l}\text { US Physicians (Erikson, Jones, \& } \\
\text { Whatley, 2014)(828,318) }\end{array}$ & \\
\hline Age 55 or $>$ & $57.6 \%(289)$ & $42.6 \%(349,248)$ & \multirow[t]{2}{*}{$P=0.000$} \\
\hline Age $<55$ & $42.3 \%(212)$ & $57.4 \%(479,070)$ & \\
\hline $\begin{array}{l}\text { Source of Medical } \\
\text { Degree }\end{array}$ & $\begin{array}{c}\text { PGBS } \\
\text { Respondents } \\
(501)\end{array}$ & $\begin{array}{l}\text { US Physicians (Erikson, Jones, } \\
\text { Whatley, 2014) }(829,914)\end{array}$ & \\
\hline $\begin{array}{l}\text { MD- } \\
\text { US/Canada/PR* }\end{array}$ & $76 \%(379)$ & $67.4 \%(559,731)$ & \multirow[t]{3}{*}{$P=0.002$} \\
\hline MD-IMG $* * * *$ & $19 \%(94)$ & $24.2 \%(200,610)$ & \\
\hline DO** & $6 \%(28)$ & $7.3 \%(60,172)$ & \\
\hline \multicolumn{4}{|c|}{ + no statistically significant difference (chi-square test, SPSS) } \\
\hline \multicolumn{4}{|l|}{ *Medical Doctor } \\
\hline \multicolumn{4}{|c|}{ **Doctor of Osteopathic Medicine } \\
\hline \multicolumn{4}{|c|}{ ***Puerto Rico (US territory) } \\
\hline$* * * *$ International $\mathrm{M}$ & cal Graduate & & \\
\hline
\end{tabular}


Table 3.2 Demographic Comparison of PGBS Respondents (Sample) to US Physician Population (continued)

\begin{tabular}{|c|c|c|c|}
\hline \multicolumn{3}{|c|}{ Demographic review } & \multirow{2}{*}{$\begin{array}{c}\text { Similarity to } \\
\text { population }\end{array}$} \\
\hline Race / Ethnicity & $\begin{array}{l}\text { PGBS Respondents } \\
\text { (520) }\end{array}$ & $\begin{array}{l}\text { US Physicians (Boukus, } \\
\text { Cassil, \& O'Malley, 2009) }\end{array}$ & \\
\hline White & $82 \%(408)$ & $73.7 \%$ & \multirow{4}{*}{$+P=0.122$} \\
\hline Black/African Amer. & $2.82 \%(14)$ & $3.8 \%$ & \\
\hline Hispanic & $3.83 \%(23)$ & $5.3 \%$ & \\
\hline Asian or other & $15.9 \%(75)$ & $17.2 \%$ & \\
\hline Religion & $\begin{array}{c}\text { PGBS Respondents } \\
(477)\end{array}$ & $\begin{array}{l}\text { US Physicians (Curlin, } \\
\text { Lantos, Roach, Sellergren, } \\
\text { \& Chin, 2005) (1125) }\end{array}$ & \\
\hline Christian***** & $48.6 \%(232)$ & $64.4 \%(710)$ & \multirow{7}{*}{$P=0.000$} \\
\hline Jewish & $19.1 \%(91)$ & $14.1 \%(181)$ & \\
\hline Hindu & $2.1 \%(10)$ & $5.3 \%(53)$ & \\
\hline Muslim & $1.9 \%(9)$ & $2.7 \%(33)$ & \\
\hline Buddhist & $2.1 \%(10)$ & $1.2 \%(13)$ & \\
\hline Other & $4.8 \%(23)$ & $1.8 \%(18)$ & \\
\hline None & $21.4 \%(102)$ & $10.6 \%(117)$ & \\
\hline US Region & $\begin{array}{c}\text { PGBS Respondents } \\
\text { (601) }\end{array}$ & $\begin{array}{l}\text { US Physicians (Boukus et } \\
\text { al., 2009) }\end{array}$ & \\
\hline Northeast & $27.3 \%(164)$ & $23 \%$ & \multirow{4}{*}{$P=0.000$} \\
\hline South & $15.0 \%(90)$ & $32.5 \%$ & \\
\hline Midwest & $18.0 \%(108)$ & $22.4 \%$ & \\
\hline West & $21.7 \%(130)$ & $22.1 \%$ & \\
\hline Married & $\begin{array}{c}\text { PGBS Respondents } \\
\text { (488) }\end{array}$ & $\begin{array}{c}\text { US Physicians (Peckham, } \\
\text { 2014) }\end{array}$ & \\
\hline Yes & $80.5 \%(393)$ & $81 \%$ & \multirow{2}{*}{$+P=0.705$} \\
\hline No & $19.5 \%(95)$ & $19 \%$ & \\
\hline \multicolumn{4}{|c|}{ + no statistically significant difference (chi-square test, SPSS) } \\
\hline & & & \\
\hline
\end{tabular}


Table 3.3 Comparison of Sample and Population Rank Order of Specialties

\begin{tabular}{|l|l|l|}
\hline \multicolumn{2}{|c|}{$\begin{array}{c}\text { Rank Order of Specialties of PGBS } \\
\text { Respondents }\end{array}$} & \multicolumn{1}{|c|}{$\begin{array}{c}\text { Rank Order of US Specialties } \\
\text { (Erikson, Jones, \& Whatley, } \\
\text { 2014)* }\end{array}$} \\
\hline 1 & Family Medicine & Internal Medicine \\
\hline 2 & Internal Medicine & Family medicine \\
\hline 3 & Pediatrics & Pediatrics \\
\hline 4 & Anesthesiology & Obstetrics and Gynecology \\
\hline 5 & General Surgery & Anesthesiology \\
\hline 6 & Psychiatry & Psychiatry \\
\hline 7 & Obstetrics and Gynecology & Emergency Medicine \\
\hline 8 & Emergency Medicine & Radiology \\
\hline 9 & Orthopedics & General Surgery \\
\hline 10 & Cardiovascular & Cardiovascular \\
\hline 11 & Radiology & Orthopedics \\
\hline 12 & Pathology & Ophthalmology \\
\hline 13 & Neurology & Hematology/Oncology \\
\hline 14 & Ophthalmology & Pathology \\
\hline 15 & Hematology/Oncology & Gastroenterology \\
\hline 16 & Gastroenterology & Neurology \\
\hline$* 2014$ Physician Specialty Data Book (Erikson, Jones, \& Whatley, 2014) \\
\hline
\end{tabular}

More than half of practicing physicians provided some unpaid teaching to medical students, ancillary personnel or the public (Table 3.1). Unpaid teaching efforts for medical personnel were nearly equal in regards to inpatient and outpatient settings.

The next most common charitable activity among respondents after teaching activities was the implementation of a system in the physician's practice to accommodate those who have limited ability to pay. Respondents estimated the amount waived in the preceding year by choosing among a set of ranges. Extrapolating a weighted mean from the midpoints in these ranges and number of observations in each range, an estimated annual mean amount waived per physician was $\$ 22,583$ (observations 241 ; range $0-\$ 50,000$; SD $\$ 18,828$; median $\$ 12,500$ ). Using the proportion of our sample that reported waiving fees, the mean amount waived and the size of the US physician population in 2013 (Erikson, Jones, \& Whatley, 2014), our estimate of the 
total uncompensated care in such practices is $\$ 7.3$ billion in that year [ $\$ 22$, $583 \times(39 \% \times 829,962)]$ or $1.24 \%$ of total health care spending on physician care (Carey, 2014).

Of the $72 \%$ of respondents who provided uncompensated direct medical services domestically, the more common settings involved the provision of free screening physical exams and/or acting as team physician to schools or other organizations and practicing at free or sliding scale payment clinics. Far less common were domestic short term missions or disaster relief (Table 3.1).

Thirty-two percent of respondents had provided direct care to patients in LMICs in the form of planned STMMs. Of those, $77 \%$ had repeated the activity. The mean number of STMMs among all PGBS respondents was 7 (median 3); of those who reported repeated participation in STMMs, the mean number was 10 (median 5). Table 3.4 illustrates the countries by region and cumulative mission count by PGBS respondents. 
Table 3.4 Countries by Region and Mission Count by PGBS Respondents

\begin{tabular}{|c|c|c|c|c|c|c|c|}
\hline \multicolumn{2}{|c|}{ Latin America } & \multicolumn{2}{|l|}{ Africa } & \multicolumn{2}{|l|}{ Eastern Europe } & \multicolumn{2}{|c|}{ Middle East } \\
\hline Argentina & 3 & Benin & 1 & Armenia & 6 & Iraq & 2 \\
\hline Belize & 2 & Burundi & 1 & Azerbaijan & 1 & Kuwait & 1 \\
\hline Bolivia & 20 & Cameroon & 2 & Bosnia-Herzegovina & 1 & Palestinian & 3 \\
\hline Brazil & 6 & Chad & 1 & Bulgaria & 1 & Saudi Arabia & 1 \\
\hline Chile & 6 & Congo & 1 & Croatia & 3 & Syria & 4 \\
\hline Colombia & 15 & Cote'D'Ivoire & 1 & Cyprus & 1 & Turkey & 1 \\
\hline Costa Rica & 4 & Egypt & 4 & Moldova & 1 & \multicolumn{2}{|c|}{ Central Asia } \\
\hline Cuba & 3 & Ethiopia & 11 & Poland & 1 & Afghanistan & 4 \\
\hline Dominica & 39 & Ghana & 13 & Romania & 4 & Kazakhstan & 1 \\
\hline Ecuador & 41 & Kenya & 31 & Russian Federation & 3 & Mongolia & 4 \\
\hline El Salvador & 23 & Liberia & 2 & Ukraine & 1 & Pakistan & 1 \\
\hline Grenada & 2 & Malawi & 5 & \multicolumn{2}{|l|}{ Pacific Islands } & \multicolumn{2}{|c|}{ Southeast Asia } \\
\hline Guatemala & 66 & Mali & 1 & Fiji & 11 & Cambodia & 5 \\
\hline Guyana & 2 & Niger & 1 & Marshall Islands & 2 & China & 12 \\
\hline Haiti & 105 & Nigeria & 10 & Micronesia & 1 & Indonesia & 6 \\
\hline Honduras & 54 & Rwanda & 7 & Papua New Guinea & 1 & Japan & 1 \\
\hline Jamaica & 20 & Sierra Leone & 4 & Solomon Islands & 1 & Malaysia & 1 \\
\hline Mexico & 58 & South Africa & 8 & Togo & 1 & Philippines & 37 \\
\hline Nicaragua & 28 & Sudan & 1 & Turks/Caicos Islands & 5 & Thailand & 6 \\
\hline Panama & 6 & Swaziland & 2 & & & Vietnam & 30 \\
\hline Paraguay & 1 & Tanzania & 7 & & & \multicolumn{2}{|c|}{ Indian subcontinent } \\
\hline Peru & 37 & Uganda & 7 & & & Bangladesh & 6 \\
\hline Puerto Rico & 1 & Zambia & 3 & & & India & 55 \\
\hline Saint Lucia & 4 & Zimbabwe & 5 & & & Nepal & 7 \\
\hline Suriname & 1 & & & & & Pakistan & 8 \\
\hline Venezuela & 5 & & & & & Sri Lanka & 4 \\
\hline
\end{tabular}

Twenty-six percent of physicians had devoted time to the organized activities of patient support organizations such as the Arthritis Foundation and American Cancer Society. Among other choices, several respondents indicated volunteer time with professional organizations and hospital committees. Novel, non-health related activities cited by physicians included urban search and rescue, volunteer policing, animal rescue and anti-cruelty activities, judging at student science fairs, playing music and organizing 
sports events for charities. No respondents indicated the choice not to participate in any charitable or volunteer activities, although $4 \%$ indicated not yet being in a position to participate or not having participated "so far" since starting medical practice. Curiously, these "potential" participants were found across the range of years in practice and age groups of respondents and not confined to new-comers to practice.

Who does what?

Participation totals exceeded $100 \%$ of the sample for the general categories of charitable and volunteer activities and the subtypes of teaching and direct medical services, which indicates that many physicians participated in more than one activity. However, no single category statistically correlated with any other single activity to reveal a pattern of related activities (Table 3.5). For teaching subcategories, a moderate correlation exists between pro-bono teachings to civic organizations/general public and teaching in public/private schools (coefficient 0.46; correlation table for teaching subcategories not shown). Statistical correlations did not reveal any pattern among varieties of direct care services, domestic or abroad.

Table 3.5 Inter-Correlation of Physician Charitable Activities

\begin{tabular}{|c|c|c|c|c|c|c|}
\hline Correlations & Give & Teach & Domestic & Support & Waive & LMIC \\
\hline Give & 1.000 & & & & & \\
\hline Teach & 0.2146 & 1.000 & & & & \\
\hline Domestic & 0.1908 & 0.2624 & 1.000 & & & \\
\hline Support & 0.2318 & 0.2318 & 0.1385 & 1.000 & & \\
\hline Waive fees & 0.1937 & 0.2009 & 0.1619 & 0.1158 & 1.0000 & \\
\hline LMIC care & 0.0910 & 0.1087 & 0.1531 & 0.0610 & -0.0394 & 1.000 \\
\hline \multicolumn{7}{|c|}{ Legend } \\
\hline Give & \multicolumn{6}{|c|}{ Give money/donations-in-kind } \\
\hline Teach & \multicolumn{6}{|c|}{ Pro bono teaching } \\
\hline Domestic & \multicolumn{6}{|c|}{ Pro-bono domestic direct medical services } \\
\hline Support & \multicolumn{6}{|c|}{ Donate time for activities of patient/professional non- } \\
\hline Waive fees & \multicolumn{6}{|c|}{ Mechanism in practice for accommodating those with } \\
\hline LMIC care & \multicolumn{6}{|c|}{ Pro-bono direct medical services in low and middle } \\
\hline
\end{tabular}


Using each of the general activities and subtypes in Table 3.1 as binary dependent variables, multivariate regressions controlled for sixteen explanatory variables that can be conceptually aggregated in two domains. The first domain includes typically stable demographic characteristics including gender, race, Hispanic ethnicity, religious affiliation, degree (MD/DO), being born in the US, having completed medical school in the US, specialty and income level. The second domain includes those characteristics that commonly change over time including region of the US, civil status, children, city population size, cumulative years in practice and practice situation (solo practice, academic, hospital-based, government or public facility, multi-specialty group, single-specialty group) and age group. Age of responders was re-coded for groupings of 25-39, 40-55 and 56-73 years. Civil status, simplified to those who were legally married or not. For the analysis, specialties were aggregated into four broad categories including adult medicine, pediatric medicine, surgery and anesthesia, and other respondent specialties (psychiatry, pathology, radiology, nuclear medicine, dermatology, pain medicine). Models were considered significant if a Prob $>$ chi-square of at least 0.10 was demonstrated.

Pro-bono performance of school physicals or team medical coverage was more associated with southern, midwestern and western regions than the northeast and with attending medical school in the US. Specialty category linked pediatric medicine, surgical and anesthesiology specialists with shortterm medical missions abroad, while adult medicine clinicians were more likely to provide services in free and sliding- scale clinics than surgeons or pediatricians. Being of Christian affiliation was more influential than having no religious affiliation on inpatient and community teaching, but not more than other religious affiliations. For the statistically significant models, significant independent variables were found that were different among models without clustering. None of the types or sub-types of charitable or volunteer activities could be predicted by a robust model consisting of more than two of the 16 solicited demographic and professional features in either of the two domains.

\subsection{Discussion}

The PGBS suggests that charitable and volunteer participation in healthrelated activities remains broadly prevalent among US physicians and is not 
the domain of any subset of the physician demographic dimensions we addressed. Little influence from religion as the survey's sole indicator of belief structure is seen; rather, one might speculate that the influence of oath, another codified, behavioral guideline, at least within one's professional activity, substitutes as the locus of decision-making in this societal arena. The mitigation of access to care for the underserved and propagation of knowledge by physicians continues as an undercurrent to the US's healthcare administrative evolution.

A couple of the observed explanatory characteristics of participation in particular activities appear somewhat intuitive. The procedurally focused specialties of surgery and anesthesiology may provide effective, discrete contributions to individual health in an STMM setting abroad. The internist, in contrast, may be able to provide some continuity of care at the domestic free clinic, but less so abroad. Overall, however, our regressions fail to project a fleshed-out portrait, or even a Gestalt image, of the particular type of physician performing a particular "giving-back" task. The lack of defining profiles is likely less attributable to the modest response rate or the selection of variables than to the integration of fully-trained physicians into the flow of modern medical care and education with its encompassing traditions and regulatory environment. In this regard, peer influence on the propensity for philanthropy, pro-bono work, and teaching may supersede the influence of the demographic or professional traits employed in our regression models.

Hadley and Holahan estimated in 2001 dollars that uncompensated care to uninsured persons provided by physicians, excluding those salaried by hospitals and clinics, may reach $\$ 5.1$ billion annually. Our estimate at $\$ 7.3$ billion in 2014 dollars could be said to keep pace with that earlier estimate despite the changes bought forward by managed care and more recently the Patient Protection and Affordable Care Act (PPACA) enacted in 2010 (Cunningham \& May, 2006).

Contemporarily with the latest World Giving Report, our brief online survey sought cumulative, primary data on specific types of volunteering associated with services for which a fully trained and licensed physician would typically be qualified. Although our survey did not specifically address the third aspect of the giving trilogy of the Report, the proximate exchange taking place in pro-bono medical services renders the dimension of "helping a stranger" 
integral to this type of volunteering. The popular Medscape Physician Lifestyles Surveys between 2012 and 2015 suggest that overall volunteerism by physicians runs around two-thirds, and that not ever volunteering correlates with higher rates of physician burn-out (Peckham, 2012, 2013, $2014,2015)$. While physicians working in managed care may provide less charity care, it is not apparent that that feature of change in the landscape of US healthcare delivery has had any profound effect on physician volunteerism in the new millennium (Cunningham et al., 1999). In this sense, the payback to physicians for their time and money may extend beyond "warm glow" motivation to a variation on investment exchange motivation, that being sustainability of interest in a challenging profession (Roy \& Ziemek, 2000). Cunningham and May (2006) expressed concerns over diminishing contributions of charitable medical care by physicians in providing a safety net to some 40 million Americans without insurance prior to the PPACA. Among the reasons cited for such decline at the time were the greater demands on physician schedules in managed care and institutional medicine. How the roll out of the PPACA will influence this dynamic of charitable care, through the reduction of population previously excluded from access to regular care, remains to be seen.

Roy and Ziemek have lucidly reviewed the maturation of the study of motivation for volunteerism and charitable giving that has culminated into three separable, though not exclusive theoretical models: a. Public Goods, wherein the benefit objective is altruistic, i.e., to increase the supply of the public good, b. Private Consumption, wherein the benefit objective is found in the utility of "warm glow", self-value, and joy from the act of volunteering or philanthropy, and c. Investment Exchange, wherein the benefit sought by the giver is experience, personal market value, skills, and contacts (Roy \& Ziemek, 2000; Ziemek, 2006). Of most relevance to the recipients of physician care is the first model, since health care, like the arts, education, scientific research and similar public goods, are sensitive to market failures that are mitigated through government funding and/or non-profit organizations. Others have continued to examine how this dynamic, first characterized by Becker, is influenced by concurrent political and economic circumstances and the applicability of this model to these susceptible sectors (Becker, 1974; Rose-Ackerman, 1996; Ziemek, 2003). It seems unlikely that the busy physician checks his or her motivation against these advanced theories, as it would seem wholly consistent to chase sickness beyond the requirement of making a living. The caring, professional, and teaching obligations codified in their respective medical oaths should be well enough 
imbued by the end of training. Thus the rates of volunteering seen in healthrelated functions would be expected regardless of theoretical basis.

Survey data collection remains challenging despite the ability to instantaneously deliver an instrument to considerably large subsets of a population through email or websites. Our response "click through" rate of $0.62 \%$ approximated typical response rates to email surveys propagated from the proprietary HDS database (January 2014: $25^{\text {th }}$ percentile $0.17,75^{\text {th }}$ percentile 0.72) (personal communication). Providing an opportunity to physicians to boast about their volunteerism did not apparently advantage our response rate beyond typical modest returns. Additionally, although we controlled the survey distribution to a representative cohort with respect to region, specialty and medical degree type, the respondent sample significantly correlated with US physician population only partially, i.e., with respect to race, civil status, and type of medical degree, but not with respect to gender, age, IMG status, religion, and region of the country, rendering the external validity of the sample open to question. The data analysis presented does not address incidence of volunteer participation, hours devoted nor amounts donated. No attempt to mitigate the effects of internal migration, change in civil status, practice situation or religion on the regressions was made. Though consonant with estimations from prior cited research, an abundance of caution is recommended in the use of the estimations of waived fees in view of the limitations of the value of survey data in general, and encourage reconciliation with other sources of such figures as they may become available.

\subsection{Conclusions}

"Giving back" to the profession through multifaceted unpaid teaching, and to society through direct pro-bono services, remains a quantifiable reflection of medical professionals' contribution in line with American generosity. Amounts of fees waived in practice and engagement in volunteer activities have kept pace with historic benchmarks. Participation in pro-bono activities appears broad and not the domain of a particular demographic or professional subset of US physicians. Conceivably, an oath-driven response to a deficit of a domestic public good may be the nidus of motivation in these giving-back activities domestically. Further exploration of the dimensions of inputs and motivation for pro-bono activities abroad may be warranted. 
Chapter 4: Economic Assessment of US Physician Participation in ShortTerm Medical Missions

This chapter draws from:

Caldron PH, Impens A, Pavlova M, Groot W. Economic assessment of US physician participation in short-term medical missions. JGlobalization\&Health. 2016; 12:45. DOI: 10.1186/s12992-016-0183-7 


\begin{abstract}
Background: STMMs are a form of unregulated and unsanctioned, grass roots, direct medical service aid from wealthier countries to LMICs. The US leads the world in STMM activity. The objective of this chapter is to estimate the prevalence of physician participation in STMMs from the US and the related expenditures of cash and resources.
\end{abstract}

Methods: An online survey solicited information on physician participation in STMMs. Responses regarding costs were aggregated to estimate individual and global expenditures.

Results: Sample statistics indicate an increasing participation by US physicians in STMMs. Composite expenditures for STMM deployment from the US are estimated near $\$ 3.7$ billion annually and the resource investment equates with nearly 5800 physician fulltime equivalents.

Conclusions: STMM participation and mission numbers have been increasing in the millennium. The aggregate costs are material when benchmarked against formal US aid transfers. Understanding the drivers of physician volunteerism in this activity is thereby worthy of study and relevant to future policy deliberation. 


\subsection{Introduction}

In the absence of available secondary sources of data specific to physician participation in STMMs, the PGBS was designed to assess an array of US physician volunteerism as described in Chapter 3. Embedded in the survey were questions related to physician participation in STMMs including demographic characteristics and costs associated with participation. The objectives of this study from the survey were to quantify participation in and evaluate the economic dimensions of STMMs from the US through analysis of data provided by respondents to the PGBS. Quantifying incident STMM participation and respondents' itemized direct costs allows for the objective estimation of global expenditures related to STMMs. The effects of opportunity cost are also included in the calculation. Shaping an estimate of the global costs of US physician participation in STMMs by sensitivity analysis allows reflection on the relative materiality, i.e., the composite size of the monetary costs and manpower investment, of this form of aid.

Corroborating the impression that STMM activity of US physicians is increasing is important for several reasons. Rich country physicians are generally welcomed to provide services in LMICs under the guise of intercultural exchange. Usually physicians must provide documentation of current, active licensure in the sending country via a host organization to health authorities, but do not become licensed in the host country. While the intention is primarily to provide free direct medical and surgical care, preventative health services, and both professional and patient education for the benefit of the ostensibly poor, the potential harms in receiving communities have been well characterized (Martiniuk, Manouchehrian, et al., 2012). These harms may include, among others, inadequate follow-up care, inadequate informed consent, therapeutic misadventures when visiting physicians act beyond their training or usual scope of practice, competition with or displacement of local providers of care, and dependency of communities and health authorities on traveling teams that inadvertently dampens local government investment in health resources. These risks must be outweighed by demonstrable benefits, but this assessment is stymied by the reality that the beneficial impact to community health and economics resulting from STMMs have not been measured, and are perhaps not always measurable (Sykes, 2014). Since regulatory oversight of these trips on both sides is generally weak, the composite risk may rise while the methodologies and case models to assess benefit to communities remain immature. Further, 
if this civil society effort to advance healthcare in LMICs through STMMs were found to be relatively effective in comparison to direct foreign aid, it may be prudent for rich countries, including the US, to refine and exploit this outreach for the benefit of global health, as well as for the potential projection of diplomatic soft power, i.e., the capability of attracting and winning the favor of communities by means other than coercion (Nye, 2011). Lastly, with a rise in the number of STMMs and physician participants could come a greater likelihood that harmful adverse incidents would come to public attention in an unfavorable light before the positive dimensions of STMMs are fully appreciated.

As with data on prevalence of physician participation, composite secondary sources of data to accurately assess overall costs are also not readily available. In the evaluation of the return on investment in STMMs, provider side cost data remains easier to collect than receiver side health or economic impact measurements because of the fragmented nature of STMM activity in its present state. This study is not intended as a comprehensive review or adjudication of all aspects of STMMs, nor is it powered to provide both sides of a risk-benefit equation. The importance of the data from the PGBS is to provide useful information for the input side of such an analysis through the methodology of direct solicitation from participating physicians, thereby providing researchers, policy makers, and physicians a sense of the magnitude of these inputs.

\subsection{Background}

Prevalence and incidence data on STMM participation from the US are sparse. Personal communications (December 2013) with administrations of the American Medical Association (AMA), the American College of Physicians ACP, and the American College of Surgeons (ACS) for information from their respective demographic data bases, reveal that no attempt has been made to gather data on STMM participation of their memberships ${ }^{8}$. The activity is not sanctioned by any common social

${ }^{8}$ AMA is the professional association that represents the general interests of licensed American physicians. ACP is the professional organization for American physicians with 
organization or regulatory agency. While the expenditures are generally tax exempt in the US, there are no identifiers within the US federal tax code that specifically mark these outlays in a manner that would allow them to be tabulated nor to project a demographic profile of persons who claim exemptions specifically related to STMM activity.

A 2012 survey Medscape of WebMD revealed that approximately 10\% of physicians "do" some form of "international mission work" although STMMs were not distinguished from other formats such as long term medical work, evangelism, habitat construction or other activities, nor did the report indicate whether the activity was one time, ongoing, or current year (Peckham, 2012). In a similar Medscape survey question in 2014, the overall rate of unspecified international volunteer activities were nearer 7.5\% (Peckham, 2014).

Due to the absence of sources of pooled data from individuals, governmental agencies, NGOs or medical professional societies, the economic resources expended for STMMs from the US are not readily calculable. Physicians volunteering for STMMs are generally expected to cover their own personal expenses and pay organizational fees to support administrative and other costs. Personal costs categorically include airfare, the cost of supplies or equipment that the physician may personally utilize or expend in the course of providing direct patient services, as well as organizational fees that apply to administrative costs, tolls, duties, other in-country facilitation fees, billeting and ground transportation costs. Further, the majority of participant physicians are gainfully engaged in practices where the opportunity cost, i.e., the amount of income foregone during their absence for a period of time, can be estimated. Herein we report findings from the PGBS sample on estimated participation rate and itemized and global costs. Potential policy implications of the results are discussed.

training in non-surgical and non-obstetrical medical care of adults. The ACS is a professional organization that represents the general interests of surgeons in the US. 


\subsection{Methods}

Survey methodology for the PGBS has been previously described in Chapter 3. Respondents who affirmed STMM participation were directed to alternative pathways dependent upon single-mission versus multiple-mission participation. Using a series of ranges, physicians in the single-mission group were asked to provide numerical information on income at the time of the mission, airfare expenditures and organizational fees paid, equipment costs and opportunity costs. Multiple-mission participants provided these amounts for their first and most recent missions. In order to avoid discouraging completion of the lengthy survey, the PGBS asked physicians to provide accurate monetary information to the best of their ability without extensive review of personal records. Opportunity costs refer to a scaled estimate by the physician of the amount of revenue not generated in his or her practice as a result of the time away on the STMMs. Means were calculated based on the weighted midpoints of each US dollar amount range; for the top ranges using a dollar figure "and above", the bottom value to the range was used as the multiplier.

The Statistical Package for the Social Sciences (SPSS) version 22 was utilized in the chi-square test comparisons of sample and population characteristics. The social studies proprietary statistical software STATA version 12 and Excel ${ }^{\circledR}$ proprietary software were utilized throughout the descriptive analysis of data.

\subsection{Results}

The comparability of the PGBS respondent sample to the US physician population has been reviewed in Chapter 3, section 3.3 and Table 3.2. At the time of the survey in the first quarter of $2014,32 \%$ of the physicians in the sample indicated that they had taken part in one or more STMMs. As noted in Chapter 3, the mean number of STMMs among all PGBS respondents was 7 (median 3); of those who reported repeated participation in STMMs, the mean number was 10 (median 5). Table 4.1 shows the prevalence of participation in the PGBS sample within decreasing retrospective periods through 2013, the final year of complete data from the PGBS. Also displayed in this table is the participation rate for 2012, the latest year for which statebased physician population data needed for subsequent calculations is 
available. The table suggests that the occurrence of new participation is intensifying. It should be noted that the physician participation rates are based on the total STMMs executed in each year and assumes one mission per year per physician; it is likely that a small number of physicians may participate in more than one STMM in a year which would lower the derived annual percent participation. On the other hand, respondents were asked to list the years of their first 10 STMMs only. Thirty-four of 170 STMM participants had been on more than 10, meaning that 417 STMMs without specified years were thereby not included in the representation ( 757 total STMMs by these $34 ; 757$ - $(34 \times 10)=417)$ with the possible effect of deflating annual participation rates in some years. It is also noteworthy that STMMs deployed to Haiti in 2010-2013 showed a 49\% rise (61/41) over the 1967-2009 period following that neighboring country's major earthquake.

Figures 4.1 and 4.2 respectively illustrate the increasing prevalence of new first-time STMM participation as well as overall increasing numbers of missions by PGBS respondent physicians during the period $1967-2013$. Figure 4.3 tracks new mission participants as well as the total mission participants as a percent of the survey respondents in practice at each year. The percent of sample physicians that participate in missions for the first time is keeping up with, if not slightly exceeding, the number of respondent physicians entering practice during each survey year. Further, the total number of PGBS respondents participating in a mission each year is increasing relative to the respondents in practice for the survey year. The results are in range with the Medscape 2012 Physician Lifestyle Survey that suggested a roughly $10 \%$ incidence in international mission work by US physicians in recent years. 
Table 4.1 Mean Annual Percent STMM Participation Over Defined Periods

\begin{tabular}{|l|c|c|}
\hline Period & $\begin{array}{c}\text { Period Mean Annual } \\
\text { \% physician participation in } \\
\text { STMMs }\end{array}$ & Retrospective period \\
\hline $\mathbf{1 9 7 3 - 2 0 1 3}$ & $5.7 \%$ & 40 years \\
\hline $\mathbf{1 9 8 3 - 2 0 1 3}$ & $6.8 \%$ & 30 years \\
\hline $\mathbf{1 9 9 3 - 2 0 1 3}$ & $8.7 \%$ & 20 years \\
\hline $\mathbf{2 0 0 3 - 2 0 1 3 *}$ & $12.5 \%$ & 10 years \\
\hline 2012** & $16.5 \%$ & 2012 only \\
\hline *Latest year for which complete PGBS data collected \\
\hline ** Latest year for which state-based physician population data available \\
\hline
\end{tabular}

Figure 4.1 Trend in New Physician STMM Participation

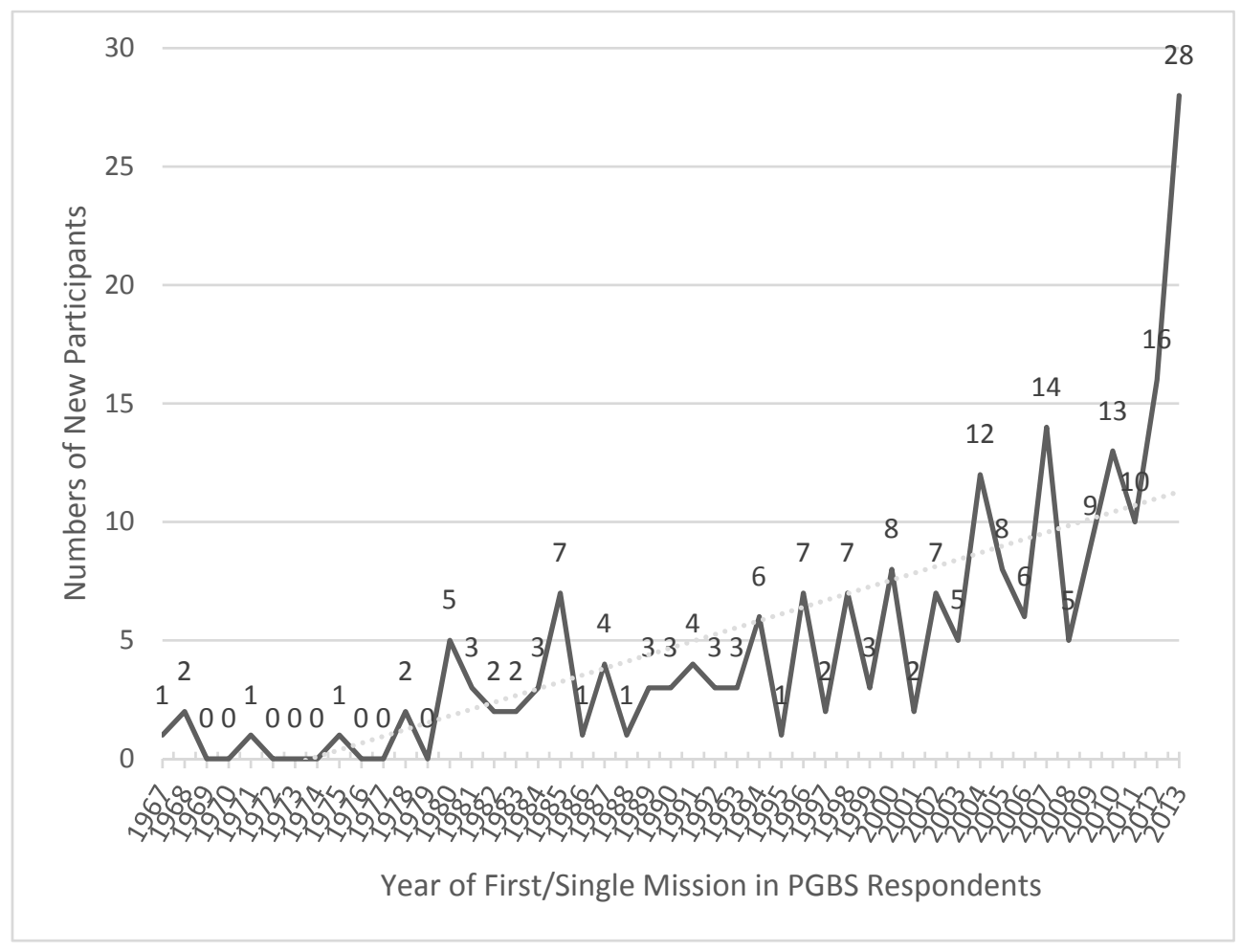


Figure 4.2 Trend in Annual Total STMMs by Physicians

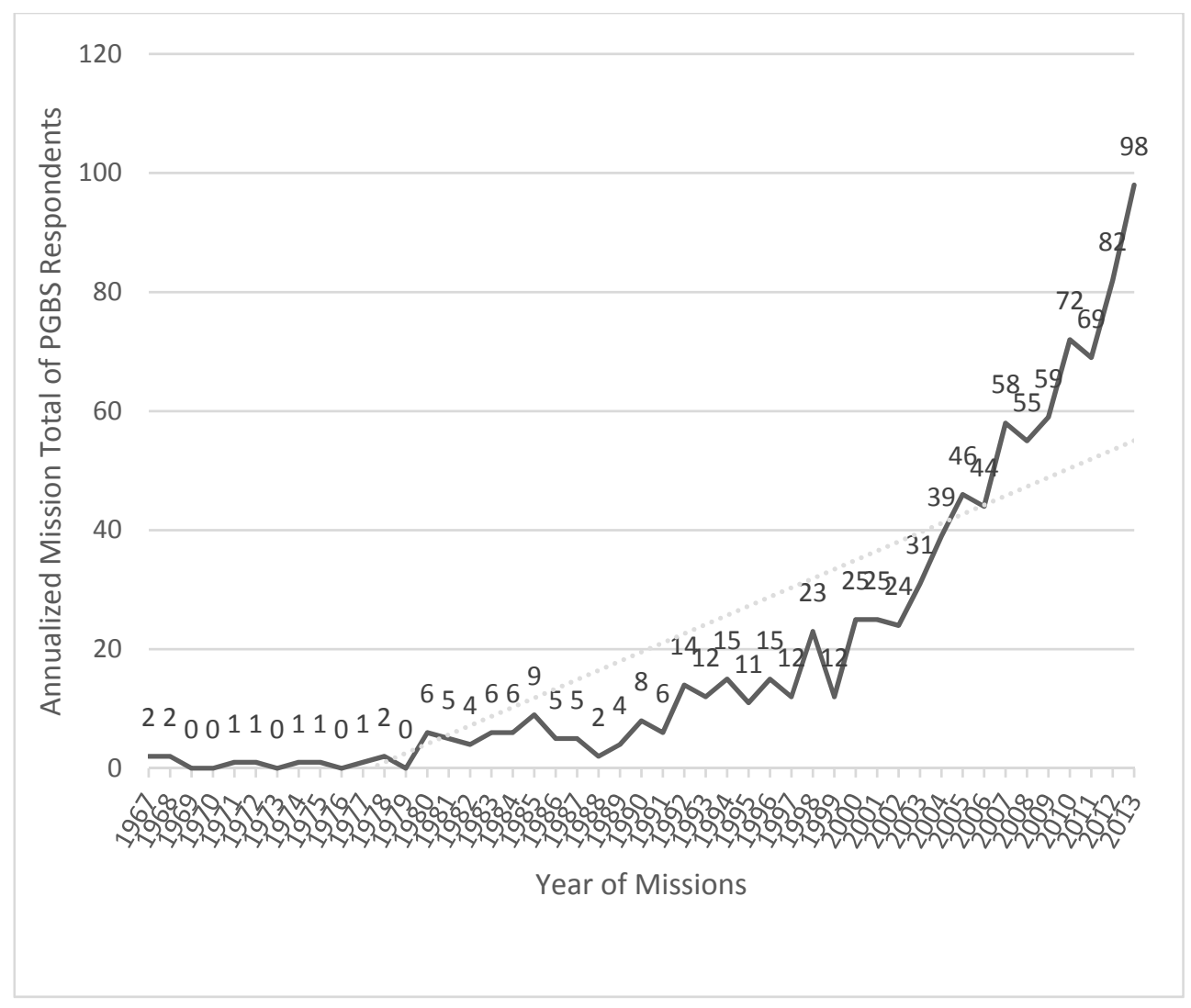


Figure 4.3 Percent of New and Total STMM Participants per Total Respondents in Sample by Year

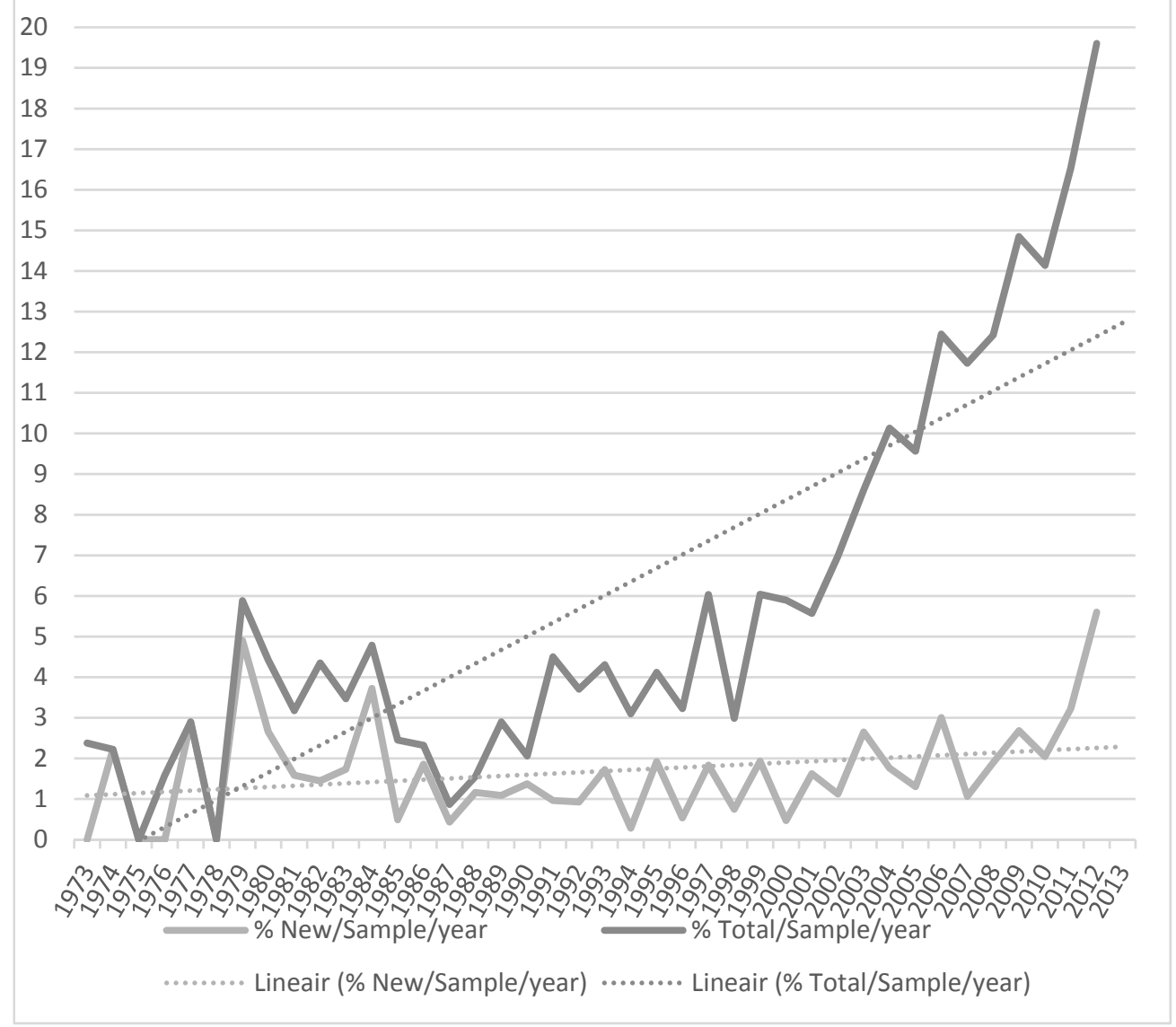

Mission length for PGBS respondents averaged 11.8 days (range 1-90 days, SD 10.3 days) for the 908 of 926 STMMs wherein the duration was reported.

Single-mission PGBS participants provided monetary information on 49 missions and multiple-mission respondents provided cost information for an additional 299 missions. Table 4.2 displays average airfare expenditures (\$1165), organizational fees $(\$ 740)$ and equipment costs $(\$ 1861)$ reported by PGBS respondents. Average individual opportunity cost in the PGBS per STMM was $\$ 7791$. Figure 4.4 illustrates the distribution characteristics for these costs. Using these calculated means, direct expenditures for a typical 
STMM in US\$ at the time of mission (not adjusted for inflation) were $\$ 3815$. If one includes opportunity cost, total economic inputs for an individual physician pursuing an STMM would be \$11,606.

Table 4.2 Itemized Estimated STMM Costs

\begin{tabular}{|l|c|c|l|}
\hline \multicolumn{1}{|c|}{ Item } & Mean & Standard deviation & \multicolumn{1}{c|}{ Range } \\
\hline Airfare & $\$ 1165$ & $+/-\$ 1035$ & $\$ 249.50-7000.00$ \\
\hline Organization fees & $\$ 740$ & $+/-\$ 881$ & $\$ 249.50-7000.00$ \\
\hline Equipment costs & $\$ 1861$ & $+/-\$ 4256$ & $\$ 0-25,000$ \\
\hline Opportunity costs & $\$ 7791$ & $+/-\$ 7173$ & $\$ 499.50-25,000$ \\
\hline
\end{tabular}

When asked about the tax ramifications of the personal direct expenses for STMM activity, 63\% indicated a belief that deductibility from personal income was less than $100 \%$. 
Figure 4.4 Distributions for Direct Costs (Airfare, Organizational Fees, Equipment Costs) and Opportunity Costs

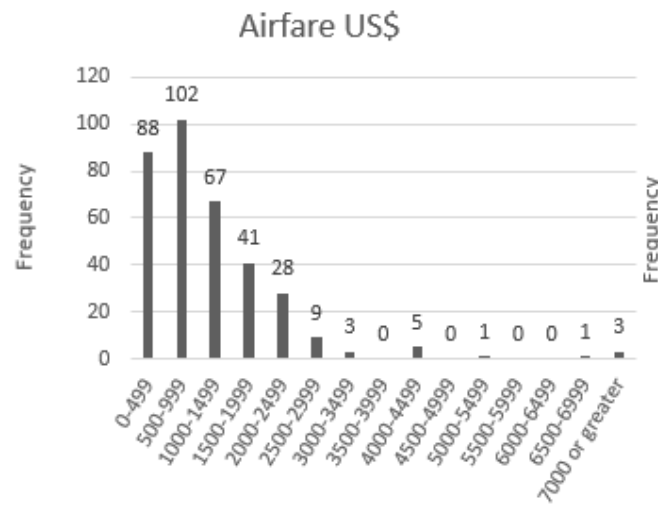

Equipment Costs US\$

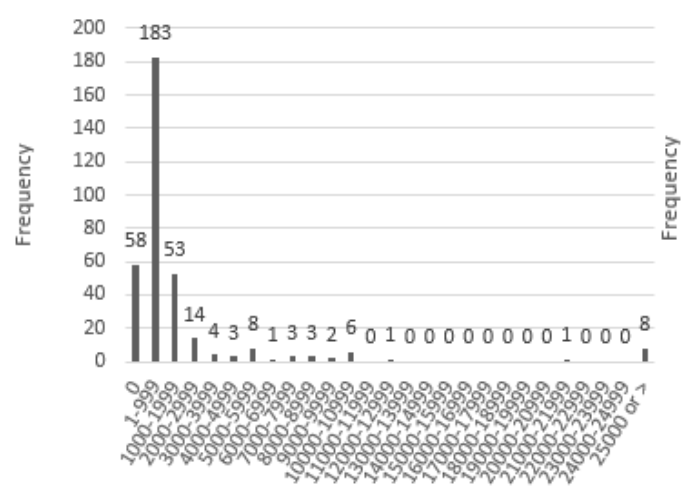

Organization Fees US\$

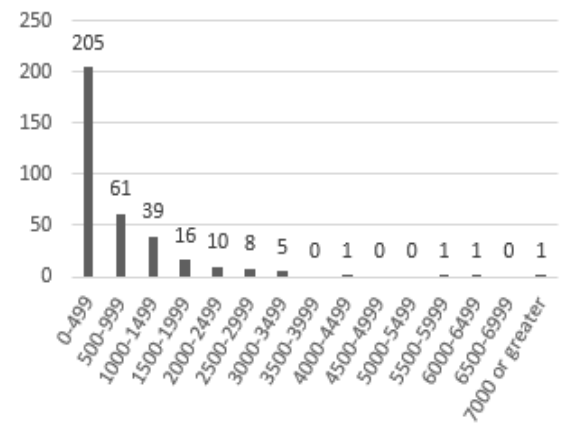

Opportunity Costs US\$

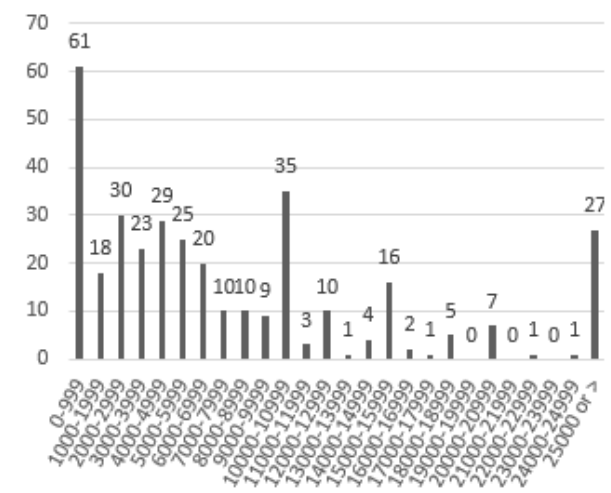

Sensitivity Analysis

To assess the scope of outlays by US physicians that accrue to conduction of STMMs, and to ponder their materiality, respondents' direct and opportunity costs in years 1983, 1993, 2003 and 2012 were multiplied by the estimated STMM participation for those years. For each of these specific years, US physician population data is available, and specific annual costs estimates are drawn from PGBS data. Year 2012 is the latest year for which similarly derived population statistics is available. US physician participation was estimated by multiplying the percent sample participation and the US 
physician population recorded in the respective year. Table 4.3 provides the resultant calculations of total costs, without and including opportunity cost. PGBS respondents provided the year and cost data for their first STMMs and cost data for their most recent STMMs. The year of the tenth STMM is imputed with the most recent STMM cost data, since the year of the most recent STMM is not specified. The totals trend upward from 1993 reaching a half billion US\$ in direct expenditures by 2012 and over four times that amount when opportunity costs are included. For comparison to these selected single year computations, Table 4.4 provides 10 -year period calculations using the actual PGBS figures of participation, an estimate of mean physician population for each decade calculated from the mean of the years when data is available, participation rates derived from the PGBS for each decade, and (a) mean costs derived for each decade, and (b) the mean costs from all STMMs for which cost data were provided in the PGBS. The single year and 10-year computation methods similarly indicate that the growth in expenditures relate to increasing participation rather than simply increasing period costs.

Sensitivity analysis is used to determine how different values of an independent variable (herein ancillary staff) may impact a particular dependent variable (herein total cost) under a given set of assumptions. Some physicians may carry out STMMs alone or in a small team of physicians, acquiring the assistance of local personnel where necessary to provide care (Dupuis, 2006). It is more likely, however, that each physician embarking on a trip is accompanied by one or more ancillary personnel to assist with medical or administrative functions. The direct costs for the additional personnel may be covered by the physician or other means. Regardless of source of funding, the travel and organization costs for the ancillary persons may be assumed to be equal to those of the physician. Equipment costs and opportunity costs would not apply to ancillary personnel. In Table 4.5, projected global costs are re-enacted adding in the outlays for 1-4 ancillary personnel per physician. Since actual reported data for all factors for the single sample year figures of Table 4.3 are available, these figures are used in the sensitivity analysis rather than 10-year averaging wherein several years' population data is not available from the same or similar source or methodology. This sensitivity analysis, via the multiplier effect of ancillary staff, witnesses the global cost of missions expanding as much as $50 \%$ of allinclusive costs for the physician alone, exceeding $\$ 3.7$ billion. 


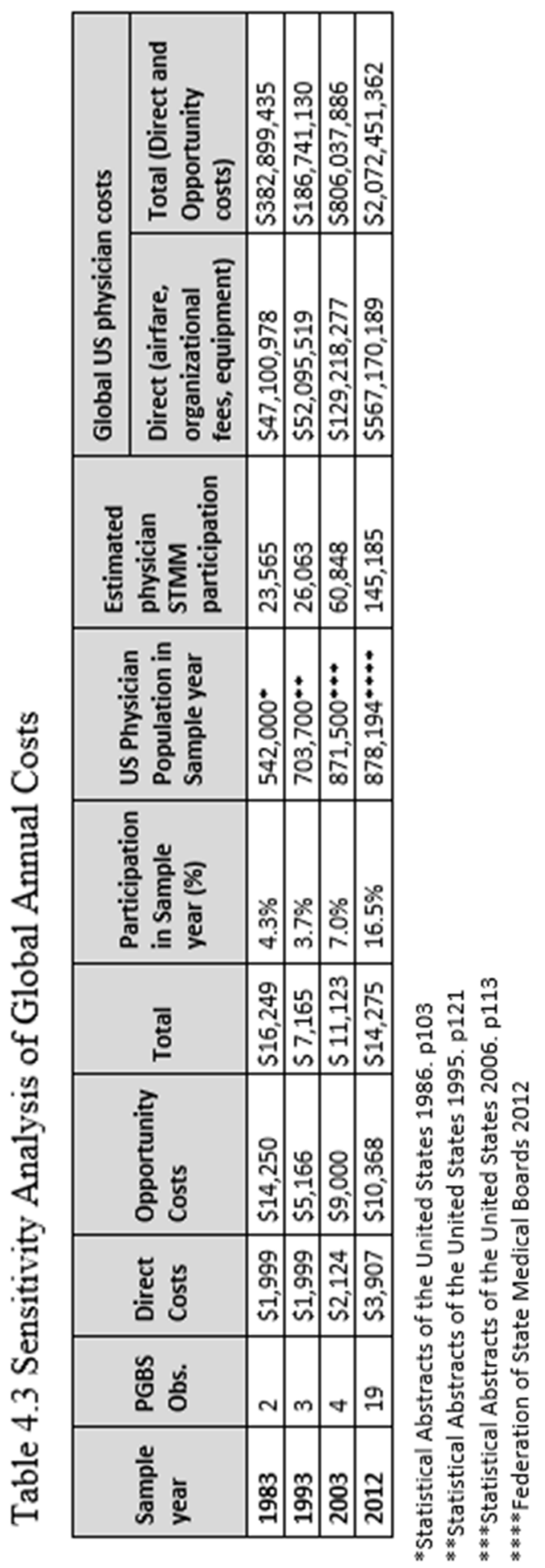




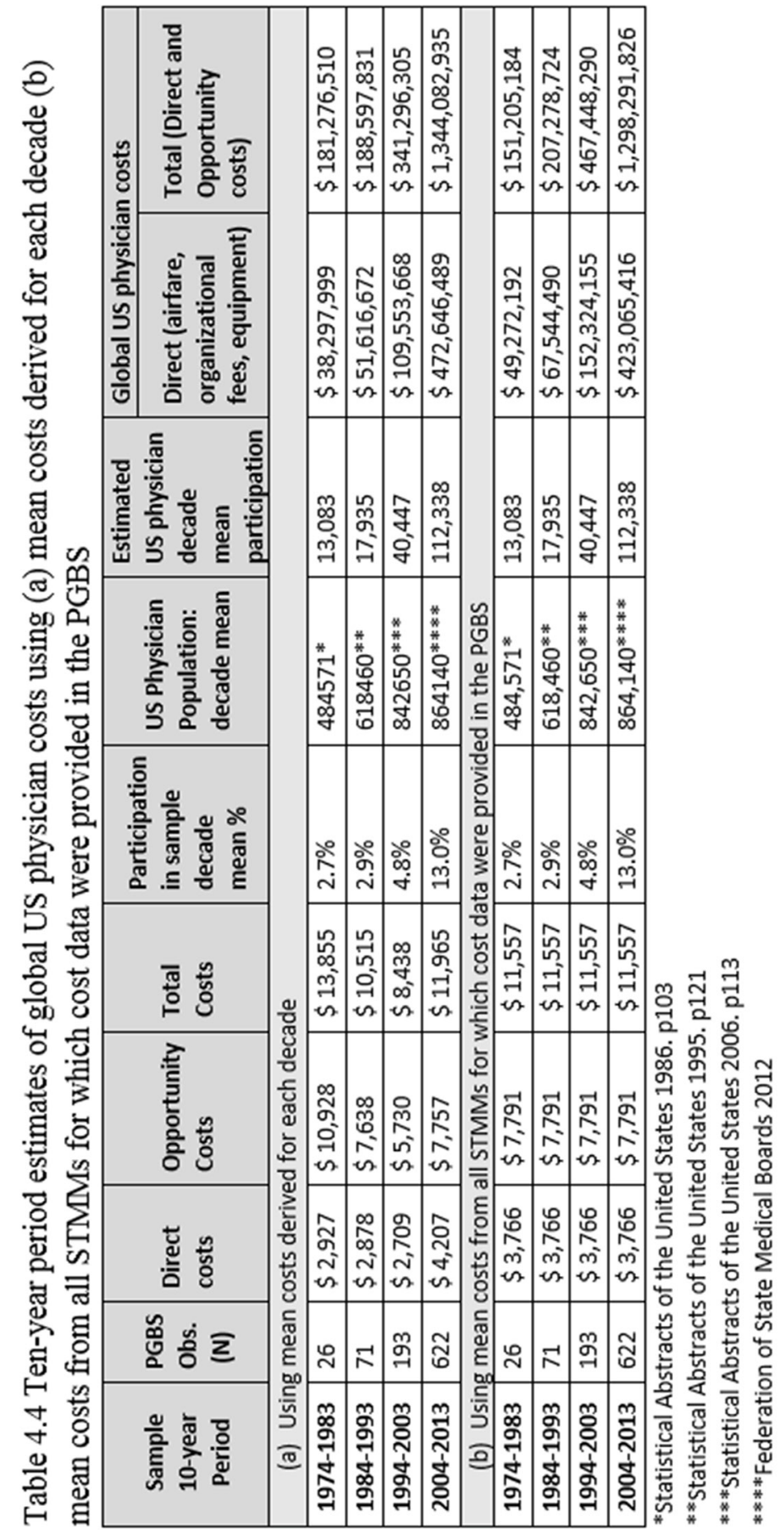




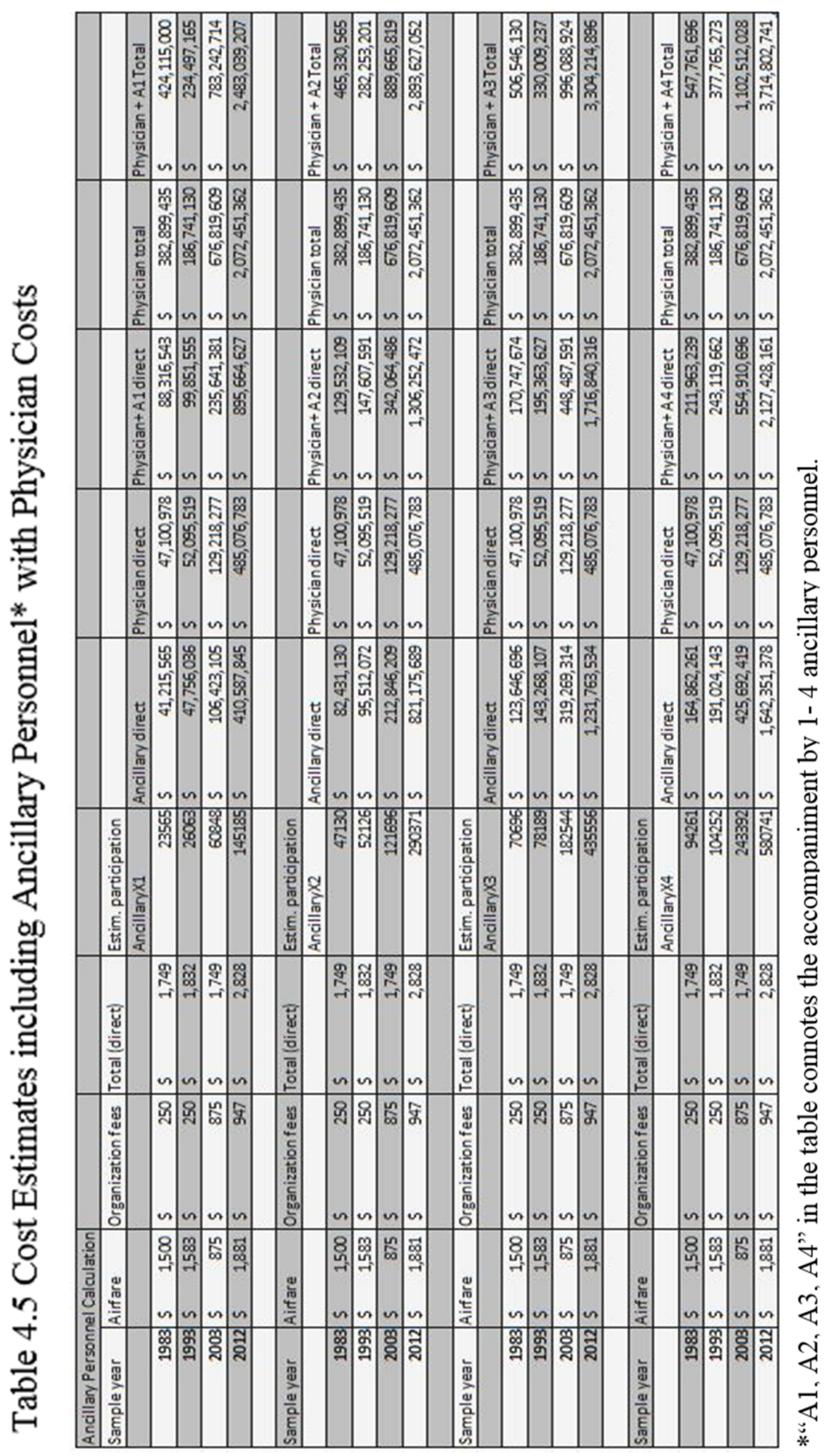




\subsection{Discussion}

PGBS responses confirm that incident US STMM participation and mission numbers have been increasing in the new millennium, consonant with the assertions of previous reports (Maki et al., 2008; Martiniuk, Manouchehrian, et al., 2012; Sykes, 2014).

Most estimates of STMM cost found in current literature relate to single missions, single persons, single NGOs or the care of single patients rather than tackling global expenditures (Chapin \& Doocy, 2010; Crown, 2005; Dupuis, 2006; Propsner, 1998). Maki et al (2008) estimated an annual global cost of at least $\$ 250 \mathrm{M}$ expended on STMMs from the US based upon an internet search to estimate the number of mission organizations, an average team cost per mission, and average number of missions per organization per year. While far less reliable than invoice data, sensitivity analysis above, based on primary costs and opportunity costs reported by sample respondents, provides a more credible estimate of direct and global costs. The calculations indicate cost figures that are magnitudes greater than previously estimated. Our data set includes only that from respondent physicians qualified by our survey; the inclusion of the multiplier of ancillary personnel draws a more realistic picture of global costs, currently exceeding US\$3.7 billion. A perspective on such a sum is facilitated by other aid benchmarks from United States Agency for International Development (USAID): total US aid to Afghanistan (\$3.1B), contributions to International Organizations and Peacekeeping Activities (\$3.7B), Consular Affairs and the Border Security Program (\$2.8 B), Humanitarian Assistance (\$4.1B), and the Global Health Initiative (\$8.3B) (Kerry, 2014). Of course, these USAID disbursements are actual costs, funded through the US tax base, and do not involve opportunity costs as do the estimates for global STMMs expenses in this chapter. On the other hand, the missed opportunities for all of these expenditures may be found in much-needed US domestic infrastructure renovation, and educational and research investments.

Nearly $63 \%$ of STMM participants in our sample believed that their expenses were only partially deductible from earned income, while in reality such expenses are generally fully deductible from taxable income. The deductibility of the costs creates a de facto federal and state subsidy for STMM activity which remains free from regulation, sanction or outcome 
measures. In some cases, academic physicians may be subsidized by their institutions if there can be demonstrated a teaching component to their STMM activity, thus resulting in less or no out of pocket costs to the physician, and such salaried physicians may be immune personally to the effect of opportunity costs.

Mission length for PGBS respondents averaged 11.8 days (range 1-90 days, SD 10.3 days) for the 908 of 926 missions reported. Extrapolating the $16.5 \%$ of responders who participated in missions in 2012 to the population of physicians at that time, each working for 10 days (of an 11.8-day average mission span), the investment of physician work days expended then approaches 1,451,850 working days or 5784 physician full time equivalents from the US physician work force $[(145,185$ X $10=1,451,850$ days $) / 251$ work days in a year]. In a country that faces a chronic manpower shortfall of tens of thousands of physicians, such a transfer of resources may be meaningful (Kirch, Henderson, \& Dill, 2012).

The evidence in this chapter suggests that STMMs are on the rise with considerable composite and personal economic and manpower inputs. Could this arc herald an underutilized dimension for advancing global health in front of direct foreign aid and relief in the face of disaster or conflict? If so, then the fragmentation of the current effort will undoubtedly require a transformation wherein the STMM dimension adopts the disciplined allocation of resources of long-term humanitarian groups like MSF, and the registration and vetting of participants that the World Health Organization (WHO) has begun in order that countries facing disaster can know that the relief is coming from reliable sources (World Health Organization, 2015). A national or international organization focused specifically on STMMs (nonemergent), as defined in our Introduction, could follow the WHO's emergency work force lead by registering and vetting willing private practice physicians as a basis for facilitating the match of skills to need in LMICs and integrating guidelines, quality assessments, and data collection protocols not only for surgical, but also for medical STMMs.

Several groups have advanced the arduous work of differentiating the quality among surgical relief trips, and a body of knowledge is accumulating on the "how to" of execution of STMMs, and the importance of long term collaborative efforts, as tabulated in Chapter 2 (Chen et al., 2012; Holt, 
2012b; Magee et al., 2010; McQueen \& Magee, 2009; Moon et al., 2012; Shrime, Sleemi, \& Ravilla, 2014b). These reports mostly address comparative effectiveness of individual trip models, patient selection for procedures, informed consent, and tracking surgical outcomes. While beyond the scope of this dissertation, what must follow is the development of methods to assess the cumulative effects on individual LMICs that all repeating STMM sources may have, and that will require intensifying social and public health research on this subject.

The increase in STMM activity and the related expenditures has several policy implications. If deductions for charitable activities are eliminated from the tax code, this could reduce the incentive for some physicians to start or continue participation. Government could ultimately determine that the crossborder ramifications of these care transfers, both in terms of lost tax revenue and the diversion of economic output and healthcare resources from the US, are substantive, and begin a process of registry and/or regulation. These should be considered as contingent scenarios that are unlikely in the near term. More realistic may be the fostering of this humanitarian activity for softpower purposes among its neighbors and non-neighbors, even though the physicians themselves may have no diplomatic agenda. Since improving health status promotes economic status, STMMs, if deemed effective, could eventually be viewed among the policy tools of wealthy countries to support development in LMICs (Smith, 1999). Registration and credentialing of participants, matching of the skillsets of volunteers to the areas of need, whether through government or a professional association dedicated specifically to STMMs, may be the steps that reduce fragmentation of effort among STMM participants and NGOs, optimize the return on the growing investment, and promote its sustainability. Narrative research on the positive views of recipient communities are accumulating (Green et al., 2009; Lasker, 2016; Maki et al., 2008; Nouvet, Chan, \& Schwartz, 2015). If future assessments of the impact on health and economic status of communities are ultimately positive, then understanding the personal drivers of physician involvement may aid in recruitment strategies as well as matching skills to community needs. Last, but certainly not least, a benchmark of the personal costs, along with a broader current perspective on STMMs, may help physicians in their own deliberation over involvement. An appreciation of the ramifications of STMMs, not only to individual patients, but also to the context of global health, may inform physicians' cooperation in organizations that act on this broader perspective. 
The assessments of the survey data should be looked upon with caution since such surveys are inherently susceptible to response bias, respondent recollection and reporting bias. Response bias, along with the assumption of one STMM per physician per year, may inflate both the total reported STMM participation (32\%) and the annual percent physician participation of the population, whereas the sizable number of STMMs for which the year was not reported and thereby excluded from the assessment may deflate the calculated rate of participation. The inexact pairing of the available tenth STMM calendar year, the latest year data gathered by the PGBS, with the most recent STMM cost data (not necessarily the tenth) induces a further degree of estimation in the sensitivity analysis, as does the unavailability of uniformly derived US physician population data for every year. While the trend over the prior 40 years to 2013 affirms increasing participation in STMMs by US physicians, a bump in trips to Haiti in the four years following its 2010 earthquake may inflate the later numbers, though the traveling physicians may as readily have gone elsewhere were it not for that disaster. As demonstrated in Chapter 3, the respondent sample significantly correlated with US physician population in respect to only 3 of 8 demographic and professional characteristics. In addition, monetary answers were solicited through selection of ranges. Therefore, individual and composite amounts are weighted estimates. Ranges of dollar amounts provided by respondents were utilized, and no attempt was made to actualize for the time value of the dollar over the reporting period. Further caution is warranted because of the small sample size and recall bias on the part of respondents. There is also a risk that, since this retrospective data collection reaches back to 1967 and some STMM participants may have died by 2014, this survey may somewhat underestimate STMM participation in those earlier years. While response bias may inflate the composite cost estimates to some degree, the failure to capture some costs, such as the sizable expense of multiple travel vaccinations, malarial prophylaxis, grants and donations-in-kind by pharmaceutical companies, surgical devices or disposables given by manufacturers, hospitals, and charities, and other uncaptured expenditures by some participants may lead to underestimation. Some ancillary personnel may incur opportunity costs from unpaid time off work; no attempt was made herein to assess or include that potential sum. 


\subsection{Conclusions}

The rates of STMM participation found in the PGBS data support prior speculation in the literature that incidence and prevalence of physician participation and mission numbers have increased. Utilizing our physician reported cost data, the annual composite outlays for US STMMs comprise a material investment in this form of unofficial aid, both economic, and related to allocation of relatively scarce manpower resources, while being indirectly subsidized through the taxation regime. Representing one of the most highly educated sectors of society, physicians are increasingly finding the trade-offs worthwhile in the non-remunerative exchange of STMMs. The materiality in terms of monetary costs and manpower justifies the effort to understand physician motivation to participate in STMMs, and merits monitoring going forward, and may influence policy considerations intended to optimize cost benefit and non-economic utility of STMMs. 
Chapter 5: Demographic Profile of Physician Participants in Short-Term Medical Missions

This chapter draws upon:

Caldron P, Impens A, Pavlova M, Groot W. Demographic profile of physician participants in short-term medical missions. Submitted for publication. 


\begin{abstract}
Background: The US is the leading sending country for STMMs, an unregulated and unsanctioned, grass roots form of direct medical service aid from richer countries to LMICs. The objective of this chapter is to profile US physicians who go on such missions by means of a survey sample of the US physician population.
\end{abstract}

Methods: An online survey solicited information on physician participation in STMMS as well as demographic and professional features. Responses were descriptively tabulated and multivariate regressions were performed to model for physician profiles related to STMM participation.

Results: Physician participants in STMMs are more likely to be a surgeon, anesthesiologist or pediatrician, married with few or no children at home, later in their career and have an income of $\$ 200-250 \mathrm{~K}$.

Conclusions: Specialty is the strongest predictor of participation. STMM participation does not differ by race, ethnicity nor religion. Descriptive statistics further provide a limited profile of participants. Direct expenses may have less influence on participation than opportunity costs. Potential clues about motivation that may be inferred from the features of the profile are discussed. 


\subsection{Introduction}

Reports that specifically profile physicians who perform STMMs in terms of demographic or professional characteristics are lacking. A mail survey of surgeons affiliated with one North Carolina hospital system that did not distinguish between domestic and international volunteering, found full time practice as the only demographic characteristic that correlated with volunteering; not age, gender, or surgical subspecialty (McGinigle, Milano, Rich, \& Viera, 2008).

The aim of this chapter is to profile the STMM physician participant using response data from the PGBS with respect to natural, professional, family and economic dimensions. Our exploration sought the demographic profile of "who" goes on uncompensated medical service trips in the prospect that it may hold some insights into "why", beyond the assumed general mechanisms of altruism that drive conventional forms of philanthropy and volunteerism (Becker, 1974; Rose-Ackerman, 1996; Roy \& Ziemek, 2000; Ziemek, 2006).

Without theoretical underpinnings or precedent literature as a guide, we constructed a set of explanatory variables that were as comprehensive as feasible, avoiding the practical challenge of a survey too lengthy or complex for busy physicians to want to click through. The final set includes a blend of typical census demographics and professional characteristics. We investigated if the stable, unchosen traits from nature and nurture such as gender, race, ethnicity, religion or being born in the US generally have more bearing on participation than more changeable life features like marital status, children, city population size, years in practice, practice situation and age group. Could region be an influence on STMM participation, related to the traditional image of the various parts of America: The Southern "Bible Belt", the Midwestern "work ethic", and coastal diversity or liberalism? Predicting who will repeat an activity may be intrinsic to the understanding of motivation. The objective of this chapter is to identify the characteristics that might impel a physician to go, not to define factors of poorer country need or social ties that may draw US physicians there, other than what may be inferred from where in the world they go. The marketing theoretical and research literature that links the "who" in demographics to "what" individuals do, buy, or watch is vast. The "what" in our study is the act of participation in STMMs. 
Though such a link to "why" is more tenuous, we will speculate on what the profile infers about motivations.

\subsection{Methods}

Survey methodology for the PGBS and comparisons of the respondent sample and the US physician population have been described in Chapter 3 . Respondents who subsequently affirmed STMM participation were directed to alternate pathways dependent upon single-mission versus multiple-mission participation. Income data was collected along with respondents' demographic and professional characteristics. STATA version 12 and Excel ${ }^{\circledR}$ proprietary software were utilized throughout the analysis of data.

Age of responders was re-coded for groupings of 25-39, 40-55 and 56-73 years to assess for an age, and thereby a life and career stage, effect. Marital status was simplified to those who were legally married or not. For the analysis, specialties were aggregated into four broad categories including adult medicine, pediatric medicine, surgery and anesthesia, and other respondent specialties (psychiatry, pathology, radiology, nuclear medicine, dermatology, pain medicine). States of domicile were aggregated into the four regions for the regression analyses. Models were considered significant if a Prob $>$ chi-square of at least 0.10 was demonstrated and the coefficients of the explanatory variables were considered significant if the $\mathrm{P}<=0.05(95 \% \mathrm{CI})$.

For the purpose of comparing the incomes of our STMM participant sample and US physician population incomes, we aggregated data on incomes of the 35 most common general practice and specialty categories from the Medical Group Management Association (MGMA) 2013 compensation report and matched these with specialty population numbers from the Physician Specialty Data Book 2013 data (Erikson, Jones, \& Whatley, 2014; MGMA Physician Compensation and Production 2013 Report based on 2012 Data, 2013).

Cross-tabulations in STATA were executed to compare the crossover rate of surgeons and anesthesiologists going on purely medical STMMs, and adult and pediatric medicine physicians going on surgically-focused STMMs. 


\subsection{Results}

Descriptive characteristics of respondents

The comparability of the PGBS respondent sample to the US physician population has been reviewed in Chapter 3, section 3.3 and Table 3.2. Thirtytwo percent of respondents indicated that they had participated in at least one STMM after completion of all training. Seventy-seven percent of mission participants had gone on more than one STMM. STMM participation prevalence (32\%), and as indicated in Chapter 3, Table 3.1, exceeded probono participation in local free or sliding scale clinics $(17.5 \%)$, domestic short term missions $(9.3 \%)$ and domestic disaster relief $(8.8 \%)$, but less with those who indicated that a system was in place in their practices to accommodate patients with limited means to pay (39.3\%). STMM length was provided for 908 of the total 926 STMMs reported and averaged 11.8 days in total (range 1-90 days, SD 10.3 days). Effectively, the mean duration STMM would require the physician to be absent from gainful practice for two weeks; if on average, physicians are remuneratively active 46 weeks yearly, then the mean loss may be $4.3 \%$ of annual income during the year they went on one mission (Peckham, 2012).

Sixty-five percent of physicians responding to the PGBS were in the upper age category (56-73 years) (Table 5.1). More physicians in this category (35\%) were mission participants than the younger two age groups; indeed, this oldest age grouping comprised $72 \%$ of all responders who had gone on an STMM. Other demographic characteristics of survey responders and the subset of STMM participants are further compared in Table 5.1. Comparison of STMM participants and non-participants is handled in the multivariate regressions and additional response implications to follow. 
Table 5.1 Demographic Characteristics of Survey Respondents and STMM Participants

\begin{tabular}{|c|c|c|c|}
\hline Demographic & Variable Category & $\begin{array}{c}\text { Survey } \\
\text { Respondents } \\
(\mathrm{N}=601) \\
\text { Percent (\%) }\end{array}$ & $\begin{array}{c}\text { STMM } \\
\text { Participants } \\
\text { (N=192) } \\
\text { Percent (\%) }\end{array}$ \\
\hline \multirow[t]{3}{*}{ Age } & 25-39 years & 4 & 3 \\
\hline & $40-55$ years & 31 & 25 \\
\hline & $56-73$ years & 65 & 72 \\
\hline \multirow[t]{2}{*}{ Gender } & Male & 58 & 64 \\
\hline & Female & 42 & 36 \\
\hline \multirow[t]{4}{*}{ Race } & White & 82 & 79 \\
\hline & Asian & 11 & 12 \\
\hline & Black / African American & 3 & 6 \\
\hline & Native Hawaiian/Pacific & 4 & 5 \\
\hline $\begin{array}{l}\text { Hispanic } \\
\text { Ethnicity }\end{array}$ & Hispanic & 5 & 5 \\
\hline \multirow[t]{2}{*}{ Naturalization } & Born in USA & 78 & 76 \\
\hline & Born outside USA & 22 & 24 \\
\hline \multirow{4}{*}{$\begin{array}{l}\text { Medical } \\
\text { Training }\end{array}$} & Med School - USA & 81 & 80 \\
\hline & Med School - abroad & 19 & 20 \\
\hline & Post-grad - USA & 97 & 97 \\
\hline & Post grad - abroad & 3 & 3 \\
\hline \multirow[t]{2}{*}{ Marital status } & Unmarried & 20 & 25 \\
\hline & Married & 80 & 75 \\
\hline \multirow[t]{4}{*}{ Religion } & Christianity & 49 & 53 \\
\hline & None & 21 & 20 \\
\hline & Judaism & 19 & 16 \\
\hline & Buddhism/Hinduism/Islam/Other & 11 & 11 \\
\hline \multirow[t]{4}{*}{ Region of US } & Northeast & 33 & 28 \\
\hline & Southern & 18 & 21 \\
\hline & Midwest & 22 & 24 \\
\hline & West & 26 & 24 \\
\hline
\end{tabular}


Table 5.1 Demographic Characteristics of Survey Respondents and STMM Participants (continued)

\begin{tabular}{|c|c|c|c|c|}
\hline Demographic & Variable Category & $\begin{array}{c}\text { Survey } \\
\text { Respondents } \\
(\mathrm{N}=601) \\
\text { Percent }(\%)\end{array}$ & \multicolumn{2}{|c|}{$\begin{array}{c}\text { STMM Participants } \\
\text { (N=192) } \\
\text { Percent (\%) }\end{array}$} \\
\hline \multirow[t]{3}{*}{ Children } & Mean & 2 & \multicolumn{2}{|c|}{2} \\
\hline & SD & 2 & \multicolumn{2}{|c|}{2} \\
\hline & Range & $0-13$ & \multicolumn{2}{|c|}{$0-6$} \\
\hline \multirow{3}{*}{$\begin{array}{l}\text { Years in } \\
\text { practice }\end{array}$} & Mean & 24 & $17^{*}$ & $11^{* *}$ \\
\hline & SD & 11 & $12^{*}$ & $10 * *$ \\
\hline & Range & $0-50$ & $0-43^{*}$ & $0-36 * *$ \\
\hline \multicolumn{5}{|c|}{$\begin{array}{l}\text { *At only STMM } \\
* * \text { At first of multiple STMMs }\end{array}$} \\
\hline
\end{tabular}

Respondents who indicated STMM experience were segregated through the PGBS algorithm as having gone on a single mission versus multiple missions. In both subsets, where category of mission was specified ( $\mathrm{N}=367$ of 928$)$, the most frequent STMM focus was medical (non-surgical) (Figure 5.1). The proportion of surgical STMMs to medical STMMs is $26 \%$ and $35 \%$ respectively, leaving aside those categorized as mixed medical / surgical STMMs. Cross-tabulations in our sample of STMM participants reveal a $15.2 \%$ cross-over by surgeons/anesthesiologists to medical missions (33\% in single STMM participants and 10\% in multiple STMM participants) and a $5 \%$ cross-over by adult and pediatric medicine physicians to surgical missions. 
Figure 5.1 STMM Focus by Category

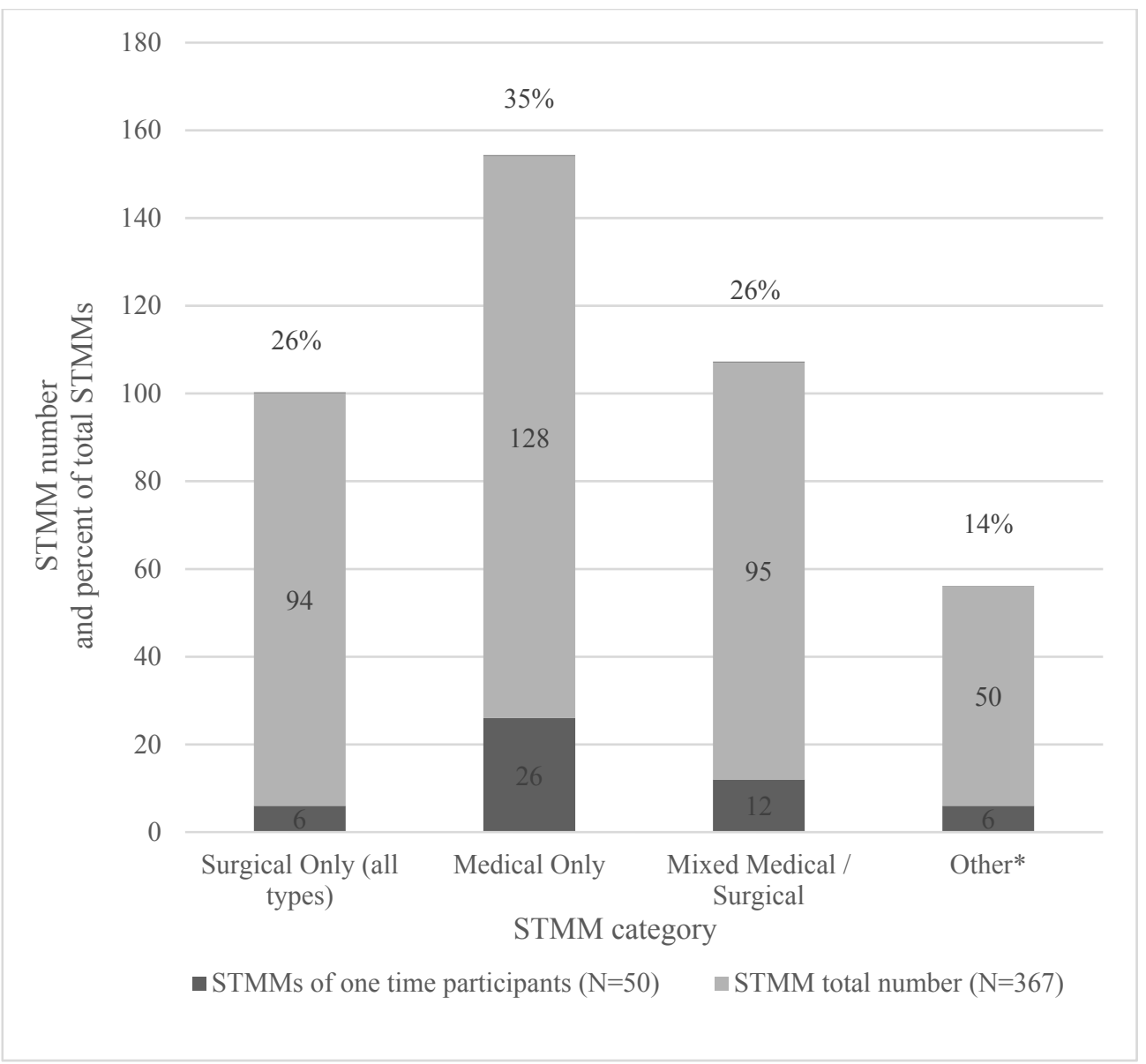

Respondents who had not participated in STMMs most commonly cited physical or social limitations (any medical or regulatory barriers to traveling abroad in the view of the physician) and practicing a specialty that is not a good fit for LMIC missions more frequently than cost constraints as the reason for non-participation (Figure 5.2). The remainder of the leading five reasons cited for primary non-participation included time, family, and work situation constraints respectively. Twelve percent felt that US domestic needs took priority over those abroad. Principal reasons given by single mission participants who chose not to repeat (secondary non-participation; 10.9\%) were expense and time away from spouse or family. 
Figure 5.2 Reasons for Primary Non-Participation in STMMs $(\mathrm{N}=354)$

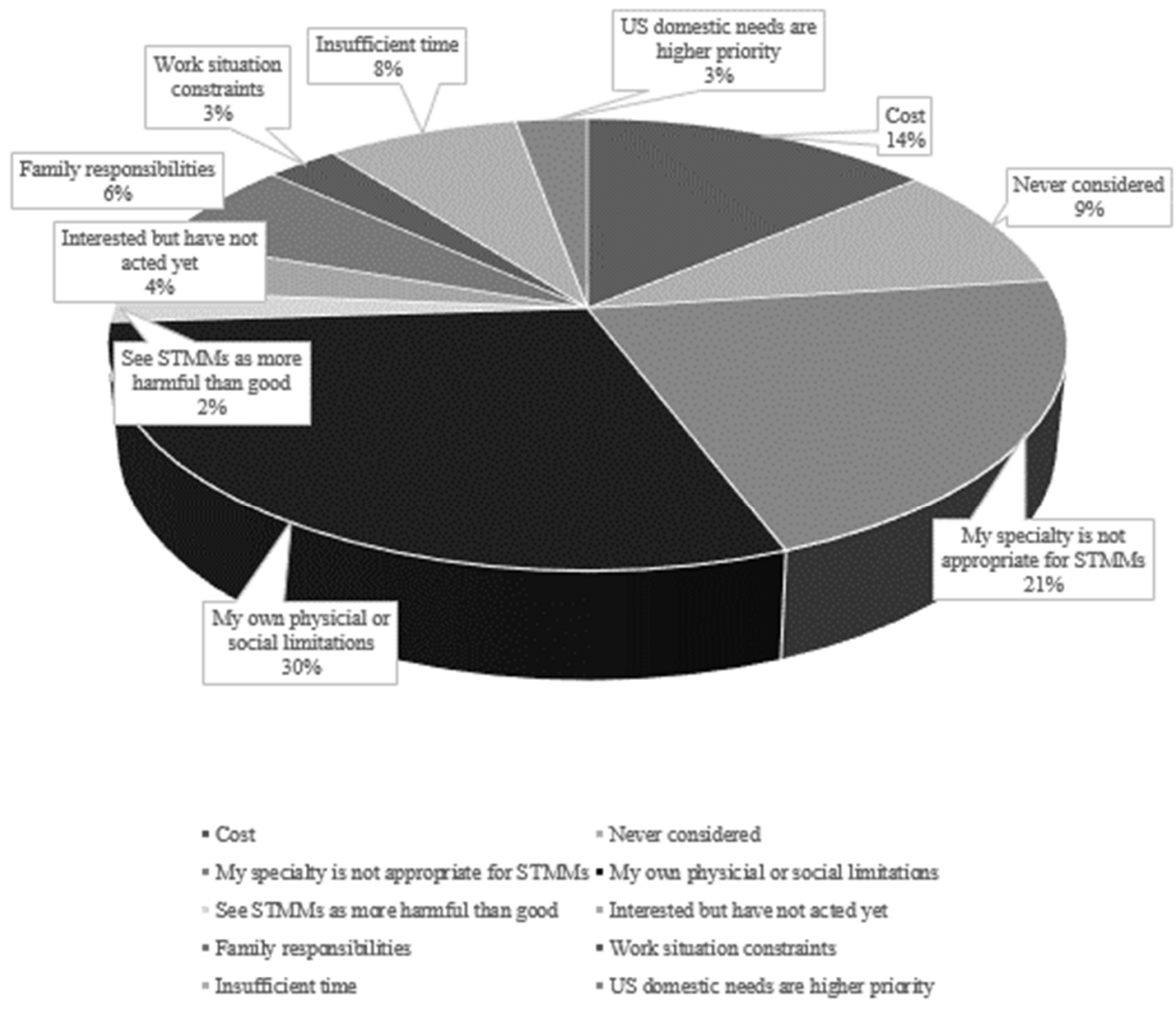

The STMM Physician Profile - Multivariate testing

Using any mission participation $(0=$ no, $1=$ yes $)$ and single versus multiple mission participation $(0=$ single, $1=$ multiple $)$ as binary dependent variables, multivariate logit regressions controlled for seventeen explanatory variables that can be conceptually aggregated in two domains. The first domain includes typically stable demographic characteristics including gender, race, Hispanic ethnicity, religious affiliation, degree (MD/DO), being born in the US, having completed medical school in the US, specialty (having completed most post graduate training in the US) and income level. The second domain includes those characteristics that commonly change over time including region of the US, marital status, children, city population size, cumulative years in practice, practice situation (solo practice, academic, hospital-based, 
government or public facility, multi-specialty group, single-specialty group) and age group. Lastly, other general types of charitable and volunteer activities typically performed by physicians (giving money or donations-inkind, pro-bono medical teaching, pro-bono domestic direct medical care, donating time to professional or patient support organizations and having a system in one's practice to accommodate those with limited ability to pay) were assessed as binary explanatory variables in separate regressions. Respondents who provided no demographic data $(n=100,16.6 \%)$ were omitted from the regression models. Five hundred one respondents who completed nearly all questions were included in the regressions. For 7 independent variables where more than 4 observations were missing, including region $(n=9)$, children $(n=9)$, practice situation $(n=9)$, marital status $(n=13)$, religion $(n=24)$, city population $(n=27)$, and highest taxable income $(n=54)$, dummy variables were added to the regressions where respondents did not report on these characteristics. Development of indicator variables to account for all missing observations for all 601 respondents did not alter the effects of explanatory variables on response variables except that participation in other charitable activities would predict STMM participation. Reduction of the models, carried out through serially withdrawing explanatory variables whose $\mathrm{P}$-values exceeded 0.10 , also did not alter the results of the regressions using original variables. The significant predictors found in these three regression models are combined in Table 5.2. 


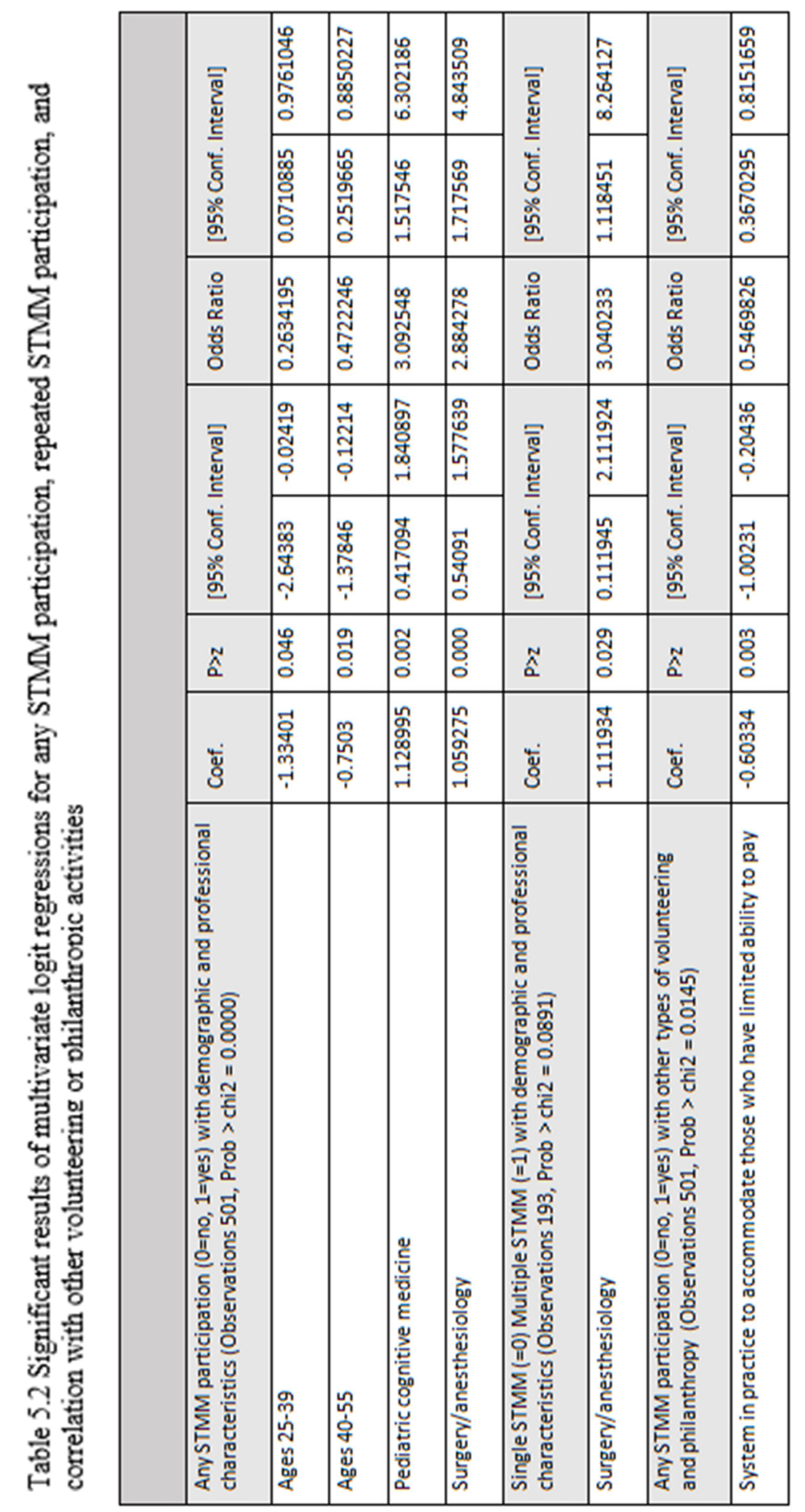


On the basis of coefficients as well as odds ratios, respondents in the age groups 25-39 and 40-55 were less likely to report STMM participation than those in the age group 56+. Further, in our sample, the US physician who volunteers for STMMs is more likely to be a pediatrician, surgeon or anesthesiologist, married, and less likely than non-participants to report their highest taxable income in our survey. Participants and non-participants were not distinguishable on the basis of other characteristics in either the static or changing domain. In the separate regression using other charitable activity options as binary independent variables, STMM participants are unlikely to have a system in their practices to accommodate those with limited ability to pay. No other philanthropic or volunteering activities appeared to have an influence on STMM participation.

The regression to distinguish single from multiple STMM participants controlling for the same set of characteristics indicated only specialty, i.e., surgical or anesthetic practice, as having an influence on the likelihood of repeated STMM participation. A logit regression controlling for other philanthropic and volunteer activities and repeated STMM participation did not produce a significant model.

Additional implications of PGBS responses on attributes of STMM participants

Having children at the time of the survey did not predict STMM participation in multivariate regressions. Nonetheless, descriptive observation suggested that the mode number of children at home at the time of an STMM was zero for $38.8 \%$ of participants regardless of mission number. Sixty percent of STMM participants had no more than one child at home at the time of a mission, and participation decreased consistently with increasing numbers of children at home (Figure 5.3). 
Figure 5.3 Number of Children at Home at Time of STMM

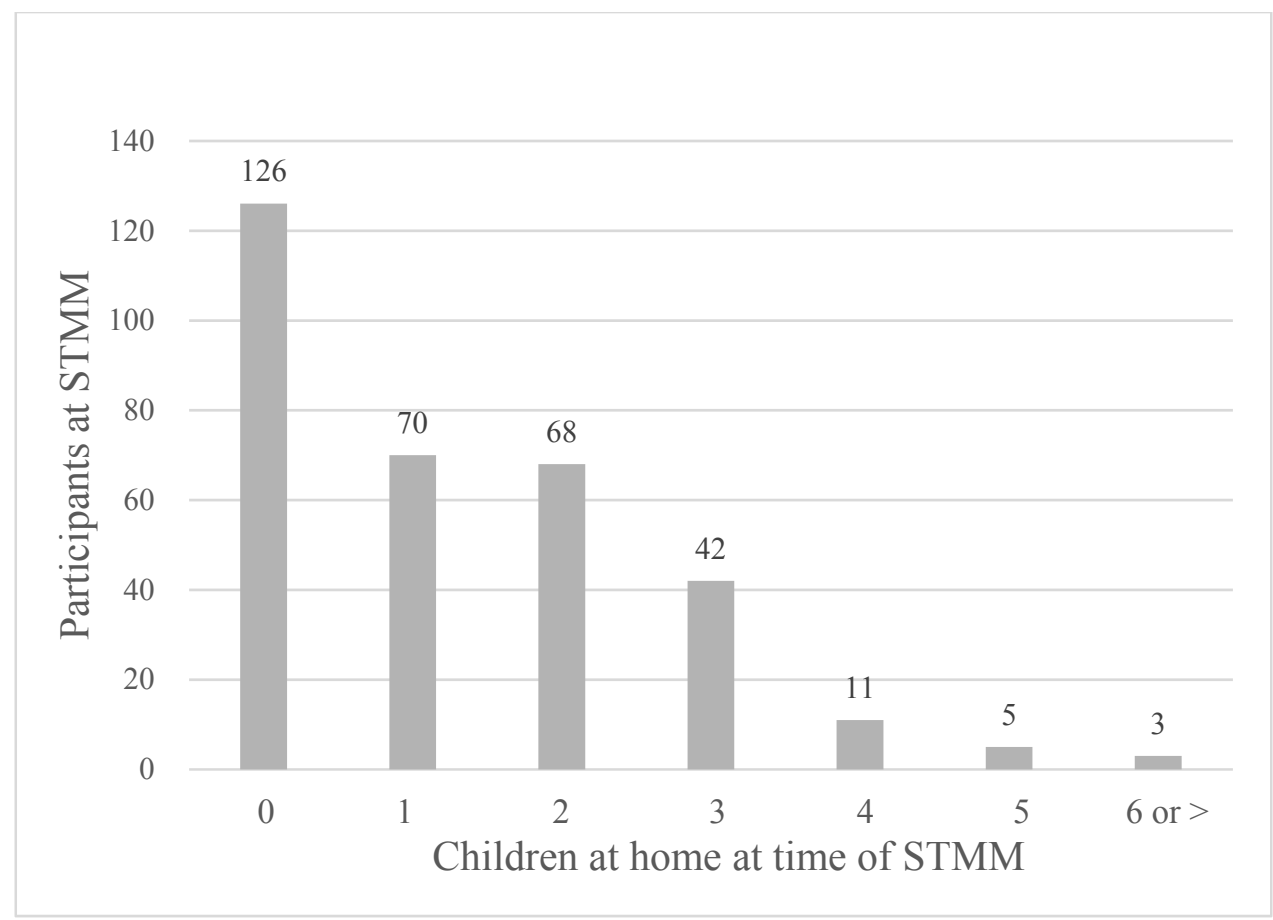

The regressions on STMM participation and repetition indicate that highest taxable income level at the time of the survey was not predictive of such participation. Figure 5.4 illustrates however that the most common highest taxable income range of STMM participants at the time of STMM was \$200,000-249,999 (mean estimated from the weighted midpoints of ranges $\$ 256,077$, SD \$324,038). Although there are no bright-line income thresholds at which physicians begin to take part in STMMs or cease to participate, there appears to be increasing participation as incomes approach the mean, then little participation beyond incomes of about $\$ 500,000$. The statistics in Figure 5.4 are similar to a composite of primary care and specialty income levels from Medscape physician survey respondent samples for the US physician population in 2014 that vary somewhat by region (Kane \& Peckham, 2014; MGMA Physician Compensation and Production Survey 2014 Report Based on 2013 Data, 2014). Both the two year running average of groupings of 100,000 USD and totals from 3 larger groupings in our aggregated data from the MGMA 2013 compensation report and the Physician Specialty Data Book 2013 (see Methods section) would place the overall US physician population income mean in the US\$300,000-450,000 range with a less positive skew 
compared to the curve of STMM participants seen in the PGBS sample (Erikson, Jones, \& Whatley, 2014; MGMA Physician Compensation and Production 2013 Report based on 2012 Data, 2013).

Figure 5.4 Frequency Distribution - Income at Time of STMM

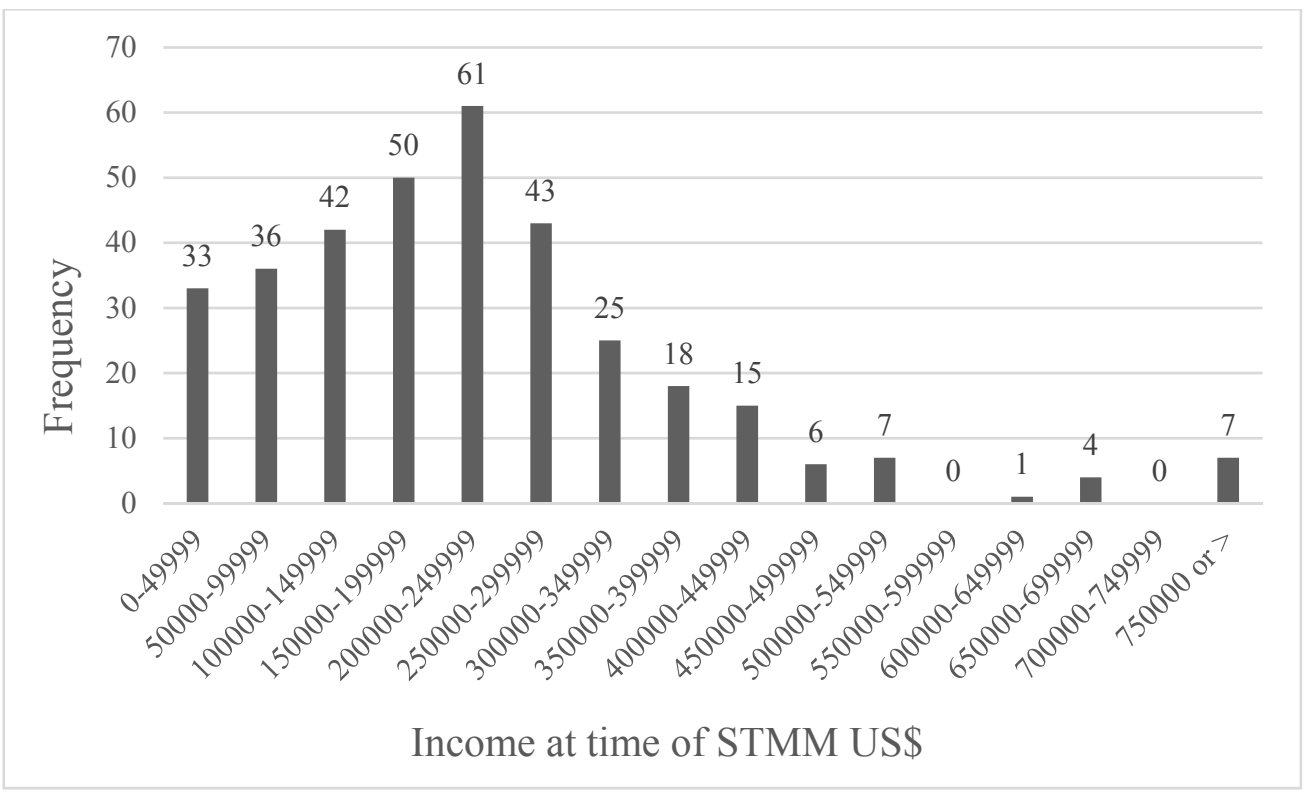

Of 926 STMMs reported by respondents, $60 \%$ were mission trips to countries in Latin America $(n=552)$ followed by Africa $(n=129)$ as the most commonly visited. The remaining STMMs were regionally distributed as follows: Africa 14\%, Southeast Asia 11\%, the Indian subcontinent 9\%, 2\% each for Eastern Europe and the Pacific Islands, and 1\% each for the Middle East and Central Asia. Seventy-six percent of STMM participants in the sample were nonHispanic whites. These physicians carried out $60 \%$ of their STMMs in Latin American countries. Ninety-five percent of STMMs by participants who identified themselves as black or African American were carried out in Latin America, and only 5\% in Africa. In contrast, Hispanic physicians performed $85 \%$ of their STMMS in Latin America. Fifty-seven percent of STMMs by Asian physicians occurred in Asian countries (Central Asia, Southeast Asia and the Indian subcontinent) and another 25\% in Latin America. Non-white Hispanics, for example Puerto Rican US citizens of African descent, were not seen in the sample. 


\subsection{Discussion}

Initial descriptive statistics from the respondent sample do not project a stark profile of the physician who participates in STMMs. Nonetheless, from the regressions and trends in descriptive statistics, an image begins to emerge of a more mature surgeon, anesthesiologist or pediatrician, married with few or no children at home, with a lower than average annual income of around $\$ 250,000$. The findings regarding marital status and children at home are consistent with the demographic attributes found in the statistics of the approximately 1 million Americans that have any kind of international volunteering each year, although that general group appears to bimodal with regard to low and high relative income levels (Lough, 2013; Lough, Mcbride, $\&$ Sherraden, 2007). The features of this image may nonetheless render clues to why physicians go. Between the domains of stable and changing characteristics, the life choices physicians make seem to tell us more about who is likely to participate than their innate traits or origins do.

More than any other single characteristic, STMM participation is influenced by specialty. Overall, surgeons and anesthesiologists are the most likely specialty categories to participate. This finding is consonant with the finding in Chapter 2 that most articles providing data, guidelines and instructions regarding STMMs are found in specialty surgical literature, presumably because surgical missions tend to provide a finite set of discrete procedures more amenable to process and outcome assessments. Global health measures such as water sanitation, mosquito net implementation, and HIV prevention can reduce a broad swath of illness, but for surgical disorders such as cataracts, cleft palates and fistulas, only one-to-one interaction with a skilled professional will help, making both the need for and the benefits accruing from surgical volunteering in underserved areas stand apart. Counterintuitively, a greater portion of missions have a medical rather than surgical focus, suggesting that medical physicians are at least as much drawn to pro-bono missions, even if the effects on local disease burden are less precisely measurable than for surgical procedures. At the same time, crosstabulations show a $15.2 \%$ cross-over to medical missions by surgeons/anesthesiologists and a $5 \%$ cross-over by medical physicians. It might be that some surgeons and anesthesiologists go on non-surgical mission trips at times perhaps to connect back to primary care skills. 
US physicians in our sample who participated in any STMM are more likely to be in the latter rather than earlier years of professional life (assuming an active practice career length of about 30 years), and in procedurally oriented specialties or pediatrics. Participation later in career may not be simply a function of longer experience, but perhaps that physicians in earlier years of practice must concentrate on a successful career start-up, and those in middle years bear more administrative responsibilities at work and have more children at home. Participation could depend less on youthful idealism and vitality, and more on these later career and life stage elements. Pediatricians in the US remain in the lower tiers of professional income (MGMA Physician Compensation and Production 2013 Report based on 2012 Data, 2013). The choice to participate in unpaid STMMs by these doctors would appear to be consistent with non-monetary gratification, i.e., less related to income and less sensitive to forgoing income by spending time on missions. Children in poverty may perhaps evoke relatively more sympathy and appear to have more need than adult targets of pro-bono care, thus triggering a response to a receiver-side characteristic. Surgeons and anesthesiologists, as are other procedurally-oriented physicians in the US, exist on the higher end of the physician income spectrum (MGMA Physician Compensation and Production 2013 Report based on 2012 Data, 2013). Such procedural orientation further lends itself to missions that encompass a few discrete procedures that can be selective and scheduled a priori.

Another counterintuitive suggestion from our regressions is that STMM participants are less likely than non-participants to have a system in place in their practices to accommodate those with limited ability to pay. Wherein physicians are willing to give their time and talent in charitable circumstances for no compensation at all (and even at substantial personal cost), should we interpret that, in their own practices, they would maintain a stricter policy for payment and thereby clearly demarcate where they do business and where they do charity?

In the regression models, income was not seen to predict participation in STMMs. No shelf is seen in the distribution curve to indicate a threshold income allowing for or dissuading from STMM participation. Nonetheless, one interpretation of the positive skew of the curve of Figure 5.4 is that opportunity cost incurred at higher incomes is more influential than out-ofpocket costs, since opportunity cost sensitivity would be positively correlated with income generating potential. This may suggest a sort of "price elasticity" 
for the non-monetary rewards of pro-bono work. Decreasing participation with increasing income in the sample cannot be solely attributed to effects of aging or seniority since the sample showed relatively higher participation by older physicians. US physician incomes appear to plateau early relative to the market, i.e., as suggested by comparing median compensation figures at 6 years from starting practice in $2011^{9}$ to the median in $2011^{10}$, and consonant with 2004 data from MGMA (Gans, 2005). Therefore, incomes are not necessarily correlated to seniority. In our sample, relatively more physicians are participants in the latter portion of their careers. Other factors that may underlie the inverse relationship of higher incomes and less mission participation are not ruled out by this analysis.

In order of importance, respondents indicate that time, work situation and family constraints exceed direct expenses as the primary reasons for not selecting STMMs among the options for volunteer activity. Reciprocally, the act of participation is unimpeded by these factors, implying that situational and emotional drivers outweigh innate demographic features in predicting who participates in STMMs.

It is perhaps somewhat counterintuitive to find in our sample that physician STMM participation was not predicted by religion, despite the many faithbased organizations sponsoring STMMs readily found online. The $21 \%$ of respondents reporting no religious affiliation in this predominately Christian yet fundamentally tolerant country is in keeping with the reported trend towards non-affiliation with religions in the West and the opposite movement in the developing world (Cooperman, Smith, \&Ritchey, 2015). Rather than religion as a prime driver of physician involvement in this activity, the decision to participate may be more closely related to tenets of medical oath than to tenets of faith, or to the degree of religiosity rather than the particular faith identification. The incomplete profile that emerges in our study falls

\footnotetext{
9 PayScale Human Capital. Posted on September 16, 2011 at www.physician-salary.org, Accessed 18 July 2015.

${ }^{10}$ Physician Compensation and Production 2012 Report Based on 2011 Data. Medical Group Management Association Datadrive Accessed 18 July 2015
} 
short of shining a spotlight on the key impulse to participate. Our results do suggest that acting on the motivation is extensively regulated by the physical, professional, family and opportunity cost modifiers discussed.

A large majority of Hispanic physicians went to Latin American countries, but the same was true for black or African American physicians and nonHispanic whites. Asians did lean towards Asia, so the attraction to ethnic roots or giving back to one's heritage is mixed. It could be seen as encouraging that there is such limited attraction bias in that these donors of time and skill may be flexible enough to go where the need or best likelihood of impact calls them, rather than the destination being determined solely by their ethnic ties or donor preferences (Barnett \& Walker, 2015). A perhaps more likely alternative explanation for the Latin American mission target predominance would be the proximity to the US resulting in less travel cost and time, more of the time away being time on the ground working, relatively less jetlag, and perhaps a longer cumulative experience with Latin American communities over time. Such a conclusion could seem more valid were a similar regional connection to be found in future research for European and Australian physicians that do STMMs.

The limitations in our profile of the STMM physician begin with the relatively small sample size that is typical of email blast surveys. All such surveys are subject to response bias, and it is reasonable to anticipate that a survey on volunteerism risks more responses from those who do volunteer. In addition, one-sample chi square testing indicated incomplete external validity of our sample to the US physician population. The models are not powered to mitigate the effects of internal migration, change in marital status, practice situation or religion. Religion was not explored at the denominational level in our survey. Neither the effect of geographic variability in income nor the effect of dual income households on propensity to participate were assessed. Controlling for a high number of independent variables may induce insensitivity for all but the most robust relationships in small samples. A link between "who" to "why" may be unknowable and limited to inference. For all these reasons, applying the interpretations from this chapter in the course of policy formulation requires prudence.

Narrative collections from STMM participants could be helpful to bridge the gap between what demographic and economic data can tell us and the 
conscious process of a "go" decision, and thus from the "who" to the "why". Narratives might also reveal how closely the personal reasons for attending in STMMs reflect the concepts related to the Public Goods, Private Consumption and Investment Exchange theories of philanthropy, and how the reward of "warm glow" may relate to opportunity costs that physicians are willing to trade for it (Andreoni, 1990; Ziemek, 2006).

\subsection{Conclusions}

Respondents to the PGBS have documented that while there is no defined subset of the population that dominates the STMM participation, the participant is more likely to be a surgeon, anesthesiologist or pediatrician, married, and in the latter part of one's career. The participant characterization may be extended by the influence of modes; the doctor has most likely reached an annual personal income level of 200-250K USD and has no children in the home. These attributes may render the STMM participant less cost sensitive and more likely to repeat STMM participation. Nonparticipation is more attributable to physical or social limitations or a sense that one's specialty is not a fit for STMMs than direct costs, although higher incomes may dissuade participation due to larger opportunity cost. Latin American countries have been the targets of most US-sourced STMMs regardless of race or ethnicity, except that most Asian physicians go to Asian destinations. Skilled and structured interrogatives with STMM physicians at various stages should add much value to understanding how the choice to participate is made. 
Chapter 6: Why Do They Care? Narratives of Physician Volunteers on Motivations for Participation in Short-Term Medical Missions Abroad

This chapter draws from:

Caldron PH, Impens A, Pavlova M, Groot W. Why do they care? Narratives of physician volunteers on motivations for participation in short-term medical missions abroad. Submitted for publication 


\begin{abstract}
Background: STMMs refer to the provision of direct pro-bono medical services in LMICs for periods ranging from days to a few weeks by physicians from rich countries. The participation and number of missions appears to be increasing in relative and absolute terms. Survey data have provided limited information on the demographic and professional profiles of participants as well as monetary and manpower inputs. Our understanding of why physicians participate, however, remains incomplete. The objective of this chapter is to further elucidate physician motivation to participate in STMMs through interviews with experienced participants.
\end{abstract}

Methods: Semi-structured interviews of physicians were conducted to explore motivational themes. Physicians meeting study criteria were identified by snowball recruitment. Interview transcripts were analyzed manually and using narrative software.

Results: Twenty subjects representing an array of demographic backgrounds and medical specialties were interviewed. Through responses in several domains and an open forum, subjects identified the important personal aspects of their decisions to participate and the relative influence of economic, diplomatic, value-related and emotive constructs.

Conclusion: Personality traits may be more influential to participation than demographic, professional or socio-economic determinants. Word-of-mouth recruitment appears to underlie the increase in STMM activity, facilitated by information technology. Reported key motivators for physician participation in STMMs tend to parallel schools of thought regarding philanthropy and volunteering and include satisfaction from helping in challenging conditions with limited resources, learning experiences, appreciation from patients, sense of renewal and the legacy effect of teaching. 


\subsection{Introduction}

Chapters 4 and 5 of this dissertation have provided a glimpse of the physician more likely to participate in STMM activity as well as the economic and manpower inputs, but those profiles and inputs alone do not bridge the broad gap in our understanding of the reward systems relevant to physicians. Although the literature is replete with individual reflections on mission experiences, structured analyses of the underlying motivations of physicians are not readily found (Martiniuk, Manouchehrian, et al., 2012; Sykes, 2014). The medical and social literature's attention to STMMs is expanding in the new millennium. Medical training programs are working to meet the call to expose students and post-graduates to global health experiences (Association of American Medical Colleges. Matriculating Student Questionnaire: 2012 All Schools Summary Report. Washington, DC: Association of American Medical Colleges; 2012; Khan, Guerrant, \& Sanders, 2013). These observations give further purpose to our quest for clearer insights into the participant mindset and psychosocial environment.

As globalization has laid bare the chasms in access to healthcare resources between the rich and the poor in developing countries, the motivations driving the expansion in this novel form of aid are important not only to research, but also for assessing the role that STMMs might play in policy deliberations on global governance in health (Kickbusch, 2002; Otterson \& McNeill, 2014). Understanding the determinants of physician participation, including personal motivations, may inform policy efforts to promote or regulate STMMs.

The objective of this chapter is to solicit directly from physicians their motivation(s) to participate in STMMs through in-depth interviews. Selected question areas ask firsthand not only how issues probed in Chapters 2-5 actually enter into the decision, but also allow for an open, direct discourse that may expose heretofore unrecognized factors and circumstances relevant to participation. 


\subsection{Methods}

Our approach in this research was exploratory and not an attempt to test theory or hypothesis. The objectives were pursued through the analysis of narrative accounts of STMM participating physicians through interviews. Although this is a non-interventional study, the physicians interviewed for this project are referred to as 'subjects' in this report in order to avoid confusion with physicians who participate in STMMs in general or referenced in contexts other than as participants in this narrative study. An interview guide was developed to facilitate the exploration of several themes of potential influence to motivation based on concepts conveyed in published articles of a reflective nature, systematic reviews, and results from the PGBS (Bryden, 2007; Carrigan, 2005; Mitka, 2005). Notwithstanding, each interview included relevant exploratory questions of the author's interests, and concluded with an open forum section to identify concepts not previously queried. The question areas and their rationales and discussion points are summarized in Table 6.1. 
Table 6.1 Question Areas and Rationale

\begin{tabular}{|l|l|l|}
\hline \multicolumn{2}{|c|}{ Question areas } & $\begin{array}{l}\text { Question area rationale and } \\
\text { discussion points }\end{array}$ \\
\hline Demographics and participation history & $\begin{array}{l}\text { Characterize subjects and } \\
\text { experience in STMMs (Curlin } \\
\text { et al., 2005; Erikson, Jones, \& } \\
\text { Whatley, 2014) }\end{array}$ \\
\hline $\begin{array}{l}\text { 1. Introduction to } \\
\text { STMMs }\end{array}$ & $\begin{array}{l}\text { How were you introduced } \\
\text { to STMMs? }\end{array}$ & $\begin{array}{l}\text { Exploratory: How did the } \\
\text { idea arise? }\end{array}$ \\
\hline 2. Key driver(s) & $\begin{array}{l}\text { What would you say is the } \\
\text { key driver in your } \\
\text { motivation to do STMMs? } \\
\text { Among oxploratory: Evoke visceral } \\
\text { opportunities for giving or } \\
\text { response, uninfluenced by } \\
\text { interrogation. } \\
\text { you chose STMMs? }\end{array}$ & \\
\hline $\begin{array}{l}\text { 3. Country and } \\
\text { organization } \\
\text { selection }\end{array}$ & $\begin{array}{l}\text { How did you select the } \\
\text { organization(s) with which } \\
\text { you worked? How did you } \\
\text { select the country (ies) } \\
\text { that you visited on } \\
\text { STMMs? }\end{array}$ & $\begin{array}{l}\text { Exploratory: Understand the } \\
\text { influence of ties to countries } \\
\text { or organizations on } \\
\text { participation in STMMs. on }\end{array}$ \\
\hline
\end{tabular}


Table 6.1 Question Areas and Rationale (continued)

\begin{tabular}{|c|c|c|}
\hline \multicolumn{2}{|c|}{ Question areas } & $\begin{array}{l}\text { Question area rationale and } \\
\text { discussion points }\end{array}$ \\
\hline $\begin{array}{l}\text { 4. Professionalism } \\
\text { and } \\
\text { professionalization }\end{array}$ & $\begin{array}{l}\text { How would you describe } \\
\text { the level of } \\
\text { professionalism among } \\
\text { physicians that participate } \\
\text { in STMMs from your } \\
\text { experience? Compare } \\
\text { standards of care observed } \\
\text { on STMMS to the } \\
\text { standards of care in US? } \\
\text { How would you feel about } \\
\text { such an overarching } \\
\text { professional organization } \\
\text { for STMMs and how do } \\
\text { you think it would (or } \\
\text { would not) be helpful? }\end{array}$ & $\begin{array}{l}\text { Review of the literature } \\
\text { suggests that } \\
\text { professionalization in } \\
\text { STMMs (formation of } \\
\text { national/international } \\
\text { organization, regular } \\
\text { publication, general } \\
\text { standards and policies, } \\
\text { specific training efforts, } \\
\text { memberships, certifications) } \\
\text { appears underdeveloped } \\
\text { (Chapter 2). Subjects were } \\
\text { asked about their perception } \\
\text { of the level of } \\
\text { professionalism witnessed } \\
\text { during their STMM } \\
\text { experience and whether an } \\
\text { over-arching national or } \\
\text { international bald be } \\
\text { organization would } \\
\text { desirable or influential. }\end{array}$ \\
\hline
\end{tabular}


Table 6.1 Question Areas and Rationale (continued)

\begin{tabular}{|c|c|c|}
\hline \multicolumn{2}{|c|}{ Question areas } & $\begin{array}{l}\text { Question area rationale and } \\
\text { discussion points }\end{array}$ \\
\hline $\begin{array}{l}\text { 5. Economic } \\
\text { aspects }\end{array}$ & $\begin{array}{l}\text { How important are the } \\
\text { direct costs to you? What } \\
\text { are the chances the direct } \\
\text { costs would be high enough } \\
\text { to deter you from } \\
\text { participating? } \\
\text { important is opportunity } \\
\text { costs, i.e., the income not } \\
\text { earned because you are } \\
\text { away? How influential is the } \\
\text { tax deductibility on a } \\
\text { physician's decision to go or } \\
\text { not? What do you do, } \\
\text { typically, if anything, to put a } \\
\text { clear demarcation between } \\
\text { your business activity and } \\
\text { pro-bono activity? }\end{array}$ & $\begin{array}{l}\text { Influence on STMM } \\
\text { participation of economic inputs } \\
\text { as well as domestic pro-bono } \\
\text { service activity has been studied } \\
\text { by other methodologies } \\
\text { (Chapters 2, 4, 5) (Hadley \& } \\
\text { Holahan, 2003). Subjects were } \\
\text { asked about the effects of direct } \\
\text { and opportunity costs as well as } \\
\text { the tax implications on their } \\
\text { decision to participate. }\end{array}$ \\
\hline
\end{tabular}


Table 6.1 Question Areas and Rationale (continued)

\begin{tabular}{|c|c|c|}
\hline \multicolumn{2}{|c|}{ Question areas } & Question area rationale and \\
\hline $\begin{array}{l}\text { 6. Diplomatic } \\
\text { aspects }\end{array}$ & $\begin{array}{l}\text { What importance would you } \\
\text { place on the level of cross- } \\
\text { cultural acumen and } \\
\text { awareness of the } \\
\text { implications of soft power } \\
\text { on the part of participating } \\
\text { physicians and their support } \\
\text { teams? How does the } \\
\text { potential for conveying } \\
\text { positive (or negative) } \\
\text { impressions of America } \\
\text { enter into one's decision to } \\
\text { participate or actions while } \\
\text { on the STMM? }\end{array}$ & $\begin{array}{l}\text { Evidence for diplomatic and } \\
\text { social determinants in STMMs } \\
\text { has been sought in systematic } \\
\text { literature review (Chapter 2). } \\
\text { Subjects were asked to consider } \\
\text { "soft power" implications that } \\
\text { may be found in the social } \\
\text { persuasion elements of } \\
\text { healthcare-related transfers by } \\
\text { USAID as well as US military } \\
\text { efforts in disaster relief and its } \\
\text { navy hospital ships (Chapter 2). } \\
\text { The examples of Cuba and } \\
\text { Taiwan deploying direct health }\end{array}$ \\
\hline $\begin{array}{l}\text { 7. Attitudes } \\
\text { towards } \\
\text { foreign aid }\end{array}$ & $\begin{array}{l}\text { What thoughts do you have } \\
\text { about how STMM activity } \\
\text { fits into the realm of foreign } \\
\text { aid? Can you describe any } \\
\text { effects that your STMM } \\
\text { experience has had on your } \\
\text { view of foreign aid? How has } \\
\text { your experience affected the } \\
\text { attitudes of others in your } \\
\text { family or circle of friends or } \\
\text { social network on the issue } \\
\text { of foreign aid? }\end{array}$ & $\begin{array}{l}\text { power intentions were mooted } \\
\text { (Chiu et al., 2012; de Albornoz, } \\
\text { 2006). How these constructs } \\
\text { applied to STMMs, i.e., cross- } \\
\text { cultural awareness and the } \\
\text { implications of soft power were } \\
\text { discussed with subjects. }\end{array}$ \\
\hline
\end{tabular}


Table 6.1 Question Areas and Rationale (continued)

\begin{tabular}{|l|l|l|}
\hline \multicolumn{2}{|c|}{ Question areas } & $\begin{array}{l}\text { Question area rationale and } \\
\text { discussion points }\end{array}$ \\
\hline $\begin{array}{l}\text { 8. Faith, oath, core } \\
\text { value systems }\end{array}$ & $\begin{array}{l}\text { How do survey results that } \\
\text { fail to find correlation with } \\
\text { religion a factor in STMM } \\
\text { participation fit with your } \\
\text { impressions of the role of }\end{array}$ & $\begin{array}{l}\text { Evidence for influence of } \\
\text { participation by faith and other } \\
\text { demographic attributes has } \\
\text { been studied (Chapter 5). The } \\
\text { religion in physing back" aspect of US } \\
\text { motivation to participate in } \\
\text { physician motivation has been } \\
\text { characterized (Chapter 3). } \\
\text { STMMs? Would you say } \\
\text { that your decision to } \\
\text { participate is influenced } \\
\text { more by religious faith, by } \\
\text { were explored. } \\
\text { medical oath or some other } \\
\text { core set of values? What } \\
\text { role do you think the } \\
\text { theological viewpoint of } \\
\text { redemption and salvation } \\
\text { might play for rich nation } \\
\text { doctors to give of their skills } \\
\text { to "the poorest of the poor" } \\
\text { overseas? Tell about any } \\
\text { characteristics of your } \\
\text { family or any personal } \\
\text { experiences or exposures } \\
\text { that occurred while growing } \\
\text { up that may have } \\
\text { predisposed mong } \\
\text { participation in STMMs. }\end{array}$ \\
\hline
\end{tabular}


Table 6.1 Question Areas and Rationale (continued)

\begin{tabular}{|l|l|l|}
\hline \multicolumn{2}{|c|}{ Question areas } & $\begin{array}{l}\text { Question area rationale and } \\
\text { discussion points }\end{array}$ \\
\hline $\begin{array}{l}\text { Motivational } \\
\text { models }\end{array}$ & $\begin{array}{l}\text { Rank these three popular } \\
\text { theoretical models of } \\
\text { motivation for philanthropy } \\
\text { and volunteering so as to } \\
\text { reflect your motivation to } \\
\text { participate in STMMs. }\end{array}$ & $\begin{array}{l}\text { Benchmarking of subject } \\
\text { motivation against more } \\
\text { secular popular theories was } \\
\text { pursued. Subjects were asked } \\
\text { to characterize their } \\
\text { motivations in reference to the } \\
\text { following prominent theoretical } \\
\text { models for motivation towards } \\
\text { philanthropy and volunteering } \\
\text { that have matured in recent } \\
\text { years (Chapter 3) (Ziemek, } \\
\text { 2003). } \\
\text { a. Public Goods, wherein the } \\
\text { benefit objective is altruistic, } \\
\text { i.e., to increase the supply of a } \\
\text { public good for which there is a } \\
\text { deficiency. } \\
\text { b. Private Consumption, } \\
\text { wherein the benefit objective is } \\
\text { found in the utility of "warm } \\
\text { glow", self-value, and joy from } \\
\text { the act of volunteering or } \\
\text { philanthropy. } \\
\text { c. Investment Exchange, } \\
\text { wherein the benefit sought by } \\
\text { the giver is experience, } \\
\text { personal market value, skills, } \\
\text { and contacts. }\end{array}$ \\
& \multicolumn{1}{|c}{} \\
& &
\end{tabular}


Table 6.1 Question Areas and Rationale (continued)

\begin{tabular}{|c|c|c|}
\hline \multicolumn{2}{|r|}{ Question areas } & Question area rationale and \\
\hline $\begin{array}{l}10 . \\
\text { Transactional } \\
\text { analysis }\end{array}$ & $\begin{array}{l}\text { How would you characterize } \\
\text { the transaction between } \\
\text { STMM physicians and } \\
\text { recipients of care? What does } \\
\text { the doctor get? }\end{array}$ & $\begin{array}{l}\text { Exploratory: Question assessing } \\
\text { of subjects' computation of the } \\
\text { market transaction between } \\
\text { the parties. See text. }\end{array}$ \\
\hline $\begin{array}{l}\text { 11. Personal } \\
\text { reflections }\end{array}$ & $\begin{array}{l}\text { Describe your thoughts and } \\
\text { feelings when having a face- } \\
\text { to-face encounter with a } \\
\text { recipient of your care while } \\
\text { on an STMM? How is that } \\
\text { different from an encounter } \\
\text { with a recipient of care in } \\
\text { your practice at home? }\end{array}$ & $\begin{array}{l}\text { Exploratory: Question of } \\
\text { thoughts and feelings regarding } \\
\text { the personal interactions and } \\
\text { as motivator. See text. }\end{array}$ \\
\hline $\begin{array}{l}\text { 12. Viewpoint } \\
\text { of the } \\
\text { receiver side }\end{array}$ & $\begin{array}{l}\text { What is your perception of } \\
\text { the receiver side of the } \\
\text { equation? How has that } \\
\text { perception influenced your } \\
\text { participation? }\end{array}$ & $\begin{array}{l}\text { Querying of subjects' } \\
\text { perception of the receiver } \\
\text { viewpoint and its effect on their } \\
\text { motivation to continue } \\
\text { participation. Minimal research } \\
\text { has accumulated of the } \\
\text { receiver side (patient, country, } \\
\text { ministry level) regarding STMM } \\
\text { value and requires further } \\
\text { attention (Green et al., 2009; } \\
\text { Maki et al., 2008; Nouvet, Chan, } \\
\text { \& Schwartz, 2015). }\end{array}$ \\
\hline Open Forum & $\begin{array}{l}\text { Any other thoughts that may } \\
\text { convey a better } \\
\text { understanding of STMM } \\
\text { activity, motivation to } \\
\text { participation and value? } \\
\text { What has not been asked } \\
\text { that should be asked? }\end{array}$ & $\begin{array}{l}\text { Exploratory: Subjects were } \\
\text { encouraged to make any } \\
\text { additional comments about } \\
\text { their STMM experiences, } \\
\text { especially if there were issues } \\
\text { of motivation that had not been } \\
\text { addressed in any of the } \\
\text { preceding question areas. }\end{array}$ \\
\hline
\end{tabular}


Expedited approval was granted on 18 September 2015 by the Institutional Review Board of the Midwestern University Office of Research and Sponsored Programs, Downers Grove, Illinois, USA. Recruitment of subjects was pursued by snowball sampling of small, specialized populations (Guidelines for Investigators Using Snowball Sampling Recruitment Methods, 2015). For this study, the snowball sampling began with contacting three physicians who had participated in multiple STMMs with whom the researcher is personally acquainted who live in cities in the Southwest, Northeast, and Northwest regions of the US. Study subjects were selected according to the inclusion and exclusion criteria in Table 6.2. Only physicians who had been licensed to practice the full scope of medicine within the US with the degree MD or DO at the time of their STMM involvement were included. Qualifying STMMs included uncompensated, direct patient care. The requirement for a minimum of two qualifying STMMs, i.e., excluding any training experiences, was imposed to establish a floor level of experience and that the subject had made the choice to repeat STMM participation. Recall bias was mitigated through selection of subjects who had completed their most recent STMM no more remotely than calendar year 2010. 
Table 6.2 Subject selection criteria

\begin{tabular}{|l|l|}
\hline \multicolumn{1}{|c|}{ Inclusion criteria } & \multicolumn{1}{|c|}{ Exclusion criteria } \\
\hline $\begin{array}{l}\text { 1. Subject is a physician with the } \\
\text { degree MD or DO who is or has been } \\
\text { gainfully employed in the practice of } \\
\text { medicine in the US with a federal or } \\
\text { state license issued in the US. }\end{array}$ & $\begin{array}{l}\text { 1. Non MD or DO clinicians including } \\
\text { dentists, chiropractors, naturopathic } \\
\text { physicians, nurses or nurse } \\
\text { practitioners or physician assistants. } \\
\text { (Subjects who obtained MD-equivalent } \\
\text { degree in other countries and were } \\
\text { subsequently licensed to practice in } \\
\text { the US and meet all other inclusion } \\
\text { criteria are not excluded.) }\end{array}$ \\
\hline $\begin{array}{l}\text { 2. During the time when gainfully } \\
\text { employed in the practice of medicine } \\
\text { in the US, the subject has participated } \\
\text { in two or more (STMMs) from the US } \\
\text { to lower or middle income countries as } \\
\text { defined in the introduction. (Direct } \\
\text { patient care contact.) }\end{array}$ & \begin{tabular}{l} 
calendar years (2010 forward). \\
\hline $\begin{array}{l}\text { 3. Subject had completed all general } \\
\text { and specialty medical training by the } \\
\text { time of the qualifying two or more } \\
\text { STMMs. (Having participated in other } \\
\text { medical trips abroad while in training } \\
\text { or otherwise does not exclude subject } \\
\text { from participation in the study as long } \\
\text { as two STMMs have been attended } \\
\text { after completion of all general and } \\
\text { specialty training.) }\end{array}$
\end{tabular} \\
$\begin{array}{l}\text { compensated for participation in the } \\
\text { medical care delivered abroad on the } \\
\text { two minimum qualifying STMMs. }\end{array}$ \\
\end{tabular}


Table 6.2 Subject selection criteria (continued)

\begin{tabular}{|c|c|}
\hline Inclusion criteria & Exclusion criteria \\
\hline $\begin{array}{l}\text { 4. The subject's most recent STMM } \\
\text { participation has occurred within the } 5 \\
\text { calendar years ( } 2010 \text { forward) prior to } \\
\text { the interview. }\end{array}$ & $\begin{array}{l}\text { 4. The STMM participation did not } \\
\text { include direct care of patients, but } \\
\text { rather included purely training } \\
\text { exercises or interactions, public health } \\
\text { ventures, evangelistic, social, } \\
\text { intergovernmental, or construction } \\
\text { activities. (Such non-direct patient care } \\
\text { activities do not constitute an } \\
\text { exclusion if they occurred proximately } \\
\text { to or concomitantly with the direct } \\
\text { care activity.) }\end{array}$ \\
\hline $\begin{array}{l}\text { 5. Subject agrees to participate in the } \\
\text { study interview voluntarily and may do } \\
\text { so without coercion, duress or } \\
\text { requirement to participate by an } \\
\text { employer, supervisor, colleague, } \\
\text { organization or any other person or } \\
\text { entity. }\end{array}$ & $\begin{array}{l}\text { 5. Subject is considered physically or } \\
\text { emotionally unable to complete the } \\
\text { interview process. }\end{array}$ \\
\hline $\begin{array}{l}\text { 6. Subject is agreeable to providing up } \\
\text { to an hour of time, continuously or in } \\
\text { parts, for the interview. }\end{array}$ & \\
\hline
\end{tabular}

Verbal informed consent for conduction of an interview, its recording, transcription and analysis under strict confidentiality was integrated into the interview guide and obtained from each subject and documented in the interview recordings (Appendix B). Interviews were generally conducted visually via Skype ${ }^{\mathrm{TM}}$ (Microsoft ${ }^{\mathrm{TM}}$ proprietary voice-over-Internet-protocol software), although due to technical limitations, two interviews relied on audio interaction alone. Additional subjects were enrolled until the single interviewer (PC) could not identify any new concepts exposed within two of the latest three interviews. Transcripts of the audio portions were crosschecked for accuracy by reviewing the recordings with transcripts and hand notes taken during the interviews for completeness and accuracy. Finalized transcripts were then analyzed manually first and secondarily utilizing QSR $\mathrm{NVivo}^{\mathrm{TM}}$ proprietary software, version 10. 
We utilized directed qualitative content data analysis allowing for quantification of responses to concepts from prior research and our own preconceived interests while not obviating the additional purpose of mining the interviews for grounded, de novo revelations and relationships (Hsieh \& Shannon, 2005). Thereby, the interview guide was designed to gather, in sequence, demographic and historical data, how a subject was introduced to STMM activity, and an unrehearsed response regarding their motivation(s) to participate in STMMs before a more probing agenda was pursued. In order to establish the subjects' confidence in the interview process, questions involving broader social and economic topics were pursued before more personal perspectives and perceptions were discussed. Subject quotes were encoded according to an assigned narrative research number (NR-01 to NR20). The response rate denominator for the questions is twenty except where otherwise indicated; rarely, subjects were not asked or could not render an answer to a particular question.

\subsection{Results}

The results of the interviews are separated into the factual aspects about the subjects and their STMM experience, followed by examination of their comments in the question areas.

\subsubsection{Subject and STMM Characteristics}

Twenty semi-structured interviews were conducted between 28 September and 10 November 2015. Table 6.3 provides an array of demographic and professional attributes of the subjects as well as their data on STMM participation. All subjects were married and all but 2 had children. Mean age at interview was 60 years; mean age at first STMM was 45 . The average number of STMMs performed by subjects was 18 , median 10 , with a range of 2-61, assuring a spectrum of relative experience. Figure 6.1 Illustrates that subjects represented all four regions of the US. Figure 6.2 displays collectively the regions of the world containing the countries of subjects' STMM deployments. As a reflection of the comparability of interviews, the range of coded responses in NVivo was 54-73 (mean 62.3, median 64, SD $5.3)$. 
Table 6.3. Demographic and Experience Characteristics of Study Subjects

\begin{tabular}{|c|c|}
\hline Specialties & $\begin{array}{l}\text { General pediatrics (3), pediatric oncology (1), internal } \\
\text { medicine/critical care (1), family medicine (2), } \\
\text { rheumatology (1), emergency medicine (2), } \\
\text { neuroradiology (1), } \\
\text { obstetrics/gynecology/perinatology (1), } \\
\text { general/pediatric surgery (3), plastic surgery (1), } \\
\text { thoracic surgery (1), hand surgery (1), anesthesiology } \\
(2) .\end{array}$ \\
\hline Degree & MD 18, DO 2 \\
\hline $\begin{array}{l}\text { Practice } \\
\text { situation }\end{array}$ & Academic 6 , hospital-based 3, private practice 11 \\
\hline Age at interview & range 39-74, mean 60 \\
\hline Years in practice & range $9-50$, mean 27 \\
\hline Gender & Male $16 \quad$ Female 4 \\
\hline Civil Status & All married $(20)$ \\
\hline Children & $\begin{array}{l}\text { All except } 2 \text { had children; range } 0-6 \text {, mean } 2.7 \text {, median } \\
\text { and mode } 3\end{array}$ \\
\hline Race & 2 Asian, 18 white \\
\hline $\begin{array}{l}\text { Religious } \\
\text { background }\end{array}$ & 1 Jewish, 1 Hindu, 18 Christian \\
\hline STMM number & range $2-61$, mean 18 , median 10 \\
\hline $\begin{array}{l}\text { Age at first } \\
\text { STMM }\end{array}$ & range $30-64$, mean 45 , median 45 \\
\hline
\end{tabular}


Figure 6.1 Regions where subjects live (US).

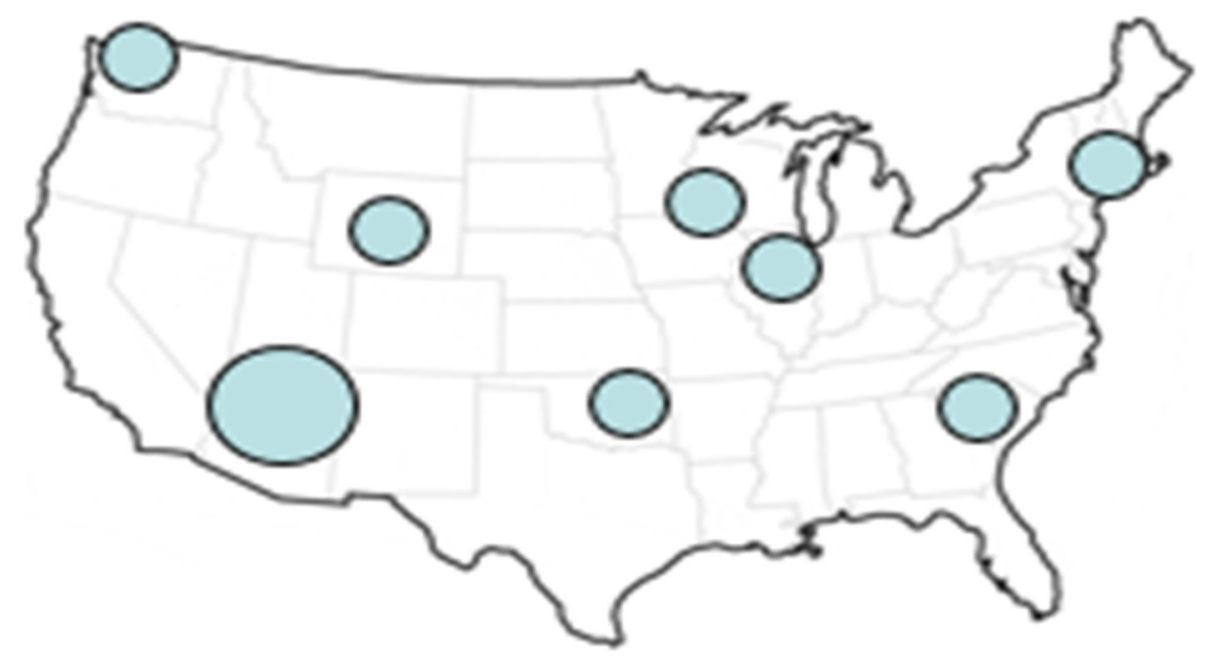

Figure 6.2 Regions of subject STMMs.

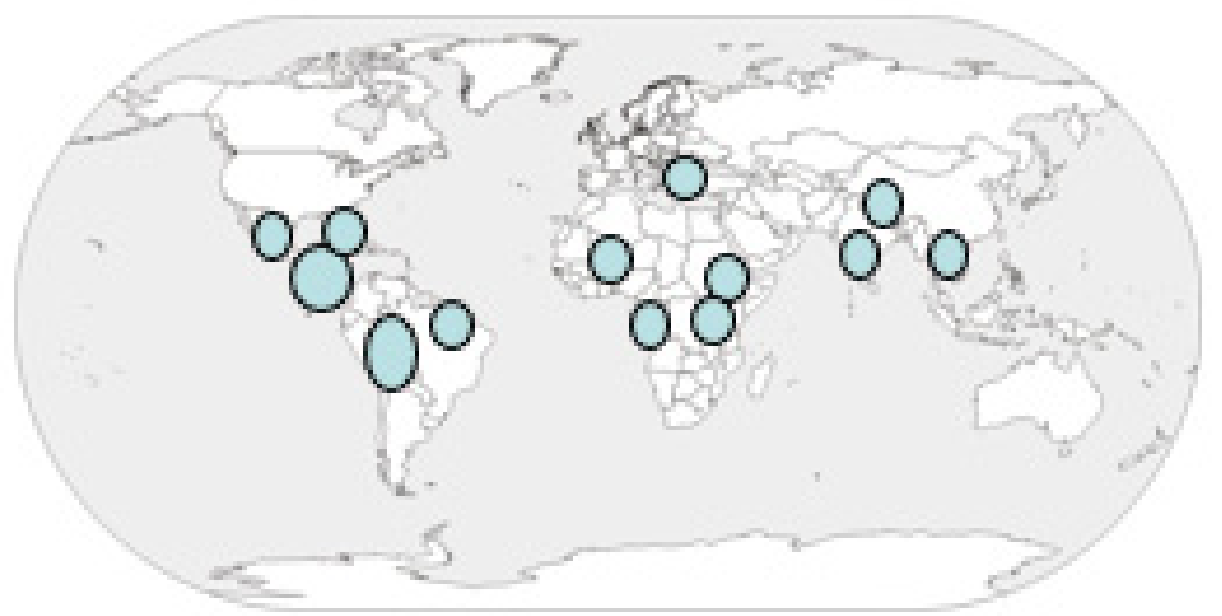




\subsubsection{Results from Question Areas}

Opening Motivational Statements

Most subjects (13/20) were initially introduced to STMM activity by a physician colleague or through other educational exposure, some by family members $(4 / 20)$ or by their church $(3 / 20)$. The primary responses to the opening question of their drivers to participate in STMMs involved more than one key motivation for most subjects. The most common (10/20) were "to help" or "to do something good". Among the additional motivators, subjects cited the following ideas with similar frequency: adventure $(5 / 20)$, opportunity to educate $(4 / 20)$, special skills for this activity $(4 / 20)$, desire for spiritual interaction $(3 / 20)$, return to simple medicine $(3 / 20)$, need to give back/act on social justice (4/20), learn about cultures/gain world perspective $(3 / 20)$.

"Helping people in need and being of service. I had these inclinations from the beginning that I needed to do something for other people without expecting anything in return." (NR-20)

"I feel like I was blessed to be born in America. I have been blessed to have a job as a pediatric surgeon that makes an income that is much more than most people and more than many doctors. I think I would feel stingy if I didn't give back when I was able to." (NR-08)

"I knew I could perform well even if we didn't have everything we have here in a United States operating room. It didn't bother me the way I know it bothers some of my partners if they didn't have an electrocardiograph machine or a certain drug to use. I could just figure out a way to do whatever needed to be done safely but with whatever materials we had there.” (NR-14)

"To me it's a challenge because you have to rely entirely on your clinical skills" (NR-15) 
"Well, the first thing is curiosity - new country, new culture, and new way of doing things. And the second thing, not to sound corny, is motivation be another member in the world, a "world citizen" so to speak. We all have similar life experiences, how they solve problems, how they love their families. Sometimes they're husbands and wives, parents and sometimes they're not. They experience most of the same pluses and minuses that we do, but in a different background or on a different stage - the basics feelings, emotions, pains, even illnesses are fairly similar.” (NR-10)

Four indicated that interaction with other medical and support team members was as valuable to them as the patient interaction. Eight of 20 indicated that their motivations evolved from those of their initial exposures to those of later trips as indicated in reflection on Motivation Models (to follow).

"My initial draw was that I enjoyed doing clefts. We don't see that many clefts here in the states, but there is an unlimited number of clefts in those countries. But once I started doing them and met the people we were helping and some of the amazing circumstances these people went through to get to us to help their kids, that's what got me hooked." (NR-09)

Nine subjects specified that they also provided domestic pro-bono services outside their earning situation. Further, 9 of 11 subjects in private practice indicated maintaining a process within their domestic operations to mitigate fees for those with limited ability to pay. Two consistently demarcated their professional business activity from pro-bono activity. Perception of greater relative need in LMICs $(5 / 20)$ and the draw of new and different experiences $(8 / 20)$ were expressed by subjects as the principal reasons for pursuing probono work abroad rather than confining their voluntary direct care to domestic opportunities.

"The degree of health disparities abroad is orders of magnitude different than the health disparities we may see in the U.S." (NR-19)

"Because when you talk about poverty in the U.S. and you talk about people not getting medical care, you can get it here in the United States. There is no poverty in the United States when you see what's really going on in these countries." (NR-09) 


\section{Organization and country selection}

Ties to specific countries or organizations as motivational elements were sought through asking how subjects choose the organization(s) and countries with which they cooperated to perform STMMs. Most commonly, subjects selected organizations based on characteristics such as types of missions, ongoing facilities, and accountability (8/20). Cognitive (non-surgical) subjects expressed the importance of being assured that an organization's clinics were fixed or at least moving from a mode of ad hoc, remote village, day clinics to more stable locales and formats. Four subjects indicated Christian faith focus as their leading organizational determinant. After working with third party organizations at the beginning of their STMM experiences, four subjects had leveraged their foreign contacts and experience to organize their own excursions and sites. Five subjects indicated they simply went where and with whom invited, most often a colleague or a church.

"I look for an organization that is a) sustainable, b) had tremendous local involvement and c) whose valid goal was to make themselves unnecessary and irrelevant in the future. In other words, to train and work themselves out of a job." (NR-16)

Country selection was also most commonly passive; subjects went where invited by colleagues, organizations or churches. Some country choice was influenced by language ability (Spanish, English). Relative distance influenced regional selection, i.e., since it would be more affordable to go from the US to Latin America than Africa or Asia and required less time away. Four subjects selected countries perceived as more (2) or less (2) challenging in which to work.

Professionalism and professionalization

Subjects generally characterized professionalism among physicians on STMMs as consistently high, although about one-third (8/20) had witnessed some unprofessional behavior or attitudes among colleagues, such as inappropriate relations among staff, comments about host country staff capabilities, or wanting to conclude workdays before the work was finished. Eleven of twenty subjects vocalized that that while standards of care were 
defined by local resource limitations, standards of physician conduct remained high despite the resource limitations, indicating that all attempts were made to optimize care within the setting. Subjects on surgical STMMs felt that supplies and techniques they brought with them raised local standards of care and others indicated that teaching seemed to enhance professionalism of the process $(2 / 20)$.

"Physicians that participate are highly professional people who really see this mission to deliver healthcare to underserved populations as very important thing to what they do." (NR-03)

A strong majority (15/19) would favor a national or international organization mainly to foster general preparedness while not generating overly restrictive guidelines. Effectiveness of such an organization would be enhanced if it received high level participation and delivered content locally or with high accessibility. Overall, however, recruitment of participation currently appears to occur primarily on a local, person-to-person basis (12/20). One subject suggested that an STMM guild would bring attention to STMMs as a legitimate form of foreign aid.

"I think having a national organization like that would help make sure that those who are doing it are well-prepared and well-educated to do it well. When you bring up the concept of professionalization, if we did that, then certainly I think the perception of (STMMs) being U.S.-based foreign aid would be a lot stronger. (NR-17)

Personal Costs

\section{- $\quad$ Direct Costs}

A majority of subjects (13/20) considered direct costs (airfare, organizational fees, equipment, supplies, and personal vaccines) potentially influential, but not yet a deterrent. Some adjusted the frequency and distance of STMMs to accommodate their budgets. A few justified costs as their "form of tithing" $(2 / 20)$, or a "cost of social justice" (1/20). Three subjects indicated awareness 
that a variety of supporters may profit from the humanitarian zeal in STMMs, yet none expressed a deterrent effect of such enterprise.

\section{- Opportunity Costs}

For about one-third, opportunity cost was not applicable due to their academic or employment position such that annual personal income was not negatively impacted. Half of the rest felt that opportunity costs were influential, even "severely punishing" by way of impact on personal annual income. The remainder indicated that opportunity costs were not influential for them, but likely a concern for others (9/11). Some expressed more concern over the time opportunity rather than opportunity cost, i.e. time away from family. Some subjects had mitigated this aspect by bringing one or more family members along on STMMs (4/20), a scenario that for many became a subsequent key motivation despite the direct cost multiplier effect. Three suggested that opportunity cost may be a barrier for some physicians due to a propensity for ostentatious living, accumulated personal debt or insecurity about their financial status or referral base.

"Family physicians in general make about $\$ 130,000$ to $\$ 150,000$ a year, whereas orthopedic surgeons and cardiovascular surgeons make about three quarters of a million dollars a year. So for them to take a week off is a lot more lost income than for those of who make less (income). But on the other hand, they should have enough salary that they could forego that income for a couple of weeks." (NR-13)

\section{Influence of Tax Implications}

Within the framework of US tax code, the direct costs for STMM activity typically qualifies for a reduction in taxable income as charitable expense. One could thereby view the tax ramifications as a federal subsidy for this otherwise unregulated activity. Subjects were evenly split on whether or not the tax deductibility of direct costs were influential to themselves or others.

"Not an influence for me and I don't really think it affects people that much." (NR-11) 
"Yes, definitely. I think we would probably have done our last one if we couldn't deduct some of the expenses involved." (NR-10)

"I'm not sure if they would be less likely, but they might go less often (if deductions were eliminated)." (NR-15)

\section{Diplomatic Soft Power as a Motive}

The majority of subjects felt that some cross-cultural competency is essential to participation in STMMs (11/20), one subject attributing more importance to such skill in the STMM setting than in ad hoc disaster relief situations.

"I hope whatever I do leaves a sufficiency good impression with the people I deal with and see that they take away a good impression of medicine in the United States, or the group we are representing. I realize it is a lot easier for someone to do something stupid and insult people and leave a bad taste than to do something wise and have people come away thinking you're a great group of people." (NR-02)

"(STMMs as) soft power, in my opinion, is wonderfully persuasive and it is the best method of diplomatically relating to a group of people. Providing for their poor and incorporating their fellow citizens in activities that provides for their poor is a very good thing. It truly stumped people when I was in Nepal, in Ghana and Kenya as they didn't understand it. Their profile of the U.S. was that we were a greedy group of people who only want to militarily punish people." (NR-12)

Though nearly half of subjects felt that STMMs may have a soft power effect, only two subjects indicated that purveying a positive image of the US was an objective in their motivation. On the contrary, three subjects acknowledged that at times they were reluctant to broadcast their American nationality out of embarrassment about US government or individual behaviors domestically and abroad. 
Before the interview, fewer than half of subjects had conceived of STMMs as foreign aid (9/20). However, a majority felt that their experience had changed their attitude about US foreign aid (12/20). The prevalent observation was that this form of direct aid, perceived as person-to-person rather than countryto-country aid (12/20), is more efficient and less subject to waste, diversion and corruption than federal cross-border transfers $(12 / 20)$.

"Honestly, a lot of times I think the U.S. government is throwing away money to other countries just to buy their favor as opposed to doing this from a "grass roots" perspective where the medical care does more good for the people of the country than the standard foreign aid." (NR-13)

Discussing their STMM experiences within family and social network did not affect others attitude about foreign aid in general, but seemed to have a "contagious" effect on the desire by other physicians and non-physicians to participate in STMMs (12/20). One subject suggested that the expected reciprocity inherent in government aid was absent in STMM with the exception of some evangelistic organizations wherein religious interaction may be a requisite for the medical care on offer.

\section{Values and Locus of Decision-Making}

Although many subjects expressed some level of a faith basis to their motivations $(6 / 20)$, only $20 \%$ were surprised to learn that a previous nationwide survey had shown no effect of any particular religion on participation as indicated in Chapter 5. Subjects cited a personal set of core values twice as often as either faith or medical oath as their locus of decisionmaking regarding participations in STMMs. Descriptions of these core values have been grouped in Table 6.4. 
Table 6.4 Alignment of Subjects' Core Values and Schools of Moral Thought Related to Health Care

\begin{tabular}{|c|c|}
\hline Subjects' descriptions of their core values & $\begin{array}{l}\text { Schools of moral thought } \\
\text { related to health care (Alkire } \\
\& \text { Chen, 2004) }\end{array}$ \\
\hline $\begin{array}{l}\text { - "Humanism" (NR-16) } \\
\text { - "Being a human being, I guess" (NR-10) } \\
\text { - "These people need help... are parents } \\
\text { and they will do whatever. I have four } \\
\text { kids and if I had to, I would walk three } \\
\text { days to try and get medical care. I would } \\
\text { do the same thing that these people are } \\
\text { doing." (NR-09) }\end{array}$ & $\begin{array}{l}\text { a. Humanitarianism, acting } \\
\text { virtuously towards those in } \\
\text { need, based on compassion, } \\
\text { empathy, or altruism as } \\
\text { mandated in the philosophy } \\
\text { of great religions }\end{array}$ \\
\hline $\begin{array}{l}\text { - "Obligated to use the specialized } \\
\text { - "Yabilities I have" (NR-14) } \\
\text { - must do the right thing." (NR-20) } \\
\text {-It is integrated and my medical oath is } \\
\text { my core set of values" (NR-03) }\end{array}$ & $\begin{array}{l}\text { b. Utilitarianism, maximizing } \\
\text { aggregate subjective } \\
\text { happiness, since general good } \\
\text { health is in the best interest } \\
\text { of all including those not } \\
\text { inclined to altruism }\end{array}$ \\
\hline $\begin{array}{l}\text { - "Sense of responsibility for the } \\
\text { miraculous act that (I) happened to be } \\
\text { born at a certain point in the time } \\
\text { continuum that has given me a } \\
\text { tremendous number of opportunities." } \\
\text { (NR-16) } \\
\text { "See so many with so little and I have so } \\
\text { much." (NR-04) }\end{array}$ & $\begin{array}{l}\text { c. Equity, a fairer distribution } \\
\text { of health capabilities }\end{array}$ \\
\hline $\begin{array}{l}\text { - "Medicine as social justice" (NR-19) } \\
\text { - "Most important is...to validate the } \\
\text { worth of the person" (NR-01) }\end{array}$ & $\begin{array}{l}\text { d. Rights - fulfilling our } \\
\text { obligations so others are } \\
\text { dignified }\end{array}$ \\
\hline
\end{tabular}

Subjects were queried as to whether the religious concepts of redemption, salvation, or moral debt held by some religions or denominations might be relevant to motivation to perform these works. While most denied that a need for redemption, salvation or moral debt motivated them, more than half felt that such ideology might apply to other physicians' motivations. 
Half of the subjects felt that they were predisposed to STMM work because of family influence or exposures growing up.

“Albert Schweitzer got the Nobel Prize back in the 1950's; he was kind of my hero." (NR-10)

“My dad worked with Project Hope.” (NR-05)

\section{Motivation Models}

In composite, subjects ranked their motivation vis-a-vis the theoretical models of motivation as Public Goods $>$ Private Consumption $>$ Investment Exchange (see Table 6.1). Over one-third of subjects indicated that the bestfit model for themselves had shifted from their early missions to subsequent missions, usually from Public Goods to Private Consumption. Subjects generally ranked other physicians' motivations more evenly across the three models. (See Figure 6.3.)

Figure 6.3 Subject Motivations Reflected by Theoretical Models for Volunteering and Philanthropy

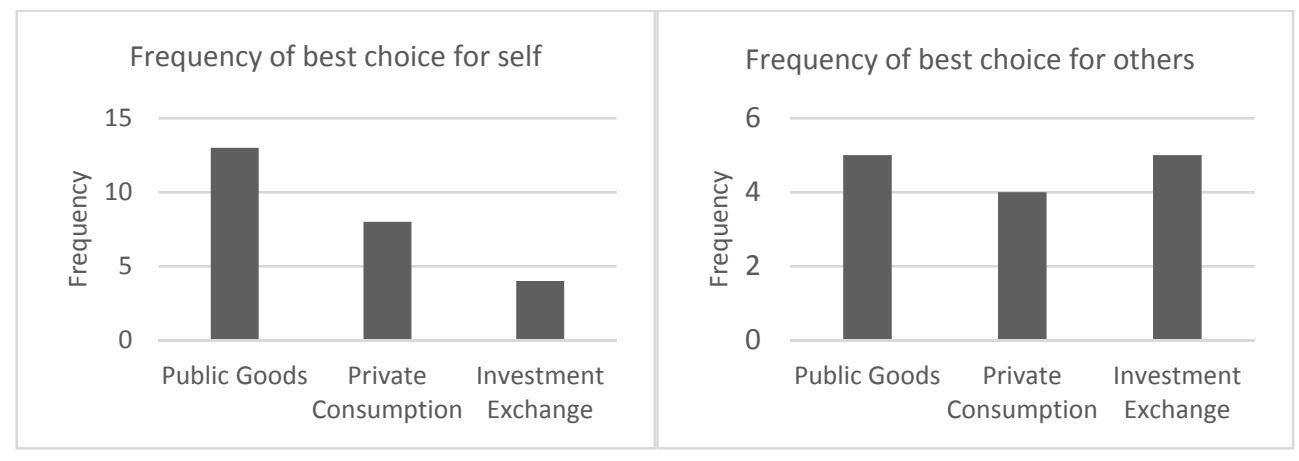

Balancing the Equation

Fundamental to all markets and human interactions are transactions wherein each party seeks to satisfy its enlightened self-interests. Acknowledging the 
tacit bargain taking place between medical service providers and the recipients of medical services in the setting of STMMs, subjects were asked to consider the inputs and benefits that create a balanced equation for patients and physicians. Conceptually, poor patients in LMICs may have to travel long distances by foot, bus or other means that create costs, purchase or prepare food for the journey, accommodate the needs of children or elderly while foregoing gainful work. To balance the equation, the patient may receive a competent physical examination, diagnosis, medicine or a surgical procedure as appropriate, and may benefit from the social interaction. The physician equation requires direct costs of travel, organizational fees, equipment and supply costs and lost income. Since no fungible payment is transferred, what does the physician get? To balance their equation, these repeat mission participants most commonly imputed the satisfaction of helping. Other returns included the value of the experience and accompanying learning, and the high level of gratitude and appreciation felt. Several subjects cited a sense of caregiver renewal related to the simplified setting found in STMMs and a return to reliance on basic medical skills. The opportunity to teach either local healthcare providers or US medical students and thus leave a legacy that endures beyond the short-term dimension of the process was repeatedly identified as a key motivator. The relative weight of these non-monetary returns among the subjects is illustrated in Figure 6.4. 
Figure 6.4 Balancing the Equation

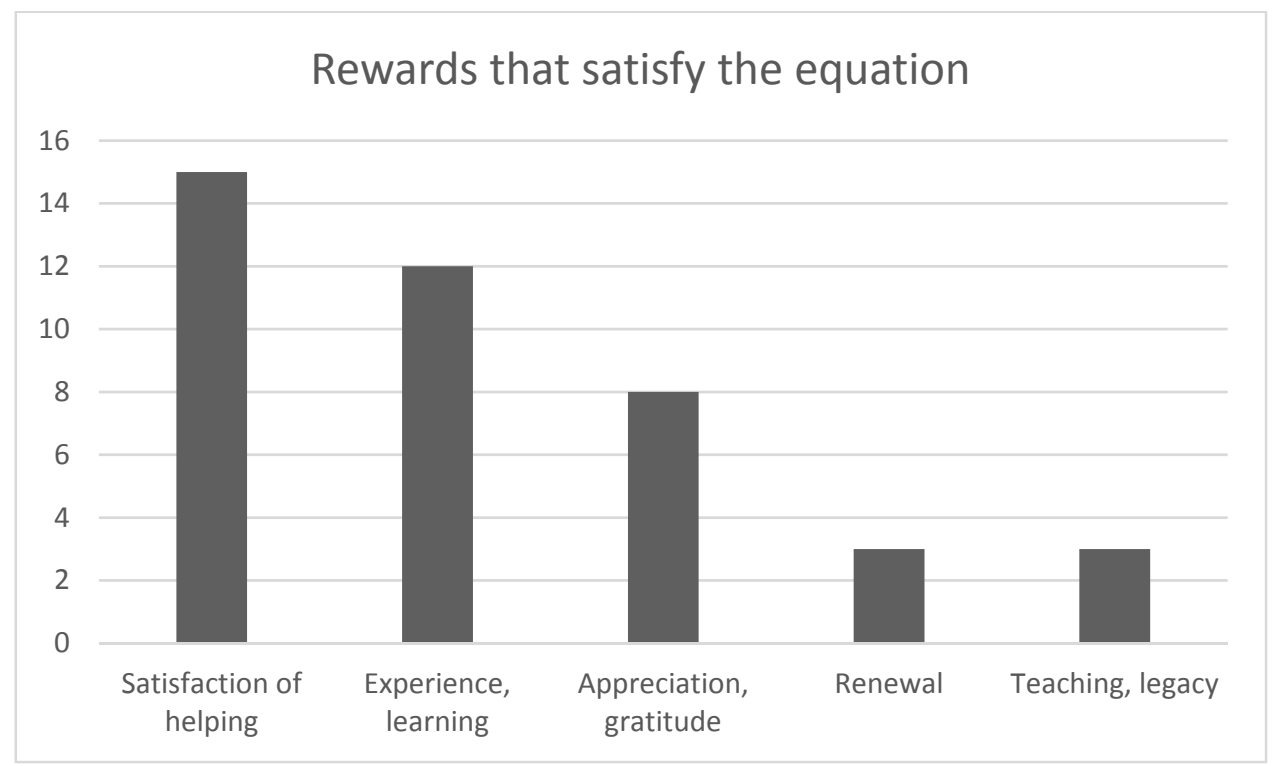

Face-to-Face Encounters

Healthcare professionals apply their objective technical capabilities in a subjective, humanistic domain. In the interview process, it was often challenging to move the subjects' response mode from the technical "how" in what they do to the emotive "why" they chose to do this. In pursuit of the emotional motivators that may arise within the context of the interactions of physicians and patients during typical STMM encounters, subjects were asked to visualize themselves back in such a setting. Considering the notable differences in countenance, dress and language as well as the context related to occupation and comparative living standards, subjects were asked to describe their thoughts and feelings. Physicians generally responded through stories of one or two exceptionally memorable interactions, beginning almost always from how the diagnostic or therapeutic task was accomplished in challenging circumstances. When pressed in the dialogue for more subjective impacts, several content-rich extracts could be crystalized. Paraphrased quotes on their thoughts and feelings during STMM interactions capture the majority of sentiments conveyed by subjects. 
"I enjoy figuring out what their situation is, their living situation and where they are at - it's a challenge." (NR-11)

"It is not just the individual encounter with that patient; it is the process of going out of your comfort zone, reaching out to people you don't know, to help them" (NR-06)

"I want to be compassionate and empathic, but never pity them because pity denigrates them. I think "good for you to be able to survive". (NR-01)

"When you put your hands on them, it becomes personal. It is not a logical process of the brain or a cost analysis; rather all you see is a fellow human who is miserable. When you lift a hand to this (read: when one takes action), yes, I would say it is somewhat addictive. It is the enjoyment of something different. You meet beautiful children, wise elderly men and women. The experiences are cumulative and valuable, more than gold." (NR-12)

"These are human to human connections, where a smile and a touch means a lot (reference to language barrier); the differences... draw me in." (NR-17)

"I can easily intellectualize the medical process, but the human aspect of the interaction renews my faith in humanity. I see people (in deprivation) still living virtuous and unselfish lives. I see good people with all the material things stripped away.” (NR-18)

"It touches my heart. I think why do these people suffer and so many of us have so much? Often the wealth of a developing country grows, but the lives of these people stays the same." (NR-20)

"The value placed on life in developing countries is not the same as it is in the United States. That has left a significant impression." (NR-07)

"So in other words, it's an ethic that is not about a macroeconomic outcome being valued, it's an ethic of an individual interaction with another human being valued. That's something that has a strong visceral feel, and if that's 
the acceptable contribution, it's very easy to feel that you have been successful in your contribution." (NR-18)

"What is attractive to most American physicians and the reason they go back is that a lot of the patient/physician interactions in our own country have become, for a variety of reasons, incredibly cynical." (NR-05)

When asked to contrast these thoughts and feelings with those during an encounter within their home practices, subjects most commonly described the sensations of patient visits at home with less of a sense of gratitude $(5 / 20)$ and that favorable outcomes are always expected (3/20), leading to cynicism on both sides (3/20). A similar number (3/20) could make no distinction between their emotional response to patients at home or abroad.

\section{Viewpoint of the Host Side}

Commonly expressed concerns about potential harm from STMM activity were discussed that may include, among others, crowding out or undermining local physicians, creating dependency on foreign medical teams, deflecting local healthcare investment by authorities and inadequate follow-up. Subjects reported generally positive views of their reception by receiver side stakeholders, citing as evidence the effort so many people make to be seen during these short term missions (20/20). Several physicians indicated that where they go, there is no healthcare infrastructure with which to compete and patients have absolutely no means to pay for services, medicines or procedures $(4 / 20)$.

"Almost without exception in the places I have been, when I haven't been teaching, I have been in austere environments where there are no other health providers. It is not as if I am competing or potentially burning the enmity of local providers; they just don't exist." (NR-16)

Nevertheless, the most common caution expressed by subjects was to be aware of displacement of or competition with locally available healthcare (9/20) that is best mitigated by proper planning and communication. When 
asked, eighty percent of subjects felt that the positive reception played a role in their continued participation.

\section{Open Forum}

Of perhaps greatest relevance to our objective, subjects frequently suggested that there is a personality profile or personal skill set that would distinguish STMM participants from non-participants (7/20). In composite, those who participate have high self-confidence, flexibility, unselfishness, "tolerance for dirt", i.e., less sanitary conditions, and strong ethics. Selfish, avaricious or inflexible personalities "cannot do this and should stay home". Perceived barriers for non-participants were principally personal safety concerns and opportunity costs.

Three motives indicated in previous question areas were repeatedly emphasized in open forum. The chance to educate and thereby leave a more lasting legacy than the short period of care in-country can deliver is highly motivating to STMM physicians. In addition, "this is the cure for burnout" was echoed by three subjects. Lastly, bonding through the humanitarian experience with spouse, children or other family members became a substantial part of the attraction for some subjects $(4 / 20)$.

"The other thing contributing is, as my children have gotten older, all of them have gone to Guatemala with me, so it has also been a way to introduce my kids to doing service work and a bonding experience for us. My youngest son has gone 3 times and ran an eye clinic with donated eye glasses. Made national news in Guatemala." (NR-05)

Two subjects spoke about the difficulty in identifying STMM opportunities in the early days of their efforts. Now, as subjects pointed out, one can find hundreds of non-governmental organizations online that provide opportunities such that the internet has made it much easier to participate. Though not a motivating force, subjects suggested that the digital era has perhaps facilitated the observable rise in participation and STMM sorties. Subjects further acknowledged that many entities, both foreign and domestic, are tapping into physician motivation and altruism, and an industry appears to have arisen to satisfy the pent-up demand. 
Using NVivo, relationships between coded responses to the interview areas and demographic, professional and participation attributes of the subjects were analyzed. The small number of interviews precludes a meaningful probe for statistical correlations among response types and the attributes. Among the more notable trends identified, male subjects proportionately more than females recalled family traits or childhood experiences that predisposed them to STMM work, identified more with Public Goods theory of philanthropy than Private Consumption, and cited personal core values more than faith or oath as their locus of decision-making regarding STMM participation. Cognitive (non-surgical/anesthesia) subjects were far more receptive to the potential benefits of a national or international organization dedicated to the advancement of the STMM praxis than surgeons and anesthesiologists. All four subjects who ultimately organized their own missions (no third party organization) had more than the median number of STMM experiences; 3 were surgeons and the fourth was a pediatrician with an exceptional personal background in the US diplomatic sector.

\subsection{Discussion}

Adult and pediatric cognitive, surgical and anesthesia, and other practice specialties were represented in our cohort of interviewed subjects. Degree, gender, and religious faith are reflected in relative proportions to the US physician population and those who participate in STMMs (Chapter 3) (Erikson C, Jones K, Whatley, 2014). As a result, though statistical correlations cannot be applied, the directed content analysis and new themes from this narrative study are relevant to the investigation of motivation of US physicians to participate in STMMs as defined. Aside from geographic proximity or presence or lack of language skills, subjects revealed no deeper ties to the countries where their STMMs were deployed.

Perhaps an original recognition from this narrative study is the light shone on two process elements that are likely contributory to the increase in participation rate of physicians and the number of STMM deployments: a. that word-of-mouth inspiration through the stories of those who have gone on STMMs promotes a multiplier or snowball effect on recruitment; $b$. the 
Internet's ability to facilitate the abundant opportunities for this service has become most relevant in the last 15-20 years.

Though arguably a sine qua non that all physicians would desire to do good deeds and help other people, our subjects suggest that a collage of personality traits that forms a foundation for attraction specifically to STMMs, and success therein, are less uniform among physicians. High self-confidence, flexibility, unselfishness, tolerance for arduous and less sanitary conditions and strong ethics seem to be core requirements. This is consistent with the admonition with which Birman and Kolkin opened their brief article advising hand surgeons on volunteering overseas (Birman \& Kolkin, 2013). The authors describe a mindset of humility, compassion, patience and flexibility, and encourage consideration of whether one is prepared to operate and teach under challenging conditions and limited resources. Indeed, the special abilities to which some subjects alluded as motivational was seeing in themselves the ability to accommodate effectively for conditions that would unsettle many of their colleagues. Since they could do it well, it seems their obligation or fate to do so. Such a personality trait profile may better correlate with propensity to participate than any stark demographic or professional profile. Educational or healthcare policy designed to promote participation in STMMs might therefore face limitations inherent in natural selection.

The choice to pursue foreign pro-bono work in addition to or in place of such work domestically was justified by several subjects based on poor patients' relative access to care in LMICs than in the US rather than a value judgement on relative need. As juxtaposed in Table 4, we found the expressions of core values by subjects readily align with the schools of moral thought related to health care as elegantly described in "Global health and moral values" (Alkire $\&$ Chen, 2004). Congruently, as is common in the US, nearly all subjects in private practice, where opportunity costs are most palpable, maintained a process at home of waiving full fees for those with limited ability to pay (Chapter 3) (Hadley \& Holahan, 2003).

Faith-based motivation is substantial, yet not a majority theme. Probing about the concepts of redemption and salvation that might indicate a depth of religiosity beyond religious affiliation, alas, did not reveal these concepts as intrinsic to motivation. Some medical and surgical cures mediated through STMMs have existential impact on individual lives. Nonetheless, subjects 
repeatedly find the legacy effect of teaching and interactive learning, whether among individual patients, local physicians, team members, medical or other students, and not least, to their own family members who come along, essential to their motivation to repeat. This perception of residue of the short periods to which these physicians may commit appears sustaining to repeat participation and satisfaction. In reference to the prominent and competing theoretical models for motivation towards philanthropy and volunteering that have matured in recent years, subjects generally seek to supplement Public Goods while acknowledging openly the attraction of Private Consumption or the "warm glow" reward of their efforts (Ziemek, 2003).

Associated direct and opportunity costs are influential and physicians find ways to mitigate them as necessary so as not to preclude participation. Opportunity costs may be more relevant at higher physician income, at times rooted in ostentatiousness or accumulated personal debt. Awareness that a side industry of supporters has developed both domestically and in-country to exploit these humanitarian yearnings seems not to concern participants.

Nationalistic motivations appear minimal. The "soft power" implications that accompany healthcare-related transfers by USAID, US military efforts in disaster relief and its navy hospital ships, as well as the examples of Cuba and Taiwan who deploy direct health care services with overt soft power intentions rarely resonate with the motivations of US STMM participants (Chapter 2) (Chiu et al., 2012; de Albornoz, 2006). More so, subjects emphasized their acquired perceptions that these one-to-one transactions constitute a more efficient effort than routing tax dollars through federally sanctioned aid programs, counterbalancing the potential criticisms regarding a lack of evidence for economic or health status effects of STMMs on LMICs (Martiniuk, Manouchehrian, et al., 2012). Absent the reciprocity objective of federal aid, subjects, in composite, characterize STMM activity as perhaps a more persuasive fiber of soft power projection within the served communities (Doherty-Bigara, 2014).

Since individual members of professions seek legitimacy through the status that societies grant them, motivation may be associated with group dynamics. It is reasonable to assume that individuals desiring to uphold their status would avoid situations that may be seen to compromise their own professionalism, including by association. Further, when occupations or other 
activities grow and mature, then trade and collegial societies typically arise for the benefit of all stakeholders (Abbott, 1991; Wilensky, 1964). This has not yet happened for STMMs (Chapter 2). Subjects in this study generally see a potential benefit for a national or international organization to foster the objectives and knowledge of, and preparedness for STMMs, as long as such an organization did not spoil the effort by espousing high-minded, risk-averse guidelines that would hobble more than help in these resource-poor environments. Neither institutional peer pressure nor peer review mechanisms appear as yet to motivate participation nor modify performance in STMMS.

The adventure aspect of STMM involvement seems certainly to be a compelling element, yet it is not simply about place, culture or unusual and interesting pathologies that can be found in other adventure travel and domestic grand rounds exercises. Rather it extends deeply into an attraction of human beings from different walks of the human condition to know and understand each other. The medical platform allows the parties to set aside national and cultural formalities and brings them face-to-face to begin a conversation that opens on an objective health issue. The categorical imperative for the physician is to utilize whatever comprehensive ingenuity he or she may possess to effect a positive outcome. Whether a tangible, objective result is achieved or not, the engagement appears remedial to both. From these deeper emotional and psychological elements may arise the sense of personal renewal for a profession fraught with increasing rates of burn-out in the US (Eckhauser \& Freishlag, 2005; Peckham, 2015; Shanafelt et al., 2015). The gratification of more complex learning experiences that arise from these human interactions exceed that of conventional tourism and is readily available to healthcare providers. One subject confronted the potential criticism of physicians using STMMs as tax-deductible adventure travel when the medical days of a trip are followed by visits to the local wonders. Rather than being opportunistic, the subject suggested such exploration is a necessary part of the decompression physicians should pursue before reentering their daily lives after what can be an intense experience.

Collectively, the results of our various interrogative approaches to these subjects depict a virtuous cycle impelling the susceptible physician to satisfy an ingrained urge to do good through medical services and teaching, positive feedback of appreciation, complex learning and personal renewal, followed by the inclination to repeat. 
Minimal research has accumulated on the receiver side (patient, country, ministry level) regarding STMM value and requires further attention (Green et al., 2009; Maki et al., 2008; Nouvet et al, 2015). While sensitive to the potential unintended consequences of their activity such as crowding out local care, creating dependency on foreign teams, inadequate follow-up and dampening investment in local healthcare, subjects consistently found motivation from positive reception for their work from in-country stakeholders. More research on the receiver side should sharpen the effectiveness of this form of outreach and could serve to pique participants' motivation. One subject focused on the value of the primary interactions with individual patients as the sole determinant of the value of his work and divorced all secondary or tertiary concerns from judgment.

We used standardized recruitment and data analysis methods for qualitative research and conformed to Guba's constructs for trustworthiness in this study (Shenton, 2004). Nonetheless, our results and conclusions are vulnerable to the limitations inherent in narrative formats, the bias related to snowball rather than the randomized recruitment, and risks to external validity from a small sample. Unconscious bias may be introduced by utilizing subjects who are acquainted with the researcher through presetting of expectations or other influence. The choice to study only experienced STMM participants may leave out potential important viewpoints of those who may have chosen not to do or not to repeat STMMs from our sources for understanding participant motivation. The cohort accumulated for this study may be extraordinary in regards to experience (number of STMMs: mean 18, median 10) compared to that from the Physicians' Giving Back Survey (number of STMMs of repeat participants: mean 10, median 5; Chapter 3). There is inherent operator bias in coding of response content and in which response relationships to investigate and report among innumerable options. Finally, as a risk in the directed content analysis approach, the prior literature review results in Chapter 2 and the survey research results in Chapters 3, 4, and 5 may condition the interpretation of the data contained in the narratives (Hsieh \& Shannon, 2005).

\subsection{Conclusions}

Motivation to participate in STMMs is compelled most commonly by a personal core set of values, may rest on a background of personality traits, 
and appears to be sustained by feedback of a rich blend of emotional and cognitive triggers. The increase in STMM activity is fueled by local, word of mouth recruitment and facilitated by the exposure of opportunities through internet technology and nearly void of government or professional society stimulus and only sometimes instigated by faith.

In large measure, this narrative study brings the literature full circle in the search for an understanding of why physicians participate repeatedly in STMM activity. Systematic literature reviews and statistical survey analyses have probed for external motivators related to demographic, economic, social and nationalistic influences. Alas, the subjective benefits espoused in the hundreds of reflective articles on STMMs that are rejected from more evidence-seeking reviews have been borne out in this grounded, narrative approach to understanding the motivation for STMM participation. The satisfaction of helping, the adventure, the renewal of focus and perspective, and the learning of many things compute a positive margin on the investment of funds, time and other trade-offs, discomfort and sweat. These intangibles remain the evident fungibles from the tacit bargain of STMMs.

Valuable future research that may complement the concepts developed here could be more robust efforts to identify not only the perceptions of receiver stakeholders to the current practice, but to query leadership and ministries of health in LMICs about how their citizens could best utilize these volunteers as an interim measure while countries improve long-term, inclusive services. Fostering improved alignment of needs and talents in order to optimize outcomes in general could be a policy objective of a nascent national or international organization. 
Chapter 7: General Discussion 


\subsection{Introduction}

The principle aims of this dissertation are to examine the prevalence, profile and motivations of private physicians in high-income countries, herein specifically the US, who participate in STMMs, and the measurable economic and manpower inputs of the activity. Chapter 1 provides the specific parameters of the type of humanitarian medical "excursions" under examination and general knowledge about STMMs. In Chapter 2, a systematic review of the literature searches for evidence of social, economic and diplomatic forces that might underlie the increasing tide of this grass roots aid. Chapter 3 reports on the data mined from a nationwide survey of US physicians to understand the spectrum of opportunities for pro-bono professional work in which physicians participate. With this in perspective, Chapter 4 itemizes response data from the survey to understand the dimensions of participation, to show evidence of growth in participation, and to assess the economic and physician labor expenditures. Chapter 5 analyzes responses in order to forecast a profile of the physician participant through demographic and professional characteristics, as well as asking where they live and where they go on STMMs, in the search for clues as to the draw of STMM involvement. Closing the circle ever more tightly, Chapter 6 exposes the accounts of participants with their direct vocalization of their principal motivators, and reflection on the relative influence of social, economic and diplomatic forces examined previously through systematic review as well as the profile characteristics and cost calculations from the PGBS. Chapter 7 herein capsulizes the literature review, and the qualitative and quantitative components of this dissertation in 6 key statements. These 6 statements are grouped first by what has been learned about why physicians go, and then by what has been discovered about the resource inputs that makes it relevant to know why they participate. Each statement is corroborated in whole or in part by more than one element of the empiric research of this dissertation.

The focus of the dissertation is confined to the provider side of this form of aid, specifically US physicians. The discussion of the 6 key statements of the dissertation reviews the supporting evidence found in the empiric research as well as the study limitations. Relevant policy and future research implications are woven into the arguments for the statements. 
While emphasizing the specific focus of the dissertation, we acknowledge that that this work may ignore several important aspects of STMMs that would provide a richer perspective of the subject in the context of the broader world of humanitarian medicine. Where instructive and related to the results of this dissertation, some perspectives on recipient communities, supporting NGOs, comparisons to Médecins Sans Frontières (MSF), and lessons from the global debate on aid are added, followed by the general conclusions of the dissertation.

\subsection{The Demographic, Professional and Personal Determinants of Physician Participation in STMMs.}

The first three statements relate to the first question of the dissertation about why US physicians chose to participate in STMM activity, and focus on the observable characteristics of participants, personality traits, and the drivers that physicians vocalize.

Statement 1: The US physician who participates in STMMs is most likely to be a mature surgeon, anesthesiologist or pediatrician, married with few or no children at home, with a lower than average annual income compared to other US physicians, and goes to Latin America because of its proximity.

The literature on STMMs holds virtually no data on the characteristics of physicians who are attracted to the process of these humanitarian "excursions". Chapter 5 cited the singular limited mail survey of surgeons affiliated within a single hospital system in one state (McGinigle et al., 2008). While not distinguishing between domestic and international volunteering, only full time practice correlated with volunteering.

In contrast, the primary data from the PGBS executed as part of this dissertation provided a gestalt profile of the STMM participant from the US. Regression models of a multiplicity of professional and demographic characteristics in Chapter 5 found that being in the specialty grouping that includes surgeons and anesthesiologists or that of pediatrician, being in the oldest of the three age groupings, and being married predicted participation. It may be perhaps inferred that older physicians, whose careers were spawned during a time of relatively less technological intensity, are more comfortable 
returning to environments where their hands-on, unassisted clinical assessment skills become more relevant again. Participation appears to decrease inversely to the number of children at home. The regressions showed that STMM participants were more likely than non-participants to withhold reporting their highest earned income. Close analysis of descriptive data brought more nuances to the profile, including a highest reported income somewhat lower than average for US physicians. Reflections on direct and indirect costs from the narratives resonated with the survey data in that physicians were less sensitive to the opportunity costs. Despite the lack of overall ethnic, language or historical ties, most go to Latin American countries on their STMMs, likely due to relative proximity. Only Asian physicians separately showed some predilection to go to Asian countries per the data from the PGBS. Similarly, the narrative responses collected for Chapter 6 showed no natural ties to countries of destination such as race or ethnic characteristics in the study cohort.

The size of both the survey sample and the narrative group constrain the power of the analysis and the inferences. The external validity of the analysis of the PGBS data is limited because the representativeness is found with respect to three demographic characteristics (race, civil status, type of medical degree), but not with respect to five other characteristics (gender, age, international medical graduate (IMG) status, religion, and region of the country). Since those who volunteer may be more likely to respond, response bias in a survey on volunteerism is inherent. Further, the survey data is retrospective and may suffer errors related to recall.

Should institutions, NGOs or the US government seek to modify the participation of physicians in STMMs through policy decisions meant to affect strategic soft power, reputation building, recruitment or other broader objectives, the recognition of who has been naturally attracted to STMMs may provide the basis for targeting of recruitment. Physicians may be willing to go wherever practical bottlenecks related to cost and distance are manageable, rather than being bound by pre-existing ties.

Future research that accumulates larger datasets would provide a more reliable basis for analysis. One conceivable methodology to do this would be a profession-wide effort to coordinate data gathering with periodic relicensure through a few pointed questions related to pro-bono activities. If 
promoted by the major professional bodies, the American Medical Association and the American Osteopathic Association, state boards would likely comply.

Statement 2: A set of personality traits forms a foundation for attraction to and satisfaction with STMMs and consists of high self-confidence, flexibility, unselfishness, tolerance for arduous and less sanitary conditions, and strong ethics.

A recurring theme from both procedurally-oriented physicians and medical physicians in the narrative study of Chapter 6 was the notion that a certain personality type that is not uniform among all physicians was shared by physicians that repeated STMM participation, including the capability to function effectively in arduous and technically unsophisticated circumstances. Further, this group of physicians seemed to express less cost sensitivity, particularly with respect to opportunity costs, congruent with the implication from Chapter 5 that opportunity costs may be a barrier to initiating or to continuing STMM participation.

Missing from this investigation are narratives from physicians who have never participated or not repeated after a first STMM experience, in order to understand their lives and perceptions in contrast with participants. Chapter 5 provided survey data from PGBS on primary and secondary reasons for nonparticipation. Prominent among the former were personal limitations, but the survey did not allow for physicians to specify their limitations other than constraints of time, family, and work situation. In the PGBS, non-repeaters most commonly cited expense and time away from spouse or family. Why these would not have been primary barriers is not clear. Perhaps the choice not to repeat STMMs may actually lie in one's inability to adapt easily to the circumstances.

In an open and free society, it is anticipated that individuals migrate to vocations and avocations suitable to their strengths and sources of fulfillment, while minimizing exposure of their relative deficiencies and vulnerabilities. If the value proposition of STMMs is to be optimized, matching not only technical but also personality profiles of physicians to the activity may be crucial. If future research were to validate the concept, the comparison of results from participant and non-participant physicians using standard, 
validated personality instruments such as the Myers-Briggs Type Inventory (MBTI), Minnesota Multiphasic Personality Inventory (MMPI) or others may help in the development of a mechanism to identify physicians more likely to perform effectively in STMMs. Physicians might wish to self-screen with a validated instrument, and some organizations may encourage them to do so.

Statement 3: The US physician's most common key motivator, the satisfaction from helping others, usually springs from personal core values, rather than religious affiliation or religiosity, or medical oath. Feedback from both face-to-face experiences with patients and teaching legacy effect stimulate a virtuous cycle of repetition.

Despite the ease of identifying numerous church-based organizations sponsoring STMMs, the regression model results in Chapter 5 failed to demonstrate a correlation between any religion and STMM participation. In the narratives of Chapter 6 , a minority of physicians $(6 / 20)$ cited their religious beliefs as the basis of motivation for their repeated participation, and only $20 \%$ were surprised to learn that no particular religion had been shown to predict participation. Interviewed STMM participants cited a personal set of core values more often than faith or medical oath as their locus of decisionmaking regarding STMM participation. These observations tend to dispense with the question that more intense religiosity rather than affiliation with a particular religion is a force that propels STMM participation.

As determined respectively in the one-sample chi-square testing in Chapter 2 and the demographic regression model in Chapter 5, the difference in medical degree (MD or DO) as a reflection of a more or less holistic philosophical approach to medicine, while comparable between survey sample and the population, did not differentiate a propensity to participate (Ahmed \& More, 2016).

In Chapter 6, physicians' most intimate reflections on face-to-face experiences with patients in STMMs revealed the satisfying elements related to their desire to repeat the activity. The most common professional pro-bono activity of physicians, as illustrated in Chapter 2, is teaching, and the legacy effect of teaching that carries over into STMMs seems to stimulate motivation as well as to mitigate the discontinuous nature of STMMs. The direct transfer of both services and knowledge form much of the attraction to STMMs. This 
bodes well for university based models of long-term LMIC site relationships described by Morse for the future of global medicine (Morse, 2010).

Other predictors could emerge from larger samples or by population input during the re-licensure process by probing professional pro-bono contributions. Value may be also found in the development of a standardized instrument to gather data continuously from STMM participants in the field, by means of hand-held tablets sending to a cloud-based research database, from as many organizations as possible, without even requiring the organizations to be linked or otherwise cooperate. A dramatic simplification of the instruments developed by Maki and colleagues could be a starting point for such instruments (Maki et al, 2008). A cautionary note to future research arising from the results of this dissertation is that the composite of profile characteristics suggests more influence by attributes that physicians have chosen rather than those that are innate or resulting from a developmental path. The attraction to this type of activity may therefore not be best understood through assessment of the latter characteristics.

\subsection{The Economic and Manpower Impacts Measured: Why a Deeper Understanding of Physician Participation in Short-Term Medical Missions is Needed}

The latter three statements underscore the need to know better the motivations of physicians to participate in STMMs since the participation has reached a level that has economic and manpower implications. The following statements relate to the growth in the activity, the quantification of measurable inputs, and how growth has been facilitated. These findings are relevant to the second question of the research regarding the impact of physicians' choice to participate.

Statement 4: The absolute and relative prevalence of US physician participation in STMMs and mission numbers are increasing. Participation prevalence may have approached 16\% in 2012.

The allegation conveyed by earlier authors that the number of STMMs is increasing appears to be based on their personal observations and the growing number of STMM opportunities offered online. No statistical data on 
participation levels have been previously available. The survey portion of this dissertation (PGBS) appears to be the initial attempt to gather empiric data from physicians on this matter. As determined in Chapter 4, the sample data suggests an increasing prevalence of participation within decreasing retrospective periods. Increasing prevalence of new first-time STMM participation as well as overall increasing numbers of STMMs occurred during the period 1967 - 2013, although attrition from mortality may result in under-reporting for earlier years. Lastly, new and total STMM participants as a percent of the survey respondents in practice at each year appears to be increasing. As noted in Chapter 4, the physician participation rates cited are based on the total STMMs executed in each year and assumes one mission per year per physician. A small number of physicians may participate in more than one STMM in a year which would lower the calculated percent participation. The results are consistent with other data sources such as the Medscape 2012 Physician Lifestyle Survey that suggested a roughly 10\% incidence in international mission work by US physicians in recent years (Peckham, 2012).

From a policy perspective, the increase in numbers of US physicians and ancillary staff that go on STMMs may have foreign relations implications, both positive and negative. The potential for international incidents from detention of US citizens by unfriendly regimes or criminal elements may present future challenges for the Department of State. On the other hand, monitoring the expansion or contraction of STMM activity, countries visited and how frequently, by means of an efficient, non-onerous, online relicensure regime, could benefit the US, not only as part of a process for understanding trends in global healthcare, but also keeping track of the ongoing civil society relationships taking place with its neighbors.

Statement 5: Tax exempt annual composite outlays for US STMMs are comparable to benchmarks of official US foreign aid, and the man-hours devoted to them may stress already stretched physician resources in the US.

Considering that each physician embarking on a trip is likely to be accompanied by one or more ancillary personnel to assist with medical or administrative functions, the direct costs per physician per trip averaging $\$ 3815$, as derived in Chapter 4, becomes amplified, whether they are to be covered by the physician or by other means. The sensitivity analysis in 
Chapter 4 suggests that, at a rate of 4 ancillary personnel per physician, the annual global cost of US STMMs, when physician estimated monetary opportunity costs averaging $\$ 7791$ each are also imputed, exceed $\$ 3$ billion annually as of 2012. Contemporary benchmarks from the United States Agency for International Development (USAID), such as total US aid to Afghanistan (\$3.1B), contributions to International Organizations and Peacekeeping Activities (\$3.7B), Consular Affairs and the Border Security Program (\$2.8 B), and Humanitarian Assistance $(\$ 4.1 \mathrm{~B})$, provide a perspective on the scope of this expenditure (Kerry, 2014).

Opportunity cost sensitivity would be positively correlated with income generating potential. One interpretation of why the positive skew of the income distribution curve of participant physicians is greater than that of the physician population is that opportunity cost incurred at higher incomes is more influential than out-of-pocket costs. Decreasing participation with increasing income in the sample cannot be explained by seniority since the sample showed relatively higher participation among older physicians. An element of "price elasticity" for the non-monetary rewards of pro-bono work may be operant. The inverse relationship between opportunity cost and participation broadly suggests a direct relationship between Private Consumption, i.e., "warm glow" and opportunity costs. Narrative respondents in Chapter 6 naturally indicated that opportunity cost had not been a barrier for them, but they also indicate that opportunity costs can be "punishing", and may deter physicians with higher incomes from joining in.

Other factors that may underlie the inverse relationship of incomes and STMM participation cannot be ruled out. The comparisons of benchmarks must be viewed with caution because of the inclusion of opportunity costs in the calculation of annual expenditures, while the expenditures by USAID are all direct. In this research, the impact of cost on the decision to go has not factored for an effect from dual income households nor normalized for dollar value over the 64-year span of the data period. In addition, some costs have not been included, such as those for personal immunizations suggested by the Centers for Disease Control for travelers to different areas, which may amount to several hundred dollars per year per physician.

Using the methodology in Chapter 4, the cumulative man hours devoted to STMMs by US physicians in 2012 roughly equate with nearly 5800 physician 
fulltime equivalents. The United States, with a physician population approaching 900,000, still faces a chronic manpower shortage of tens of thousands of physicians, so such a transfer of resources may be meaningful (Kirch et al., 2012). Physicians participating in STMMs will likely continue to mitigate their own individual unavailability through cross-coverage rather than cease going because of this chronic physician shortage. As the US struggles to meet its own demand for healthcare resources, it also currently fails to provide training opportunities for all of its own medical graduates. Upon recognizing the increasing outflow of medical effort to other countries, healthcare policy makers in the US could adopt the attitude that STMMs represent a lowering of domestic output inadvertently supported by the tax regime, bring more scrutiny to its regulation, and conceivably strangle much of the activity by removing the related exemptions.

Future research on expenditures could combine the approach of tracking the activities reported by physicians at re-licensure with expenditures reported by sponsoring NGOs to the US Internal Revenue Service. (These expenditures should also be reflected in the NGOs' annual reports.) Such a marriage of resources would constitute a major refinement to the retrospective approach by Maki et al who used voluntary organizational survey responses on STMM costs (Maki et al., 2008). Their tabulation of \$250M would seem to have grossly underestimated composite annual US STMM costs.

The income range curve of participant physicians as seen in Chapter 4 are commensurate with comments by interviewees in that higher income echelons of US physicians are not the ones responding to the attraction of STMMs. "Warm glow," the term originated by James Andreoni in the development of theory on charitable giving, appears relevant to this observation on STMM participation that suggests an equivalency between opportunity costs and warm glow (Andreoni, 1990). For Andreoni, applying the concept of relative degrees of altruism was important to tax and subsidy policy formulation. Nunes and colleagues have published heady discussions of their results regarding warm glow as it factors into contingent evaluation and willingness-to-pay calculations for public goods particularly in an environmental context (Nunes \& Onofri, 2004; Nunes \& Schokkaert, 2003). Further exploration of published research beyond the scope of this dissertation could bring more light to the understanding of the transactional nature of these medical interfaces from both the physician's and the patient's perspective. 
Statement 6: STMM growth is fueled by word-of-mouth, facilitated by the exposure of opportunities through internet technology, and is disconnected from nationalistic motives and medical professional societies.

The systematic review in Chapter 2 has found little evidence of influence of diplomatic concerns or influence by established medical societies. No allinclusive national or international society has arisen to promote quality, participation or standardization of STMMs. It would appear then, that the increase in STMMs numbers and proportion of physicians participating represents the release of a pent-up demand for the rewards found by physicians in STMMs. Subjects of the narrative study in Chapter 6 make the case that the rise is driven by the ready identification of opportunities with a simple online search, a discovery process that only 2 decades ago took substantial networking. Proliferation through person-to-person connections and word of mouth promotes a snowball effect as more participants connect with other interested physicians. Although based on the comments of relative few narrative subjects, the absence of countervailing evidence from literature identifying other factors in the increase, and the power of social media to fuel political and social revolutions, makes this no surprise.

Despite the lack of professionalization of STMM participation, narrative subjects generally favored the development of a national or international organization devoted to STMMs. Development of such a club may simply await some critical mass. Enhancing preparedness for cross-cultural interaction, orientation to international political economy for physicians, and matching skills to community needs would be the likely raison d'etre of such an organization, rather than recruitment.

A study of the internet effect on other volunteering formats may be revealing. Fundraising for other public goods has been well studied. Marketing for humanitarian services, both high and low skill, has taken hold, and solicits both the manpower and the requisite donations needed for projects and facilities from its targets. Clarifying the scope, impact and trajectory of such marketing would be valuable for warm-hearted yet vulnerable consumers of warm glow. The established Humanitarian Healthcare Ethics Research Network in Canada may be a valuable collaborative forum for such work. 


\subsection{Placing this Dissertation in Context with Other Important Aspects of STMMs}

The supply side-specific focus of this dissertation identifies the prevalence, characteristic, and motivations of US physicians who take part in STMMs and the measurable inputs. This portion of the General Discussion briefly examines other important aspects of STMMs including perspectives from recipient communities, motivations of supporting NGOs, comparisons to MSF, and applicable concepts for STMMs from the global debate on aid. These aspects that do not conform to the foci of the prior chapters, but deserve attention where instructive and related to the results of the empiric chapters. None draw on evidence from this dissertation, yet each is important because it informs the reflection on and provides context to the findings of this dissertation.

\section{Perspectives from Host Communities}

The subjects of narratives in Chapter 6 were nearly uniform in the perception that their efforts are valued by the receivers, that the transaction is equitable, and that both parties are gratified. How much evidence is there from other sources that validates these favorable attitudes? Systematically obtained and published feedback from patients and community stakeholders regarding STMMs is limited; what is available opens a portal into the other side of the tacit bargain.

Green et al interviewed both foreign and local participants in a medical outreach in Guatemala including 23 local healthcare providers and five government health officials (Green et al., 2009). No direct patient interviews were obtained, although a group of seven parents of children who had received care were included. Most Guatemalan physicians and specialists are packed into the capital city since adequate cash does not flow to rural communities to support ongoing practices. With regard to foreign assistance, some host-country staff in this Latin-American country viewed Cuban expatriate physicians as having a bigger impact than short-term missions from the US due to the Cubans' extended deployments in some communities. 
In her contemporary and eclectic accumulation of viewpoints and attitudes regarding STMMs published as Hoping to Help: The Promises and Pitfalls of Global Health Volunteering (2016), Lasker includes her own series of interviews of fifty-five host-country staff members from Ecuador, Haiti, Ghana and Niger (Lasker, 2016). The interviewers were not part of a mission team and the interview subjects were not patients. Further, their comments were not confined to nor specific to physicians.

A study by Nouvet et al published a relevant compilation of direct feedback from the target recipients of care from STMMs (Nouvet et al., 2015). This study was the solitary publication identified during an online search in May 2015 of Spanish language literature on STMMs seeking host country perspectives. The same article is also available in English through the sponsor organization for the research, the Humanitarian Healthcare Ethics research consortium. Interviews were obtained in July through August 2013 from 33 patients along with 19 other host-country nationals including patients' relatives, local healthcare organizers and medical professionals from rural Nicaraguan communities receiving repeated STMMs, as well as a few individuals from the communities who avoided going to the missions. These interviews were procured by a single Spanish-fluent interviewer (although not of Latino ethnicity), and on an occasion separate from a concurrent STMM. Patients tended to perceive the foreign medical capabilities as being relatively superior. A key limitation expressed by the authors lay in patientinterviewees" sense of "powerlessness" conveyed as "beggars can't be choosers".

From these three study groups (Green, Lasker, and Nouvet), several common and remarkably consistent STMM host community themes emerge.

1. From countries where host community interviews or surveys were performed, near unanimous approval and appreciation for recurring STMMs were noted from local staff, healthcare personal and authorities, and patients. STMMs are perceived as "doing good" and expressed gratitude for the foreign missions. Over time, resentment by local professionals and local organizers tends to give way to an appreciation of mutual learning and comradery among nationals and foreigners when volunteers come more culturally prepared and mutually exchange knowledge with local professionals. Lasker took 
numerical ratings from fifty-two host-country staff members ranging from 1-10 on the value of having health volunteers come to their countries, and calculated composite scores comprehensively and for each country. Overall, the positive value rating for the four countries was 8.16; individually, for Ecuador 8.9, Niger 8.85, Haiti 7.63, and Ghana 6.75. The sample for these global assessments is quite small, but nonetheless may serve as an initial "satisfaction survey" benchmark from which one may assess the impact of changes in operations and better preparation.

2. Areas of dissatisfaction that could be gleaned in this context centered around inadequate communications about when missions would arrive, what communities would be served, and uncertainty about what kinds of assistance may be available. These uncertainties compounded the hardship of the long queues, wait times, and witnessing personally-connected individuals being allowed to skip the lines. Respondents emphasized the need for better coordination with local health care providers and organizations.

3. Local health professionals want more time set aside for teaching by incoming specialists.

4. Respect appears to be a salient issue at all levels. Host country staff emphasized the need for foreign physicians and staff to work respectfully alongside local caregivers, a key point of satisfaction is that patients are treated with dignity and respect, as equals, and that patients and staff truly appreciated the caring attitude from the "gringos". The sense of inequity and indignity with which public health system staff treated the poor in deference to those with means to pay contrasted with the fondness for the STMM groups who treated the poor with considerable respect, dignity and personal affection.

5. Host-country staffers reminded researchers that the local economic and human resources consumed by host organizations trying to accommodate rich-country volunteers often seems to go underrecognized and unappreciated. A repeated aspiration was that STMM sponsoring organizations would provide more monetary support to 
defray local investments and expenses, and leave more valued supplies and equipment.

6. Being free-of-charge was exceptionally valued among the poor rural communities served since public sector and local private care was generally not accessible for monetary and practical reasons. Differing viewpoints were heard among local caregivers as to whether STMM managers should make more effort to distinguish which patients could and could not pay for local health care, and whether sliding scale payments should be assessed or all care should be free.

7. Recalcitrant poverty and the lack of healthcare infrastructure, problems that foreign surgeons and STMMs cannot fix, were identified by respondents as the basis for chronic healthcare needs. Among the more troubling features unveiled was the near absence of hope that the host governments would ever rectify the scarcity of care available to the rural poor. The hope that there would be more such missions belied the sense of dependence on the foreign surgical and primary care brigades.

Parallels are readily drawn between many themes captured in the interviews of nationals by all of these groups and the responses of the physician subjects who provided the narratives in Chapter 6 . The importance of coordination with in-country hosts, collaboration with local health care staff and authorities, two-way teaching, and respect for local epidemiological and administrative nuances is mutually vocalized. The appreciation so critically perceived by physicians as a motivator is validated in these independent qualitative studies of patients at STMM locations in Nicaragua and Guatemala. The value and attractiveness of the interaction is expressed at a very personal level from both sides of the exchange. The shared sense that every effort is made to do the best that can be done is conveyed by both parties. The dignity that physicians hold for their patients in STMMs is authentically felt by such patients. STMM physicians wish to improve the impact of their missions' services and teaching, and, reciprocally, hostcountry nationals want more of both. The tendency for dependence on STMMs is a reality that both parties recognize, and it is concerning that the volunteers from the United States may reserve more hope than do the affected 
nationals that health care inequalities will eventually be resolved through their government's future efforts.

\section{Comparisons to MSF}

Because it is the most widely recognized entity for direct humanitarian medical services worldwide, the Nobel Peace Prize-winning organization MSF is often the de facto anchor of reference for those who are unfamiliar with STMMs. It is helpful, therefore, to contrast these models specifically regarding the findings of this dissertation.

Broadly speaking, STMM physicians are gainfully employed at home and are unpaid for their short-term humanitarian work, whereas MSF physicians receive a base salary and have their costs of living covered through funding sources. Although physician incomes in MSF are relatively low compared to fulltime domestic practice, one can make a living and accumulate savings. Another distinguishing characteristic is level of risk; MSF purposely goes to areas where populations are at risk from conflict, whereas STMM volunteers typically do not, and may be restricted from travel to conflict areas by the US State Department.

Comparing the demographic and professional characteristics of STMM and MSF physicians is frustrated by the paucity of such data catalogued by MSF human resources coordinators. From Chapter 5, the male to female ratio for US STMM physicians is 64\%:36\%; for MSF international physicians (those that travel to another country) the male to female ratio is $52 \%: 48 \%$, although this data does not demarcate physicians from paramedical personnel (Prepared by IDRH platform, 2015). Seventy-two percent of STMM physicians were between 56 to 73 years of age; mean age for all MSF medical personnel was 40.3 years. No data is collected for race, religion, marital status, children at home, or most frequent specialties.

Comparing the qualitative features of motivation of STMM and MSF physicians is similarly wanting for focused research. In an article on the rise of MSF and characteristics of those who are attracted to and remain with MSF, Siméant described the socio-cultural milieu that witnessed the rise of MSF during a time of political and religious crisis in France in the 1970's that 
created a vacuum for people longing for social reform, and included the backgrounds and narratives on motivation of MSF volunteers including physicians. (Siméant, 2001). The collage of the personal stories that Siméant retells portray the MSF physician as disengaged from traditional medical practice, related not only to constrained availability of employment in the field and to societal devaluation of the medical profession, but also to the attraction to the honor of activism, virile flaunting of one's courage, and noble risk-taking. Humanitarian medical practice would allow one to be more than just a physician, and to remain an honorable physician without being a fulltime one. The blending of diverse backgrounds, inclusive of those with Jewish ancestry and foreigners, allowed MSF to develop as a nonnationalistic movement. From these beginnings, challenge, risk and adventure have been the durable retention factors for volunteers, creating somewhat of a veritable "risk aristocracy". Many attracted to humanitarian careers have had difficulty as adult professionals, not with their knowledge or skills, but rather with integrating comfortably into the professional establishment. Professional humanitarians identify and recruit such individuals. Exposure to discrimination, family trauma that lead to unexpected responsibility at a young age, and having a hero or social militant figure in the family were repeating themes. Long-term expatriate humanitarian careers are commonly triggered after the death or separation from a significant other. Finally, Siméant calls attention to the advantages of short-term volunteerism since career expatriate humanitarian physicians may find their core skills becoming arcane and experiencing psychosocial difficulties with re-entry into their native social structure.

Scattered testimonials found within the MSF-USA webpages bear more recent but similar insights to MSF physician motivation and reflect on a blend of components that may include escape from a past life or current social situation, desire for adventure and challenges, money (though modest, it can be steady work), and idealism, the hope to be a positive force for humanity.

Half of US physician subjects in the Chapter 6 narratives identified influences of family or events while growing up as instrumental in pre-disposing them to take part in STMMs, and most of these acknowledged key figures in their lives with whom they identified. Siméant's MSF interviewees also commonly pointed to a "hero" within the family. Siméant further noted how commonly the experience of having been a boy scout and having had other socializing experiences such as monastery or military were part of the background for 
MSF physicians. This feature was not noted for the American physicians interviewed for the narratives in this dissertation, though such a background association was not pursued in our interviews and may certainly be there.

Physicians and organizations involved in humanitarian care in both long-term and short-term endeavors that go beyond public health measures to face-toface care encounters occupy the same space at the effector end of the process. Each of these humanitarian medical pathways present their own sources of friction to the professional: cost and practice stress on the STMM road and perhaps some professional stagnation on the MSF road. The acuity of the MSF response demands continuous activation and forward planning. It succeeds on the rails of tapping into a world of donors who care, and volunteers who are less encumbered by the circumstances of life that hold others to existing commitments. In contrast, STMM physicians fit their impulses for altruism into lives fully integrated into the domestic social fabric and its continuous demands. The two dynamics, and all the nuances in between, are not competitive for the hearts and minds of physicians, but rather complementary. As Siméant insinuates, humanitarian medical work is a matter of coupling of the individual physician life circumstances to differing venues for the same purpose.

\section{Motivations of Supporting NGOs}

NGOs great and small that facilitate most STMMs could reasonably be viewed as the "market makers" of STMMs, so their motivations are relevant in a discussion of the motivations of participating physicians. Lasker and her research assistants sought to survey the population of 702 identified STMM organizations in the US that placed volunteers or students outside the US with a health component to their activity, lasting 6 months or less (Lasker, 2015). Among the 177 responding organizations, $50 \%$ were faith-based, $35 \%$ were non-faith-based NGOs, and $15 \%$ were educational programs. The authors further interviewed a convenience sample of 27 mission organizers from 5 faith-based organizations, 14 non-faith-based NGOs, 6 from educational institutions and 2 from for-profit corporations. The objective of the dual methods study was to examine the goals of sending organizations.

Through open-ended questioning, most organizations identified some aspect of healthcare as the organization's principal goal, such as primary care 
provision, access to specialties, capacity building, community health and health education. Non-health-related goals commonly identified as either principal or corollary objectives were evangelism ("mission work"), student experiences, staff education, fund raising for the core organizational activities and for host-country expenses and direct investments, recruitment and retention of more members and students, fostering international organizational partnerships, organization reputation enhancement, research, and non-health-related host-country projects. Another espoused goal was to identify and nurture future leaders in global health. As clarified in Chapter 1, other activities that may exist as "global health" that do not include direct physician participation in the care of patients should be viewed in a different context from STMMs that are the focus of this dissertation.

A natural concern would be that such non-health-related goals of organizations sending STMMs may divert substantial staff time and energy as well as material resources from healthcare-related objectives. A presumption that such missions are tainted and inferior to those without such goals nonetheless may be premature since no evidence of comparative impact of STMMs on community health or economic status is available. On the contrary, secondary goals may potentially stimulate more involvement, investment, frequency, motivation, intensity or output during a trip. It is clear that health-related volunteer opportunities are readily available to physicians in the US, as reviewed in Chapter 3. For some physicians, taking the extra step to go abroad may initially be heavily dependent on the facilitation by organizations that clearly have their own self-interests to satisfy. The ancillary benefits accruing to organizations may be reasonable trade-offs in the overall effort to alleviate the deficiencies of access to health care in the recipient communities.

The host-country staff that Lasker interviewed underscored the need for organizations to provide more pre-travel orientation to volunteers regarding the culture, language and conditions they would encounter (Lasker, 2016). The corollary goals of organizations tabulated in Lasker's survey and her interviews of host-organization representatives did not differentiate which types of organizations tend to fall short in that aspect. Providing pre-travel training and cultural orientation was not identified as a characteristic of organizations that have primarily non-health-related objectives, though one might assume that training would be commensurate with the objectives of the outreach. 
The concomitant growth of involvement by organizations, physicians and patients in the marketplace of healthcare disparity suggests that each party is finding some satisfaction of its needs in the STMM transaction. Lack of access to quality healthcare in LMICs may be construed as market failures left unaddressed by governing regimes (Mendoza, 2009; Orbinski, 1999). This perspective does not necessarily preclude that health care market dynamics that shape organizations could simultaneously satisfy consumers of warm glow. Until evidence of comparative impact on health or economic status of host communities emerges, judgments on organizational motivations should probably be, for the most part, reserved. Over time, the praxis of STMMs is likely to find that physicians and other volunteers will gravitate to mission models and organizations on the basis of such evidence of impact, just as new knowledge constantly alters all market decisions.

Lasker reported nothing from her study on STMM-sending NGOs to suggest that a call for attention to the failures of governing regimes or market mechanisms is an NGO objective. The non-medical objectives of organizations, as outlined previously, remain apolitical. Similarly, the STMM narrative subjects in Chapter 6 rarely featured the projection of nationalistic goals in their own motivations, and their selection of organizations to work with had no basis in political messages.

The stakeholders whose viewpoints on STMMs we know least about are host country governments. Nothing has been found in the exhaustive online literature search for this dissertation in English or Spanish languages to illustrate how governments weigh in on this relatively obscure process, since their attention may be more focused on trade, foreign direct investment and state-to-state transfers. More enlightened regimes will be needed in LMICs to address inequities in their societies through build-up of local resources, and avoiding violence and disruption in the process. Until then, solutions for more effective aid found in the careful study of what works best, and listening to the end users of aid remain paramount. STMMs are no exception.

\section{Applicable Concepts for STMMs from the Global Debate on Aid}

If STMMs, as suggested in Chapter 4, are indeed becoming a force within the multipronged world response to poverty and its associated health disparities, then the larger debate on aid effectiveness is cogent to discussions on the 
supply side of STMMs. In Dead Aid: How Aid is Not Working and How There Is a Better Way for Africa. Dambisa Moyo has made the case that one trillion dollars of aid foisted on Africa since the 1940s has failed in the effort to foster economic development and poverty alleviation (Moyo, 2009). Moyo emphasizes that the aid to Africa has been not just unhelpful, but has done great harm to the prospects of African poor. The manner in which aid has been routed through corrupt regimes merely compounds the lack of accountability they have to their people, and it empowers dictators. The displacement of local producers through direct provision of supplies dampens growth of local producers and entrepreneurs. The example often used is the disruptive effect on local fabricators by the distribution of free mosquito nets by non-governmental organizations (NGOs) to reduce the incidence of malaria transmission. The tendency for aid organizations to use their own nationals to provide services and implement programs rather than staffing locally contributes to unemployment, enhances the sense of dependency on foreigners, and triggers neocolonial sentiments. Others have identified examples of waste and inefficiencies in aid delivery as such occurs with food transfers as well as medical services and supplies ("Helping whom, exactly?", 2013).

As shown in Chapters 4, STMMS represent a material expenditure of funds and human capital that is transferred from rich countries to poorer ones, though lacking any government directive or objective. Characteristic of the broader criticisms of traditional transfers, Hoover et al have pointed out how the logistical nightmares for any substantive medical support equipment undermines the quality of STMMs (Hoover, Cole-Hoover, et al, 2005). Visiting medical teams may adversely impact a local provider; if the incursion occurs often enough, needy communities could be left perilously dependent on uncertain foreign traveling teams. Unless carefully coordinated with longterm indigenous community goals in mind, the pressure for host-country regimes to invest in rural healthcare is diminished, thereby creating a bottleneck to sustained progress.

Remedies to address global failures of international transfers to improve the plight of those in poverty have recently focused heavily on two approaches: 1. evidence from trials on which tactics show best results, and 2. listening to input from those served about what does and does not work, as well as developing the vision for long term solutions from the bottom up. 
With respect to the first approach, researchers have championed the use of randomized, controlled trials (RCTs) to understand what strategies of poverty alleviation work better (Banerjee \& Duflo, 2011). Along the same lines, although not at the rigor of RCTs, comparative data based on disability adjusted life years saved (DALYS) is beginning to emerge from STMM literature on how surgical teams may optimize the effectiveness of their trips using foreign or local staff and processes (Chen et al., 2012; Dupuis, 2006; Moon, Perry, \& Baek, 2012; Wolfberg, 2006). Objective measures to capture any actual impact on local population health, worker productivity and similar effects on human capital development need to be identified and implemented.

Emphasis on the second approach, as it relates to policy development and planning in STMMs, has been mounting in recent years. Improving aid effectiveness by actively listening to the communities served has been mooted as the cornerstone to planning more effective assistance programs (Anderson, Brown, \& Jean, 2012; Bonino, Jean, \& Clarke, 2014; Christian Aid, 2009; Cohen, 2008; Doyle, 2013; Jacobs \& Wilford, 2010; Martiniuk et al., 2008). Understanding local needs, expectations and the experiences of daily living of the poor requires qualitative analytics. As in other aid efforts, seeking feedback through the perceptions of individuals from STMM-receiving communities goes beyond assessing output of services and outcomes for individual patients. Understanding the expectations created and their fulfillment form the basis of a shared mind-set of the stakeholders, essential to sustainability and progress. So, compiling here the available results of qualitative research on STMMs shows not only that fledgling efforts have begun in listening to host-country stakeholders, but also we can see evidence that supports physicians' impressions about the value of their efforts in the eyes of recipient communities.

Insights from these Additional Aspects of STMMs

In his 1999 Nobel acceptance address for MSF, James Orbinski linked short and long term medical humanitarian outreach in his statement:

"Despite the grand debates on world order, the act of humanitarianism comes down to one thing: individual human beings reaching out to their counterparts who find themselves in the most difficult circumstances." 
The exposition of these additional aspects provides a number of insights pertinent to the results of this dissertation. STMM physicians' perceptions of appreciation from patients and local health care personnel are at least in part validated. Host country stakeholders appreciate the benefits of the medical and surgical services provided by the traveling physicians, yet as Lasker has pointed out, the tacit bargain is dependent on mutuality and continuity in the relationship to be most effective (Lasker, 2016). Physicians, as core actors in global health, share common basic medical training, but have differing human personal characteristics and life trajectories that bracket how they may express their humanitarian inclinations. Organizational objectives differ and are complementary, yet organizations remain the principal market-makers for physician-patient interaction in humanitarian health. The global debate on aid likely has lessons for all formats.

\subsection{General Conclusions}

Why do US physicians go on STMMs?

The empirical work of this dissertation suggests that physicians who are gainfully occupied in their profession in the US choose to participate in STMMs primarily because of the sense of satisfaction of helping. This desire arises mostly from what physicians perceive as their core values, more often than from their religious faith and the sense of duty from their medical oath. This satisfaction is enhanced by a renewal of focus and perspective, adventure, the legacy effect of their teaching, and the learning from experiences outside their day-to-day lives, and is reinforced through a mix of emotional and cognitive triggers. These non-monetary rewards from the interaction found in STMMs are perceived not only as equitable, but as a positive return on the investment of funds, time, toil and inconveniences, and other trade-offs. Accumulating evidence from the host country stakeholder interviews corroborates the value to recipients perceived by STMM physicians and reinforces their key motivations.

While most physicians in the US perform some professionally related probono care and teaching services at home, and commonly provide a level of reduced fee services within their own practices, some participate in STMMs both because of the sense of greater need and more limited healthcare access in LMICs, and by the greater experiential value of going abroad. Physicians 
who find the trade-offs of STMMs appealing tend to share a set of personality traits including more than average self-confidence, flexibility, unselfishness, tolerance for arduous and less sanitary conditions, and strong ethics. These physicians tend to have lower than average income, so are less influenced by the opportunity costs that appear to constrain participation by US physicians more than do the direct costs.

If the PGBS, a cross-section sample, is representative of the population, then about $25 \%$ of US physicians have repeated participation in STMMs, beyond the approximate $10 \%$ loosely suggested in the Medscape Lifestyles surveys referenced in Chapter 4. Thus, about a quarter of physicians share the susceptibility characteristics for participation. Upon this substrate, the rates prevalence of physician participation and mission numbers have increased, catalyzed by word-of-mouth propagation and the internet's showcase of available STMM opportunities and sponsoring NGOs whose agendas may vary. Pre-existing ties to particular regions of the world, nationalism, and influence of professional organizations seem to be generally absent from the factors of participation.

Even among those otherwise predisposed by being surgeons, anesthesiologists, or pediatricians and, coincidentally, married, timing is an element of physician participation in STMMs. Being further along in age and thereby career, and having fewer children at home appear to have a bearing on participation. The choices that physicians have made in terms of specialty, marital status, and income level seem to characterize them in terms of propensity to participate in STMMs more than do innate characteristics of gender, race, ethnicity, or religious background. The contrasts with physicians in long-term arrangements, using MSF as the example, are readily made.

What Are the Measurable Economic and Manpower Inputs Related to STMMs from the US?

Extrapolations of the reporting from the PGBS survey sample indicate direct costs averaging \$3815 and monetary opportunity costs averaging \$7791 (total $\$ 11,606)$ per physician per STMM. The average monetary opportunity cost to the physician is about $4 \%$ of annual income. 
Sensitivity analysis that uses this total figure per physician, estimated total number of physicians participating in the year, and includes direct costs for 4 ancillary personnel per physician, suggest that the annual global cost of STMMs from the US exceed $\$ 3$ billion annually as of 2012. Of this, the total direct costs are estimated at $\$ 2.13 \mathrm{~B}$ and physician opportunity cost of $\$ 1.58 \mathrm{~B}$. Since the direct costs are tax deductible, the activity reduces the federal tax base by approximately $\$ 2 \mathrm{~B}$ and economic output by approximately $\$ 1.5 \mathrm{~B}$. This $\$ 3.7$ billion total cost figure for STMM activity in 2012 is in line with recognizable benchmarks of federal expenditures for foreign aid, providing a perspective on the scope of this expenditure.

STMM length for PGBS respondents averaged 11.8 days for the more than 900 missions for which length was reported in the sample. Considering that this duration represents 10 working days, the investment of physician work days expended, when extrapolated to the population, approaches the productivity of nearly 5800 fulltime physician equivalents. This re-allocation of manpower is notable in a country that struggles to meet domestic demand for physician services and training. Trade-offs are made in a resource limited world. As both the increasing monetary and manpower inputs render STMMs relevant on the humanitarian stage, stakeholders of STMMs may need to organize in order to up their game as responsible members of the donor community.

\section{Future Directions}

This dissertation has provided new and previously missing knowledge about STMMS. The perspectives discussed on the results of the dissertation call for a progressive trajectory on professionalization of this form of transfer. Professional societies seem to have no impact on physician participation, and with the exception of the American College of Surgeons' Operation Giving Back, these associations seem to have little interest in promoting, monitoring, or acknowledging STMM involvement. With the increasing magnitude of physician personal investment, the time may be approaching for the development of an STMM society dedicated to maximizing the return through matching skill to need worldwide, identifying best practices, and coordinating and tracking the allocation of resources nationally and internationally. Such an organization could foster, among other matching and quality functions, the facilitation of research by working with the AMA and the AOA through to 
gather data at re-licensure and via filed reporting on hand-held devices a suggested in 7.2, Statement 3. The elements of professionalization such as guidelines, codified instructions and of cost benefit analyses that are accumulating in more recent literature, the nascent research on the practice as a whole, and the increasing interest of medical schools to provide students with exposures to international health challenges together amount to a groundswell of professional interest that could be leveraged for the betterment of global healthcare in the near term. 


\section{Works Cited}

Abbott, A. (1991). The Order of Professionalization: An Empirical Analysis. Work and Occupations, 18(4), 355-384. http://doi.org/10.1177/0730888491018004001

Ahmed, M., \& More, R. (2016). DO vs MD - What's the difference and which is better?, 1-13. Retrieved from http://myheart.net/articles/md?vs?do/ Accessed 16 April 2016

Albrecht, G. L., Fitzpatrick, R., \& Scrimshaw, S. C. (1999). The handbook of social studies in health and medicine. Book, SAGE Publications Limited.

Alkire, S., \& Chen, L. (2004). Global health and moral values. Lancet, 364, 1069-74. http://doi.org/http://dx.doi.org/10.1016/S01406736(04)17063-3

Anderson, M. B., Brown, D., \& Jean, I. (2012). Time to Listen; Hearing People on the Receiving End of International Aid. CDA Collaborative Learning Projects (First edit). Cambridge, Massachusetts: Collaborative for Development Action, Inc. Collaborative Learning Projects. http://doi.org/10.7748/nm2012.07.19.4.9.p8699

Andreoni, J. (1990). Impure altruism and donations to public goods: a theory of warm-glow giving. Economic Journal, Royal Economic Society, 100(401), 464-477. Journal Article.

Association of American Medical Colleges. Matriculating Student Questionnaire: 2012 All Schools Summary Report. Washington, DC: Association of American Medical Colleges; 2012. (n.d.). Retrieved from Accessed January 17, 2016

Aziz, S. R., Ziccardi, V. B., \& Chuang, S. K. (2012). Survey of residents who have participated in humanitarian medical missions. J Oral Maxillofac Surg, 70(2), e147-57. Journal Article. http://doi.org/10.1016/j.joms.2011.10.007

Badlani, G. (2009). International Volunteerism-Is it Medical Tourism or Does it Make a Difference? American Urological Association News, 28. Journal Article. 
Banerjee A.V., \& Duflo E. (2011). Poor Economics: a radical rethinking of the way to fight global poverty. Book, Philadelphia: PublicAffairs.

Barnett, B. M., \& Walker, P. (2015). Regime Change for Humanitarian Aid: How to make relief more accountable. Foreign Affairs, 94 (4)(July/August).

Becker, G. S. (1974). A Theory of Social Interactions. Journal of Political Economy, 82(6), 1063-1093.

Berry, N. S. (2014). Did we do good? NGOs, conflicts of interest and the evaluation of short-term medical missions in Sololá, Guatemala. Social Science \& Medicine. http://doi.org/10.1016/j.socscimed.2014.05.006

Birman, M. V, \& Kolkin, J. (2013). How to volunteer overseas. The Journal of Hand Surgery, 38(4), 802-3. http://doi.org/10.1016/j.jhsa.2012.12.040

Bonino, F., Jean, I., \& Clarke, P. K. (2014). Closing the loop: effective feedback mechanisms in humanitarian contexts - practitioner guidance.

Boukus, E., Cassil, A., \& O’Malley, A. S. (2009). A snapshot of U.S. physicians: key findings from the 2008 Health Tracking Physician Survey. Data Bulletin (Center for Studying Health System Change), (35), 1-11.

Boyd, A. S. (2012). Medical missions: a therapeutic primer. J Am Acad Dermatol, 66(1), e5-8. Journal Article. http://doi.org/10.1016/j.jaad.2010.07.025

Bryden, L. (2007). Getting involved: donating time, money and expertise to global health. CMAJ, 177(9), 1020-1021. Journal Article. http://doi.org/10.1503/cmaj.071361

Buchman, S. (2007). Tariro Finding hope in Zimbabwe. Canadian Family Physician, 53, 1971-1973. Journal Article.

Butler, M. W. (2009). Fragmented international volunteerism: need for a global pediatric surgery network. J Pediatr Surg, 45(2), 303-309. Journal Article. http://doi.org/10.1016/j.jpedsurg.2009.10.064

Caldron, P. H., Impens, A., Pavlova, M., \& Groot, W. (2015a). A systematic 
review of social, economic and diplomatic aspects of short-term medical missions. BMC Health Services Research, 15(1), 380. http://doi.org/10.1186/s12913-015-0980-3

Caldron, P. H., Impens, A., Pavlova, M., \& Groot, W. (2015b). The Physicians' Giving Back Survey: Keeping up with American generosity. Journal of Compassionate Health Care, 2(1), 8. http://doi.org/10.1186/s40639-015-0017-0

Caldron, P. H., Impens, A., Pavlova, M., \& Groot, W. (2016). Economic Assessment of US physician Participation in Short-term Medical Missions. JGlobalization\&Health, 12(45), 1-10. http://doi.org/10.1186/s12992-016-0183-7

Caldron, P., Impens, A., Pavlova, M., \& Groot, W. (2016). Demographic profile of physician participants in short-term medical missions, Submitted.

Campbell, A., Sullivan, M., Sherman, R., \& Magee, W. P. (2011). The medical mission and modern cultural competency training. J Am Coll Surg, 212(1), 124-129. Journal Article. http://doi.org/10.1016/j.jamcollsurg.2010.08.019

Carey, M. A. (2014). Growth In U . S . Health Spending In 2013 Is Lowest Since 1960. Kaiser Health News, December 3, 1-3. Retrieved from http://khn.org/news/growthinushealthspendingin2013islowestsince196 $0 /$

Carrigan, M. (2005). Medical missions: Two views. Professional renewal through missions. Tenn Med, 98(12), 574,576. Journal Article. Retrieved from http://www.ncbi.nlm.nih.gov/pubmed/16401048

Casey, K. M. (2007). The Global Impact of Surgical Volunteerism. Surg Clin North Am, 87(4), 949-60, ix. Journal Article. http://doi.org/10.1016/j.suc.2007.07.018

Chapin, E., \& Doocy, S. (2010). International short-term medical service trips: guidelines from the literature and perspectives from the field. World Health \& Population, 12(2), 43-53. Retrieved from http://www.ncbi.nlm.nih.gov/pubmed/21157197

Charities Aid Foundation. (2014). World Giving Index 2014, (268369), 1-44. 
Retrieved from https://www.cafonline.org/pdf/CAF_WGI2014_Report_1555AWEBFi nal.pdf

Chen, A. T., Pedtke, A., Kobs, J. K., Edwards, G. S., Coughlin, R. R., \& Gosselin, R. a. (2012). Volunteer orthopedic surgical trips in Nicaragua: a cost-effectiveness evaluation. World Journal of Surgery, 36(12), 2802-8. http://doi.org/10.1007/s00268-012-1702-1

Chiu, Y. W., Weng, Y. H., Chen, C. F., Yang, C. Y., \& Lee, M. L. (2012). Perceptions and Efficiency of Short-Term Medical Aid Missions Among Key Groups of Health Professionals. Eval Health Prof. Journal Article. http://doi.org/10.1177/0163278712461503

Christian Aid. (2009). Listening and responding to our stakeholders: Christian Aid's Accountability. Retrieved from http://www.christianaid.org.uk/images/ChristianAid_accountability.pdf

Cohen, R. (2008). Listening to the Voices of the Displaced : Lessons Learned. Brookings-Bern Project on Internal Displacement. Retrieved from https://www.brookings.edu/wpcontent/uploads/2016/06/09_internal_displacement_cohen.pdf

Cooperman, A., Smith, G., \& Ritchey, K. (2015). America's Changing Religious Landscape: Christians Decline Sharply as Share of Population; Unaffiliated and Other Faiths Continue to Grow. Pew Research Center. Retrieved from www.pewresearch.org Accessed 22 July 2015

Crown, L. (2005). Two views. Paging Dr Schweitzer: a contrarian's viewpoint. Tenn Med, 98(12), 575-576. Journal Article. Retrieved from http://www.ncbi.nlm.nih.gov/pubmed/16401049

Cruess, S. R., Johnston, S., \& Cruess, R. L. (2004). “Profession ”: A Working Definition for Medical Educators. Teaching and Learning in Medicine: An International Journal. http://doi.org/10.1207/s15328015tlm1601

Cunningham, P. J., Grossman, J. M., St Peter, R. F., \& Lesser, C. S. (1999). Managed care and physicians' provision of charity care. JAMA: The Journal of the American Medical Association, 281(12), 1087-1092. http://doi.org/10.1001/jama.281.12.1087 
Cunningham P.J., May, J. H. M. (2006). A growing hole in the safety net: Physician charity care declines again. Center for Studying Health System Change Tracking Report., 13.

Curlin, F. A., Lantos, J. D., Roach, C. J., Sellergren, S. A., \& Chin, M. H. (2005). Religious characteristics of U.S. physicians: A National Survey. Journal of General Internal Medicine, 20(7), 629-634. http://doi.org/10.1111/j.1525-1497.2005.0119.x

Currier, J. (2008). Health, Wealthy, and Wise: Economic Status, Poor Health in Childhood, and Human Capital Development. NATIONAL BUREAU OF ECONOMIC RESEARCH Working Paper 13987 (Vol. 1). Retrieved from http://www.nber.org/papers/w13987

de Albornoz, S. C. (2006). On a mission: how Cuba uses its doctors abroad. BMJ (Clinical Research Ed.), 333(7566), 464. http://doi.org/10.1136/bmj.333.7566.464

Decamp, M. (2011). Ethical Review of Global Short-Term Medical Volunteerism. HEC Forum, 91-103. http://doi.org/10.1007/s10730011-9152-y

Doherty-Bigara, J. (2014). Understanding the Foreign Aid Debate. Georgetown Public Policy Review, 1/5. Retrieved from http://gppreview.com/2014/01/26/understandingtheforeignaiddebate/ Accessed December 6, 2015

Doyle, L. (2013). It's Good to Talk, but Better to Listen. “The Tanbou project harnesses people power to combat corruption in Haiti." Retrieved from http://www.alnap.org/resource/11083.aspx

Dupuis, C. C. (2006, March). Smaller teams for humanitarian missions in the Third World. Plastic and Reconstructive Surgery. http://doi.org/10.1097/01.prs.0000201207.86127.d0

Eberlin, K., \& Zaleski, K. (2008). Quality assurance guidelines for surgical outreach programs: a 20-year experience. The Cleft Palate-Craniofacial Journal : Official Publication of the American Cleft Palate-Craniofacial Association, 45(3), 246-55. http://doi.org/10.1597/07-094.1

Eckhauser, F., \& Freishlag, J. (2005). Volunteerism. Arch Surg, 140(Nov), 1063-1065. 
Emanuel, E. J., Wendler, D., Killen, J., \& Grady, C. (2004). What makes clinical research in developing countries ethical? The benchmarks of ethical research. The Journal of Infectious Diseases, 189(5), 930-7. http://doi.org/10.1086/381709

Erikson C, Jones K, Tilton, C. (2012). 2012 Physician Specialty Data Book. Retrieved from https://members.aamc.org/eweb/upload/2012 Physician Specialty Data Book.pdf Accessed 22 Jul 2015

Erikson C, Jones K, Whatley, M. (2014). 2014 Physician Specialty Data Book.

Erlinghagen, M. (2003). Die individuellen erträge ehrenamtlicher Arbeit. Zur sozioökonomischen Theorie unentgeltlicher, haushaltsextern organisierter Produktion. Kölner Zeitschrift Für Soziologie Und Sozialpsychologie, 55, 737-757.

Fisher, Q. A., \& Fisher, G. (2014). The case for collaboration among humanitarian surgical programs in low resource countries. Anesthesia and Analgesia, 118(2), 448-53. http://doi.org/10.1213/ANE.0000000000000053

Fowles, J. (1989). Orthopedics Overseas: The Other Side of the Coin. Orthopaedic Review, XVIII(1), 13-14.

Frank, E., Breyan, J., \& Elon, L. K. (2015). Pro bono work and nonmedical volunteerism among U.S. women physicians. Journal of Women's Health (2002), 12(6), 589-598. http://doi.org/10.1089/154099903768248294

Gans, D. N. (2005). On the Edge : Examining industry trends Pulling their own weight Evaluating new docs' financial contributions to the practice. MGMA Connection, 5(9), 2004-2007.

Gorney, M. (2005). Plastic Surgery as a Weapon of Foreign Policy. Plastic and Reconstructive Surgery, 116(7), 2030-2032. http://doi.org/10.1097/01.prs.0000191215.28365.ba

Gosselin, R. A., Gialamas, G., \& Atkin, D. M. (2011). Comparing the costeffectiveness of short orthopedic missions in elective and relief situations in developing countries. World J Surg, 35(5), 951-955. Journal Article. http://doi.org/10.1007/s00268-010-0947-9 
Grande, D., \& Armstrong, K. (2008). Community volunteerism of US physicians. Journal of General Internal Medicine, 23(12), 1987-1991. http://doi.org/10.1007/s11606-008-0811-x

Graves, S. B., \& Langowitz, N. S. (1993). Innovative productivity and returns to scale in the pharmaceutical industry. Strategic Management Journal, 14, 593-605. http://doi.org/10.2307/2486859

Green, T., Green, H., Scandlyn, J., \& Kestler, A. (2009). Perceptions of shortterm medical volunteer work: a qualitative study in Guatemala. Global Health, 5, 4. Journal Article. http://doi.org/10.1186/1744-8603-5-4

Grimes, C. E., Maraka, J., Kingsnorth, A. N., Darko, R., Samkange, C. a, \& Lane, R. H. S. (2013). Guidelines for surgeons on establishing projects in low-income countries. World Journal of Surgery, 37(6), 1203-7. http://doi.org/10.1007/s00268-013-1999-4

Gruen RL, Pearson SD, B. T. (2004). Physician-Citizens: public roles and professional obligations. JAMA, (291), 94-8.

Guidelines for Investigators Using Snowball Sampling Recruitment Methods. (2015). Retrieved from http://research.boisestate.edu/compliance/institutional-review-boardirb-home/guidelines-for-researchers/guidelines-for-investigators-usingsnowball-sampling-recruitment-methods/ Accessed December 31, 2015

Hadley, J., \& Holahan, J. (2003). How Much Medical Care Do the Uninisured Use, And Who Pays For It? Health Affairs - Web Exclusive, (W3), 6678. http://doi.org/10.1377/hlthaff.w3.66

Hadlock, T. et. al. (2008). Multistaged Reconstructive Efforts Via Medical Missions: Keys to Optimizing Outcome. Arch Facial Plast Surg, 10(5), $350-352$.

Heidarian, A. R., Kelarijani, S. E. J., Jamshidi, R., \& Khorshidi, M. (2015). The relationship between demographic characteristics and motivational factors in the employees of social security hospitals in Mazandaran. Caspian Journal of Internal Medicine, 6(3), 170-174.

Helping whom, exactly? (2013). The Economist, (Apr 27-May 3, 2013). Journal Article. 
Hollier, L. H., Sharabi, S. E., Koshy, J. C., Schafer, M. E., O’Young, J., \& Flood, T. W. (2010). Surgical mission (not) impossible--now what? The Journal of Craniofacial Surgery, 21(5), 1488-92. http://doi.org/10.1097/SCS.0b013e3181edc593

Holt, G. R. (2012a). Ethical Conduct of Humanitarian Medical Missions: I. Informed Consent. Arch Facial Plast Surg., 14(3), 215-7.

Holt, G. R. (2012b). Ethical Conduct of Humanitarian Medical Missions II. Use of Photographic Images. Arch Facial Plast Surg, 14(4), 295-6.

Hoover, E. L., Cole-Hoover, G., Berry, P. K., Hoover, E. T., Harris, B., Rageh, D., \& Weaver, W. L. (2005a). Medical volunteers: Guidelines for Success and Safety. Journal of the National Medical Association, 97(1), 85-90.

Hoover, E. L., Cole-Hoover, G., Berry, P. K., Hoover, E. T., Harris, B., Rageh, D., \& Weaver, W. L. (2005b). Private Volunteer Medical Organizations: How Effective Are They? J Natl Med Assoc, 97(2), 270275. Journal Article.

Hsieh, H., \& Shannon, S. (2005). Three approaches to qualitative content analysis. Qualitative Health Research, 15(9), 1277-88. http://doi.org/10.1177/1049732305276687

Im, B. (2016). Weill Cornell Bugando Program. Retrieved from http://weill.cornell.edu/globalhealth/majorinitiatives/weill_cornell_program_in_bugando/ Accessed 26 Jun 2016

Jacobs, A., \& Wilford, R. (2010). Listen First: a pilot system for managing downward accountability in NGOs. Development in Practice, 20(7), 797-811. http://doi.org/10.1080/09614524.2010.508113

Kane, L; Peckham, C. (2014). Medscape Physician Compensation Report: 2014. Retrieved from http://www.medscape.com/features/slideshow/compensation/2014/publ ic/overview Accessed 22 Jul 2015

Kerry, J. (2014). Highlights of the Department of State and U.S. Agency for International Development Budget. Retrieved from http://www.state.gov/r/pa/prs/2013/04/207281.htm Accessed December 31, 2014 
Khan OA, Guerrant R, Sanders J, et al. (2013). Global health education in U.S. medical schools. BMC Med Educ. 2013;13:3., 13(3).

Kickbusch, I. (2002). Influence And Opportunity: Reflections On The U.S. Role In Global Public Health. Health Affairs, 21(6), 131-141. http://doi.org/10.1377/hlthaff.21.6.131

Kightlinger, R. S. (2003, March 21). Practical tips for medical volunteers. Medical Economics. Retrieved from http://www.ncbi.nlm.nih.gov/pubmed/12698627

Kingham, T. P., Price, R. R., Casey, K. M., Rogers, S. O., \& Kushner, A. I. (2011). Beyond volunteerism: augmenting surgical care in resourcelimited settings. Bulletin of the American College of Surgeons, 96(7), 16-21. Retrieved from http://www.ncbi.nlm.nih.gov/pubmed/22315897

Kirch, D. G., Henderson, M. K., \& Dill, M. J. (2012). Physician Workforce Projections in an Era of Health Care Reform. Annual Review of Medicine, 63(1), 435-445. http://doi.org/10.1146/annurev-med-050310134634

Kollock, P. (1998). Social Dilemmas: The Anatomy of Cooperation. Annual Review of Sociology. http://doi.org/10.1146/annurev.soc.24.1.183

Krishnaswami, J. (2010). Exploring health care and medical tourism in a modernizing society: journey in Chennai, India. Perm J, 14(1), 78-89. Journal Article. Retrieved from http://www.ncbi.nlm.nih.gov/pubmed/20740137

Kukanja, M. (2013). Influence of Demographic Characteristics on Employee Motivation in. Hospitality, 19(1), 97-107.

Landau, S. (2001). Do it yourself medical mission. A step-by-step approach. $N C$ Med $J$, 62(3), 140-146. Journal Article. Retrieved from http://www.ncbi.nlm.nih.gov/pubmed/11370316

Lasker, J. N. (2015). Global Health Volunteering; Understanding Organizational Goals. VOLUNTAS: International Journal of Voluntary and Nonprofit Organizations. http://doi.org/10.1007/s11266-015-96614

Lasker, J. N. (2016). Hoping to Help: The Promises and Pitfalls of Global 
Health Volunteering. Cornell University Press, Ithaca, New York.

Lindenmeier, J. (2008). Promoting Volunteerism: Effects of Self-Efficacy, Advertisement-Induced Emotional Arousal, Perceived Costs of Volunteering, and Message Framing. VOLUNTAS: International Journal of Voluntary and Nonprofit Organizations, (19), 43-65. Journal Article.

Lough, B. (2013). International Volunteering from the United States between 2004 and 2012. Center for Social Development, George Warren Brown School of Social Work, Washington University in St. Louis, (13), 1-8.

Lough, B., Mcbride, A. M., \& Sherraden, M. S. (2007). The Estimated Economic Value of a US Volunteer Abroad The Estimated Economic Value of a US. Center for Social Development Working Papers, George Warren Brown School of Social Work, Washington University in St. Louis, (7).

Magee, W. P., Vander Burg, R., \& Hatcher, K. W. (2010). Cleft lip and palate as a cost-effective health care treatment in the developing world. World Journal of Surgery, 34(3), 420-7. http://doi.org/10.1007/s00268-0090333-7

Maki, J., Qualls, M., White, B., Kleefield, S., \& Crone, R. (2008). Health impact assessment and short-term medical missions : A methods study to evaluate quality of care. BMC Health Services Research, 8, 1-8. http://doi.org/10.1186/1472-6963-8-121

Marta, E., Guglielmetti, C., \& Pozzi, M. (2006). Volunteerism During Young Adulthood: An Italian Investigation into Motivational Patterns. VOLUNTAS: International Journal of Voluntary and Nonprofit Organizations. http://doi.org/10.1007/s11266-006-9015-3

Martiniuk, A. L. C., Adunuri, N., Negin, J., Tracey, P., Fontecha, C., \& Caldwell, P. (2012). Primary Care Provision by Volunteer Medical Brigades in Honduras: A Health Record Review of More Than 2,500 Patients Over Three Years. International Journal of Health Services, 42(4), 739-753. http://doi.org/10.2190/HS.42.4.i

Martiniuk, A. L. C., Manouchehrian, M., Negin, J. A., \& Zwi, A. B. (2012). Brain Gains: a literature review of medical missions to low and middleincome countries. BMC Health Services Research, 12, 134. 
Martiniuk, A. L. C., Millar, H. C., Malefoasi, G., Vergeer, P., Garland, T., \& Knight, S. (2008). Cooperation, integration, and long-term commitment: what Solomon Islanders and development workers say about health sector aid. Asia-Pacific Journal of Public Health / Asia-Pacific Academic Consortium for Public Health, 20(4), 287-97. http://doi.org/10.1177/1010539508322251

May, R. (2012). Time to listen. Nursing Management, 19(4), 9-9. http://doi.org/10.7748/nm2012.07.19.4.9.p8699

McGinigle, K. L., Milano, P. M., Rich, P. B., \& Viera, A. J. (2008). Volunteerism among surgeons: an exploration of attitudes and barriers. Am J Surg, 196(2), 300-304. Journal Article. http://doi.org/10.1016/j.amjsurg.2007.10.015

McInnes, C. J. (2004). Looking beyond the national interest: reconstructing the debate on health and foreign policy. The Medical Journal of Australia, 180(4), 168-70. Retrieved from http://www.ncbi.nlm.nih.gov/pubmed/14960137

McQueen, K., \& Magee, W. (2009). Application of outcome measures in international humanitarian aid: comparing indices through retrospective analysis of corrective surgical care cases. Prehospital and ..., 24(1), 3946. Retrieved from http://www.ncbi.nlm.nih.gov/pubmed/19557956

Melby, M. K., Loh, L. C., Evert, J., Prater, C., Lin, H., \& Khan, O. A. (2015). Beyond Medical "Missions" to Impact-Driven Short-Term Experiences in Global Health ( STEGHs ): Ethical Principles to Optimize Community Benefit and Learner Experience. Academic Medicine, XX(X), 1-6. http://doi.org/10.1097/ACM.0000000000001009

Mendoza, R. L. (2009). Public health policy and medical missions in the Philippines: the case of oral--facial clefting. Asia-Pacific Journal of Public Health / Asia-Pacific Academic Consortium for Public Health, 21(1), 94-103. http://doi.org/10.1177/1010539508327028

MGMA Physician Compensation and Production 2013 Report based on 2012 Data. (2013). 
on 2013 Data. (2014).

Mills, A. (2014). Health care systems in low- and middle-income countries. The New England Journal of Medicine, 370(6), 552-7. http://doi.org/10.1056/NEJMra1110897

Mitka, M. (2005). Volunteering overseas gives physicians a measure of adventure and altruism. JAMA: The Journal of the American Medical Association, 294(6), 671-2. http://doi.org/10.1001/jama.294.6.671

Moher D, Liberati A, Tetzlaff J, A. D. (2009). Preferred Reporting Items for Systematic Reviews and Meta-Analyses: The PRISMA Statement. PLoS Medicine, 6(7), 1-6. http://doi.org/10.1371/journal.pmed1000097

Montgomery, L. M. (1993). Short-Term Medical Missions: Enhancing or Eroding Health? Missiology: An International Review, 21(3), 333-341. http://doi.org/10.1177/009182969302100305

Moon, W., Perry, H., \& Baek, R.-M. (2012). Is international volunteer surgery for cleft lip and cleft palate a cost-effective and justifiable intervention? A case study from East Asia. World Journal of Surgery, 36(12), 2819-30. http://doi.org/10.1007/s00268-012-1761-3

Morse, M. (2010). Defining the Future of Academic Medicine Globally: How U.S. Universities Should Step Up to the Plate. Harvard Public Health Review, 5, 1-7.

Mowen, J., \& Sujan, H. (2005). Volunteer behavior: A hierarchical model approach for investigating its trait and functional motive antecedents. Journal of Consumer Psychology, 15, s. 170 - 182. Journal Article.

Moyo, D. (2009). Dead Aid: How Aid is Not Working and How There Is a Better Way for Africa. New York: Farrar, Strauss and Giroux.

Norton, S. A. (1999). The dermatologist's Baedeker. Preparation for medical assistance missions. Dermatologic Clinics, 17(1), 187-208, ix-x. Retrieved from http://www.ncbi.nlm.nih.gov/pubmed/9987003

Nouvet, E., Chan, E., \& Schwartz. (2015). Perspectivas de los beneficiarios sobre el desempeño de las brigadas de atención médica Humanitaria en Nicaragüa : El estudio BPREP nicaragüense . Un estudio cualitativo con el apoyo del Consorcio de Investigación Ética en la Atención Médica 
Humanitaria A, 1-51.

Nouvet, E., Chan, E., \& Schwartz, L. (2015). BPREP: Beneficiary perspectives on the performance of humanitarian healthcare missions in Nicaragua. (H. H. E. R. G. (HHERG), Ed.).

Nunes, P. A. L. D., \& Onofri, L. (2004). The Economics of Warm Glow: A Note on Consumer's Behaviour and Public Policy Implications. FEEM Working Paper No. 113.04. Manuscript.

Nunes, P. A. L. D., \& Schokkaert, E. (2003). Identifying the warm glow effect in contingent valuation. Journal of Environmental Economics and Management, 45(2), 231-245. Journal Article. http://doi.org/10.1016/s0095-0696(02)00051-7

Nye, J. S. (2011). The future of power (1st ed.). Book, New York: PublicAffairs.

Orbinski, J. (1999). Medecins Sans Frontieres - Nobel Lecture. Oslo: The Nobel Foundation. http://doi.org/Nobelprize.org. Nobel Media AB 2014

Otterson, O. P., \& McNeill, D. (2014). The Political Determinants of Health. Equilibri. Retrieved from http://www.equilibri.net/nuovo/articolo/political-determinants-health Accessed December 6, 2014

Oxfam. (2014). Foreign Aid 101: A Quick and Easy Guide to Understanding US Foreign Aid. Retrieved from www.oxfamamerica.org_static_media_files_Foreign-Aid-101Mar2014-single-Oxfam-America Accessed 01 August 2015

Patel, A., Sawh-Martinez, R. F., Sinha, I., Watkins, J. F., Magee, W. P., \& Persing, J. a. (2013). Establishing sustainable international burn missions: lessons from India. Annals of Plastic Surgery, 71(1), 31-3. http://doi.org/10.1097/SAP.0b013e3182898cd5

Peckham, C. (2012). Medscape Physician Lifestyle Report 2012. Retrieved July 22, 2015, from http://www.medscape.com/features/slideshow/lifestyle/2012/public

Peckham, C. (2013). Medscape Physician Lifestyle Report 2013. Retrieved July 22 , 2015, from 
http://www.medscape.com/features/slideshow/lifestyle/2013/public\#11

Peckham, C. (2014). Medscape Physician Lifestyle Report 2014. Retrieved July 22, 2015, from http://www.medscape.com/features/slideshow/lifestyle/2014/public/ove rview\#12

Peckham, C. (2015). Medscape Physician Lifestyle Report 2015. Retrieved April 19, 2015, from http://www.medscape.com/features/slideshow/lifestyle/2015/public/ove rview\#9

Peters, D. H., Garg, A., Bloom, G., Walker, D. G., Brieger, W. R., \& Hafizur Rahman, M. (2008). Poverty and access to health care in developing countries. Annals of the New York Academy of Sciences, 1136, 161-171. http://doi.org/10.1196/annals.1425.011

Pezzella, A. T. (2006). Volunteerism and humanitarian efforts in surgery. Curr Probl Surg, 43(12), 848-929. Journal Article. http://doi.org/10.1067/j.cpsurg.2006.09.002

Politis, G. D., Schneider, W. J., Van Beek, A. L., Gosain, A., Migliori, M. R., Gregory, G. a, ... Flick, R. (2011). Guidelines for pediatric perioperative care during short-term plastic reconstructive surgical projects in less developed nations. Anesthesia and Analgesia, 112(1), 183-90. http://doi.org/10.1213/ANE.0b013e3181fdfab7

Prepared by IDRH platform. (2015). MSF Human Resources Indicators 2014 - Report to the International General Assembly.

Propsner, N. M. (1998). Medical volunteers make global impact. New Jersey Medicine: The Journal of the Medical Society of New Jersey, 95(11), 22-5. Retrieved from http://www.ncbi.nlm.nih.gov/pubmed/16013124

Ramirez-Fort, M. (2013). Organizing a dermatology service mission. International Journal of Dermatology, 52, 342-349. Retrieved from http://onlinelibrary.wiley.com/doi/10.1111/j.13654632.2012.05750.x/full

Rivero, J. (1996). Cuban doctors in Africa. The Lancet, 348, 1996.

Roberts, M. (2006). Duffle Bag Medicine. JAMA, 295(13), 1491-1492. 
Rose-Ackerman, S. (1996). Altruism, non-profits and economic theory. Journal of Economic Literature, 34(2), 701-728.

Roy, K., \& Ziemek, S. (2000). On the Economics of Volunteering. ZEF Bonn, (August).

Schneider, W. J., Migliori, M. R., Gosain, A. K., Gregory, G., \& Flick, R. (2011). Volunteers in plastic surgery guidelines for providing surgical care for children in the less developed world: part II. Ethical considerations. Plastic and Reconstructive Surgery, 128(3), 216e-222e. http://doi.org/10.1097/PRS.0b013e31822213b4

Schneider, W. J., Politis, G. D., Gosain, A. K., Migliori, M. R., Cullington, J. R., Peterson, E. L., ... Van Beek, A. L. (2011). Volunteers in plastic surgery guidelines for providing surgical care for children in the less developed world. Plastic and Reconstructive Surgery, 127(6), 2477-86. http://doi.org/10.1097/PRS.0b013e3182131d2a

Shanafelt, T. D., Hasan, O., Dyrbye, L. N., Sinsky, C., Satele, D., Sloan, J., \& West, C. P. (2015). Changes in Burnout and Satisfaction With WorkLife Balance in Physicians and the General US Working Population Between 2011 and 2014. Mayo Clinic Proceedings, 90(12), 1600-1613. http://doi.org/10.1016/j.mayocp.2015.08.023

Shenton, A. (2004). Strategies for ensuring trustworthiness in qualitative research projects. Education for Information, 22, 63-75. http://doi.org/10.1111/j.1744-618X.2000.tb00391.x

Sheth, J. (2016). Demographics in Consumer Behavior; Dissatisfaction with Models in Economics and Sociology, 1-10. Retrieved from file://C:/Users/user/Desktop/Demographics in Consumer Behavior _ Jagdish Sheth.html Accessed 26 Jun 2016

Shrime, M. G., Sleemi, A., \& Ravilla, T. D. (2014). Charitable Platforms in Global Surgery: A Systematic Review of their Effectiveness, CostEffectiveness, Sustainability, and Role Training. World J Surg. http://doi.org/10.1007/s00268-014-2516-0

Siméant, J. (2001). Entrer, rester en humanitaire : des fondateurs de msf aux membres actuels des ong médicales françaises. CAIRN.INFO Presses de Sciences

Po

(P.F.N.S.P.),

51(1),

47-72. http://doi.org/10.3917/rfsp.511.0047 
Sims, C., West, B., \& Lujan, F. (2012). Both Sides of the COIN - Defining War After Afghanistan. Foreign Affairs, January/Fe. Electronic Article. Retrieved from http://www.foreignaffairs.com/articles/136960/christopher-simsfernando-lujan-and-bing-west/both-sides-of-the-coin>.

Smith, J. P. (1999). Healthy bodies and thick wallets: the dual relation between health and economic status. The Journal of Economic Perspectives: A Journal of the American Economic Association, 13(2), 144-66. http://doi.org/10.1257/jep.13.2.145

Snilstveit, B., Oliver, S., \& Vojtkova, M. (2012). Narrative approaches to systematic review and synthesis of evidence for international development policy and practice. Journal of Development Effectiveness, 4(3), 409-429. http://doi.org/10.1080/19439342.2012.710641

Suchdev, P., Ahrens, K., \& Click, E. (2007). A model for sustainable shortterm international medical trips. Ambulatory Pediatrics, 7(4), 317-320. Retrieved from http://www.sciencedirect.com/science/article/pii/S1530156707000597

Sykes, K. J. (2014). Short-Term Medical Service Trips: A Systematic Review of the Evidence. American Journal of Public Health, 1-11. http://doi.org/10.2105/AJPH.2014.301983

Sykes, K. J., Le, P. T., Sale, K. A., \& Nicklaus, P. J. (2012). A 7-year review of the safety of tonsillectomy during short-term medical mission trips. Otolaryngology--Head and Neck Surgery : Official Journal of American Academy of Otolaryngology-Head and Neck Surgery, 146(5), 752-6. http://doi.org/10.1177/0194599812437317

Unger, L. S. (1991). Altruism as a motivation to volunteer. . Journal of Economic Psychology, 12(1), 71-100. Journal Article. http://doi.org/10.1016/0167-4870(91)90044-T

Van Tilburg, C. S. (1995). Attitudes toward medical aid to developing countries. Wilderness Environ Med, 6(3), 264-268. Journal Article. Retrieved from http://linkinghub.elsevier.com/retrieve/pii/S1080603295710626?showa $11=$ true

Vyas, R. M., Eberlin, K. R., \& Hamdan, U. S. (2013). Implementation of an 
emergency response protocol for overseas surgical outreach initiatives. Plastic and Reconstructive Surgery, 131(4), 631e-6e. http://doi.org/10.1097/PRS.0b013e3182827776

Wallace., L. J. (2012). Does Pre-Medical "Voluntourism" Improve the Health of Communities Abroad? Journal of Global Health Perspectives., $\operatorname{Aug}(1)$.

Welling, D., Ryan, J., Burris, D., \& Rich, N. (2010). Seven sins of humanitarian medicine. World Journal of Surgery, 34(3), 466-70. http://doi.org/10.1007/s00268-009-0373-z

Wilensky, H. L. (1964). The Professionalization of Everyone? American Journal of Sociology, 70(2), 137. http://doi.org/10.1086/223790

Withers, M., Browner, C. H., \& Aghaloo, T. (2013). Promoting volunteerism in global health: lessons from a medical mission in northern Mexico. $J$ Community Health, 38(2), 374-384. Journal Article. http://doi.org/10.1007/s10900-012-9627-z

Wolfberg, A. J. (2006). Volunteering overseas--lessons from surgical brigades. The New England Journal of Medicine, 354(5), 443-5. http://doi.org/10.1056/NEJMp058220

World Health Organization. (2015). Global Health Emergency WorkforceReport by the Director General. In Sixty-Eighth World Health Assembly (pp. 1-11). Retrieved from http://apps.who.int/gb/ebwha/pdf_files/WHA68/A68_27-en.pdf Accessed 30 Apr 2016

Yeow, V. K. L., Lee, S.-T. T., Lambrecht, T. J., Barnett, J., Gorney, M., Hardjowasito, W., ... Wilson, L. (2002). International Task Force on Volunteer Cleft Missions. The Journal of Craniofacial Surgery, 13(1), 18-25. Retrieved from http://www.ncbi.nlm.nih.gov/pubmed/11886986

Ziemek, S. (2003). Economic Theories on Motivations for Vounteering - A Cross-Country Analysis. Center for Development Research (ZEF Bonn) Working paper.

Ziemek, S. (2006). Economic analysis of volunteers ' motivations - A crosscountry study. Journal of Socio-Economics, 35, 532-555. http://doi.org/10.1016/j.socec.2005.11.064 


\section{Appendices}

\section{Appendix A: Physicians' Giving Back Survey}

Cover email:

Physicians “Giving Back” Survey

Americans are generous people and that includes American doctors. Physicians often give their free time for teaching and supporting causes and organizations. Some US physicians provide free ("pro-bono") medical care to the needy domestically and/or go to developing countries to care for the poor. Such activities go beyond other cash donations to charities.

This instrument is designed to gather information on physician preference in choices of pro-bono activities, their prevalence and a few details on some activities. The research is part of a PhD dissertation with the University of Maastricht Graduate School of Governance/UNU-MERIT. As a physician, however you express your generosity, your anonymous response to the survey is critical to the analysis. Completion should take 2-15 minutes depending on your experiences.

For each 500 responses completed, $\$ 1000$ will be donated to Doctors Without Borders, Habitat for Humanity or Grameen Foundation USA (in rotating order). Help drive the numbers!

You may also request to receive the data compilation and analysis at the completion of the project.

Paul H. Caldron, DO, FACP, FACR, MBA

4550 E. Bell Rd, Suite 172

Phoenix, Arizona 85032 USA

pcaldron@global.t-bird.edu 


\section{Physicians Giving Back Survey}

*1. I am a physician (MD/DO) who resides (resided) and practice (practiced) principally in the US and have completed my general and specialty training: (If you are still in clinical or supervised training, please answer "No".)

$C$ Yes

C No 


\section{Physicians Giving Back Survey}

*2. My professional volunteerism and giving activity since finishing all my training has been expressed in the following ways (please check all that apply):

$\Gamma$ There is a system in my practice to accommodate those who have limited means to pay

$\Gamma$ Pro-bono teaching to medical personnel

$\Gamma$ Monetary or donations-in-kind to causes and/or organizations

Dro-bono medical care in local / domestic clinics or outreaches (sports physicals, kids' camps, etc.)

$\Gamma$ Pro-bono medical care in developing countries (short-term medical missions)

$\Gamma \mathrm{I}$ am not yet in a position to participate in any volunteer or giving activities

$\Gamma$ Time devoted to the organized activities of patient support organizations (Arthritis Foundation, Cancer Society, etc.)

No activities so far since I have been in medical practice

$\Gamma$ I choose not to participate in any such activities

Other (please specify)

3. My pro-bono (unpaid) teaching activities since I have been in practice have included the following settings (please check all that apply):

$\Gamma$ None

$\Gamma$ Medical students, residents, fellows, nurses or ancillary service persons in an office setting

Medical students, residents, fellows, nurses or ancillary service persons in a hospital setting

$\Gamma$ Health - related teaching to civic organizations or general public

Health - related teaching to public or private schools 


\section{Physicians Giving Back Survey}

4. In my individual practice, the estimated annual amount of money that is intentionally left uncollected from persons with limited means to pay (highest year estimate) is:

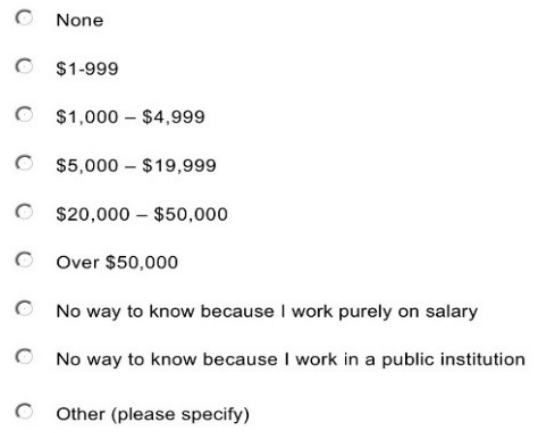

5. My pro-bono local / domestic medical services have included (please check all that apply):

ГNone

$\Gamma$ Local free / sliding scale clinic after my usual practice hours

$\lceil$ Non- paid screening physicals, team or group doctor for schools or other organizations

$\Gamma$ Local / domestic disaster response wherein I provide free medical services

ГDomestic short-term mission work for which I must schedule time away from my practice

○ther domestic pro-bono medical services

* 6. My pro-bono participation in a short-term medical mission in a developing country has been:
None
One time
More than once 


\section{Physicians Giving Back Survey}

* 7. I have not participated in a short-term mission abroad because of (check all that apply):

My own physical or social limitations

$\Gamma$ Cost

Г Belief that the activity is potentially harmful

ГNever considered

$\Gamma$ No interest

Belief that the activity is not cost effective

- My specialty is not suitable for remote, low-technology environments

$\lceil$ I previously participated in full-time medical mission work abroad

Г Belief that the activity is ineffective

$\Gamma$ Other 


\section{Physicians Giving Back Survey}

Where in the US were you living at the time of the short-term medical mission?

*8. State:

$\checkmark$

\section{City/town population:}

*10. What was your practice situation at the time of the mission?

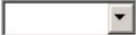

*11. How many years had you been in practice at the time of the mission? 工

*12. In what country was your mission?

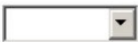

*13. In what year was your mission?

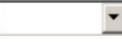

*14. How long was your mission (number of days away)?

$\rightarrow$

*15. Your age at time of mission:

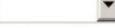

*16. What was your civil status at the time of the mission?

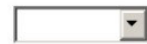

17. If you had children (biologic and/or adopted), how many were living at home at the time of the mission?

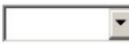

*18. What was the focus of the mission's medical service?

C Medical only

C General Surgical

Specialty Surgical

C Mixed Medical and Surgical

Other (please specify) 


\section{Physicians Giving Back Survey}

Mission Expenses: Most short-term medical mission organizers require that physician participants pay a fee that covers mission costs including lodging, meals, ground transportation and support for mission staff, supplies and other fees. Individuals must usually arrange and cover their own air travel to the receiving country. Further, some physicians and surgeons donate supplies, equipment, implantable devices or hardware, etc. at their own personal expense.

To the best of your immediate recollection, for your mission, your expenses were:

*19. Airfare:

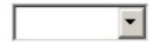

\section{*20. Mission organization fees paid:}

*21. Additional personal expenses for donated supplies, equipment, implantable devices or hardware, etc.: (Provide your best immediate estimate.)

Now, please consider the time you were away from your practice for the mission and your stated income range at the time of the mission. Estimate the total earnings that you could have earned if you had not gone on the mission (taxable income as well as retirement funding or other deferments):

*22. What were the total earnings you could have earned? (Provide your best immediate estimate.)

*23. What percentage of your medical mission total expenses was deductible from your Federal taxable income?

C $100 \%$

Other \% (please specify)

*24. In the year you went on your short-term medical mission to a developing country, what was your total annual income as reported on your Federal Tax return in the calendar year prior to the mission? (Provide your best immediate estimate.) 


\section{Physicians Giving Back Survey}

25. Would you consider going on additional short-term medical missions?

$\circ$ Yes

No 


\section{Physicians Giving Back Survey}

\section{If you answered "No", why not? (please check all that apply)}

Cost is prohibitive

$\lceil$ I sacrificed too much income going on the mission

$\lceil$ My own physical or social limitations

$\lceil$ My specialty is not suitable for remote, low-technology environments

Г Too much time away from spouse and/or family

$\lceil$ Belief that the activity is not cost effective

Г Belief that the activity is potentially harmful

C Belief that the activity is ineffective

$\Gamma$ Other 


\section{Physicians Giving Back Survey}

*27. Number of short-term medical missions

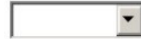

*28. Please enter information about your missions:
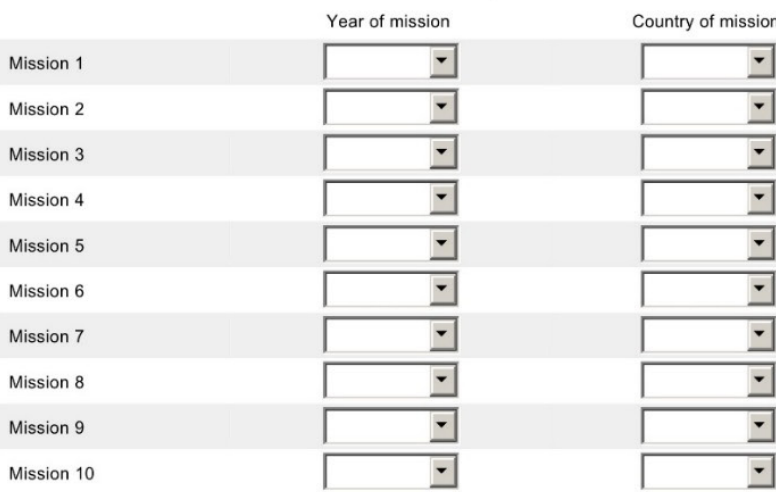

Number of days on mission

29. If you've been on more than $\mathbf{1 0}$ medical missions, please enter additional information in the box.

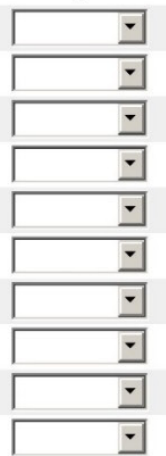




\section{Physicians Giving Back Survey}

Where in the US were you living at the time of your FIRST short-term medical mission?

*30. State:

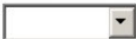

31. City/town population:

$\square$

*32. What was your practice situation at the time of the FIRST mission?

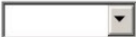

* 33. How many years had you been in practice at the time of the FIRST mission?

*34. Your age at time of FIRST mission:

$\nabla$

* 35. What was your civil status at the time of the FIRST mission?

36. If you had children (biologic and/or adopted), how many were living at home at the time of the FIRST mission?

I

* 37. What was the focus of the FIRST mission's medical service?

C Medical only

C General Surgical

Specialty Surgical

C Mixed Medical and Surgical

Other (please specify) 


\section{Physicians Giving Back Survey}

Mission Expenses: Most short-term medical mission organizers require that physician participants pay a fee that covers mission costs including lodging, meals, ground transportation and support for mission staff, supplies and other fees. Individuals must usually arrange and cover their own air travel to the receiving country. Further, some physicians and surgeons donate supplies, equipment, implantable devices or hardware, etc. at their own personal expense.

To the best of your immediate recollection, for your FIRST mission, your expenses were:

\section{*38. FIRST medical mission airfare:}<smiles>[CH]C1CC1</smiles>

\section{*39. FIRST medical mission organization fees paid:}

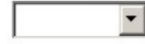

\section{* 40. FIRST medical mission additional personal expenses for donated supplies,} equipment, implantable devices or hardware, etc.: (Provide your best immediate estimate.)

Now, please consider the time you were away from your practice for your FIRST mission and your stated income range at the time of the mission. Estimate the total earnings that you could have earned if you had not gone on the mission (taxable income as well as retirement funding or other deferments):

* 41. What were the total earnings you could have earned? (Provide your best immediate estimate.)

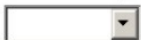

* 42. What percentage of your FIRST medical mission total expenses was deductible from your Federal taxable income?

C $100 \%$

Other \% (please specify)

* 43. In the year you went on your FIRST short-term medical mission to a developing country, what was your total annual income as reported on your Federal Tax return in the calendar year prior to the FIRST mission? (Provide your best immediate estimate.) 


\section{Physicians Giving Back Survey}

Where in the US were you living at the time of your MOST RECENT short-term medical mission?

*44. State:

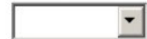

45. City/town population:

$\square$

* 46. What was your practice situation at the time of the MOST RECENT mission?

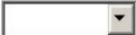

* 47. How many years had you been in practice at the time of the MOST RECENT mission?

* 48. Your age at time of MOST RECENT mission:

* 49. What was your civil status at the time of the MOST RECENT mission?

\section{-}

50. If you had children (biologic and/or adopted), how many were living at home at the time of the MOST RECENT mission?

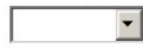

* 51. What was the focus of the MOST RECENT mission's medical service?

C Medical only

General Surgical

Specialty Surgical

C Mixed Medical and Surgical

Other (please specify) 


\section{Physicians Giving Back Survey}

Mission Expenses: Most short-term medical mission organizers require that physician participants pay a fee that covers mission costs including lodging, meals, ground transportation and support for mission staff, supplies and other fees. Individuals must usually arrange and cover their own air travel to the receiving country. Further, some physicians and surgeons donate supplies, equipment, implantable devices or hardware, etc. at their own personal expense.

To the best of your immediate recollection, for your MOST RECENT mission, the expenses were:

*52. MOST RECENT medical mission airfare:<smiles>[CH]C=[CH]</smiles>

*53. MOST RECENT medical mission organization fees paid:

*54. MOST RECENT medical mission additional personal expenses for donated supplies, equipment, implantable devices or hardware, etc.: (Provide your best immediate estimate.) $\square$

Now, please consider the time you were away from your practice for your MOST RECENT mission and your stated income range at the time of the mission. Estimate the total earnings that you could have earned if you had not gone on the mission (taxable income as well as retirement funding or other deferments):

* 55. What were the total earnings you could have earned? (Provide your best immediate estimate.)

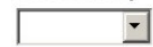

* 56. What percentage of your MOST RECENT medical mission total expenses was deductible from your Federal taxable income?

( $100 \%$

Other \% (please specify)

* 57. In the year you went on your MOST RECENT short-term medical mission to a developing country, what was your total annual income as reported on your Federal Tax return in the calendar year prior to the MOST RECENT mission? (Provide your best immediate estimate.) 


\section{Physicians Giving Back Survey}

*58. In what year were you born?

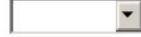

*59. What is your gender?

C Female

C Male

60. Are you of Hispanic, Latino or Spanish origin?

C Yes

No

61. What is your race? For purposes of this question, persons of Spanish/Hispanic/Latino origin may be any race.

White

B Black or African American

American Indian or Alaska Native

Asian

Native Hawaiian or other Pacific Islander

Other (please specify)

*62. How many years have you been in practice?<smiles>[CH-]C</smiles>

*63. What is your principal practice specialty?

*64. Were you born in the USA?

0 Yes

C No

65. If not in the USA, in what country were you born?

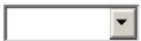




\section{Physicians Giving Back Survey}

*66. Did you attend medical school in the USA?

C Yes

○ No

67. If not in the USA, in what country did you attend medical school? $\square$

*68. Did you do most of your postgraduate training (internship, residency, fellowship) in the USA?

C Yes

○ No

69. If not in USA, in what country did you do most of your post graduate training? $\nabla$

*70. What is your medical degree?

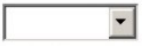




\section{Physicians Giving Back Survey}

71. What is your current civil status?

$\rightarrow$

*72. The total number of children (biologic and/or adopted) you have now is:

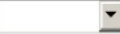

73. What is your religious affiliation?

$\rightarrow$

Where in the US do you live now?

*74. State:

75. City/town population:

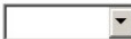

* 76. What is your current practice situation?

77. What is the highest annual income you ever reported on your Federal tax return? (Provide your best immediate estimate.) 


\section{Physicians Giving Back Survey}

Thank you so much for taking the time to complete this survey and assisting in my research on physician volunteerism. Your input is invaluable in the further understanding and description of this activity.

To request the data compilation and analysis at the completion of the project, please contact me at pcaldron@global.t-bird.edu. You may also contact me at this email if you have questions or wish to share related information.

Thank you,

Dr. Paul H. Caldron

4550 E. Bell Rd, Suite 172

Phoenix, Arizona 85032 USA

pcaldron@global.t-bird.edu 


\section{Appendix B Interview Guide for Physician Experts on STMMs}

Study Title: Narratives of physician volunteers on motivations for participation in short-term medical missions abroad.

Introduction: The following explanation of the objective of the research, that is, to better understand the motivations of physicians to participate in shortterm medical missions (STMMs). Define parameters of STMM being studied and ascertain that we are talking about the same activity:

"Short-term medical missions refer to the activity whereby physicians who are gainfully engaged in medical or surgical practice in their home countries spend short periods away, typically from one day to three months, in lower and middle income countries, without pay, to provide services directly to the ostensibly poor. Such "missions" are planned and are distinguished from ad hoc responses to domestic or external disasters, compensated full-time relief practice such as MSF, military and other governmental relief expeditions and residency training programs."

Expected interview time: 30-60 minutes.

Questionnaire for inclusion and exclusion criteria

Inclusion criteria:

1. Subject is a physician with the degree MD or DO who is or has been gainfully employed in the practice of medicine in the US with a federal or state license issued in the US.

2. During the time when gainfully employed in the practice of medicine in the US, the subject has participated in two or more short-term medical missions (STMMs) from the US to lower or middle income countries as defined in the introduction. (Direct patient care contact.)

3. Subject had completed all general and specialty medical training by the time of the qualifying two or more STMMs. (Having participated in other medical trips abroad while in training or otherwise does not exclude subject from participation in the study as long as two STMMs have been attended after completion of all general and specialty training.)

4. The subject's most recent STMM participation has occurred within the 5 calendar years (2010 forward) prior to the interview. 
5. Subject agrees to participate in the study interview voluntarily and may do so without coercion, duress or requirement to participate by an employer, supervisor, colleague, organization or any other person or entity.

6. Subject is agreeable to providing up to an hour of time, continuously or in parts, for the interview.

Exclusion criteria:

1. Non MD or DO clinicians including dentists, chiropractors, naturopathic physicians, nurses or nurse practitioners or physician assistants. (Subjects who obtained MD-equivalent degree in other countries and were subsequently licensed to practice in the US and meet other inclusion criteria are not excluded.)

2. No STMM participation in the past 5 calendar years (2010 forward).

3. Physician has been monetarily compensated for participation in the medical care delivered abroad on the two minimum qualifying STMMs.

4. The STMM participation did not include direct care of patients, but rather included purely training exercises or interactions, public health ventures, evangelistic, social, intergovernmental, or construction activities. (Such nondirect patient care activities do not constitute an exclusion if they occurred proximately to or concomitantly with the direct care activity.)

5. Subject is considered physically or emotionally unable to complete the interview process.

\section{$\underline{\text { Script for Study Informed Verbal Consent }}$}

You are invited to participate in a research study on short term medical missions (STMMS) conducted by Drs. Ann Impens from Midwestern University (Downers Grove, IL) and Paul Caldron (private practice, Phoenix, Arizona). The objective is this study is to gather narratives from experts, that is, physicians who have participated in more than one STMM, in order to develop an understanding of their motivation to participate in this form of benevolent work. The importance of this study is relevant not only to academic research on STMMs, but may also contribute to understanding of motivation and may affect future policy recommendations. The results of the study are intended for publication in peer reviewed medical or social science journal. 
You are asked to participate in an interview lasting an estimated 30-60 minutes. The interview is conducted by Dr. Paul Caldron. The interview will be recorded and transcribed for further analysis both manually and utilizing NVivo, a software program to assist in analysis of narrative qualitative research. Your identity will remain confidential to the study team. You will be given a study ID number and this number will be used in the transcriptions, analyses, and reporting. Your comments may be collated with the responses of other participants, may be paraphrased or quoted verbatim in reporting of the analysis of the interviews. At no time will comments be directly attributed to any Study Participant in the reporting of the analysis of the results.

There is no direct benefit to you from your participation. You may benefit indirectly by being able to contribute to the base of knowledge on the subject of short-term medical missions and influencing forward thought, policy recommendations and future research.

Although every effort will be made by the investigators to protect your identity, there is a very small risk that your identity and comments could become known to others.

By consenting to proceed with the interview, you acknowledge that you understand the foregoing information about this research study and hereby consent to participate by undergoing an interview about your participation in short-term medical missions and aspects of motivation. You understand that you may withdraw my consent at any time during the interview process and if you do withdraw, none of your comments will be included in the study analysis. You understand that your identity will remain confidential and protected by the study team except to another Study Participant who may have referred you to this study.

Do you, (state name), understand this explanation and agree to proceed with the interview? Yes No

Demographic information: Name State , Specialty , Age , civil status , City children , years in practice , practice situation , number of of missions most recent STMM medical mixed, other) , country(ies) of missions: , type of missions (surgical, 
Let me make a request before we move forward. As you know the decisions we make in any number of circumstances are usually the result of very personal calculations of any number of factors. In this confidential interview where your identity is protected and responses will not be linked to you, let me ask you to put aside any preconceived notions of what you think society would expect of your responses and be as candid as you can about your thoughts.

For many of the 12 question areas, I will provide some orienting comments and then ask for your perspectives. For some physicians, some of these questions may seem to "come from left field", but each question area has a basis from some external viewpoint of STMM activity. In a number of questions, I will want to get your answer as the issue affects you and then how you feel it relates to STMM participants in general.

If we experience a slowdown in Skype transmission, I will turn off my camera, which usually helps to smooth the transmission. You will then see my still photo.

Question areas:

Introduction to STMMs: How were you introduced to doing STMMs? Seek them out? Introduced by a friend? From a presentation at a meeting? Previous exposure in medical school or post-graduate training?

Key Drivers to participate: I'm going to be asking you several questions intended to help us gain an understanding of the influence of several concepts of volunteering and foreign aid, if any, on your motivation to participate in STMMs. Before getting into these questions, let me ask you to express, a priori,

What would you say is the key driver in your motivation to do STMMs?

Many opportunities are available to physicians for charitable work or giving (teaching, free clinic, team physicals, non-medical volunteering, organizations, church, food bank).

Among other opportunities for giving or pro-bono work, why did you chose STMMs? 
Country and organization selection:

How did you select the country (ies) that you visited on STMMs?

How did you select the organization(s) with which you worked?

Professionalism and professionalization: Review of the literature suggests that professionalization in STMMs (formation of national organization, regular publication, general standards and policies, specific training efforts, memberships, certifications) appears underdeveloped, though elements of professionalization such as guidelines, codified instructions and implementation of cost benefit analysis are accumulating in individual reports. Let me first ask you about professionalism, then professionalization:

How would you describe the level of professionalism among physicians that participate in STMMs from your experience?

Compare standards of care observed on STMMS to the standards of care in US?

So far, there appears to be no overarching professionalization of STMM activity, i.e., a national or international organization with an ongoing journal, national meetings, and development of guidelines, certifications or policies. Such an organization could serve as a platform for quality enhancement, but may run the risk of increasing the regulatory burden on physicians. Imagine an organization that would promote participant development in terms of cultural and geopolitical awareness, relative need and best practices.

How would you feel about such an organization and how do you think it would (or would not) be helpful?

Economic aspects: Analysis of a recent survey suggested that there is about 3 billion dollars expended annually for STMMs from the US. This calculation included direct costs of physicians (avg. \$1862 per STMM) and staff as well as the opportunity costs of physicians (avg. \$7791 per STMM) (avg. total $\$ 11,606$ per STMM). The average time on a mission was 11.8 days. It was calculated that the accumulated hours US physicians spent on STMMs in 2012 equated with 4600 FTEs. The direct expenses from STMMs are tax deductible. 
How important are the direct costs to you? What are the chances the direct costs would be high enough to deter you from participating?

How important is opportunity costs, i.e., the income not earned because you are away?

The direct costs are tax deductible. How influential do you think that is in a physician's decision to go or not? If the direct costs were not deductible, how would that affect the decision to go? Do you think the tax structure is influential in your own decision to participate?

What do you do, typically, if anything, to put a clear demarcation between your business activity and pro-bono activity?

Diplomatic aspects: Diplomatic "soft power": Much is written in the diplomatic literature in recent years about the social perception and social persuasion elements of soft power. Many countries provide monetary and technical support for healthcare to LMICs. Regarding direct medical care, a few overt examples can be found wherein there is an intent to export medical care for soft power objectives: Cuba (long term medical missions) and Taiwan (STMMs).

How does the potential for conveying positive (or negative) impressions of America enter into one's decision to participate or actions while on the STMM?

What importance would you place on the level of cross-cultural acumen and awareness of the implications of soft power on the part of participating physicians and their support teams?

Attitudes towards foreign aid: STMMs constitute a form of grassroots, private foreign aid. You may be aware of the controversy within the donor community about the effectiveness and potential harm of traditional foreign aid methodologies.

Can you describe any effects that your STMM experience has had on your view of foreign aid?

How has your experience affected the attitudes of others in your family or circle of friends or social network on the issue of foreign aid? 
What thoughts do you have about how STMM activity fits into the realm of foreign aid?

Faith, Oath, other core value systems: Analysis of a recent survey failed to show a significant influence of religion on the propensity to participate in STMMs.

How does that fit with your impressions of the role of religion in physician motivation to participate in STMMs?

Would you say that your decision to participate is influenced more by religious faith, by medical oath or some other core set of values?

In some faiths, the concepts of "redemption" and "salvation" suggest that one must pay dues for their own failures to be right in the eyes of God and that that may be achieved by helping others.

What role do you think the theological viewpoint of redemption and salvation might play for rich nation doctors to give of their skills to "the poorest of the poor" overseas?

Please tell me about any characteristics of your family or any personal experiences or exposures that occurred while growing up that may have predisposed your participation in STMMs.

Theoretical models: Prominent theoretic models for philanthropy and volunteering in recent years have included the following:

a. Public goods, wherein the benefit objective is altruistic, i.e., to increase the supply of the public good,

b. Private consumption, wherein the benefit objective is found in the utility of "warm glow", self-value, and joy from the act of volunteering or philanthropy, and

c. Investment Exchange, wherein the benefit sought by the giver is experience, personal market value, skills, and contacts.

While one's motivation to perform any philanthropic work may include a blend of these aspects, which would you say best characterizes your motivation specifically to participate in STMMs? 
Transactional analysis: Transactional analysis and study of other market dynamics is lacking in the literature on STMMs; the enlightened self-interest of the parties in the exchange, a universal motivator, is not openly explored. In most encounters and relationships, there is some form of exchange between parties, otherwise they do not come together. Both marketplace and interpersonal transactions are grounded in either explicit or implied contracts. The nature of contracts provides that individual parties mutually benefit in their own way.

How would you characterize the transaction between STMM physicians and recipients of care?

How would you put that into an equation? For example, a patient may travel a distance on foot or by bus, leave behind work, etc. Doctor has costs of travel, organizational fees, equipment costs, leaves work behind, etc. Patient gets diagnosis, medicine or procedure out of the transaction; what does physician get?

How is that different from an encounter with a recipient of care in your practice at home?

Personal reflections: Whether this form of aid is effective or not, data from a recent survey indicates that participation rates seem to be increasing especially in the new millennium. There are gaps in our understanding how this grassroots form of aid attracts physicians and why doctors are willing to expend so much time and cash to do this despite lack of measurable evidence of effectiveness as yet on the economic or health status of the recipient countries or relationships with countries. We are trying to understand its appeal. It is reasonable to assume that the attraction to STMM activity has a highly personal element. As one author put it, "In the context of the face-toface interactions occurring in pro-bono medical missions, the intangible reward system may indeed be layers more complex, more habit-forming and compelling than other forms of philanthropy and begs to be better understood."

Please take a moment to picture yourself back in a face-to-face moment with a patient during an STMM. From the best of your recollection, please describe what your thoughts are and what are your feelings when having an individual face-to-face encounter with a recipient of your care while on an STMM? 
How is that different from an encounter with a recipient of care in your practice at home?

Are there any other thoughts you can share that may convey a better understanding of STMM activity, motivation to participation and value?

(Optional, if time allows) Viewpoint of the receiver side: There are concerns expressed in the literature about potential adverse effects of STMMs on local populations, i.e., crowding out or undermining local physicians, creating dependency on foreign medical teams, deflecting local healthcare investment by authorities, inadequate follow-up, etc.

What is your perception of the receiver side of the equation? Are STMMs welcomed and valued by the people, local physicians, and local health authorities?

How has that perception influenced your participation? 


\section{Summary}

Short-term medical missions (STMMs) refers to a grassroots form of transnational aid wherein physicians who are gainfully employed in wealthy countries travel to low- and middle-income countries (LMICs) to provide direct medical care to the poor who have limited or no access to medical services. An impression has been conveyed in related literature that this activity is increasing, although data to support the impression of growth is not found. Based upon a prior literature review, the United States (US) leads among the four countries that most commonly source these deployments, along with Canada, the United Kingdom, and Australia. These trips are distinguished from other humanitarian medical efforts by several features: (a) they are planned in advance rather than as a response to natural disasters, famine or conflict; (b) they are short term, lasting a day to a few weeks; (c) the physicians involved are not compensated monetarily for the work.

STMMs are not regulated by any agency of the US government, nor a dedicated professional society. The meager but growing body of literature that provide evidence concerning the practice describes positive elements of the therapeutic output of these trips, guidelines and comparisons of organizational models, as well as potential negative externalities that may include, among others, inadequate follow-up of medical or surgical care, the risk of physicians providing treatments outside their training and skillset, crowding out the efforts of local physicians, and creating dependency on these traveling teams by dampening investment in local healthcare services by host country authorities. The literature also provides a body of reflective articles by physicians on their personal experiences during STMMs, but lacks research evidence on the motivational determinants for US physicians to participate in these excursions and the magnitude of the physician manpower and economic resources expended annually.

Upon this background, Chapter 1 introduces the two main aims of this research: (1) to characterize the determinants and motivations of US physician participation in STMMs, and (2) to gather an estimate of the economic and manpower resources employed. Three complementary methodologies were utilized to satisfy these aims. First, a systematic review of the literature sought to analyze published information on social, economic and diplomatic aspects of STMMs from prior published work that may 
addresses these aims. Is there an undercurrent of professional peer influence or nationalism in physician motivation? How well organized is the activity in the US or internationally? What is already known about supply side costs and how participation is affected by them? Secondly, a survey sample of the US physician population was taken to gather numeric data on the prevalence of physician participation in STMMs vis-à-vis other options for voluntary professional work, personal and composite costs associated with STMMs, the magnitude of the human resource investment, and the demographic and professional variables that predict participation or otherwise characterize the profile of participating physicians. Lastly, physicians who had repeatedly traveled on STMMs were interviewed to collect and analyze qualitatively their narratives on motivations to participate. The empiric findings from these overlapping approaches of the dissertation are then organized into Chapters $2-6$, followed by the general discussion of the findings in Chapter 7 . While the dissertation is focused only on the supply side of the activity, i.e., physician motivation and inputs, Chapter 7 provides, for context, a brief reflection on the receiver side of STMM-based care as it corroborates reported aspects of physician motivation, a brief comparison of STMMs to Médecins Sans Frontières (MSF), the most widely recognized long-term form of direct medical assistance, comments on the motivations of STMM-promoting nongovernmental organizations (NGOs) where relevant to physician participation, and how the global debate on aid relates to STMM activity.

The results of the systematic literature review are compiled in Chapter 2. Forty-one unique articles from a search spanning the 67 years between 1947 and 2014 met the criteria for their relevance to STMMs and to at least one of five key questions around which the review was focused: (1) evidence for critical analysis of STMMs with respect to normative values of volunteering, altruism, and philanthropy; (2) evidence for professionalization of the activity of STMMs; (3) evidence for analysis of the transactional nature of the interface of physicians and patients in this setting or other market mechanisms at play; (4) data on personal costs or cost-effectiveness of STMMs; and (5) evidence of spill-over effects with respect to attitudes on foreign aid or on US diplomacy. Most articles bearing useful information appeared in specialty surgical journals since 2000. Little is found on formal analysis of motivation, market or transactional features, or the aid or diplomatic implications that might conceivably accrue to this transnational activity. Information on costs are mostly limited to single experiences. There is an accumulating body of instructions on how to conduct STMMs, guidelines for specialty trips and ethical considerations, yet the level of professional codification has, so far, 
not led to the development of any central national or international organization for the advancement or professionalization of STMMs.

The results of the survey of US physicians referred to as the Physicians' Giving Back Survey (PGBS), conducted by email, are divided among Chapters 3-5. A description of the general scope and types of physician volunteering is provided first, followed by assessment of the economic and manpower inputs in the STMM form of volunteering, and lastly the demographic characteristics of physicians who participate in STMMs that may provide clues to motivation. One-sample chi-square testing verified that the respondents to the survey were statistically similar by to the US physician population in three characteristics (race, marital status, and type of medical degree (MD vs. DO)), and statistically dissimilar in five other characteristics (gender, age, domestic or foreign medical training, religion, and region of the country). The distribution of PGBS respondents by specialty closely resembled the distribution among the US physician population.

Chapter 3 illustrates that uncompensated medical teaching is the most common domestic profession-related pro-bono activity among US physicians (54\% participation), followed by the waiving of fees in their practices for patients with limited ability to pay (39\%). Thirty-seven percent give monetary or donations-in-kind to charitable organizations. Overall, $32 \%$ of US physicians in this cross-section had been on at least one STMM. Twenty-six percent donate time to professional organizations or to patient support organizations. Other less common activities include providing care in free clinics after usual practice hours, unpaid screening physicals for schools and other athletic team organizations, and medical relief in domestic disasters. Pediatricians, surgeons and anesthesiologists were linked more commonly with STMM activity, whereas adult medicine physicians were more linked with providing services in free or sliding scale clinics. A robust profile of the typical physician volunteer did not otherwise emerge. Overall, nonetheless, US physicians are shown to play their part in the American generosity that topped the World Giving Index in 2014.

The principal findings drawn from the PGBS regarding the magnitude of personal and cumulative expenditures on STMMs and the physician manpower inputs are conveyed in Chapter 4. The results appear to confirm the impressions of prior authors that STMM numbers and participation are on 
the rise. The evidence is illustrated by an increasing prevalence of new, firsttime participants over the span of the survey years, increasing numbers of STMMs per year, and increasing new participants as a percentage of survey respondents in practice at each year. The proportion of new, first-time participants is keeping up with, if not slightly exceeding, the number of physicians entering practice during each survey year.

Cumulative data from 908 trips show an average STMM duration of 11.8 days. If 10 days of each trip is spent seeing patients, the number of STMM work days for 2012, based on the proportion of participants in the survey extrapolated to the population, suggest that nearly 5800 full time equivalents of physician time were expended in that year on STMMs. The back drop for this transferred physician economic output is the challenge that the US faces from a chronic shortage of tens of thousands in needed physician manpower and insufficient post-graduate training positions.

Physicians spend an average of about $\$ 3815$ on direct expenses including airfare, organizational fees, and equipment and supplies. While away from their regular jobs, their opportunity costs average $\$ 7791$ per trip. Within the current tax regime, $100 \%$ of STMM direct expenses are generally deductible from income; however, $63 \%$ of physicians think that the deductibility is something less.

A sensitivity analysis of global costs that included a multiple of the physicians' direct costs for up to four support persons or students per physician, applying airfare and organizational fees and excluding the equipment and opportunity costs that apply to physicians, suggests that by 2012 , cumulative costs approximated $\$ 3.7$ billion US dollars. This figure can be benchmarked to other direct aid objectives of the United States Agency for International Development (USAID) such as contributions to the International Organizations for Peacekeeping Activities (\$3.7B), Consular Affairs and the Border Security Program (\$2.8B), and to Humanitarian Assistance (\$4.1B). The backdrop of STMM cumulative expenditures is that the forfeited tax revenue, while behaving as an indirect subsidy for an aid activity not regulated by the government, represents an opportunity cost to the central government whose alternatives can be seen in crumbling US infrastructure. 
Capturing the profile of the typical participant and their life circumstances may convey insights into why some physicians pursue STMM activity. Regression models of demographic and professional characteristics of STMM participants from the PGBS, developed in Chapter 5, tell us that STMM participation is predicted by being among the surgeon and anesthesiology grouping or among pediatricians, by being in the older age category (56-73), and by being married. Religion did not predict participation. Descriptive statistics suggest that these physicians tend to participate later in their careers, having few or no children at home. They also tend to have a somewhat lower than average US physician income. Indeed, STMM participants were statistically less likely to divulge their highest taxable income than nonparticipants.

A number of inferences may be drawn from these findings. The plight of underserved children may be a relative powerful draw for pediatricians. Surgical STMMs may be, in some ways, more manageable, since patients can be pre-selected for a low number of relatively routine procedures that have huge impact on the quality of life for the individual. STMM participation is more prominent during a time in life when the physician is not scrambling to start a career and not in the peak of family demands. Physicians in the lower half of the income strata may be intrinsically less driven by wealth accumulation, and their opportunity costs are proportionately lower.

Chapter 5 also looks at where physicians go on their pro-bono activity for clues to pre-existing ties that may draw them to the activity. Whereas $57 \%$ of Asian physicians reported doing their STMMs on the Asian continent, no other racial, ethnic, historical or language ties could be identified. Sixty percent of STMMs from the US sample were conducted in Latin America; the relative nearness of this region makes it less time-consuming and costly to travel to these countries.

In Chapter 6, the empiric research of the dissertation moves on from the motivational clues and supply side inputs found in the quantitative methodology to the qualitative dimension wherein physicians are queried directly. All interviewees were repeat participants. Using semi-structured interviews, physicians who were identified through snowball recruitment were first asked to convey their conscious motives, followed by a series of question areas designed to probe how the social, economic, and diplomatic 
matters of the foregoing chapters influence their decision to participate in STMMs. STMM participants were further asked about early experiences and role models, as well as the value systems that inform their decision-making, in search of patterns common to participants. Ultimately, the interviewees were encouraged to share their most personal reflections on patient encounters, and how they perceived their work was valued by host country recipients. Responses were processed by direct content analysis both manually and assisted by narrative research software.

The pre-eminent driver voiced by the majority of the interviewed physicians was satisfaction derived from helping the less fortunate. Other key motivators included the gratification that comes from personal learning through international interaction and the adventure of foreign travel, the "warm glow" of the perceived appreciation and gratitude from patients and local staff, the sense of renewal from practicing simple medicine devoid of administrative annoyances, and the legacy left through teaching host country healthcare workers and patients.

Physicians more commonly attributed their locus of decision-making on participation in STMMs more to personal core values than to faith or to medical oath. In order of theoretical concept of philanthropy, physicians matched their motivation foremost to the altruistic desire to contribute to the Public Goods, then to "warm glow" or Personal Consumption, and lastly to the gains of Investment Exchange. One theme that arose from the interviews is that a personality type not uniform among physicians is essential to the attraction to and good performance in STMMs. The elements of the personality profile include high confidence, flexibility, unselfishness, strong ethics, and a tolerance for arduous and less sanitary conditions. Deeply felt, positive, interpersonal connections in this setting were found to stimulate both cognitive and emotional triggers propelling repetition of STMM activity among these physicians.

In contrast, diplomatic objectives and considerations regarding effective foreign aid did not substantially enter into physician motivations towards the STMM process. While these physicians did not perceive the direct or opportunity costs as critical barriers for themselves, nor did they see the tax break as highly influential, they commonly acknowledged that these 
economic factors, particularly opportunity costs, may be inhibitory to other physicians' decisions to participation in STMMs.

The narratives of Chapter 6 also mooted the notions that the increase in STMMs has been spurred by the enthusiasm conveyed in word-of-mouth communications from an ever-increasing pool of participants and from the abundance of readily found organizations online supporting a plethora of STMM opportunities from which to choose.

To conclude, Chapter 7 stacks the results of the quantitative and qualitative elements of the dissertation against the two questions of the research: (a) why do physicians go on STMMs, and (b) what are the measurable impacts on the supply side.

By 2014 , about $32 \%$ of physicians in the US had participated and about $25 \%$ had repeated participation in short-term pro-bono trips providing medical and surgical services to patients in LMICs. These physicians are somewhat more likely to be surgeons, anesthesiologists and pediatricians, to be among the lower half of US physicians in regard to income, to be in a later stage in their careers, and to be married with few or no children at home at the time of their STMMs. They display high levels of confidence, flexibility, ethics, unselfishness, and capacity to operate effectively in remote and arduous circumstances. Their core values are the primary source of motivation, and incentives to repeat are led by the satisfaction received in helping others, the learning and teaching involved, the gratitude felt, and sense of renewal. They are not impeded by the costs, and give little weight to conceivable spill-over effects that relate to diplomatic, foreign aid, or to tax effects on their related expenditures. No national or international organization dedicated to STMMs is driving the increase in the activity, but elements of professionalization are accumulating, most strongly in the specialty surgical literature.

The number of STMMs being deployed, physician participation, and the related expenditures are all mounting. The physician human resources input recently is approaching 5800 full-time equivalents. When compared with other government outlays for aid, STMM costs are material. Opportunity costs may be a quantifiable disincentive for physician participation. 
The focus of this dissertation has been limited to the supply side of the transaction of STMMs. To provide value through context, Chapter 7 includes brief overview of the literature on receiver side sentiments that corroborate physicians' perceptions that their services are indeed valued by patients and host country staff. The objectives of NGOs that organize many STMMs are varied and strategic; the quality of an STMM program may reflect those organizational self-interests and will require ongoing evaluation. In contrast to STMMs, the physicians who pursue the long term deployments of MSF fit less well into the routine structure of day-to-day healthcare delivery and civil society, and activism is an extension of their medical professionalism. The concept arising from the global aid debate wherein listening to and abiding the bespoke needs of recipient communities appears paramount to effective assistance, and resonates well as a prescription for progress in the effectiveness of STMMs. 


\section{Valorization Addendum}

This dissertation looks into the humanitarian activity referred to as ShortTerm Medical Missions (STMMs), a grass-roots form of aid conducted by medical professionals from wealthy countries to underserved communities in low- and middle-income countries (LMICs). The physicians involved in this activity typically earn a living in their home country and provide their medical and surgical services without compensation to the LMIC communities they visit for periods of days to a few weeks. The US appears to be the country sending the most STMMs. The dimensions of this activity, in terms of the magnitude of physician participation and the costs involved, are vague for many reasons. The format of these outreaches is highly variable in terms of the personnel involved and the services provided. The individuals and nongovernmental organizations (NGOs) that arrange and execute these excursions are not linked through any common association or agency, nor do they necessarily share common motivations. No regulatory body oversees the process in the US. In addition, the motivations of physicians, who are central to the activity of the direct medical care delivered in these encounters has not been systematically studied. Therefore, this dissertation was structured to assess why US physicians participate in STMMs and to gather some approximations of the inputs from the US in terms of costs and manpower.

The data generated from the research of the dissertation may provide the first numerical evidence reported from physicians to confirm that STMM activity originating from the US is increasing in the last 30 years, both in terms of the numbers of excursions and relative physician participation. The cumulative direct and opportunity costs approximating US $\$ 3.7 \mathrm{~B}$ are material when compared to federal public outlays for foreign aid from the US. Opportunity costs to physicians may influence the choice to participate. Physician manpower equates to nearly 5,800 full-time equivalents annually.

Surgeons, anesthesiologists, and pediatricians are more likely to participate in STMMs. Participating physicians tend to be older with relatively lower income than average physicians, and are married without children at home. Medical (non-surgical) STMMs are proportionately more common than surgical STMMs. Motivations center around the satisfaction of providing medical services to underserved populations and teaching health professionals abroad, but are not demonstrably linked either to nationalistic intentions or religious affiliation. 
The premise underscored by the title of the dissertation, "The Tacit Bargain..." is that there are two parties seeking to have needs satisfied and a market exists for that exchange. The dissertation outlines the blend of determinants and motivators that impel physicians to seek out the rewards found in STMMs; patients seek and often receive medical and surgical benefits from the visiting physicians that may not otherwise be affordable or accessible to these poorer people. Generically, cash flows to those entities providing transport, housing, visa fees, medications and medical supplies, travel vaccinations and prophylaxis, and administrative and coordinating services to enable this exchange. There is money to be made in satisfying these complementary demands, even if that cash flow is unilaterally sourced.

The findings of the research may be of direct value to the US and the world community by providing evidence of the current volume and recent growth of STMM activity emanating from one major participant country. Other societies may find indirect value from observation of elements of the US experience depicted herein. Understanding the motivations of physicians who play a pivotal role in this direct care and capacity building activity may assist in policy formation from governments and non-governmental organizations, and individual physicians as well, on how the process and its related monetary and manpower allocations and investments may be made more effective. Should institutions, NGOs or the US government seek to modify the participation of physicians in STMMs through policy decisions meant to affect strategic soft power, reputation building, recruitment or other broader objectives, the recognition of who has been naturally attracted to STMMs may provide the basis for targeting of recruitment. If the value proposition of STMMs is to be optimized, matching not only technical skills but also personality profiles of physicians to the activity may be crucial. Physicians might wish to self-screen for their own aptitude and fitness for STMMs with a validated instrument, and some organizations may encourage them to do so.

Another consideration is the impact of STMMs on physician "burn-out," or collapse of motivation under the strain of the profession. Burn-out among physicians in the US is alarmingly high and increasing. Finding ways to mitigate this pressure on already stressed US healthcare system is likely to become an increasing sociologic challenge. The narrative portion of the dissertation gives voice to participation in STMMs as one mechanism for selfrestoration for some physicians. As a method for addressing burn-out, done well, the end result would not necessarily be a unilateral benefit. 
The most common professional pro-bono activity of US physicians is teaching, and the legacy effect of teaching that carries over into STMMs seems to stimulate motivation as well as to mitigate the discontinuous nature of STMMs. The direct transfer of both services and knowledge form much of the attraction to STMMs. This may bode well for university based models of long-term LMIC site relationships.

Value may be also found in the development of standardized instruments to gather useful data continuously from STMM participants in the field. The results of this dissertation confirms the growing number of outreaches being deployed annually from the US and the research interest in the nature and impact of STMMs. By means of hand-held tablets, information on participants, patients, disorders encountered, etc., could be sent to a cloudbased research database, from as many organizations as possible, without even requiring the organizations to be linked or otherwise interact. Such a database could become proprietary to a university or other entity.

At least in theory, there is a tacit approval and indirect support from the US government for STMM momentum, since the tax revenues deducted and diverted to this activity could have found other applications. Although the exercise of soft power is not an express motivator for US physicians, if done well, such a positive externality could result, as long as nuances of neocolonialism can be avoided. 


\section{Acknowledgments}

A Maastricht $\mathrm{PhD}$ for me was the "path less trodden" that I chose, like "a free man at the start of a long journey whose conclusion is uncertain" (Frank Darabont, Shawshank Redemption). My educational odyssey through seminary, military academy, medical school, global business school, and brief exposures in humanitarian medicine amid 32 years of domestic practice (and, by the way, the Economist), led me to Maastricht in hopes of going once again out of my comfort zone, be among purposeful people from many elsewheres, and maybe make a contribution in the process.

Mindel Van de Laar is a gambler; she took a chance on me and it was a long shot. Thanks, Mindel, for taking that bet, for your courage in taking a nontraditional candidate under your wing, for being straight forward about what this would require, and for giving a little push when it would have been easier for both of us to fold. Your intuition paid off again on the hunch that Wim and Milena could manage me very well.

My enormous thanks to Professor Dr. Wim Groot, my supervisor and promoter, for having acquired the acumen and patience that instilled the confidence I needed. Your readiness to discuss all things political, economic and philosophical with a rank amateur was the kind of experience I sought through the $\mathrm{PhD}$ adventure. Your humor is so immaculately precise, and a bonus to my experience.

My deepest gratitude to Dr. Milena Pavlova, my Maastricht co-supervisor, and mistress of all things numerical, for teaching me all the tools needed to get the work done. Your bright face and warm smile penetrated the time zones for our 0-dark-30 Skype sessions wherein you maintained patience with my somnolent brain, and managed to get statistical concepts and STATA across to me against all odds.

What serendipity it was to find Dr. Ann Impens, my US co-supervisor and most favored Belgian-American. You repeatedly helped me make sense of it all. Your keen, dispassionate eye for all my foibles in thought and writing kept me rolling. An unexpected, cherished friendship has been born.

To someone whose life has mainly been on the front lines applying the science and knowledge that others produce, the Maastricht Graduate School of Governance with its GPAC2 permutation seems a marvelous place of orchestrated chaos, a constant whirlwind of smart people and challenging 
ideas that get hammered into shape by scientific rigor. My sojourn at these global commons has led me to connect all the better with my fellow travelers on this planet with gravity for which we must take common ownership. To all those who graciously embraced this curious one amongst them, I am grateful.

I landed in town with such a remarkable cohort. What a privilege and a pleasure to be among the likes of Super Sylvia, Clovis, Andrea, Camillo, Ali, Brenda, Mutinta, Luiz, Julia, Mohammed, Nocepho, and Jan. May we all find excuses to find each other again beyond these days. Same goes for our forerunners like Derek, Leny, Corinne, Shelley, Richard, Ana, Catie, Farida and so many others who welcomed us to sudsy football matches and other hair-down gatherings. And to those doing hard time at Maastricht, Hassen Wako and Julieta Marotta, who sat with me in vivo and from across the pond to help me grasp essentials on managing my quantitative and qualitative data: your handprints are embedded in my work.

How could we go wrong with elite coordinators like Guney and Carlos, Saba and Charlotte, Shivani and Janyl, who felt our pain and eased the steps forward. You guys made herding cats look routine. Too many faculty members to name seemed consistently to go beyond the call of duty to enrich our experience, but enlightening exchanges with Eddie Szirmai, Sonila Tomini, Michael Cichon and Tatiana Skripka will stay with me for a long time. Visiting faculty Louis Volante and Fabrice Weissman will not soon be forgotten, especially if their thoughts of wandering over and down to Arizona come to pass.

My endless gratitude belongs to my wife and soul mate Kelly, the enabler of all my joy and pursuits, who makes our life as I make our living, and to my kids Christian, Taylor, and Anna Brielle, who are ok with me not being quite like the other dads. 


\section{Curriculum Vitae}

Paul Henry Caldron was born on August 7, 1952 in Tulsa, Oklahoma, United States of America. He spent time during formative years in a Catholic seminary, started post-secondary school in a federal military academy, and ultimately completed undergraduate education at the University of Tulsa with a major in Zoology in 1973. Medical training was completed in 1979 at Oklahoma State University. Medical post graduate training included residency in internal medicine and fellowship in rheumatic and immunologic diseases at the Cleveland Clinic Foundation in Ohio. He has functioned in private practice since 1984 in Chicago, Illinois and later in Phoenix, Arizona.

In 2002, Paul completed a master's degree in business administration at the Thunderbird School of Global Management and has subsequently led the growth of a prominent group for the practice of and clinical research in rheumatologic disorders, and has been a principal in a contract research organization that conducts clinical trials primarily in the Russian Federation. Paul has participated in numerous short-term medical missions principally in Latin America. He has pursued the Maastricht $\mathrm{PhD}$ while continuing practice and furthering his interest in global affairs and humanitarian medicine.

\section{Publications in English language peer-reviewed journals}

Caldron PH, Calabrese LH, Lederman RJ: A Survey of Musculoskeletal Problems of High Level Musicians. Med J Performing Arts, Dec., 1986.

Caldron PH, Wilborune AJ, Bravo EL, Mitsumoto H: Gold Myokymia Syndrome: A Rare Toxic Manifestation of Cryotherapy; Cleveland Clinical J Med 1987 54(3): 225-228.

Bogacz K, Caldron PH: Enteric Coated Aspirin Bezoar: Elevation of Serum Salicylate Level after Barium Study; A Case Report and Review of Medical Management, AM J Med 1987; 83:783-786.

Perlman SG, Connell K, Clark A, Robinson MS, Conlon P, Caldron PH, Gecht M, Sinicore JM: Dance-based Aerobic Exercise for Rheumatoid Arthritis. Arthritis Care and Research. March 1990; 3(1): 29-35.

Whalen TJ Jr., Caldron PH, Segal AM, Scherbel AL: Increased Incidence of Nephrolithiasis in Ankylosing Spondylitis (Abstract). Arth Rheum 1984; 27:4. 
Roth SH, Mitchell CS, Bennett RE, Caldron PH, et al: Reduced risk of gastropathy (GI mucosal toxicity) with non-acetylated salicylate (Salsalate): An endoscopic study. Sem Arthr Rheum 1990, 19(4 Suppl. 2): 11-19.

Roth SH, Bennett RE, Caldron PH, et al: A Long-Term Endoscopic Evaluation of Arthritis Patients Treated with Nabumetone vs. Naproxen. Journal of Rheumatology 21:6; 1118-1123, 1995.

Roth SH, Bennett RE, Caldron PH, Mitchell CS, Swenson CM: Endoscopic Evaluation of the Effects of Diclofenac Sodium and Naproxen on the Upper Gastrointestinal Mucosa, Pharmacovigilance, Adis Intl., Ltd., Clinical Drug Invest 9 (3) 171-179, 1995.

Tesser JR, Ballehr L, Jay R, Keske B, Konya M, Brown S, Caldron P, Starr J, Peters E, Bennett R, Swarup A, Jajoo R, Bolignese J, Chhaya S, D’Onofrio M. MRI RAMRIS Scores in Rheumatoid Arthritis: Experience in a Large Community Based Rheumatology Practice. Arthritis Rheum 56(suppl 9): S653, 2007.

Levy RM, Khokhlov A, Kopenkin S, Bart B, Ermolova T, Kantemirova R, Mazurov V, Bell M, Caldron P, Pillai L, Burnett BP. Efficacy and safety of flavocoxid, a novel therapeutic, compared with naproxen: a randomized multicenter controlled trial in subjects with osteoarthritis of the knee. Adv Ther. 27(10):731-742, 2010.

Levy RM, Khokhlov A, Kopenkin S, Bart B, Ermolova T, Kantemirova R, Mazurov V, Bell M, Caldron P, Pillai L, et al. Efficacy and safety of flavocoxid compared with naproxen in subjects with osteoarthritis of the knee - a subset analysis. Adv Ther. 27(12) 953-962, 2010

Barry S. Skikne, Kari Punnonen, Paul H. Caldron, Michael T. Bennett, Mari Ervasti, Gail H. Gasior, Janna S. Chamberlin, Linda A. Sullivan, Kurtis R. Bray, Paula C. Southwick. Improved differential diagnosis of anemia of chronic disease and iron deficiency anemia: A prospective multicenter evaluation of soluble transferrin receptor (sTfR) and the sTfR / log ferritin index (sTfR Index). Am. J. Hematol. 86:923-927, 2011.

Caldron PH, Gavrilova SI, Kropf S. Why (not) go east? Comparison of findings from FDA Investigational New Drug study site inspections performed in Central and Eastern Europe with results from the US, Western 
Europe, and other parts of the world, Drug Design, Development \& Therapy (6) 53-60, 2012

Caldron PH, Impens A, Pavlova M, Groot W. A systematic review of social, economic and diplomatic aspects of short-term medical missions. BMC Health Serv Res. 2015; 15(1):380. Doi: 10.1186/s12913-015-0980-3.

Caldron PH, Impens A, Pavlova M, Groot W. The Physicians' Giving Back Survey: Keeping up with American generosity. J Compassionate Heal Care. 2015; 2(1):8. Doi: 10.1186/s40639-015-0017-0

Caldron PH, Impens A, Pavlova M, Groot W. Economic assessment of US physician participation in short-term medical missions. JGlobalization\&Health. 2016; 12:45. DOI: 10.1186/s12992-016-0183-7

\section{Book chapters}

Caldron PH: Screening for Rheumatic Disease. In Boissonnault W (ed). Examination in Physical Therapy: Screening for Medical Disease, Churchill Livingston, 1991.

Roth SH, Caldron PH, Bennett RE: Rheumatoid Arthritis. In Taylor, RB (ed.) Difficult Medical Management, Philadelphia, WB Saunders, 1991:586-597. 


\section{MGSoG Dissertation Series}

Mahmut Kobal

Customs \& Excellence

A comparative approach on administrative and regulatory compliance perspectives of the EU-Turkey customs union

MGSoG Dissertation Series, nr 69 (2016)

Craig Loschmann

Essays on Conflict-related Migration and Development in the Case of Afghanistan

MGSoG Dissertation Series, nr 68 (2016)

Andrea Milan

Rural Livelihoods, Location and Vulnerable Environments:

Approaches to Migration in Mountain areas of Latin America

MGSoG Dissertation Series, nr 67 (2016)

Farida Lada

On Guarding the Welfare of Clinical Trial Subjects While Promoting Novel Drug Innovation: A Game Theoretical Approach

MGSoG Dissertation Series, nr 66 (2016)

Simona Vezzoli

Borders, Independence and Post-colonial Ties: the Role of the State in Caribbean Migration

MGSoG Dissertation Series, nr 65 (2015)

Silvia Consuelo Gómez Soler

Civil Conflict and Education: How Does Exposure to Civil Conflict Affect Human Capital Accumulation? Evidence from Standardized Exit Exams in Colombia

MGSoG Dissertation Series, nr 64 (2015)

Paula Nagler

Occupational Choice in the Developing World

MGSoG Dissertation Series, nr 63 (2015) 
Jasmin Kientzel

Determinants of Professional Commitment to Environmental Sustainability MGSoG Dissertation Series, nr 62 (2015)

Mehmet Güney Celbiş

Regional Policies: Convergence, Trade, and the Allocation of Public Capital MGSoG Dissertation Series, nr 61 (2015)

Florian Henning

Living Up to Standards

Interoperability Governance and Standards Adoption in Government Information Networks

MGSoG Dissertation Series, nr 60 (2015)

Niels P. Groen

The Never-Ending Project: Understanding E-Government Project Escalation MGSoG Dissertation Series, nr 59 (2015)

Derek Copp

Teacher-Based Reactivity to Provincial Large-scale Assessment in Canada MGSoG Dissertation Series, nr 58 (2015)

Michaella Vanore

Family-Member Migration and the Psychosocial Health Outcomes of Children in Moldova and Georgia

MGSoG Dissertation Series, nr 57 (2015)

Sonja Fransen

The Economic and Social Effects of Remittances and Return Migration in Conflict-Affected Areas: The Case of Burundi

MGSoG Dissertation Series, nr 56 (2015)

Ibrahim Khalil Conteh

The Impact of Floods on Primary School Education in Zambia

MGSoG Dissertation Series, nr 55 (2015)

Richard Bluhm

Growth Dynamics and Development

Essays in Applied Econometrics and Political Economy

MGSoG Dissertation Series, nr 54 (2015) 
Nevena P. Zhelyazkova

Work-Family Reconciliation and Use of Parental Leave in Luxembourg Empirical Analysis of Administrative Records

MGSoG Dissertation Series, nr 53 (2015)

Sachin Kumar Badkas

Metachoice and Metadata

Innovating with Environmental Policy Analysis in Europe

MGSoG Dissertation Series, nr 52 (2014)

Irina S. Burlacu

An Evaluation of Tax-Benefit Systems Impact on the Welfare of Frontier Workers: The Case of Luxembourg and Belgium

MGSoG Dissertation Series, nr 51 (2014)

Özge Bilgili

Simultaneity in Transnational Migration Research:

Links Between Migrants' Host and Home Country Orientation

MGSoG Dissertation Series, nr 50 (2014)

Yulia Privalova Krieger

Reshaping the Big Agenda: Transnational Politics and Domestic Resistance Financial crisis and social protection reform in Bosnia and Herzegovina MGSoG Dissertation Series, nr 49 (2014)

Marieke van Houte

Moving Back or Moving Forward? Return migration after conflict

MGSoG Dissertation Series, nr 48 (2014)

Oxana Slobozhan

Global Governance in the Management of Natural Resources

The Case of the Extractive Industries Transparency Initiative (EITI)

MGSoG Dissertation Series, nr 47 (2014)

Luis Bernardo Mejia Guinand

The Changing Role of the Central Planning Offices in Latin America:

A Comparative Historical Analysis Perspective (1950-2013)

MGSoG Dissertation Series, nr 46 (2014) 
Cheng Boon Ong

Ethnic Segregation in Housing, Schools and Neighbourhoods in the

Netherlands

MGSoG Dissertation Series, nr 45 (2014)

Luciana V. Cingolani

Bureaucracies for Development: Oxymoron or Reality?

Studies on State Capacity in Challenging Governance Contexts

MGSoG Dissertation Series, nr 44 (2014)

Carlos Cadena Gaitán

Green Politics in Latin American Cities - Sustainable Transport Agendas

MGSoG Dissertation Series, nr 43 (2014)

Katie Kuschminder

Female Return Migration and Reintegration Strategies in Ethiopia

MGSoG Dissertation Series, nr 42 (2014)

Metka Hercog

Highly-Skilled Migration and New Destination Countries

MGSoG Dissertation Series, nr 41 (2014)

Margaret Agaba Rugadya

Can Remittances Influence the Tenure and Quality of Housing in Uganda?

MGSoG Dissertation Series, nr 40 (2014)

Ilire Agimi

New Governance Under Limited Statehood: The Case of Local Government Reform in Kosovo

MGSoG Dissertation Series, nr 39 (2014)

Kristine Farla

Empirical Studies on Institutions, Policies and Economic Development

MGSoG Dissertation Series, nr 38 (2013)

Marina Petrovic

Social Assistance and Activation in the Pursuit of Happiness:

Shedding New Light on Old Policy Solutions to Social Exclusion

MGSoG Dissertation Series, nr 37 (2013) 
Laura Torvinen

Assessing Governance Assessments; The Case of Mozambique

Governance Assessments in the Context of Aid Effectiveness Discourse

MGSoG Dissertation Series, nr 36 (2013)

Biniam Egu Bedasso

Institutional Change in the Long Shadow of Elites

Essays on Institutions, Human Capital and Ethnicity in Developing Countries MGSoG Dissertation Series, nr 35 (2013)

Sepideh Yousefzadeh Faal Deghati

Childhoods Embargoed: Constructing and Reconstructing Multidimensional Child Poverty in Iran 1984-2009

MGSoG Dissertation Series, nr 34 (2013)

Robert Bauchmüller

Investing in Early Childhood Care and Education:

The Impact of Quality on Inequality

MGSoG Dissertation Series, nr 33 (2013)

Martin Rehm

Unified Yet Separated: Empirical Study on the Impact of Hierarchical Positions within Communities of Learning

MGSoG Dissertation Series, nr 32 (2013)

Dorcas Mbuvi

Utility Reforms and Performance of the Urban Water Sector in Africa

MGSoG Dissertation Series, nr 31 (2012)

Lina Salanauskaite

Distributional Impacts of Public Policies:

Essays in Ex-Ante and Ex-Post Evaluation

MGSoG Dissertation Series, nr 30 (2012)

Esther Schüring

To Condition or not - is that the Question?

An Analysis of the Effectiveness of Ex-Ante and Ex-Post Conditionality in Social Cash Transfer Programs

MGSoG Dissertation Series, nr 29 (2012) 
Joe Abah

Strong Organisations in Weak States

Atypical Public Sector Performance in Dysfunctional Environments

MGSoG Dissertation Series, nr 28 (2012)

Zina Samih Nimeh

Social Citizenship Rights: Inequality and Exclusion

MGSoG Dissertation Series, nr 27 (2012)

Lenka Eisenhamerová

Legitimacy of 'Humanitarian Military Intervention'

MGSoG Dissertation Series, nr 26 (2011)

Sonila Tomini

Informal Payments for Health Care Services in Albania

MGSoG Dissertation Series, nr 25 (2011)

Jinjing Li

Dynamic Microsimulation in Public Policy Evaluation

MGSoG Dissertation Series, nr 24 (2011)

Aziz Atamanov

Rural Nonfarm Employment and International Migration as Alternatives to Agricultural Employment: The Case of Kyrgyzstan

MGSoG Dissertation Series, nr 23 (2011)

Frieda Vandeninden

Poverty Alleviation: Aid and Social Pensions

MGSoG Dissertation Series, nr 22 (2011)

Juliana Nyasha Tirivayi

The Welfare Effects of Integrating AIDS Treatment with Food Transfers:

Evidence from Zambia

MGSoG Dissertation Series, nr 21 (2011)

Agnieska Ewa Sowa

Who's Left Behind? Social Dimensions of Health Transition and Utilization of Medical Care in Poland

MGSoG Dissertation Series, nr 20 (2011) 
Emmanaouil Sfakianakis

The Role of Private Actors in the Provision of Public Goods with Applications to Infrastructure and Financial Stability

MGSoG Dissertation Series, nr 19 (2011)

Siu Hing Lo

White Collars Green Sleeves: An Interonganizational Comparison of Determinants of Energy-Related Behaviors among Office Workers

MGSoG Dissertation Series, nr 18 (2011)

Treena $\mathrm{Wu}$

Constraints to Human Capital Investment in Developing Countries:

Using the Asian Financial Crisis in Indonesia as a Natural Experiment MGSoG Dissertation Series, nr 17 (2011)

Henry Espinoza Peña

Impact Evaluation of a Job-Training Programme for Disadvantaged Youths:

The Case of Projoven

MGSoG Dissertation Series, nr 16 (2011)

Florian Tomini

Between Family and Friends

Understanding the Interdependency of Private Transfers

MGSoG Dissertation Series, nr 15 (2010)

Michał Polalowski

The Institutional Transformation of Social Policy in East Central Europe:

Poland and Hungary in comparative and historical perspective

MGSoG Dissertation Series, nr 14 (2010)

Maha Ahmed

Defining, Measuring and Addressing Vulnerability:

The Case of Post Conflict Environments

MGSoG Dissertation Series, nr 13 (2010)

Pascal Beckers

Local Space and Economic Success

The role of spatial segregation of migrants in the Netherlands

MGSoG Dissertation Series, nr 12 (2010) 
Victor Cebotari

Conflicting Demands in Ethnically Diverse Societies

Ethno political Contention and Identity Values in Europe

MGSoG Dissertation Series, nr 11 (2010)

Dennis Gyllensporre

Competing and Complementary Perspectives on the EU as a Crisis Management Actor: An Examination of the Common Security and Defence Policy through the Lenses of Idealism and Realism

MGSoG Dissertation Series, nr 10 (2010)

Judit Vall Castello

Business Cycle and Policy Effects on Labour Market Transitions of Older and Disabled Workers in Spain

MGSoG Dissertation Series, nr. 9 (2010)

Keetie Roelen

False Positives or Hidden Dimensions: the definition and measurement of child poverty

MGSoG Dissertation Series, nr. 8 (2010)

Denisa Maria Sologon

Earning Dynamics in Europe

MGSoG Dissertation Series, nr. 7 (2010)

Melissa Siegel

Money and Mobility: Migration and Remittances

MGSoG Dissertation Series, nr. 6 (2010)

Jessica S. Hagen-Zanker

Modest Expectations: Causes and effects of migration on migrant households in source countries

MGSoG Dissertation Series, nr. 5 (2010)

Mirtha R. Muniz Castillo

Human Development and Autonomy in Project Aid: Experiences from four bilateral projects in Nicaragua and El Salvador

MGSoG Dissertation Series, nr. 4 (2009) 
Christiane Arndt

Governance Indicators

MGSoG Dissertation Series, nr. 3 (2009)

Britta Augsburg

Microfinance - Greater Good or Lesser Evil?

MGSoG Dissertation Series, nr. 2 (2009)

Geranda Notten

Measuring and Managing Poverty Risks

MGSoG Dissertation Series, nr. 1 (2008) 